\title{
MODELLING THE HUMAN HEART
}

Human stem cell-based models lead the way in physiological, pathological, and toxicological research

Rolf H. Slaats 


\section{MODELLING THE HUMAN HEART}

HUMAN STEM CELL-BASED MODELS LEAD THE WAY IN PHYSIOLOGICAL, PATHOLOGICAL, AND TOXICOLOGICAL RESEARCH

\section{Rolf Herman Slaats}




\section{Graduation Committee:}

Chair / secretary:

prof. dr. J.L. Herek

\section{Promotor}

prof. dr. P. C. J. J. Passier

\section{Co-promotors}

dr. V. Schwach

dr. M. Catarino Ribeiro

\section{Committee members:}

prof. dr. J.P.G. Sluijter

prof. dr. J. Van der Velden

prof. dr. C.V.C. Bouten

prof. dr. M.M.A.E. Claessens

prof . dr. J. Prakash
University of Twente

University of Twente

University of Twente

University of Twente

UMC Utrecht

Amsterdam UMC

TU Eindhoven

University of Twente

University of Twente

\section{UNIVERSITY | TECHMED OF TWENTE. CENTRE}

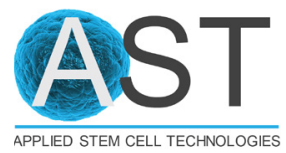

The research presented in this thesis was carried out at the department of Applied Stem cell Technologies at the TechMed Centre for Biomedical Technology and Technical Medicine at the University of Twente in Enschede, the Netherlands.

Financial support by the Dutch Heart Foundation and the foundation Proefdiervrij for the publication of this thesis is gratefully acknowledged.

Cover design: R. H. Slaats

Printed by: Gildeprint B.V.

Lay-out: R. H. Slaats

ISBN: 978-90-365-5231-8

DOI: $10.3990 / 1.9789036552318$

(C) 2021 Rolf H. Slaats, The Netherlands. All rights reserved. No parts of this thesis may be reproduced, stored in a retrieval system or transmitted in any form or by any means without permission of the author. Alle rechten voorbehouden. Niets uit deze uitgave mag worden vermenigvuldigd, in enige vorm of op enige wijze, zonder voorafgaande schriftelijke toestemming van de auteur. 


\section{MODELLING THE HUMAN HEART \\ HUMAN STEM CELL-BASED MODELS LEAD THE WAY IN PHYSIOLOGICAL, PATHOLOGICAL, AND TOXICOLOGICAL RESEARCH}

\section{DISSERTATION}

to obtain

the degree of doctor at the University of Twente, on the authority of the rector magnificus, prof. dr. ir. A. Veldkamp, on account of the decision of the doctorate board, to be publicly defended

on Wednesday 15 September 2021, at 16:45 hours

by

\section{Rolf Herman Slaats}

Born on the $5^{\text {th }}$ of Januari, 1989 in Bladel en Netersel, The Netherlands 
This dissertation has been approved by:

prof. dr. ir. P.C.J.J. Passier, promotor

dr. M. Catarino Ribeiro, co-promotor

dr. V. Schwach, co-promotor 


\section{Samenvatting}

Het hart een is onmisbaar orgaan van het (menselijk) lichaam, verantwoordelijk voor het rondpompen van bloed door de bloedvaten, dat onder andere de uitwisseling van voedingsstoffen, afvalstoffen en communicatiemiddelen mogelijk maakt tussen organen. Het pompvermogen van het hart wordt gegenereerd door hartspiercellen, die door middel van een electrische prikkel gedreven worden om op gecoördineerde wijze samen te trekken om zo de hartkamer te verkleinen en het bloed in de slagaderen te stuwen. Problemen in de (coördinatie van de) samentrekking van de hartspiercellen leidt tot hartfalen, in het ergste geval met de dood tot gevolg. Het is daarom van belang om te begrijpen hoe de pompfunctie van het hart kan worden verstoord en hoe dat dan opgelost kan worden. Tot op heden wordt veel gebruik gemaakt van proefdieren om het hart als orgaan, maar ook de ziekte of vergiftiging ervan beter te begrijpen. Echter, dierenharten gedragen zich anders dan mensenharten en zijn daarom van lage voorspellende waarde. Dit leidt tot onvermogen om bepaalde hartfuncties in mensen adequaat na te bootsen en tot schijnveligheid bij het testen van medicatie op toxiciteit. Het veelbelovende alternatief voor proefdieren is het gebruik van pluripotente stamcellen, waarmee cellen en weefsels van het menselijk hart kunnen worden nagemaakt. Pluripotente stamcellen kunnen alle celtypen van het menselijk lichaam vormen en zijn afkomstig uit embryo's (hESCs), of kunnen worden verkregen uit cellen van volwassen mensen of patiënten via reprogrammering. Deze laatste geïnduceerde pluripotente stamcellen (hiPSCs) zijn in het bijzonder veelbelovend, omdat er geen ethische bezwaren tegen zijn, en ze een bron van patiënt-specifieke stamcellen kunnen vormen, waarmee dan een ziektemodel met de genetische achtergrond van de patiënt kan worden gemaakt.

Helaas zijn de hartcellen verkregen uit pluripotente stamcellen niet zo volwassen als de hartcellen die we in patiënten tegenkomen, maar blijven ze steken op een foetaal niveau. Dit maakt dat ze zich niet precies zo gedragen als de cellen in het mensenhart, waardoor ze als model niet altijd geschikt zijn. Eerdere studies suggereerden dat hartcellen verkregen uit stamcellen een onvolwassen metabole activiteit laten zien, en dat foetussen voor de geboorte al beïnvloed worden door de blootstelling aan hun directe omgeving in de baarmoeder. In hoofdstuk 2 reflecteren we daarom op de literatuur om een oplossing te vinden voor deze onvolwassenheid door de directe metabole omgeving van de ontwikkelende hartcellen in menselijke foetussen beter na te bootsen in het lab. We geven een aangepaste formulatie voor het kweekmedium, waarmee een stap gemaakt zou kunnen worden om de hartcellen in het lab naar een volwassener niveau te tillen.

Desalniettemin kunnen we de hartspiercellen die worden verkregen uit stamcellen al wel gebruiken voor het maken van relevante (ziekte-)modellen. 
In hoofdstuk 3 gebruiken we deze cellen, voorzien van een fluorescent label aan sarcomeer-eiwit alfa-actinine, (de DRRAGN cellijn) voor het bestuderen van het effect van weefselstijfheid op de samentrekking van de hartspiercellen en in het bijzonder, de sarcomeren. We vonden dat een hartspiercel meer kracht levert in geval van een verhoogte stijfheid, maar dat er een maximale stijfheid is waarbij de hartspiercel nog kan compenseren met extra kracht. Boven deze plafondwaarde trekken de sarcomeren nog wel samen, maar verkort de cel zelf niet meer, een ontkoppeling die wellicht ten grondslag ligt aan het ontstaan van hypertrofie en falen van het hart.

Ook gebruiken we stamcellen om, naast hartspiercellen, pacemakercellen te verkrijgen. Deze cellen kunnen worden gebruikt voor onderzoek naar ritmestoornissen of voor het ontwikkelen van comlexere 3D modellen van het hart. In hoofdstuk 4 verkennen we de bestaande protocollen gevonden in de literatuur, en passen deze toe op de DRRAGN stamcellen om te testen of deze ook tot pacemakercellen differentiëren. De DRRAGN cellijn is hiervoor bijzonder geschikt, omdat de combinatie van fluorescente labels in deze cel zorgt voor een met het ook zichtbaar onderscheid tussen hartspiercellen en pacemakercellen, wat de beoordeling van de differentiatie ten goede komt. We identificeren het protocol dat de hoogste efficiëntie toont voor het genereren van pacemakerachtige cellen, maar verkrijgen niet de volledig volwassen pacemakercellen die in het mensenhart gevonden worden. Het protocol moet dus nog verder worden geoptimaliseerd.

In hoofdstukken 5 en 6 worden respectievelijk de bestaande op stamcellengebaseerde modellen voor toxiciteit van anthracylines (kankermedicatie) beschreven zoals deze in de literatuur kunnen worden gevonden, en passen we zelf hartcellen van iPSCs en ESCs toe om een platform te genereren voor het voorspellen van toxiciteit van het hart veroorzaakt door kankermedicein Doxorubicin. Ook voor deze medicatie is in het verleden vooral getest op dieren voordat het in de kliniek werd toegepast, en ondanks de goede werking tegen kanker, veroorzaakt het middel ook regelmatig ernstige schade aan het hart. $\mathrm{Er}$ bestaat nog geen goed model om deze toxiciteit op te evalueren en om alternatieven voor Doxorubicin op te testen zonder gebruik van dieren. Daarom presentieren we in hoofdstuk 6 een combinatie van essays die het mogelijk maakt om de toxiciteit van Doxorubicin te evalueren en om analogen van het middel te vergelijken met Doxorubicin met betrekking tot de schadelijke effecten op hartspiercellen. We demonstreren dat we met het platform de bekende mechanismen van toxiciteit kunnen aantonen, en ontdekken dat een analoog van Doxorubicin, Amrubicin, veel minder schade toebrengt aan onze hartspiercellen dan Doxorubicin, wat suggereert dat deze analoog wellicht een betere keuze is in de kliniek. 
Het proefschrift wordt afgesloten met een algemene discussie over al het werk dat in de voorgaande hoofdstukken is beschreven, alsmede met een vooruitblik naar de toekomst. 


\section{Summary}

The heart is a vital organ of the (human) body, responsible for maintaining blood circulation through the blood vessels, which facilitates, among other things, the exchange of nutrients, waste and communicative molecules between organs. The pumping force of the heart is generated by cardiac muscle cells, which are stimulated by an electrical signal to contract in coördinated fashion in order to compact the heart chamber and force the blood into the arteries. Issues with (the coördination of) contraction of the heart muscle cells may lead to heart failure, which in worst case scenario could be fatal. It is therefore of great importance to understand how the pumping action of the heart could be disrupted and how this could be solved. Up until now, animal models have been used often to model the heart itself, and also diseases of the heart or cardiac toxicity. However, animal hearts behave quite different from human hearts and therefore suffer from a reduced predicability. This makes modelling certain human heart features difficult to reproduce in animals, and could lead to a false sense of safety when screening drugs. The promising alternative to animal models is the use of pluripotent stem cells, which can be used to develop cardiac cells and tissues of a human nature. Pluripotent stem cells are able to form every cell type of the adult human body and can be derived from embryos ( $\mathrm{hESCS}$ ) or by reprogramming adult cells from a donor or patient. The latter, called induced pluripotent stem cells (iPSCs), are especially advantageous because of the absence of ethical objections and because they form a source of patient-specific stem cells, which could be used to create disease models with the exact genetic background as found in the patient.

Unfortunately, stem cell-derived cardiac cells do not reach the level of maturity of those found in human adults or patients, but rather they resemble more the cells of the fetal heart. This difference means that the cells behave somewhat different from the human adult heart, which means that they are not always appropriate for modeling adult disease. Previous studies have shown that cardiac cells derived from stem cells present a fetal-like metabolic activity that may contribute to their overall immature status. In chapter 2 , we therefore reflect on literature to find a solution for the immaturity by better replicating the metabolic environment of the human heart during fetal development. We suggest an altered composition of the culture medium, which may enable or drive further maturation of cardiac cells in the lab.

Nevertheless, cardiac muscle cells derived from stem cells can already be used for the development of relevant (disease-) models. In chapter 3 , we use cardiomyocytes derived from embryonic stem cells, containing a fluorescent tag for sarcomeric protein alpha-actinin (the DRRAGN cell line), to study the effect of tissue stiffness on contraction of the cells, and in particular, the sarcomeres 
within the cell. We found that a cardiomyocyte can increase contraction force in response to increased stiffness, but that this compensation has a limit. At stiffness higher than the limit, the sarcomeres within the cell can still contract, but the cell itself does not shorten anymore: A dyssynchrony that may be the trigger for cardiomyocyte hypertrophy and heart failure.

Next to cardiomyocytes, we also apply stem cells to derive cardiac pacemaker cells. These cells could be used for research on cardiac arrhythmias, or for the development of more complex 3D models of the heart. In chapter 4, we explore the existing protocols found in literature to derive pacemaker cells from stem cells and apply these on the DRRAGN stem cells. The DRRAGN cell line is particularly appropriate to use for this purpose, since the combination of fluorescent labels within the cell enables us to quickly, by microscopy, destinguish between cardiomyocytes and pacemaker cells. We identified the protocol that lead to the highest efficiency of pacemaker derivation, but the pacemaker cells that we obtained did no completely match the adult cells that can be found in adult human hearts. The protocol therefore requires further optimization.

In chapters 5 and 6 , we explore the existing stem cell-based models that predict toxicity to the heart induced by anthracyclines (a type of cancer medication), and apply our own assays based on stem cell-derived cardiac cells to evaluate the toxicity of Doxorubicin (a common anthracyline). Also for this class of medication, safety screening was mostly relying on animal models, before the compounds were admitted into the clinic. Despite a potent action against cancer cells, it was found to trigger severe cardiac complications in certain patients after treatment. There are no adequate models to predict or evaluate the toxicity of Doxorubicin on the heart without the use of animals. That is why we present in chapter 6 a combination of assays that enables the evaluation of Doxorubicin toxicity and facilitates the screening of Doxorubicin analogues for their potentially less toxic effects on the heart. We demonstrate that we can recapitulate the known toxic mechanisms of Doxorubicin in our platform and then we apply the platform to identify a potentially less toxic analogue of Doxorubicin, called Amrubicin, which may hold promise for future clinical application.

The disseration is concluded with a general discussion on the work presented in the chapters and with a future outlook on these subjects. 


\section{Contents}

Chapter 1 Introduction

Chapter 2 Metabolic environment in vivo as a blueprint for differentiation and maturation of human stem cell-derived cardiomyocytes

Chapter 3 A cardiomyocyte show of force: A fluorescent alphaactinin reporter line sheds light on human cardiomyocyte contractility versus substrate stiffness

Chapter 4 Generation of cardiac pacemakers from DRRAGN cells

Chapter 5 Human pluripotent stem cell-derived cardiomyocytes for assessment of anticancer drug-induced cardiotoxicity

Chapter 6 A hPSC-CM-based safety screening platform reveals reduced cardiotoxic effect of doxorubicin analogue 


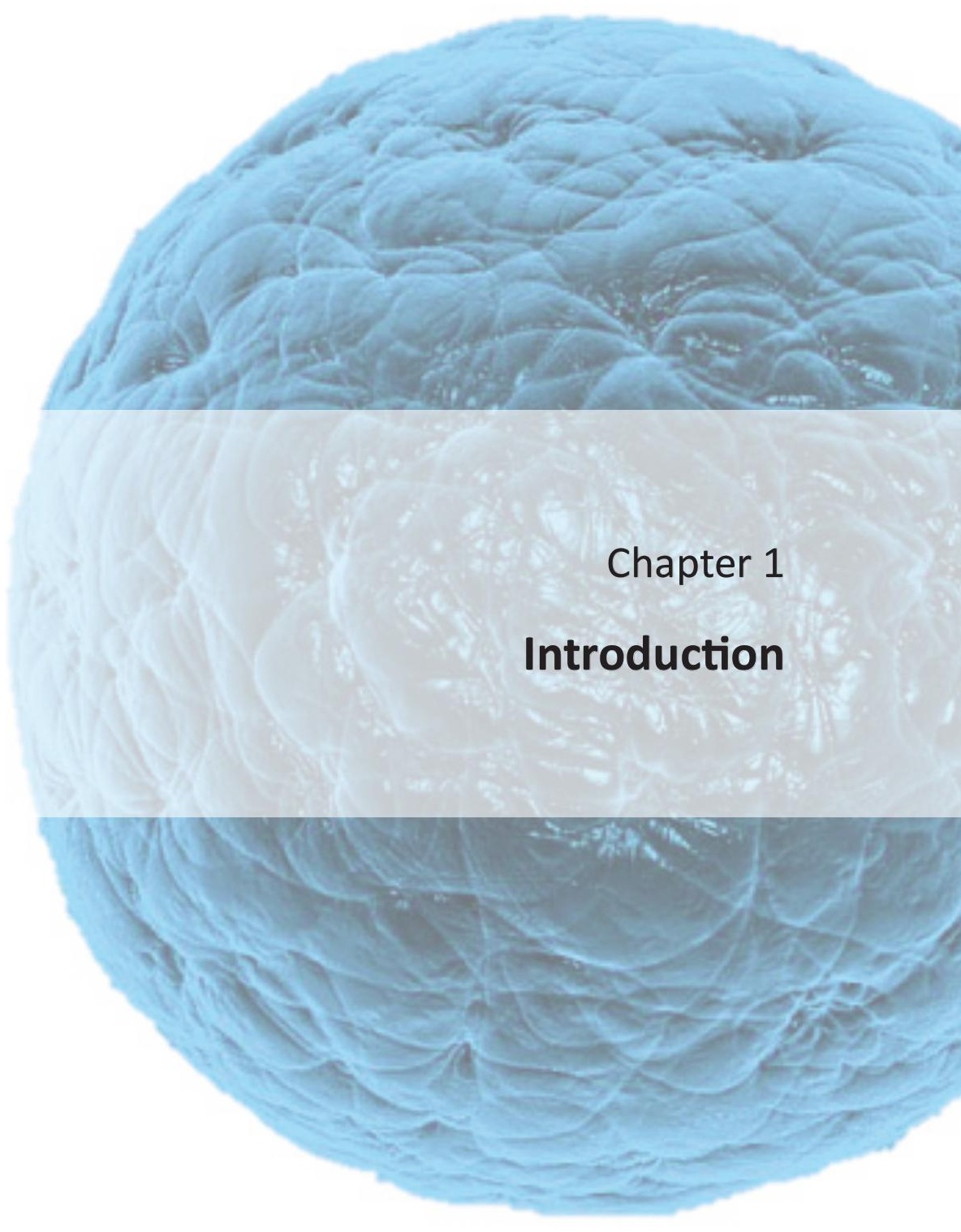




\section{Chapter 1: Introduction}

\section{An introduction to the heart}

The heart is a vital organ, conserved widely among almost all animals throughout evolutionary history, and can be found in the tiniest ant and the biggest whale. Even though the organ may differ in morphology and physiology from species to species, its function remains the same: to provide a never-ceasing flow of blood that acts as the road network of the body, transporting resources, waste and information from cell to cell. Without a circulatory system driven by the heart, vital resources such as oxygen and nutrients could not reach the cells in the interior of our bodies, and waste would accumulate indefinitely, so that cells could not survive there. Oxygen can only diffuse through tissue for about 200 $\mu \mathrm{m}$, which marks the maximal thickness of a multicellular entity if no circulation is present.(9) Due to this severe limitation in logistics, the formation of a heart in evolution was required for the development of multicellular organisms that are bigger than a grain of sand. Clearly, this development was a major step in evolution, without which we could not exist. For such a critical organ, it has a remarkably low capacity for self-repair. It is well known that the human heart cannot overcome substantial loss of viable tissue.(10) Whereas you can remove up to $70 \%$ of a liver and still have it grow back to its original size, for the human heart, almost no damage can be repaired. $(10,11)$ This makes the heart incredibly vulnerable to damage or disease, but also very interesting for researchers. The lack of regenerative power of the heart has driven research to study ways to prevent damage, as well as repair it once it happens. Research on cardiovascular disease is one of the major research areas in the world and will continue to be so since most major issues have not been solved yet in the hundreds of years that cardiovascular research has been conducted. This is caused, in part, by the design of the heart itself, as for such a "simple thing" as a fluid pump, the cardiac architecture turns out to be quite intricate.

\section{Heart physiology}

The human heart consists of four compartments, two atria and two ventricles (see Fig 1). The atria receive the blood returning from the venal circulation, and pump this into the ventricles. The ventricles in turn contract to pump the blood from the heart into the arterial circulation, starting with the pulmonary arteries and the aorta. The right side of the heart receives blood from the periphery and pumps to the lungs, while the left side of the heart receives blood from the lungs and pumps it to the periphery. In that sense, the heart may be considered to be two pumps, conjoined at the septum, linked in series to keep the blood flowing. This perspective is particularly important when thinking of heart failure on one of the sides; since both parts are linked in series, they both must pump the same 


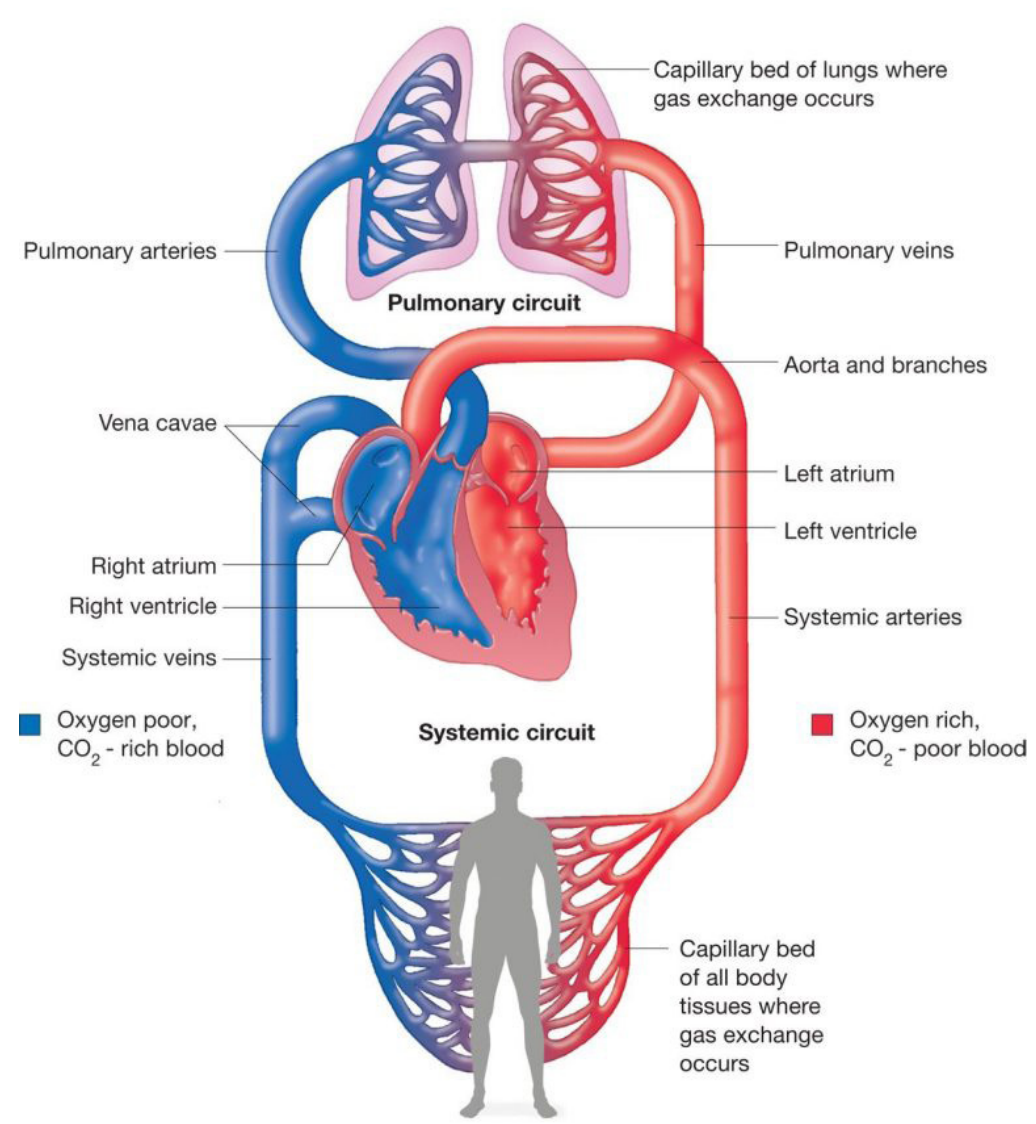

Figure 1: The heart and circulatory system in a diagram, showing the heart as a "double pump" and the parallel circulation of the lungs and the rest of the body. Adapted from (4)

volume of blood with every beat, otherwise blood builds up in either the lungs or the periphery. Such a build-up affects the function of the other side of the heart, causing failure on the longer term as well. Thus, damage or disease manifesting in a specific part of the heart eventually will affect the whole heart, which makes treatment of heart problems a race against the clock to prevent extensive whole organ disease.

Pumping of the heart is facilitated by the heart musculature, in which rectangularly shaped cardiomyocytes (CMs) are the contracting cells responsible for heart compartment constriction (Fig 2). Cardiomyocytes, similar to skeletal myocytes, contract by shortening of sarcomeres, the smallest contractile unit in the myocyte, which span the cell along the long axis from beginning to end in a series of sarcomeres called a myofibril. Sarcomeres are complex multimeric structures, featuring actin "light" filaments and myosin "heavy" filaments 


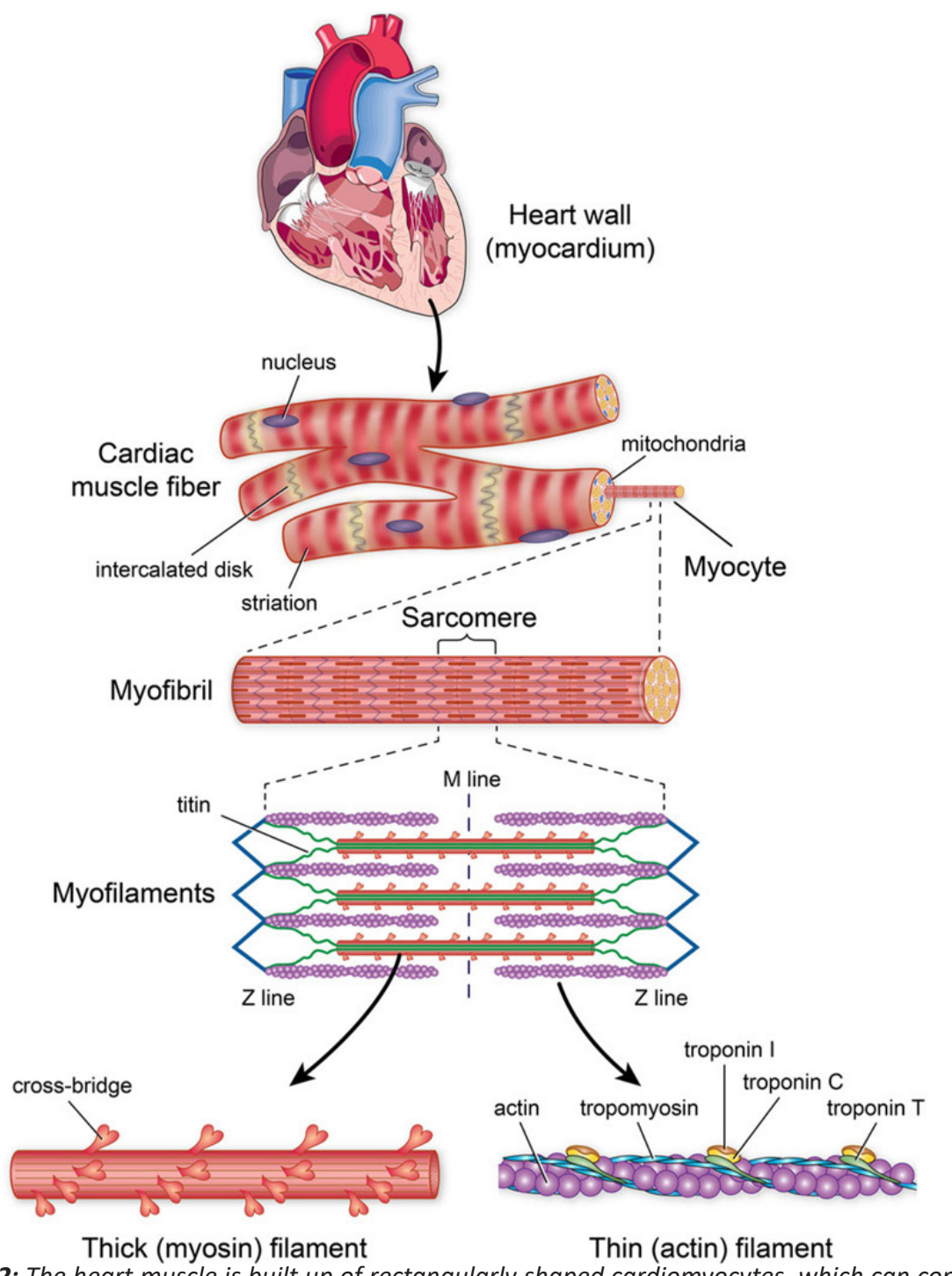

Figure 2: The heart muscle is built up of rectangularly shaped cardiomyocytes, which can contract via "sliding" of the thick (myosin) and thin (actin) filaments. Contraction is regulated through calcium-sensitive proteins tropomyosin and troponins. Adapted from (8)

organized in a parallel array, similar to interlocking fingers of two hands, so that the actin and myosin filaments can interact with each other on the long axis. This interaction is uniaxial and is the driving power of CM contraction. Upon activation, myosin heads on the myosin filaments begin interacting with the actin filaments, binding to it, then pulling it along the long axis and releasing again, repeatedly, making the sarcomere shorter and shorter, until the trigger is removed, and the filaments move back to their original, relaxed position. Since 
the myofibrils are connected to the cytoskeleton of the cell at the short edges, a simultaneous contraction of all sarcomeres within the myofibril would contract the whole cell. If properly timed, all CMs contract in a rapid sequential, almost simultaneous manner, shortening the entire cardiac wall, thus constricting the atrial or ventricular compartments, and squeezing out the blood. Timing is thus crucial, both at the level of the sarcomere as at the level of the myocardial tissue. Untimed contractions of sarcomeres within a myofibril may lead to reduced cell shortening or contractile power, whereas untimed CM contractions in the myocardium lead to cardiac arrhythmias and heart failure. As such, a system is in place at each level, facilitating coordinated contraction and proper heart function.

On a sarcomeric level, actin/myosin interaction is initiated by the influx of a relatively small amount of calcium ions $\left(\mathrm{Ca}^{2+}\right)$ into the $\mathrm{CM}$ from the extracellular space, in response to an action potential in the shape of a cell membrane potential depolarization. Calcium ions moving into the cell triggers the release of a much larger amount of $\mathrm{Ca}^{2+}$ stored in the sarcoplasmic reticulum (SR), which binds to the troponin-tropomyosin regulatory complex in the sarcomere. This binding changes the conformation of the troponin complex, exposing the binding sites of the myosin heads on the actin filaments and initiating sarcomeric shortening.

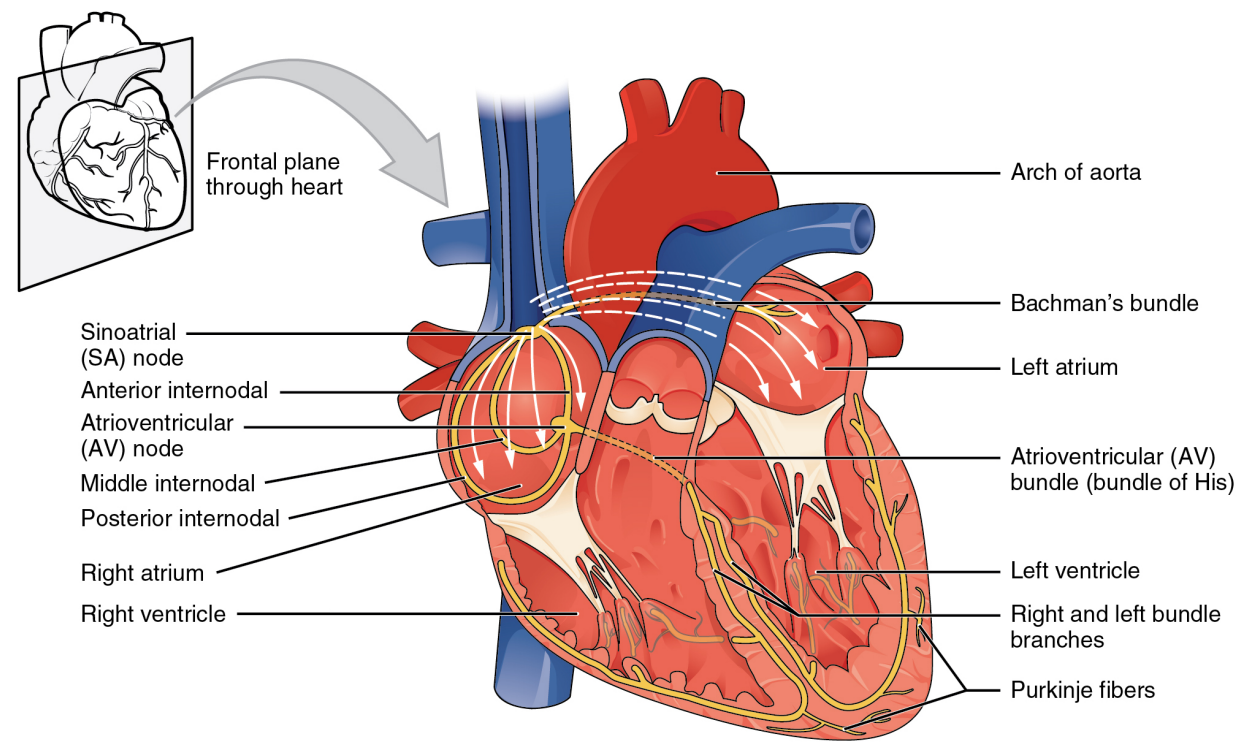

Anterior view of frontal section

Figure 3: The cardiac conduction system shown in yellow. A stimulus for contraction (action potential) is initiated in the sinoatrial node, then travels across the atrial wall towards the atrioventricular node, from where it is transported to the apex of the heart by the bundles of His and distributed across the ventricular walls by the Purkinje fibers. Adapted from (5) 
Calcium ion binding to troponin thus dictates the onset and end of contraction, as well as intensity, and should be timed perfectly in the cell to contract all sarcomeres of the myofibril at the same time. Human adult CMs therefore locate the $\mathrm{Ca}^{2+}$ channels of the cell membrane in T-tubuli, which invaginate into the cell, and the SR $\mathrm{Ca}^{2+}$ channel Ryanodine Receptor (RyR) to closely approximate each sarcomere to ensure the shortest travel distance of $\mathrm{Ca}^{2+}$ and thus the most efficient delivery of the contraction signal.

On a myocardial level, contraction is coordinated by delivery of the action potential from a central, pace setting region called the sino-atrial node (SAN). This biological pacemaker generates an action potential that is passed down to $\mathrm{CMs}$ of the atria and the ventricles via a dedicated conduction system. Through this, the SAN first activates the atrial myocardium, after which the signal is received in the atrio-ventricular node (AVN), then passed on along the bundles of His and the Purkinje fibers to the apex of the heart, from which the stimulus spreads up towards the valves of the heart. Since the exits of the ventricles, the arteries, are located at the top of the ventricles, this order of delivering the action potential ensures that the blood is pushed up towards the exit, instead of down towards the apex, a dead end. Sequential contraction of the atrial and ventricular myocardium is crucial to be able to pump blood in the right direction, and to build up enough pressure to make blood flow possible. Any disturbance in action potential transmission could jeopardize this well-coordinated muscular motion, resulting in failure of heart function and in the worst case, death. In Chapter 4: Generation of cardiac pacemakers from DRRAGN cells, we describe the efforts to develop our own pacemaker cells in vitro from human pluripotent stem cells (hPSCs, see also below), that may enable us to model diseases related to the conduction system and to develop a biologically paced cardiac tissue for arrhythmia modelling.

Proper heart function does not rely on $\mathrm{CMs}$ alone. Their contractile function is supported by numerous other cell types that contribute to normal heart development and function. Firstly, the conduction system mentioned above consists not of working CMs, but of pacemaker and signal transduction cells specialized in the generation and conduction of action potentials that pace the heart.(12) Second, residential supporting cell types play roles in organ formation and mechanical stability (such as fibroblasts), delivery of nutrients and removal of waste (including endothelial cells and smooth muscle cells), and direct CM functional support and tissue maintenance (such as macrophages and epicardial cells).(13) Dysfunction of any of these cells, including the CMs themselves, may lead to heart failure, and are thus important to include in research into cardiovascular disease (CVD). 


\section{Modelling human cardiovascular disease}

Cardiovascular disease (CVD) is a broad term for a number of causes for cardiac and vascular dysfunction, any cause that can interfere with proper pumping function of the heart or circulation of the blood. The entire group of cardiovascular diseases account for a fifth to a quarter of all deaths in the USA, making it the leading cause of mortality in that country.(14) In Europe, CVD is the cause of a third to almost a half of all deaths, and costed an estimated 210 billion euros to the EU economy in 2015.(15) The incidence (new cases) of CVD is roughly 1000 cases per 100.000 inhabitants, indicating that every year in the Netherlands alone, roughly 170.000 new cases of CVD are being diagnosed.(16) These numbers underline the threat of this group of diseases to public health, but also the economy, and the urgent need to find solutions to these illnesses.

Models that mimic heart function are important for three distinct reasons: 1) To understand fundamental developmental and functional processes of the human heart under normal circumstances. 2) To simulate the onset and progression of genetic or non-hereditary heart diseases for understanding or treatment purposes, and 3) To evaluate the potentially harmful effect of novel and existing drug agents on the heart (toxicity and safety screening).(17)

When recreating heart function or disease, predictability of the model is key. Whether the desired readout is of complex or simple nature, the chosen model should be capable of delivering the right answer to the research question. Predictability is determined by a number of factors: complexity, relevance, and read-outs. The level of complexity and relevance should be tailored to the model to achieve the highest possible predictability but does not necessarily have to be high. Historically, heart function and disease were predominantly modelled on animal hearts, either in vivo as part of a living test animal, or ex vivo in a Langendorff setup. Such in vivo heart models feature the greatest achievable complexity, since the heart is being studied in its natural environment, providing all stimuli that the heart would normally be exposed to. However, this complexity comes at the cost of technical flexibility and relevance since readouts on cellular level are difficult to obtain and animal tissue is known to respond differently to disease cues than human hearts. This does not make them inferior to models of human origin by default, but it may make them the less optimal choice in a subset of studies. More controlled and consequently less complex are the in vitro models on cellular scale. Due to the scarcity of human heart cells, in the past these models also relied heavily on cells of animal origin, reducing their relevance for human disease while also showing inferior complexity compared to in vivo models.

The arrival of hPSCs as a source for cardiac cells in vitro paved the way to 


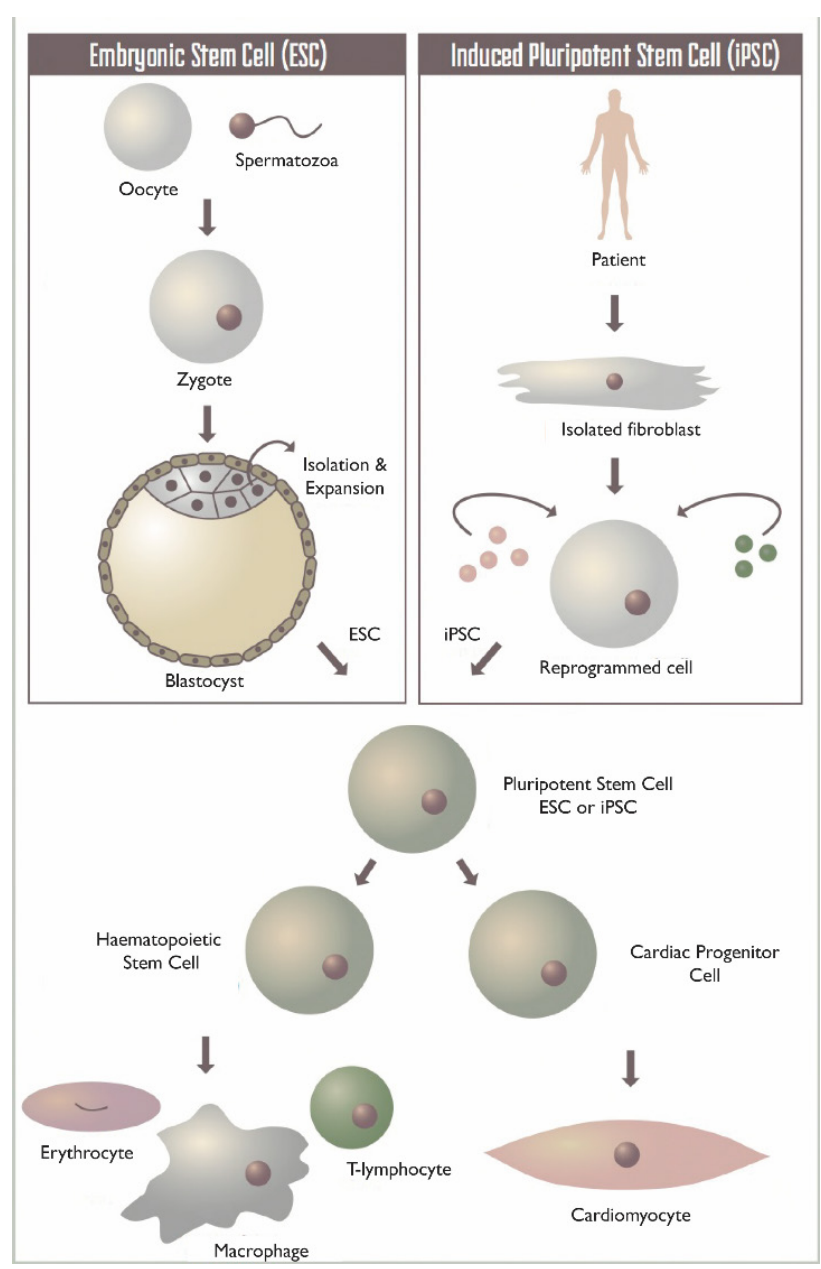

Figure 4: Stem cell sources for in vitro research. Pluripotent stem cells may be harvested from the inner cell mass of blastocyst stage human embryos (top left) or produced from reprogrammed somatic cells of donors or patients (top right). These pluripotent cells can then be differentiated to all cells of the human body, including blood cells and cardiomyocytes. Adapted from (7).

humanized cardiac models that could benefit from the technical flexibility of in vitro systems without sacrificing relevance.(18) Pluripotent stem cells can be obtained from the inner cell mass of human embryos that were no longer required for in vitro fertilization treatment in the clinic (Fig 4). These cells are capable of unlimited proliferation and of differentiating into all cells of the human body (hence "pluripotent"). In research, they can then be coerced into differentiating towards cells of a cardiac phenotype, such as cardiomyocytes, and, due to the unlimited proliferation of the stem cells, provide an inexhaustible source of human CMs for use in experiments. Using cells from human embryos is controversial though and provides only a limited diversity in genetic background 
of the cells. The development of a technique to reprogram differentiated somatic cells back to pluripotent stem cells through the induction of four essential embryonic transcription factors meant that stem cells could be derived from any patient, thus inheriting the exact genetic background of that patient.(19) These induced pluripotent stem cells (iPSCs) are ideal for studies of hereditary disease, but also for studying cardiac disease in models of phenotypical diversities. Protocols for the derivation of several cardiac cell types from hPSCs have been established over the years, enabling the study of CMs and other cardiac cells, in combination or individual, to great extent.

The specialized architecture of CMs found in vivo is often lacking in immature pluripotent stem cell-derived cardiomyocytes (hPSC-CMs) differentiated in vitro, giving these cells a less powerful and coordinated contraction signature.(18) Immaturity is a persistent flaw of hPSC-CMs, and continuing research to this day is performed to improve the mature state of the derived CMs. Factors known to enhance $\mathrm{CM}$ maturity include 1) mechanical stimulation, in the shape of stretch or compression of the cell or by substrate-related cues, 2) electrical stimulation, using electrical pacing equipment to deliver a steady beating rhythm, 3) 3D (co-) culture, where interaction with $\mathrm{CMs}$ or other cell types on all sides of the cell improve the function of the $\mathrm{CM}$, and 4) the metabolic and hormonal microenvironment of the cell.(20) The latter has been underexposed in studies to date, but received more attention in recent years and will be discussed in the next chapter of this thesis (Chapter 2: Metabolic environment in vivo as a blueprint for differentiation and maturation of human stem cell-derived cardiomyocytes). In that chapter, we postulate that the current typical cell culture conditions are so far off from the in vivo situation, that generated $\mathrm{CMs}$ in vitro are retained in an immature state. By matching the exposure to metabolites and hormones as closely as possible to the in vivo development, the maturity of hPSC-CMs may be enhanced or facilitated through a more mature metabolism.

\section{The pathophysiology of CVD and the complexity of disease modelling}

CVD may be caused directly by genetic defects, environmental factors, or a combination of both, as well as indirectly as a result of other body system failures.(16) As mentioned earlier, any cause of reduced contractile function of the cardiac wall may cause a cascade towards total organ failure if not handled appropriately, due to the intrinsic response of the heart to failure. This response compensates for the loss in cardiac output and is termed cardiac remodelling. On a cellular level, remodelling includes an adaptive response of the CMs to increase their contractility to improve cardiac contraction through hypertrophy.(21) On 
tissue level, the increased ventricular wall stress and loss of cells both lead to enhanced deposition of collagen, as lost CMs cannot be replaced with new cells. Cardiomyocytes may be lost due to ischemic heart disease, myocarditis or toxicity, all of which leads to irreversible damage to the heart. Underperforming CMs due to genetic defects or a hostile working environment respond by increasing in size, hypertrophy, which helps on the short term, but sustained hypertrophy often leads to cell loss. Other stresses to the heart, such as high blood pressure, moderate ischemia, or cardiac arrhythmias, often lead to a fibrotic response of the myocardial wall. These distinct cardiac illnesses therefore have in common that they may all trigger extensive cardiac remodelling, including fibrosis formation and CM hypertrophy.(21) Collagen deposition makes the myocardial wall more fibrotic, strengthening it against pressures and stresses, but hindering the required contractile motion of the muscle by increasing the stiffness, and thus the resistance, of the muscle tissue.(21) In addition, fibrous tissue acts as a conduction block for action potentials, through which it may generate a more favourable substrate for additional arrhythmias to occur or be sustained. Fibrosis of the heart is therefore often a progressive phenotype, as increased stiffness of the heart wall leads to harder work of the CMs, consequent $\mathrm{CM}$ failure and additional remodelling.(22) The effect is known in the clinic, but the exact response of the $\mathrm{CM}$ to increased surface stiffness remains largely unknown. In Chapter 3: A cardiomyocyte show of force: A fluorescent alpha-actinin reporter line sheds light on human cardiomyocyte contractility versus substrate stiffness we describe an exploratory study of the contractile response of hPSC-derived $\mathrm{CMs}$ to an increased substrate stiffness, by using a fluorescent reporter cell line that continuously expresses fluorescent $\alpha$-Actinin.

Damage to the myocardium may also be caused by toxic compounds. Due to their highly active and contractile phenotype, $\mathrm{CMs}$ are rather sensitive to toxins that may affect ion homeostasis and metabolism, or induce the formation of reactive oxygen species.(23) Some drugs are marketed despite the cardiotoxic effects that it may possess, but only because the side effects are worth the risk. An example is the group of anti-neoplastic drugs called Anthracyclines, drugs that are quite potent in combatting a number of malignancies such as breast cancer. Unfortunately, they are also rather effective in targeting CMs, which makes them undesirable treatment options. In Chapter 5: Human pluripotent stem cell-derived cardiomyocytes for assessment of anticancer drug-induced cardiotoxicity, we summarize the toxicity caused by these Anthracyclines, in particular doxorubicin, and the usefulness of hPSC-CMs for the screening of toxicity in the development of these drugs, or the development of a proper strategy to reduce the side effects of the anti-cancer drugs.

Relatively many drugs present with cardiotoxic side effects either during clinical 
trial phase or after marketing.(24) Interestingly, only $9 \%$ of all rejected drugs in clinical trial phase are rejected on account of their cardiotoxic properties, while $45 \%$ of all drugs withdrawn from the market after approval are removed for the same reason.(24) This discrepancy clearly illustrates the lack of predictability of current (pre-)clinical models, often based on lab animals or simplified (animal) cell cultures. Since animals differ in their heart physiology from humans, the outcome of toxicity screening in animals is of low predictive value. There is thus a need for improved drug screening platforms to eliminate cardiotoxic compounds from the developmental phase before they enter clinical trial or indeed the market and this may be done by developing more reliable human cell-based models. In Chapter 6: Doxorubicin-induced cell-type specific toxicity can be recapitulated in vitro using hPSC-derived cardiac cells, we use hPSC-derived cells to demonstrate the toxic effect of doxorubicin on the heart using a safety screening in vitro system. Testing for toxicity is thus paramount, and the better the quality of the cardiac model, the better the prediction of potential safety failures. The development of novel drugs is an undertaking of billions of euros, of which a major part is spent in pre-clinical and clinical trial phases at the end of the developmental track. Drugs failing in this stage of development due to safety issues may have been detected earlier in development with the appropriate in vitro model, which could save large amounts of time and money in drug development. Proper in vitro models thus can contribute to a swifter drug development and lower health care costs, as well as a reduction of animal use in safety pharmacology.

\section{Advanced 3D micro-physiological human cardiac models}

Although the human identity of hPSC-derived cardiac cells greatly improves their relevance and with that their predictability, studying effects of disease or toxicity on an organ level remains a challenge. The current frontier of human heart in vitro modelling therefore lies in the development of more complex, organ-like human cardiac tissues using hPSC-derived cells to enhance complexity while retaining relevance and preferably, great read-out possibilities. Examples of such technologies include, but are not limited to, organ-on-chip (OOC) models and engineered heart tissues (EHTs, as seen in chapter 6) (Fig 5A+B). Organ-on-chip models feature microfluidic cell culture compartments that can be continuously perfused with cell culture medium, which gives them a temporal resolution within the experiment, and superior control over the cell micro-environment compared to conventional static cell culture.(25) Microfluidic heart-on-chips may range from simple, single straight channels to complex multichannel devices with coculture of several cell types in order to better recapitulate the cardiac tissue environment in vivo.(25) Due to their limited size (they often fit on top of a microscope slide) and transparency, they are ideal for real-time monitoring of cardiac responses on a cellular level. Thus, organ-on-chips weigh heavily on technical flexibility while allowing some improved complexity compared to conventional 2D static cultures. 
Novel heart-on-chips are known to house miniature cardiac 3D tissues, that combine the technical flexibility of organ-on-chip technology with the complexity of 3D cultures (Fig 5C).(3) Engineered heart tissues on the other hand are millimetre- to centimetre-sized 3D cardiac tissues organised in a ring shape that are spanned across flexible pillars (Fig 5B). $(26,27)$ These pillars provide a passive pull on the tissue, enhancing cellular organisation and arguably maturation(28), but more importantly, allow for contraction force measurements as a functional cardiac muscle readout. These models are superior to conventional 2D models in predicting the effect of a toxin or drug on the contractile function of $\mathrm{CMs}(29)$, but sacrifice in cell level resolution. Hybrid models of EHTs and heart-on-chips also exist, spanning the gap between both technologies.(30) The most complex in A

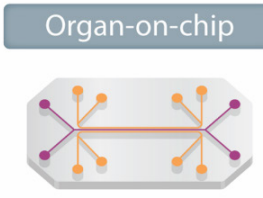

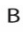
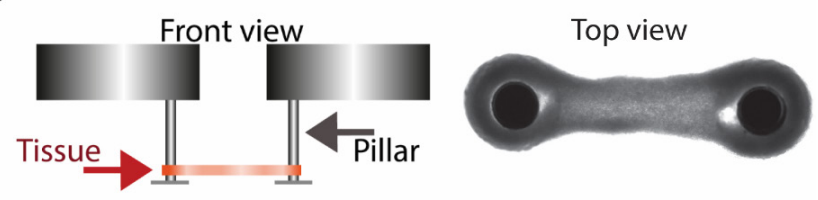

C
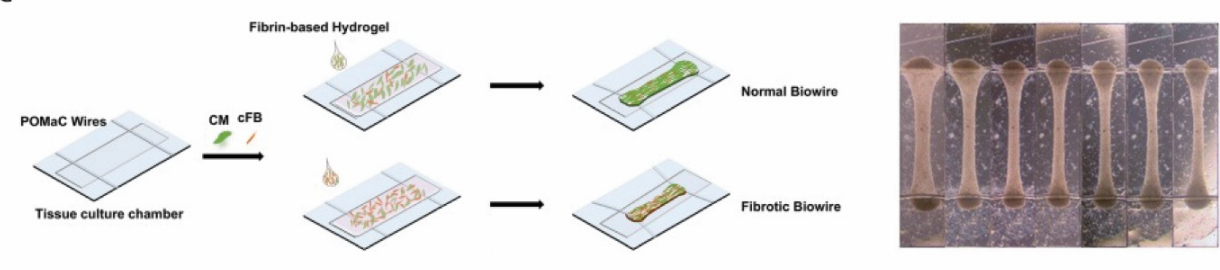

D

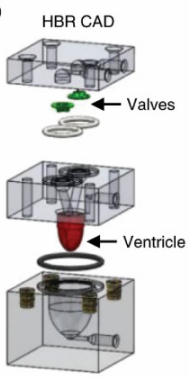

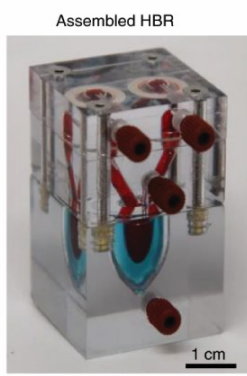

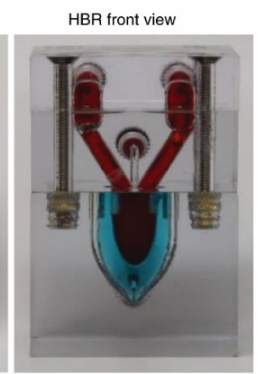

Figure 5: Towards more complex, human cell-based in vitro models for the study of health, disease, and safety pharmacology. A) A schematic representation of an organ-on-chip device in a simple, 3-channel layout. Adapted from (1) B) A schematic representation of an EHT construct of hPSC-CMs suspended between flexible pillars (left), and a top view micrograph used for live contractility measurements (right). Adapted from [Ribeiro et al 2021] C) The fabrication of EHT-like cardiac tissue constructs on horizontal wires within a microfluidic chip (left), demonstrating the convergence of microfluidics and EHT technologies. Top view Biowire tissues inside the microfluidic chip (right). Adapted from (2, 3) D) A hPSC-CM-based "mini-heart" composed of only one chamber is able to pump fluid into an "arterial" channel, enabling clinical readouts such as pressure-volume relationships, and arrhythmia on a 3D structure. Adapted from (6) 
vitro hPSC-based heart models however are developed as mini-hearts, featuring a balloon like tissue of cardiac cells containing a lumen that can be filled with medium and ejected by contraction of the cardiac tissue (Fig 5D).(6) These models go one step further in functional readouts, by enabling the measurement of ejection fraction, end-diastolic or systolic volumes, and may also be used for 3D arrhythmia modelling. In this way, the complexity of an ex-vivo heart can be approximated using cells that are relevant for human disease modelling.

\section{Concluding remarks}

Cardiac (disease) modelling is important for the understanding of heart physiology and pathophysiology, and for the safety pharmacology and drug discovery. As the heart is an intricate and vulnerable organ, and conventional models are not able to fully recapitulate heart function or pathological response, improvement of models is of upmost importance. This thesis contains work related to several aspects of cardiovascular disease. The development of the cardiac pacemaker is described as a tool for the study of arrhythmias; the toxic effect of doxorubicin is explored in hPSC-CMs as a cause for CM dysfunction and death; and the effect of increased substrate stiffness is evaluated in a custom developed reporter cell line as a model for cardiac remodelling after injury. In that sense, the development, onset of disease and aftermath are represented in this work, and, albeit not directly linked to one another, provide an impression of the capabilities of the hPSC as a tool for cardiac model development. Furthermore, a strategy to enhance the maturity of hPSC-CMs is proposed that may facilitate to improve future in vitro cardiac models. Naturally, this work is only a collection of baby steps in the scientific march to the ultimate goal of cardiac disease-free living, however my hope is that it may contribute to reaching that goal eventually. 


\section{References}

1. Paloschi V, Sabater-Lleal M, Middelkamp H, Vivas A, Johansson S, van $\operatorname{der}$ Meer A, et al. Organ-on-a-chip technology: a novel approach to investigate cardiovascular diseases. Cardiovasc Res. 2021.

2. Wang EY, Rafatian N, Zhao Y, Lee A, Lai BFL, Lu RX, et al. Biowire Model of Interstitial and Focal Cardiac Fibrosis. ACS Cent Sci. 2019;5(7):1146-58.

3. Zhao Y, Rafatian N, Wang EY, Feric NT, Lai BFL, Knee-Walden EJ, et al. Engineering microenvironment for human cardiac tissue assembly in heart-on-achip platform. Matrix Biol. 2020;85-86:189-204.

4. Furst J. What is the Function of Veins in the Circulatory System? 2020 [Available from: https://www.firstaidforfree.com/what-is-the-function-of-veinsin-the-circulatory-system/.

5. Conduction System of the Heart. 2021 [Available from: https:// anatomytool.org/content/openstax-anatphys-fig1918-conduction-system-heartenglish-labels.

6. MacQueen LA, Sheehy SP, Chantre CO, Zimmerman JF, Pasqualini FS, Liu $X$, et al. A tissue-engineered scale model of the heart ventricle. Nat Biomed Eng. 2018;2(12):930-41.

7. Somhegyi H. Stem cells: a brief history and outlook 2014 [Available from: https://sitn.hms.harvard.edu/flash/2014/stem-cells-a-brief-history-andoutlook-2/.

8. Golob M, Moss RL, Chesler NC. Cardiac tissue structure, properties, and performance: a materials science perspective. Ann Biomed Eng. 2014;42(10):200313.

9. Carmeliet P, Jain RK. Angiogenesis in cancer and other diseases. Nature. 2000;407(6801):249-57.

10. Uygur A, Lee RT. Mechanisms of Cardiac Regeneration. Dev Cell. 2016;36(4):362-74.

11. Fausto N. Liver regeneration. J Hepatol. 2000;32(1 Suppl):19-31.

12. Liang $X$, Evans SM, Sun Y. Development of the cardiac pacemaker. Cell Mol Life Sci. 2017;74(7):1247-59.

13. Hulsmans $M$, Clauss S, Xiao L, Aguirre AD, King KR, Hanley A, et al. Macrophages Facilitate Electrical Conduction in the Heart. Cell. 2017;169(3):51022.e20. 
14. Heron M. Deaths: Leading Causes for 2017. Natl Vital Stat Rep. 2019;68(6):1-77.

15. Wilkins E. European Cardiovascular Disease Statistics 2017 edition. European Heart Network. 2017.

16. Timmis A, Townsend N, Gale CP, Torbica A, Lettino M, Petersen SE, et al. European Society of Cardiology: Cardiovascular Disease Statistics 2019. Eur Heart J. 2020;41(1):12-85.

17. Savoji H, Mohammadi MH, Rafatian N, Toroghi MK, Wang EY, Zhao Y, et al. Cardiovascular disease models: A game changing paradigm in drug discovery and screening. Biomaterials. 2019;198:3-26.

18. Devalla HD, Passier R. Cardiac differentiation of pluripotent stem cells and implications for modeling the heart in health and disease. Sci Transl Med. 2018;10(435).

19. Takahashi K, Tanabe K, Ohnuki M, Narita M, Ichisaka T, Tomoda K, et al. Induction of pluripotent stem cells from adult human fibroblasts by defined factors. Cell. 2007;131(5):861-72.

20. Besser RR, Ishahak M, Mayo V, Carbonero D, Claure I, Agarwal A. Engineered Microenvironments for Maturation of Stem Cell Derived Cardiac Myocytes. Theranostics. 2018;8(1):124-40.

21. Cohn JN, Ferrari R, Sharpe N. Cardiac remodeling-concepts and clinical implications: a consensus paper from an international forum on cardiac remodeling. Journal of the American College of Cardiology. 2000;35(3):569-82.

22. Piek A, de Boer RA, Sillje HH. The fibrosis-cell death axis in heart failure. Heart Fail Rev. 2016;21(2):199-211.

23. Schwach V, Slaats RH, Passier R. Human Pluripotent Stem Cell-Derived Cardiomyocytes for Assessment of Anticancer Drug-Induced Cardiotoxicity. Front Cardiovasc Med. 2020; 7:50.

24. Ferri N, SiegI P, Corsini A, Herrmann J, Lerman A, Benghozi R. Drug attrition during pre-clinical and clinical development: understanding and managing druginduced cardiotoxicity. Pharmacol Ther. 2013;138(3):470-84.

25. Bhatia SN, Ingber DE. Microfluidic organs-on-chips. Nat Biotechnol. 2014;32(8):760-72.

26. Mannhardt I, Breckwoldt K, Letuffe-Breniere D, Schaaf S, Schulz H, Neuber C, et al. Human Engineered Heart Tissue: Analysis of Contractile Force. 
Stem Cell Reports. 2016;7(1):29-42.

27. Goldfracht I, Protze S, Shiti A, Setter N, Gruber A, Shaheen N, et al. Generating ring-shaped engineered heart tissues from ventricular and atrial human pluripotent stem cell-derived cardiomyocytes. Nat Commun. 2020;11(1):75.

28. Tu C, Chao BS, Wu JC. Strategies for Improving the Maturity of Human Induced Pluripotent Stem Cell-Derived Cardiomyocytes. Circ Res. 2018;123(5):5124.

29. Eder A, Vollert I, Hansen A, Eschenhagen T. Human engineered heart tissue as a model system for drug testing. Adv Drug Deliv Rev. 2016;96:214-24.

30. Mastikhina O, Moon BU, Williams K, Hatkar R, Gustafson D, Mourad O, et al. Human cardiac fibrosis-on-a-chip model recapitulates disease hallmarks and can serve as a platform for drug testing. Biomaterials. 2020;233:119741. 


\section{Chapter 2}

Metabolic environment in vivo as a blueprint for differentiation and maturation of human stem cell-derived cardiomyocytes 


\title{
Chapter 2: Metabolic environment in vivo as a blueprint for differentiation and maturation of human stem cell- derived cardiomyocytes
}

\author{
Rolf H. Slaats, $\mathrm{MSc}^{1}$, Verena Schwach, $\mathrm{PhD}^{1}$, Robert Passier, $\mathrm{PhD}^{1,2, \#}$ \\ ${ }^{1}$ Department of Applied Stem Cell Technologies, TechMed Centre, University of \\ Twente, Drienerlolaan 5, 7500AE, Enschede, The Netherlands, ${ }^{2}$ Department of \\ Anatomy and Embryology, Leiden University Medical Centre, PO Box 9600, 2300 \\ RC Leiden, The Netherlands, "Corresponding author: robert.passier@utwente.nl, \\ Drienerlolaan 5, 7500AE, Enschede, The Netherlands.
}

Patient-derived human pluripotent stem cell-derived cardiomyocytes (hPSCCMs) are increasingly being used for disease modeling, drug screening and regenerative medicine. However, to date, an immature, fetal-like, phenotype of hPSC-CMs restrains their full potential. Increasing evidence suggests that the metabolic state, particularly important for provision of sufficient energy in highly active contractile $\mathrm{CMs}$ and anabolic and regulatory processes, plays an important role in cardiomyocyte maturation, which affects crucial functional aspects of CMs, such as contractility and electrophysiology. During embryonic development the heart is subjected to metabolite concentration that differ substantially from that of hPSC-derived cardiac cell cultures. A deeper understanding of the environmental and metabolic cues during embryonic heart development and how these cues change postnatally, will provide a framework for optimizing cell culture conditions and maturation of hPSC-CMs. Maturation of hPSC-CMs will improve the predictability of disease modeling, drug screening and drug safety assessment and broadens their applicability for personalized medicine and regenerative medicine.

\section{Highlights}

- $\quad$ hPSC-CMs are characterized by metabolic and functional immaturity.

- Metabolism influences maturation of CMs in vivo and in vitro.

- The metabolic micro-environment in vitro differs substantially from in vivo.

- Reformulation of culture medium may enable enhanced maturation of $\mathrm{hPSC}-\mathrm{CMs}$ in vitro. 


\section{Introduction}

Advantages of human pluripotent stem cell-derived cardiomyocytes (hPSC-CMs) in the fields of disease modeling, drug screening and safety pharmacology and regenerative medicine have been convincingly demonstrated in the past decade. (1) Nevertheless, hPSC-CMs suffer from an immature fetal-like phenotype compared to adult $\mathrm{CMs}$ in vivo (1), which hamper their use in pre-clinical and clinical applications. It is therefore of paramount importance to develop defined strategies to improve maturity of hPSC-CMs. Immaturity of hPSC-CMs can, at least in part, be attributed to their non-native exposure to environmental cues.(2) While mechanical and electrical triggers for hPSC-CM maturation have been described in length (1), only recently attempts have been made to improve maturity of hPSC-CMs through metabolic cues. During embryonic, fetal and postnatal development, the heart is exposed to a variety of metabolic cues and environmental and cellular changes that affect metabolism of cells, which consequently enable, or even trigger CM functional maturation. During development, cells of the heart undergo profound changes in expression patterns of genes that are involved in metabolism, specifically controlling the use of fatty acids, glucose, and lactate as energy substrates, as well as oxygen for metabolic oxidation. Previously, it has been suggested that metabolism can be driven to a more mature state in hPSC-CMs, with a concomitant improvement of contractile function. $(2,3)$ Observations such as these suggest that lessons learned from in vivo heart development and metabolism may be translated to the in vitro situation, in order to generate hPSC-CMs that are comparable to human adult CMs. In contrast to adult CMs in vivo, hPSC-CMs rely mostly on anaerobic glycolysis instead of oxidative phosphorylation for adenosine triphosphate (ATP) generation.(3) Clearly, in order to meet with the high energy demand required to sustain contractile function in adult $\mathrm{CMs}$, a switch from anaerobic glycolysis to a more efficient mitochondrial oxidative metabolism needs to be realized.(4) Mechanisms governing the essential switch from the fetal to the adult metabolic phenotype are only partly understood. However, increasing evidence suggests that environmental changes, mainly differences in substrate availability, may play an important role.

The notion that metabolic gradients play a crucial role during embryonic development has been recognized for more than a century. Exposure of the developing heart to non-physiological concentrations of metabolites in utero may adversely affect CM or heart function later in adult life.(5) This so-called "fetal programming" may also occur in vitro during differentiation of hPSCs towards the cardiac lineage and may contribute to the observed immature phenotype of hPSC-CMs. Nevertheless, in vitro culture conditions have not been appropriately adjusted, but rather provide metabolites in a ratio and concentration that does not support proper maturation of cardiac cells.(6) Most hPSC cultures feature a 
stepwise differentiation towards the cell type of interest by controlled activation and/or inhibition of signaling pathways, accurately mimicking local signaling cascades that occur during early embryonic development. However, additional medium nutrients and components are mostly based on practical and historical considerations for survival, maintenance and expansion of cell cultures, without taking into account how in vivo conditions may facilitate $\mathrm{CM}$ maturation. Here, we will discuss micro-environmental and metabolic changes during human embryonic and postnatal cardiac development and maturation, which could serve as a blueprint for $\mathrm{CM}$ maturation in vitro.

\section{Cardiomyocyte function and metabolism in adult human hearts}

Contractile $\mathrm{CMs}$ are responsible for heart muscle shortening and subsequent pumping action of the heart. Adult $\mathrm{CMs}$ are composed of myofibril bundles that interconnect with each other via intercalated discs to form a syncytium of striated muscle. The smallest contractile unit of each myofibril, known as the sarcomere, consists of myosin 'thick' and actin 'thin' filaments, as well as a troponintropomyosin regulatory complex. Contraction is initiated upon depolarization of the cell membrane via $\mathrm{Na}^{+}$influx, which results in trans-sarcolemmal calcium influx via L-type calcium channels. This relatively low amount of calcium stimulates ryanodine receptors to induce calcium release from the sarcoplasmic reticulum (SR) storage pools. Calcium released by the SR subsequently binds to the troponin regulatory unit, enabling a conformational change that results in the detachment of the actin filament from the regulatory complex. Actin is then accessible for binding to myosin. This interaction between myosin and actin leads to the hydrolysis of the main energy carrier ATP, followed by a conformational change in the actin-myosin complex, which enables thick and thin filaments sliding along each other, resulting in contractile shortening of the sarcomere. This repetitive cycle of contractions of the heart at a rate of 60-80 times per minute requires $60-70 \%$ of the total ATP production, while the remaining ATP is primarily utilized by ATP-dependent calcium membrane transporters of the sarcoplasmic reticulum and other ATP-dependent ion pumps.(7)

It is obvious that continual cyclic contractions by $\mathrm{CMs}$ are dependent on extraordinarily high amounts of energy. An adult human heart has a turnover of an estimated 12 moles of ATP per day, which roughly equals $6 \mathrm{~kg}$ of ATP molecules that need to be synthesized each day for normal heart function.(8) Adult CMs are able to generate energy in form of ATP from several substrates. In times of sufficient oxygen supply, carbohydrates, of which the majority is glucose, but also lactate, fructose and galactose, cover only around 30\% of the total energy demands of the heart. Glucose is metabolized to pyruvate by glycolysis which yields 5 molecules of ATP. In the absence of oxygen, or during high proliferative behavior, pyruvate is fermented to lactate, which costs 3 ATP, making (an-)aerobic 
glycolysis relatively inefficient with a net gain of 2 ATP molecules per molecule glucose. However, when enough oxygen is supplied, pyruvate can also be converted to acetyl-CoA for the production of ATP via oxidative phosphorylation. Aerobic oxidation of pyruvate produces additional 25 molecules of ATP on top of the 5 ATP molecules generated in glycolysis, thus generating a total of 30 molecules of ATP when glucose is oxidized in the tricarboxylic acid (TCA) cycle.7 Due to its much higher potential ATP yield, the preferred energy source for adult CMs are fatty acids, which cover 50 to $70 \%$ of the energy demand of the heart. Fatty acids are broken down to acetyl-CoA by mitochondrial $\beta$-oxidation. Acetyl-CoA can then enter oxidative phosphorylation in the mitochondria (via TCA cycle and electron transport chain) (Figure 1). Together with the $\beta$-oxidation, the yield of ATP is much higher than that of glucose oxidation: a fatty acid of 6 carbon atoms (the same number as glucose) would yield 44 molecules of ATP, compared to the total yield of 30 ATP molecules per glucose molecule. In adult hearts, CMs therefore mainly rely on fatty acids to generate the vast amount of required energy for contraction. However, in utero, fatty acids are not available in sufficient numbers to be used as an energy source, forcing immature fetal CMs to rely on glucose metabolism.

\section{Early-stage embryonic metabolism (first trimester)}

Before fertilization, oocyte metabolism primarily uses oxidation of fatty acids, glucose and amino acids. $(9,10)$ Upon fertilization, the zygote and early developing embryo in morula stage derives its nutrients and oxygen directly from the surrounding maternal tissue through diffusion. In the human oviduct, the embryo is exposed to around $5 \%$ oxygen, a relatively high concentration of pyruvate (0.24$0.32 \mathrm{mmol} / \mathrm{L})$ and lactate $(4.87-10.5 \mathrm{mmol} / \mathrm{L})$, while the glucose concentration is relatively low $(0.5 \mathrm{mmol} / \mathrm{L}$, see Figure 2).(10) At this early stage of development, the embryo relies mostly on pyruvate, aspartate and lactate as an energy source, which are oxidized in the TCA cycle in the mitochondria (see Figure 1).(11) As the embryo further develops, glucose becomes more prominently available for energy generation through glycolysis to lactate and through oxidation in the TCA cycle, which triggers a concomitant increase in oxygen consumption by the embryo.(11) At this point, the embryonic stem cells of the inner cell mass of the blastocyst use glucose as the primary source of energy through aerobic glycolysis to facilitate rapid hyperplasia, thereby generating high amounts of lactate, despite the presence of oxygen. $(10,11)$ The high (aerobic) lysis of glucose is considered to be required particularly for biosynthesis of building blocks needed for cell growth and proliferation through the pentose phosphate pathway (PPP). (11) The blastocyst embryo takes up metabolites from the uterine fluid, which contains glucose $(3.15 \pm 0.31 \mathrm{mmol} / \mathrm{L})$, pyruvate $(0.1 \pm 0.05 \mathrm{mmol} / \mathrm{L})$ and lactate $(5.87 \pm 1.19 \mathrm{mmol} / \mathrm{L})$, and offers an oxygen tension of between 1 and $4 \%$.(10, $12,13)$ Pyruvate continues to be taken up by the embryo as a source of energy, 
however its uptake and oxidation may be reduced with increasing extracellular lactate concentration.(14) Other minor contributors to blastocyst metabolism are lactate and amino acids.(11)

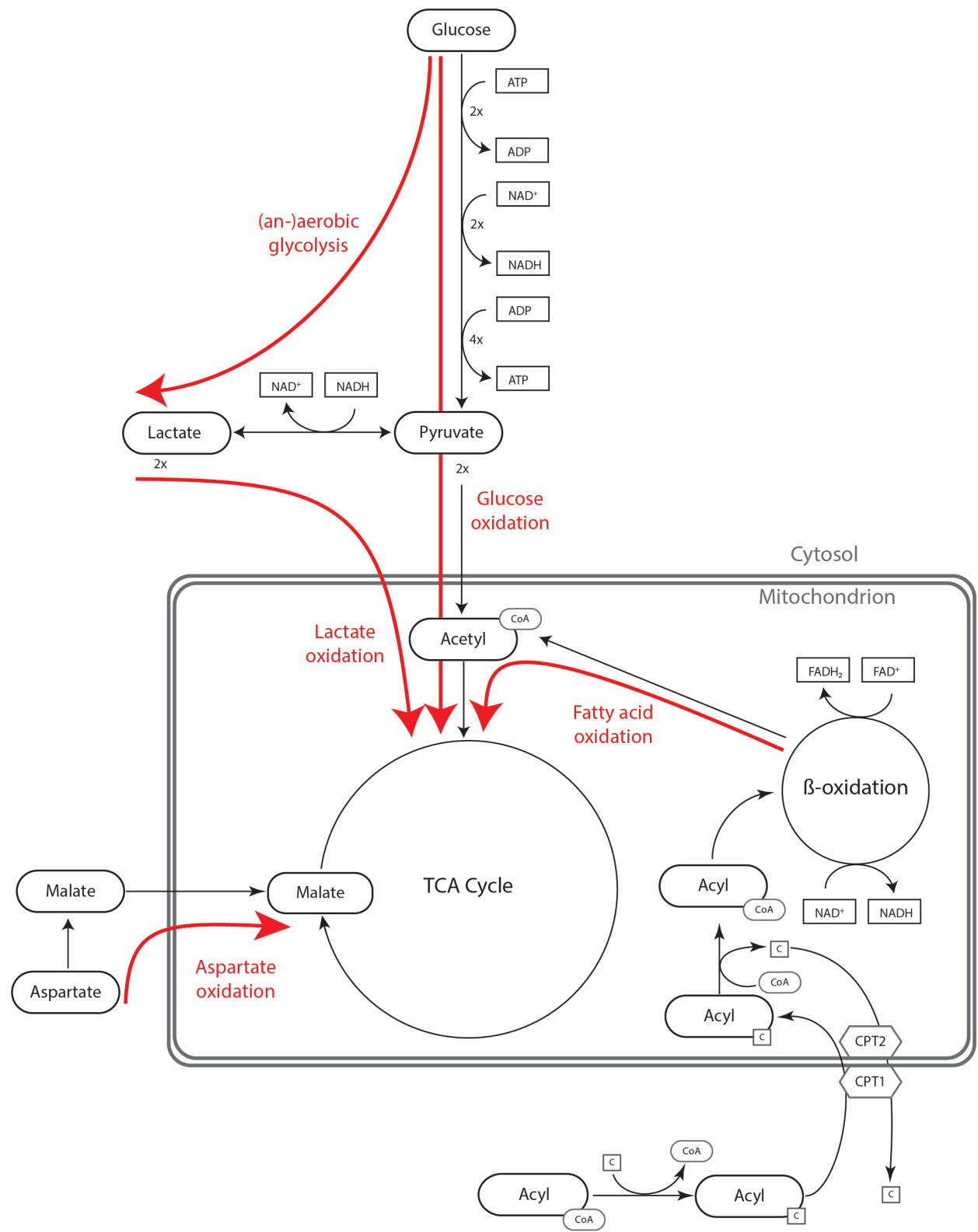

Figure 1: Schematic representation of the metabolic pathways in the cardiomyocyte. Lactate, glucose, aspartate and fatty acids (acyls) may be used by the cardiomyocyte as a substrate for oxidative phosphorylation. Glucose may also be converted to lactate when required, for example when insufficient oxygen is available for oxidative phosphorylation. $C=C a r n i t i n e, C o A=C o-e n z y m e$ A 


\section{Energy sources and oxygen concentration during fetal heart development}

During fetal growth, the developing heart is supplied with nutrients and oxygen by the fetal circulation. The availability of glucose, lactate and fatty acids are actively and passively determined by the syncytiotrophoblast layer of the placenta and remain rather constant throughout the fetal phase of development. Fetal glucose is solely provided by the mother, since gluconeogenesis is activated after birth. $(15,16)$ Glucose plasma concentration may fluctuate according to the maternal plasma concentration in a linear fashion, always lagging at $60 \%$ of the maternal concentration. $(17,18)$ In fasting state, this implies that the glucose concentration will not exceed $7 \mathrm{mmol} / \mathrm{L}$ under healthy conditions.(18) Higher glucose concentrations in mammalian cardiogenesis (including human) during gestation have been associated with an increased risk of developmental heart defects. In addition, fetuses from mothers diagnosed with diabetes mellitus, characterized by glucose plasma concentration of $>7 \mathrm{mmol} / \mathrm{L}$ in fasting state, have an increased risk of congenital heart disease. Cardiac hypoplasia, hypertrophic cardiomyopathy, septum defects and endocardial endothelial-to-mesenchymal transition (EMT) with excessive fibrosis have been reported to be more prevalent in case of gestational diabetes.(19-22) Proposed mechanisms of cell damage caused by a high concentration of glucose during heart development include: 1 ) generation of excess ROS species; 2 ) reduced intracellular folic acid and increased homocysteine, causing direct or indirect damage to cardiac progenitor cells; 3 ) endoplasmic reticulum (ER) stress(23-25); 4) oxidative stress; 5) nitrosative

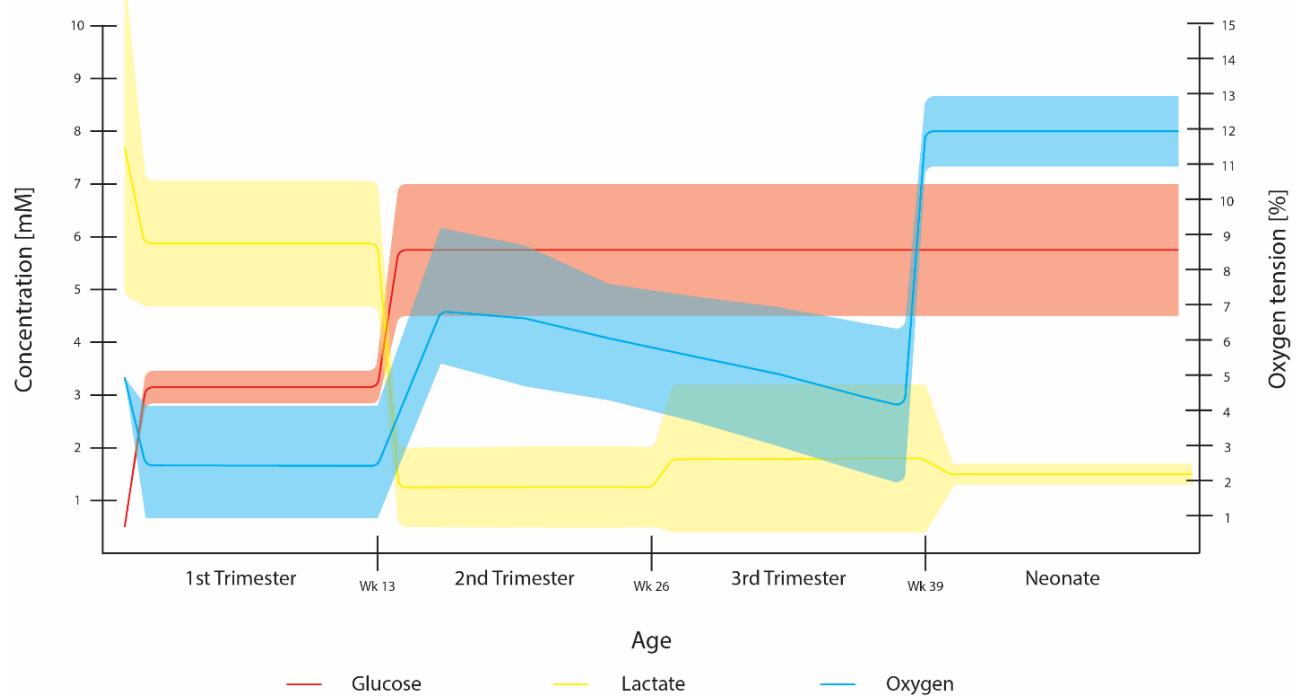

Figure 2: Metabolite plasma concentration per stage of gestation and neonatal life. Solid line represents the average, the margins represent the reported variation in literature. 
stress (26, 27); 6) lipoperoxidation and 7) caspase-8-regulated apoptotic pathway activation.(21)

\section{Fatty acids were omitted due to the low values of fatty acid concentrations throughout development.}

Glucose is the major metabolic substrate that is taken up from the maternal circulation, however the fetal heart primarily uses lactate produced by the placenta as its energy substrate for oxidative phosphorylation.(18) The placenta is a major producer of lactate during fetal development, providing lactate as the most important energy substrate for the heart. Lactate concentrations vary between $0.5-2.0 \mathrm{mmol} / \mathrm{L}$ at 18-21 weeks of gestation(28), and were measured at $1.15 \pm 0.08 \mathrm{mmol} / \mathrm{L}$ at late gestation (>35 weeks).(29) The high concentration of lactate in the fetus does not imply acidosis of the infant(30), but rather indicates a high aerobic glycolytic activity of the placenta. A high ratio of lactate over fatty acid availability mediates the primary use of lactate as an oxidative substrate for ATP synthesis. Even though gene expression involved in fatty acid metabolism is gradually increased, the contribution of $\beta$-oxidation thus remains relatively small, also due to a lack of available substrate and insufficient concentration of fatty acid transporters and $\beta$-oxidation intermediates.(18) The availability and composition of fetal plasma fatty acids is controlled by selective fatty acid binding proteins on the placenta, and are primarily selected for their role in anabolic activities of organs in the fetus.(31,32) The free fatty acid (FFA) concentration in the fetal plasma at time of delivery (term) may vary between individuals between 0.06 and $0.33 \mathrm{mmol} / \mathrm{L}$, and are enriched for the essential fatty acids (EFAs) by the placenta (Table 1). $(31,33,34)$ Deficiencies in fatty acid delivery to the fetus during development may be catastrophic for organogenesis, in particular brain and retina in the third trimester(31), however the effect on heart development is not clear. In mice, a high fat diet of the mother has been correlated to CM dysfunction in the offspring because of lipid droplet accumulation, oxidative stress and mitochondrial dysfunction, although this has not yet been reported in humans.(5)

Lactate will remain more important as an energy substrate for oxidative phosphorylation than fatty acids until birth, after which the sudden drop of fetal plasma lactate concentration and the vast increase in fatty acid concentration reverses the lactate over fatty acid ratio, thus forcing the cardiac metabolism to switch to fatty acid oxidation. Other carbohydrates only play a minor role as an energy substrate, but may have an effect on development, nonetheless. Fructose and galactose both are present in fetal plasma at a relatively low concentration, and although high intake of either carbohydrate has been shown to affect fetal development, little is known in their effect on cardiac development.(35-37) Amino acids are essential to fetal growth not in the least for protein synthesis, 
but may also account for approximately 20 percent of metabolite oxidation for energy production. Amino acid presence in the fetal circulation is higher than in maternal blood and is likely to be transported actively from the maternal to the fetal bloodstream.(30)

The fetal human heart develops under relative hypoxic circumstances. Maternal arterial oxygen partial pressure is maintained around $90-100 \mathrm{mmHg}(11-13 \%)$, while oxygen pressure in fetal umbilical vein was measured at $32-35 \mathrm{mmHg}$ $(4,2-4,6 \%)$ and in the coronary arteries at $25-28 \mathrm{mmHg}(3,3-3,7 \%)$ in fetal lambs. (38) Interestingly, umbilical cord vein partial pressure of oxygen during the fetal phase of development slowly declines with increasing gestational age, an effect speculated to function as protection against oxygen toxicity in the fetus. $(38,39)$

\section{Hormonal influence on heart development}

Several studies have shown that thyroid hormone (TH) is fundamentally important for heart development and maturation. Although TH is thought not to cross the placenta, some animal studies indicated that a drop of maternal TH 3,5,3'-triiodothyronine (T3) concentration affect normal fetal development of the heart and brain. $(40,41)$ The human fetus itself initiates the production of TH at the gestational age of 12 weeks.(42) In the first two trimesters, the less active TH thyroxine (T4) is mostly produced in the thyroid. However, when the hypothalamic-pituitary-adrenal axis becomes activated in the third trimester, cortisol-mediated conversion of T4 to T3 leads to a profound increase in T3 hormone in the fetus, reaching a concentration of $0.77 \mathrm{nmol} / \mathrm{L}$ at term. $(42,43)$ The highly active $\mathrm{T} 3$ hormone drives maturation by modulation of contractile protein myosin heavy chain $\alpha / \beta$, voltage-gated potassium channels $\left(\mathrm{K}_{v} 1.5, \mathrm{~K}_{v} 4.2\right.$ and $\mathrm{K}_{\mathrm{v}} 4.3$ ) and sarcoplasmic reticulum $\mathrm{Ca}^{2+}$-ATPase (SERCA2a) and downregulation of phospholamban (PLN).(44-46)

Insulin receptor (INSR) and insulin-like growth factor 1-receptor (IGF1R) signaling had been reported to be of high importance in the developing heart. Conditional knock-out models in mice have demonstrated that without INSR signaling, CMs remained smaller, which correlated to a reduced heart size in newborn mice.(5) Conditional knock-out of both INSR and IGF1R signaling in the developing heart resulted in severe cardiomyopathy and death of the mouse pups.(5) In mouse and other species, it has been demonstrated that insulin-like growth factor 2 (IGF2) is the main ligand for IGF1R, driving CM proliferation and morphogenesis of the ventricles in vivo(47), although IGF1 binding to the IGF1R activates a similar response. IGF2 is produced by the epicardial and endocardial layers of the heart(47) and is delivered locally. Therefore, an absolute concentration of IGF2 in the myocardium is unknown. Gestational diabetes with concurrent fetal hyperinsulinemia on the other hand, have been associated with disproportionate 
fetal cardiachypertrophyin humans, determined by intrauterineechocardiography. (48) These findings suggest that there is an optimal window for insulin signaling in relation to proper heart development. In human fetuses at term, the insulin concentration was found to be $39.2 \mathrm{pmol} / \mathrm{L}$ for infants that were at full term(49), however in the case of preterm delivery this value may be twice as high.(50)

\section{Postnatal cardiac maturation in relation to exposure of metabolites.}

Whereas fetal $\mathrm{CM}$ s are predominantly dependent on aerobic glycolysis and lactate oxidation as preferred substrate, within days after birth, a switch is made to the energetically more efficient oxidation of fatty acids. Glycolytic rates after birth decrease to less than $10 \%$ of total cardiac ATP production. Due to downregulation of the insulin-independent glucose transporter 1 (GLUT1) and replacement by the insulin-responsive GLUT-4 as the dominant transporter, uptake of glucose becomes more correlated to the insulin concentration, and thus the metabolic state of the neonate.(52) To a lesser extent, transporters GLUT-3 and GLUT-11 (with a high affinity for fructose), are also expressed in the human heart after birth.(52, 53) In the clinic, the neonatal plasma glucose concentration is targeted between 3.9 $\mathrm{mmol} / \mathrm{L}$ and $8.3 \mathrm{mmol} / \mathrm{L}$, which is comparable to the fetal glucose concentration. (54) In humans, the shock of birth causes the T3 plasma concentration in neonates to peak to $4.5 \mathrm{nmol} / \mathrm{L}$ in the first days of life (approximately 5 - to 6 -fold higher than prenatal concentration), likely as a response to a colder environment.(55) This increase in T3 concentration mediates the switch of glucose transporters to the insulin-sensitive phenotype (GLUT1 switches to GLUT4) at birth and may also be responsible for the metabolic switch from aerobic glycolysis to oxidative phosphorylation and the increase in fatty acid use for energy derivation. $(56,57)$ The importance of TH in postnatal cardiac maturation is further shown by the finding that the T3 surge is also responsible for an arrest in cell cycle of CMs. (58) The insulin concentration of neonates directly after birth was found to be $6.3 \pm 3.7 \mu \mathrm{U} / \mathrm{mL}$ or $43,8 \pm 25,7 \mathrm{pmol} / \mathrm{L}$.(59)

Fatty acids become the dominant source of energy substrate after birth, replacing lactate and glucose as the main metabolite of the heart. Within days after birth, the plasma fatty acid concentration increases from $0.1 \mathrm{mmol} / \mathrm{L}$ in the fetus, to up to $0.4 \mathrm{mmol} / \mathrm{L}$ in the neonate, while the lactate concentration drops from $2 \mathrm{mmol} / \mathrm{L}$ to $1.5 \mathrm{mmol} / \mathrm{L}$.(60) As a consequence of this metabolic switch, mitochondrial respiration in the neonatal heart accounts for $~ 90 \%$ of the total ATP production, with a 10 -fold increase in fatty acid oxidation, making it the dominant resource for oxidative phosphorylation.(60-63) To accommodate this increased rate of $\beta$-oxidation, the mitochondria in neonatal $\mathrm{CMs}$ rapidly proliferate, relocate from perinuclear to peri-myofibrillar locations in the cell, and become more mature, leading to increased inner membrane surface area (the 


\begin{tabular}{|l|l|l|}
\hline Fatty acid & Fetus at delivery(32) & Human adult(51) \\
\hline Palmitic acid & $25.4[1.1]$ & $23.7[1.97]$ \\
\hline Stearic acid & $19.8[1.9]$ & $18.64[2.91]$ \\
\hline Palmitoleic acid & $3.62[0.29]$ & $0.75[0.42]$ \\
\hline Oleic acid & $19.4[0.5]$ & $11.11[1.89]$ \\
\hline Linoleic acid & $7.81[0.30]$ & $17.65[3.81]$ \\
\hline Eicosatrienoic acid & $2.47[0.19]$ & $2.29[0.61]$ \\
\hline Arachidonic acid & $12.2[0.3]$ & $9.44[2.51]$ \\
\hline a-linoleic acid & - & $0.2[0.12]$ \\
\hline Docosahexaenoic acid & $3.99[0.16]$ & $4.16[1.53]$ \\
\hline
\end{tabular}

Table 1: Fatty acid composition in human umbilical vein sampels prior to cesarian section and human adult plasma, data in \% (mg/100mg) normal [s.e.m.]

lamellar phenotype) and a 2-4 fold increase in expression of proteins involved in respiratory activity. The metabolic switch from a fetal to an adult phenotype coincides with a higher concentration of gene expression of key regulators in fatty acid transport and oxidation(60), such as peroxisome proliferator-activated receptor (PPAR)- $\alpha$ and $\gamma$. PPARs can exhibit their function only after establishing a transcriptional complex with their co-activators, such as PPAR $y$ coactivator- $1 \alpha$ (PGC-1 $\alpha$ ). In contrast to other PPAR co-activators, PGC-1 $\alpha$ is restrictively expressed in tissues with high oxidative capacities, such as myocardial tissue. PPAR- $\alpha / P C G-$ $1 \alpha$ signaling not only increases the expression of fatty acid transporters, such as the mitochondrial rate-limiting carnitine palmitoyltransferase 1 (CPT-1), but also activates genes responsible for other steps in fatty acid metabolism, such as: 1) fatty acid transport (FATP, FAT/CD36, H-FABP), 2) activation of fatty acids for mitochondrial import (fatty acid acyl-CoA synthetase, FACS), 3) mitochondrial import ( $m C P T-I / C P T 2)$; and 4) oxidative phosphorylation (medium-chain acyl-CoA dehydrogenase, an oxidoreductase that is specific for acyl chain lengths of 4 to 16 carbons). Strikingly, PGC-1 $\alpha$ experiences an enormous increase in expression after birth, suggesting that this increase is tightly coupled to the postnatal metabolic switch of the fatty acid machinery.(64) Overall, these results demonstrate that PPAR- $\alpha /$ PGC- $1 \alpha$ signaling is essential for the establishment and maintenance of efficient mitochondrial fatty acid $\beta$-oxidation in postnatal CMs.

\section{Metabolic characteristics of hPSC-CMs compared to adult CMs}

In recent years differentiation of hPSCs towards CMs have been greatly improved, yielding $\mathrm{CM}$ cultures of $90 \%$ and higher. In defined, serum-free culture conditions undifferentiated hPSCs are directed within two weeks to functional $\mathrm{CMs}$ following a precisely controlled activation and inhibition of signaling pathways, comparable to formation of mesoderm-derived cardiac cells during 
embryonic development.(65) Although key in vivo cardiac signaling cascades are accurately mimicked in these hPSC cultures, environmental and metabolic cues are deviating considerably from the human in vivo situation, indicated by the high concentration of glucose ( $\sim 15 \mathrm{mmol} / \mathrm{L})$ and low concentration of fatty acids ( $2.6 \mu \mathrm{mol} / \mathrm{L}$ ). In order to determine real-time energy metabolism, hPSCCMs are usually seeded in multi-well plate metabolic assay platform. Based on relative contribution of glycolysis and mitochondrial respiration to total energy production by measuring the oxygen consumption (OCR) and extracellular acidification rates (ECAR), hPSC-CMs rely primarily on aerobic glycolysis instead of mitochondrial oxidative respiration when cultivated under commonly accepted non-native cell culture conditions (high glucose-low fatty acids).This immature phenotype of hPSC-CMs is supported by the low expression of genes related to glycolysis, fatty acid $\beta$-oxidation and mitochondrial respiration, when compared to gene expression concentration in adult human CMs. $(66,67)$ Furthermore, mitochondrial numbers are lower in hPSC-CMs than their adult counterparts. (67) Nevertheless, despite their immature character, hPSC-CMs have the capacity for mitochondrial respiration as indicated by a 5 to 8 -fold increase in OCR/ECAR relation when grown in presence of galactose or fatty acids and not glucose.(3) Lysis of galactose to pyruvate yields no net ATP, forcing CMs to feed the galactosederived pyruvate into the TCA cycle.(68)

\section{Substrate changes as possible strategy to optimize cardiac differentiation in hPSCs}

Mechanisms governing the essential switch from the metabolic phenotype in fetal CMs to that in adult CMs are only partly understood. However, increasing evidence suggests that differences in substrate availability may partially be involved in cardiac maturation. As the concentration of lactate decreases shortly after birth from $2 \mathrm{mmol} / \mathrm{L}$ to about $1.5 \mathrm{mmol} / \mathrm{L}$ and fatty acid concentration increases from $0.1 \mathrm{mmol} / \mathrm{L}$ to approximately $0.4 \mathrm{mmol} / \mathrm{L}$ in adult blood $(60,69)$, it is conceivable that a shift from lactate to fatty acids may be able to induce a metabolic transition in CMs, which may serve as a trigger for $\mathrm{CM}$ maturation. Considerable evidence to support this hypothesis is based on animal studies. In vivo perfusion experiments in neonatal rabbit hearts disclosed that increased fatty acid supply promotes oxidative metabolism and hence ATP generation in the neonatal heart. This increase in respiratory capacity was indeed attributable to higher fatty acid oxidation rates, given that significantly greater ATP values could be measured in hearts perfused with high palmitate concentration (2.4 $\mathrm{mmol} / \mathrm{L})$ than with low palmitate $(0.4 \mathrm{mmol} / \mathrm{L})$. Most importantly, perfusion with $2.4 \mathrm{mmol} / \mathrm{L}$ palmitate, but not $0.4 \mathrm{mmol} / \mathrm{L}$ palmitate, was sufficiently able to improve contractile function.(70) Another study evaluated the effect of longchain fatty acids on cardiac gene expression in primary cultures of neonatal rat ventricular myocytes cultured in presence of either glucose $(10 \mathrm{mmol} / \mathrm{L})$, fatty 
acids (palmitic and oleic acid, $0.25 \mathrm{mmol} / \mathrm{L}$ each) or (glucose and fatty acids) as exogenous substrates. First of all, these long chain fatty acids were taken up into the cell for storage in endogenous lipid pools until oxidation.(71, 72) This suggests that fetal CMs possess the capacity to shuttle fatty acids into the cell. Second, supplementation of fatty acids resulted in a 2 to 4 -fold increase in expression of fatty acid translocase (FAT/CD36), H-FABP, FACS and long-chain acylCoA dehydrogenase with a consecutive increase in $\mathrm{CM}$ fatty acid oxidation that ultimately more than doubled. Importantly, no obvious undesired phenotypical alterations could be detected within 48 hours.(71) Of special relevance is that fatty acids most probably exhibit their function via activation of PGC-1 $\alpha /$ PPAR- $\alpha$ "feed-forward" signaling pathway, which not only plays a pivotal role in the control of fatty acid $\boldsymbol{\beta}$-oxidation, but also in cardiac mitochondrial biogenesis(73). The activation of PPAR- $\alpha$ is not the only mode of action in which fatty acids, such as palmitate, could improve maturity in hPSC-derived CMs. Exposure to 0.5 $\mathrm{mmol} / \mathrm{L}$ palmitate for 4 hours increases nitric oxide synthase activity by about 2 -fold in cultured chick ventricular CMs resulting in an elevated cellular nitric oxide concentration(74), which has been shown to increase inwardly rectifying potassium current $\mathrm{I}_{\mathrm{K} 1}$ in human atrial CMs in another study.(75) HPSC-CMs not only exhibit very low or even absent $\mathrm{I}_{\mathrm{K} 1}$ currents, but also the majority of CMs displays little to no Kir2.1 (responsible ion channels for $I_{\mathrm{K} 1}$ currents) at the gene and protein concentration.(76) Low $\mathrm{I}_{\mathrm{K} 1}$ current results in the relatively high resting membrane potential and intrinsic automaticity in hPSC-CMs compared to their more mature counterparts. Elevated expression of Kir2.1 in hPSC-CMs leads to complete cessation of spontaneous firing along with a significant hyperpolarization of the resting membrane potential to values comparable to adult current. Although $\mathrm{I}_{\mathrm{K} 1}$ increases with time in culture, currents are dramatically lower than in adult ventricular $\mathrm{CMs}$, suggesting that the deficiency in $\mathrm{I}_{\mathrm{K} 1}$ may contribute to the functional limitations of hPSC-CMs. In addition, nitric oxide may also exert a protective function in $\mathrm{CMs}$ against detrimental effects of palmitate treatment, which has been shown to lead to a 2-fold increase in cell death within 4 hours of exogenous exposure to $0.5 \mathrm{mmol} / \mathrm{L}$ palmitate.(74) This also indicates that simply exposing CMs to an increased concentration of fatty acids may not be sufficient for optimal uptake and efficient use for $\beta$-oxidation and driving cardiac maturation. Yang et al. developed a proof-of-concept to show that hPSC-CMs have the capacity to take up approximately $25 \%$ of supplied fatty acids (105 $\mu \mathrm{mol} / \mathrm{L}$ palmitate-albumin, $81 \mu \mathrm{mol} / \mathrm{L}$ oleic acid-albumin, and $45 \mu \mathrm{mol} / \mathrm{L}$ linoleic acid-albumin complexes supplemented with $250 \mu \mathrm{mol} / \mathrm{L}$ carnitine).(77) Interestingly, absence of the amino acid carnitine reduced fatty acid uptake to about $13 \%$. This relatively low uptake suggests that fatty acid uptake by CMs is not optimal. Co-culture of CMs in direct contact with other cell types, especially endothelial cells, may be required to increase fatty acid uptake and trigger metabolic maturation in CMs. The endothelial cell-mediated fatty acid transport 
from lipid vesicles towards CMs for example has been extensively described in literature as an important source of lipids.(78)

As opposed to cardiac development in vivo, CMs generated in vitro are usually cultured in non-physiologically high concentrations of glucose and a low concentration of fatty acids and thus provide an environment that predisposes for glycolysis, inhibits fatty acid $\beta$-oxidation and thereby precludes sufficient ATP generation to support increased cardiac workload as it occurs in the adult human heart. Dzeja et al. demonstrated that a high concentration of glucose $(50 \mathrm{mmol} / \mathrm{L})$ in differentiation media reduced the formation of beating areas in murine embryonic stem cells (mESCs) differentiations.(79) In the presence of high glucose, $\mathrm{mESC}$-derived cells displayed an immature myofibrillar organization with fragmented mitochondria that had lost their connection to the myofibrils. Moreover, not only structural proteins were affected, but also electrical activity was weaker as evidenced by lower expression of membrane potential marker $\mathrm{RH} 237$. These findings support the hypothesis that a high concentration of glucose may have a detrimental effect on sarcomeric organization, mitochondrial biogenesis, electrical activation and consequently interfere with cardiomyocyte differentiation and maturation.(79)

To explore the distinct effects of different fuels on the metabolic adaptions necessary to sustain the high energy demand in CMs, Rana et al. maintained hPSC-derived CMs in media containing either 1) glucose (5.5 or $25 \mathrm{mmol} / \mathrm{L}$ ), 2) glucose $(5.5 \mathrm{mmol} / \mathrm{L})$ and fatty acids $(0.1 \mathrm{mmol} / \mathrm{L}$ oleic acid and $0.05 \mathrm{mmol} / \mathrm{L}$ palmitic acid), 3) galactose (10 $\mathrm{mmol} / \mathrm{L})$ or 4$)$ galactose $(1 \mathrm{mmol} / \mathrm{L})$ and fatty acids $(0.1 \mathrm{mmol} / \mathrm{L}$ oleic acid and $0.05 \mathrm{mmol} / \mathrm{L}$ palmitic acid) for 21 days. CMs did not show fuel-related differences in ATP production. However, the type of carbon source was shown to influence the relative contribution of active mitochondrial respiration and glycolysis. In presence of galactose and fatty acids, but surprisingly also galactose alone, CMs experienced increased levels of mitochondrial respiration relative to glycolysis.(3) Interestingly, the overall ATP content did not increase, suggesting subsequent utilization of the generated ATP. These findings may suggest a higher need for increased ATP production in hPSC-CMs. Despite the availability of fatty acids, CMs remained glycolytic when additional glucose was provided in the media. In none of the conditions, expression levels of key genes involved in glycolysis or mitochondrial respiration changed significantly.(3) A possible explanation for the highly glycolytic phenotype in these cells, even in the presence of energetically favorable fatty acids, could be related to the presence of glucose, since glucose has the capacity to inhibit fatty acid $\beta$-oxidation via the Randle cycle where fatty acids and glucose compete for their oxidation and uptake into muscle or adipose tissue. Moreover, long chain fatty acid esters of coenzyme A (LC-CoA), which are intermediates 
of fatty acid metabolism, inhibit all inwardly rectifying potassium channels $\left(\mathrm{K}_{\mathrm{ir}}\right)$ except $\mathrm{K}_{\text {ATP }}$ under conditions that promote cytoplasmic accumulation of LC-CoA, as, for instance, at high glucose concentration. A glucose concentration above $25 \mathrm{mmol} / \mathrm{L}$ has been shown to inhibit CPT-1 and thereby mitochondrial fatty acid import (figure 1). $(80,81)$ Consequently, exposure to a high concentration of glucose, not only has an inhibitory effect on fatty acid oxidation, but also directly inhibits $I_{K 1}$ currents, which are key to (electrophysiological) maturation in hPSC-derived CMs. A possible alternative to long chain fatty acids are medium chain fatty acids. In contrast to long-chain fatty acids with 14 or more carbons, medium-chain fatty acids are composed of 6 to 12 carbons and are always saturated. These structural differences confer to medium fatty acids the unique ability to cross the mitochondrial membranes regardless of the regulatory effects of CPT-1. Hence, medium fatty acids are an unlimited ATP source. Interestingly, milk, which is the primary fuel source during the postnatal period in mammals, contains a high concentration of medium fatty acids.(82)

Interestingly, in analogy to fetal CMs, hPSC-derived CMs have been shown to have the potential to metabolize lactate, unlike undifferentiated hPSCs or other non-CMs in culture. $(83,84)$ As knowledge gathered from in vivo development points to the role of substrate changes, including the switch from lactate to fatty acids, for maturation of hPSC-derived CMs, it may be preferable to maintain

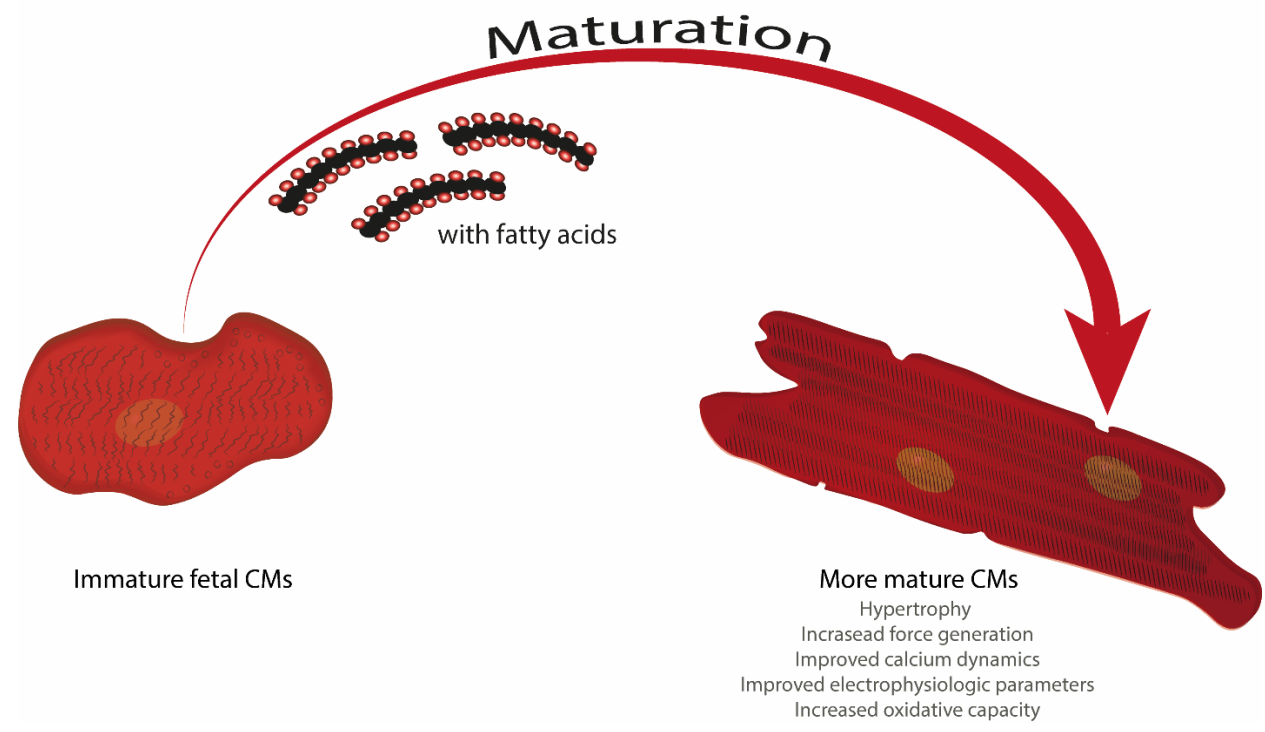

Figure 3: The effects of in vitro maturation of hPSC-CMs by culture in medium containing fatty acids. Most widely used fatty acids for cardiomyocyte maturation are palmitic acid, oleic acid and linoleic acid. Palmitate is a saturated fatty acid which is the most common one found in animals, plants and microorganisms. Oleic acid is a mono-unsaturated omega-9 fatty acid and linoleic acid, a poly-unsaturated omega-6 fatty acid, is one of two essential fatty acids for humans. 
hPSC-derived CMs in a lactate-enriched culture medium and then switch to fatty acids as major fuel. Furthermore, fatty acid supplementation in insulincontaining medium increased hPSC-CM hypertrophy, contractile force, calcium dynamics, as well as action potential up-stroke velocity (a well-described feature of electrophysiological maturation) and maximal mitochondrial respiratory capacity.(77) Together, these data implicate that exogenous fatty acids have the capacity to drive maturation in hPSC-derived CMs.

\section{Conclusions \& Recommendations}

Patient-derived hPSC-CMs often exhibit characteristics that reflect the disease pathology of the patient. For these reasons, hPSC technologies are recognized as cutting edge research platforms for disease modelling, drug discovery and regenerative medicine. Significant advances in the efficiency of CM differentiation and analytical procedures have spearheaded efforts to use patient-derived hPSCs to capture the patient phenotypes "in a dish". Nevertheless, immaturity of hPSC$\mathrm{CMs}$ remains a major obstacle to their pre-clinical and clinical applications and adoption by pharmaceutical industry. Even though strategies such as 3D culture, mechanical, and/or electrical stimulation have been developed to advance the maturity level of the hPSC-CMs, success remains limited. One other aspect that might prevent hPSC-CMs from reaching a higher maturity level is their metabolic state, which is primarily dependent on aerobic glycolysis instead of fatty acid oxidation, in contrast to adult CMs in vivo.(3) HPSC-CMs cultured in vitro are classically exposed to high glucose, low fatty acid and low lactate environment, one that does not resemble the in vivo situation of CMs during heart development. Due to the inhibitory effect of high glucose on fatty acid oxidation, described in the Randle cycle(85), it is expected that in vitro culture of hPSC-CMs in high glucose will not facilitate metabolic maturation towards fatty acid metabolism, as required and observed in highly contractile adult CMs.(4) Studies focused on embryonic heart development suggest that especially the switch from a lactate to a fatty acid-dominated environment may drive the metabolic switch to an adultlike metabolic phenotype of CMs.(62) Moreover, deviations from optimal in vivo metabolite concentration may lead to metabolic changes that endure postnatally (fetal programming)(5), or even cause cardioymopathies.(19-22) It is therefore not unlikely that culture conditions in vitro could also have a suboptimal or detrimental effect on $\mathrm{CM}$ development and function, as these culture conditions deviate strongly from the preferred in vivo concentration.

Here we summarized developmental metabolic conditions of $\mathrm{CMs}$ in vivo, in order to provide a guideline for a cell culture medium that might facilitate CM maturation in vitro. It must be emphasized that changing metabolite concentration in culture medium alone will most likely not result in extensive maturation of hPSC-CMs, since other aspects of cardiac maturation, as explained below, need 
to be considered as well. Based on metabolic concentration during gestation and shortly after birth, a fetal CM culture medium and neonatal CM culture medium can be devised (see Table 2), which consists of a lower glucose concentration (4.5 $\mathrm{mmol} / \mathrm{L}$ instead of $15 \mathrm{mmol} / \mathrm{L}$ ), lactate (especially in the fetal stage of culture), and fatty acids (present in millimolar range and thus high enough to serve as a metabolic substrate), in addition to T3 hormone and insulin.

It is important to note that reported values of metabolites during fetal development and the post-natal period were measured in plasma in umbilical cord or peripheral blood samples. This implies that those values are systemic concentrations and might not precisely correspond to the cardiac micro-environment. In vivo, CMs are shielded to some extend by the endothelial layer, which separates CMs from blood plasma. Therefore, metabolite concentration in the plasma may not directly correspond to $\mathrm{CM}$ exposure, since the effect of endothelial cell transport and metabolism is not taken into account. The metabolic micro-environment may also be directly dictated by cells in close proximity of the CM. Several studies have reported improved (partial) metabolic and functional maturity in 3D cultured cardiac tissues, with or without mechanical stimuli, and with mixed cell populations (both cardiac and non-cardiac cell-types) or purified CMs.(86-88) It is unclear whether these 3D organized cardiac tissues in vitro alters $\mathrm{CM}$ (metabolic) behavior directly through cell-cell interaction, indirectly through changes in the exposure to metabolites and oxygen of the cells in the interior of the 3D tissue, a combination of both, or via an alternative route.

Another important factor required for optimal metabolism, cell growth, differentiation and survival, is oxygen. The role of oxygen in cell signaling and stress has been well described. Indeed, some in vitro differentiation protocols utilize oxygen signaling to derive certain cardiac subtypes from hPSCs, highlighting the importance of oxygen to the cell.(89) Moreover, the significance of low oxygen tension is further underlined by a study demonstrating impaired cardiovascular development and premature fetal death in a knock-out model of HIF1a in mice.

\begin{tabular}{|l|l|l|}
\hline & Fetal medium & Neonatal medium \\
\hline Glucose & $4.5 \mathrm{mmol} / \mathrm{L}$ & $4.5 \mathrm{mmol} / \mathrm{L}$ \\
\hline Lactate & $2 \mathrm{mmol} / \mathrm{L}$ & $0.5 \mathrm{mmol} / \mathrm{L}$ \\
\hline Fatty acids & $0.06-0.3 \mathrm{mmol} / \mathrm{L}$ & $0.4 \mathrm{mmol} / \mathrm{L}$ \\
\hline Pyruvate & $0.1 \mathrm{mmol} / \mathrm{L}$ & $0.1 \mathrm{mmol} / \mathrm{L}$ \\
\hline T3 hormone & $0.7 \mathrm{nmol} / \mathrm{L}$ & $4.5 \mathrm{nmol} / \mathrm{L}$ \\
\hline Insulin & $39 \mathrm{pmol} / \mathrm{L}$ & $40 \mathrm{pmol} / \mathrm{L}$ \\
\hline
\end{tabular}

Table 2: Suggested metabolite and factor concentrations in culture medium for hPSC-derived CMs, resembling the human in vivo situation. 
(90) HIF1a protein expression is dependent on oxygen tension, where it stabilizes at low oxygen concentration ( $<7 \%)$, but is degraded at higher concentration. Loss of HIF1a (corresponding to a high oxygen concentration) disrupts cardiac development. Standard in vitro cell culture experiments are performed at oxygen concentration of around $20 \%$, which suggests that improved differentiation and maturation may be achieved at a lower oxygen concentration.

In conclusion, current typical in vitro cell culture conditions deviate substantially from the micro-environment of the developing heart in vivo, which may an important factor for suboptimal hPSC-CM differentiation and maturation, hampering their applications in disease modeling, drug screening and regenerative medicine. Based on in vivo and in vitro observations, maturation of hPSC-CMs may be (partially) achieved by adjusting culture medium and micro-environment in such a manner that it resembles more closely the native in vivo conditions during heart development and maturation. Although it may be challenging to emulate the metabolic and functional aspects of the adult human heart in its full complexity, even in highly organized multicellular 3D cardiac tissues derived from hPSCs, cultured in defined and optimal physiological and metabolic conditions, it is expected that improved cardiac maturation of patient-derived hPSC-CMs will increase their potential to capture complex disease states. Moreover, successful maturation of hPSC-CMs will spark scientists to assess clinically relevant readouts in healthy and diseases conditions and will initiate a paradigm shift for personalized medicine, cardiac disease modelling, drug discovery and safety pharmacology and regenerative medicine. 


\section{References}

1. Brandao KO, Tabel VA, Atsma DE, Mummery CL, Davis RP. Human pluripotent stem cell models of cardiac disease: from mechanisms to therapies. Dis Model Mech. 2017;10(9):1039-59.

2. Birket MJ, Ribeiro MC, Kosmidis G, Ward D, Leitoguinho AR, van de Pol V, et al. Contractile Defect Caused by Mutation in MYBPC3 Revealed under Conditions Optimized for Human PSC-Cardiomyocyte Function. Cell Rep. 2015;13(4):733-45.

3. Rana P, Anson B, Engle S, Will Y. Characterization of human-induced pluripotent stem cell-derived cardiomyocytes: bioenergetics and utilization in safety screening. Toxicol Sci. 2012;130(1):117-31.

4. Chung S, Dzeja PP, Faustino RS, Perez-Terzic C, Behfar A, Terzic A. Mitochondrial oxidative metabolism is required for the cardiac differentiation of stem cells. Nat Clin Pract Cardiovasc Med. 2007;4 Suppl 1:S60-7.

5. Govindsamy A, Naidoo S, Cerf ME. Cardiac Development and Transcription Factors: Insulin Signalling, Insulin Resistance, and Intrauterine Nutritional Programming of Cardiovascular Disease. J Nutr Metab. 2018;2018:8547976.

6. Blackstone NW. Charles Manning Child (1869-1954): the past, present, and future of metabolic signaling. J Exp Zool B Mol Dev Evol. 2006;306(1):1-7.

7. Stanley WC, Recchia FA, Lopaschuk GD. Myocardial substrate metabolism in the normal and failing heart. Physiol Rev. 2005;85(3):1093-129.

8. Kolwicz SC, Jr., Purohit S, Tian R. Cardiac metabolism and its interactions with contraction, growth, and survival of cardiomyocytes. Circ Res. 2013;113(5):603-16.

9. Leese HJ. History of oocyte and embryo metabolism. Reprod Fertil Dev. 2015;27(4):567-71.

10. Scott R, 3rd, Zhang M, Seli E. Metabolism of the oocyte and the preimplantation embryo: implications for assisted reproduction. Curr Opin Obstet Gynecol. 2018;30(3):163-70.

11. Gardner DK, Harvey AJ. Blastocyst metabolism. Reprod Fertil Dev. 2015;27(4):638-54.

12. Gardner DK, Lane M, Calderon I, Leeton J. Environment of the preimplantation human embryo in vivo: metabolite analysis of oviduct and uterine fluids and metabolism of cumulus cells**Supported by IVF America Inc., Greenwich, Connecticut and Monash IVF Pty. Ltd., Melbourne, Victoria, Australia. 
Fertility and Sterility. 1996;65(2):349-53.

13. L.D.M. O. Observations on intrauterine oxygen tension measured by fibre-optic microsensors. Reproductive BioMedicine Online. 2006;13(3):6.

14. D.K. LMG. Lactate regulates pyruvate uptake and metabolism in the preimplantation mouse embryo. Biology of Reproduction. 2000;62:7.

15. Kalhan S, Parimi P. Gluconeogenesis in the fetus and neonate. Semin Perinatol. 2000;24(2):94-106.

16. Hay WWJ. Placental-fetal glucose exchange and fetal glucose metabolism. TRANSACTIONS OF THE AMERICAN CLINICAL AND CLIMATOLOGICAL ASSOCIATION. 2006;117:20.

17. Bozzetti P, Ferrari MM, Marconi AM, Ferrazzi E, Pardi G, Makowski EL, et al. The relationship of maternal and fetal glucose concentrations in the human from midgestation until term. Metabolism. 1988;37(4):358-63.

18. Ascuitto RJR-A, Nancy T. Substrate metabolism in the developing heart. Seminars in Perinatology. 1996;20(6):22.

19. Asoglu MR, Gabbay-Benziv R, Turan OM, Turan S. Exposure of the developing heart to diabetic environment and early cardiac assessment: A review. Echocardiography. 2018;35(2):244-57.

20. Abu-Sulaiman RM, Subaih B. Congenital heart disease in infants of diabetic mothers: echocardiographic study. Pediatr Cardiol. 2004;25(2):137-40.

21. Zhao Z, Reece EA. New concepts in diabetic embryopathy. Clin Lab Med. 2013;33(2):207-33.

22. Oyen N, Diaz LJ, Leirgul E, Boyd HA, Priest J, Mathiesen ER, et al. Prepregnancy Diabetes and Offspring Risk of Congenital Heart Disease: A Nationwide Cohort Study. Circulation. 2016;133(23):2243-53.

23. Thomas SE, Dalton LE, Daly ML, Malzer E, Marciniak SJ. Diabetes as a disease of endoplasmic reticulum stress. Diabetes Metab Res Rev. 2010;26(8):61121.

24. Ozcan U, Yilmaz E, Ozcan L, Furuhashi M, Vaillancourt E, Smith RO, et al. Chemical chaperones reduce ER stress and restore glucose homeostasis in a mouse model of type 2 diabetes. Science. 2006;313(5790):1137-40.

25. Zhao Z. Endoplasmic reticulum stress in maternal diabetes-induced cardiac malformations during critical cardiogenesis period. Birth Defects Res B Dev Reprod Toxicol. 2012;95(1):1-6. 
26. Sugimura $Y$, Murase T, Oyama K, Uchida A, Sato N, Hayasaka S, et al. Prevention of neural tube defects by loss of function of inducible nitric oxide synthase in fetuses of a mouse model of streptozotocin-induced diabetes. Diabetologia. 2009;52(5):962-71.

27. Yang $\mathrm{P}, \mathrm{Cao} \mathrm{Y}, \mathrm{Li} \mathrm{H}$. Hyperglycemia induces inducible nitric oxide synthase gene expression and consequent nitrosative stress via c-Jun N-terminal kinase activation. Am J Obstet Gynecol. 2010;203(2):185 e5-11.

28. Bozzetti P. Respiratory gases, acid-base balance and lactate concentrations of the midterm human fetus. Biol Neonate. 1987;51:10.

29. Marconi AM, Cetin I, Ferrazzi E, Ferrari MM, Pardi G, Battaglia FC. Lactate metabolism in normal and growth-retarded human fetuses. Pediatr Res. 1990;28(6):652-6.

30. Battaglia F. Principal Substrates of Fetal Metabolism. Physiological Reviews. 1978;58(2):29.

31. Duttaroy AK. Transport of fatty acids across the human placenta: a review. Prog Lipid Res. 2009;48(1):52-61.

32. Ortega-Senovilla H, Alvino G, Taricco E, Cetin I, Herrera E. Gestational diabetes mellitus upsets the proportion of fatty acids in umbilical arterial but not venous plasma. Diabetes Care. 2009;32(1):120-2.

33. Schaefer-Graf UM, Graf K, Kulbacka I, Kjos SL, Dudenhausen J, Vetter K, et al. Maternal lipids as strong determinants of fetal environment and growth in pregnancies with gestational diabetes mellitus. Diabetes Care. 2008;31(9):185863.

34. Kilby MD, Neary RH, Mackness MI, Durrington PN. Fetal and maternal lipoprotein metabolism in human pregnancy complicated by type I diabetes mellitus. J Clin Endocrinol Metab. 1998;83(5):1736-41.

35. Asghar ZA, Thompson A, Chi M, Cusumano A, Scheaffer S, Al-Hammadi N, et al. Maternal fructose drives placental uric acid production leading to adverse fetal outcomes. Sci Rep. 2016;6:25091.

36. Trindade CE, Barreiros RC, Kurokawa C, Bossolan G. Fructose in fetal cord blood and its relationship with maternal and 48-hour-newborn blood concentrations. Early Hum Dev. 2011;87(3):193-7.

37. Bossolan G, Trindade CE, Barreiros RC. Blood galactose and glucose levels in mothers, cord blood, and 48-hour-old breast-fed full-term infants. Neonatology. 2007;91(2):121-6. 
38. Vali P, Lakshminrusimha S. The Fetus Can Teach Us: Oxygen and the Pulmonary Vasculature. Children (Basel). 2017;4(8).

39. Soothill PW, Nicolaides KH, Rodeck CH, Campbell S. Effect of gestational age on fetal and intervillous blood gas and acid-base values in human pregnancy. Fetal Ther. 1986;1(4):168-75.

40. van Tuyl M, Blommaart PE, de Boer PA, Wert SE, Ruijter JM, Islam S, et al. Prenatal exposure to thyroid hormone is necessary for normal postnatal development of murine heart and lungs. Dev Biol. 2004;272(1):104-17.

41. Auso E, Lavado-Autric R, Cuevas E, Del Rey FE, Morreale De Escobar G, Berbel P. A moderate and transient deficiency of maternal thyroid function at the beginning of fetal neocorticogenesis alters neuronal migration. Endocrinology. 2004;145(9):4037-47.

42. Chattergoon NN. Thyroid hormone signaling and consequences for cardiac development. J Endocrinol. 2019;242(1):T145-T60.

43. Chattergoon NN, Giraud GD, Louey S, Stork P, Fowden AL, Thornburg KL. Thyroid hormone drives fetal cardiomyocyte maturation. FASEB J. 2012;26(1):397408.

44. Janssen R, Muller A, Simonides WS. Cardiac Thyroid Hormone Metabolism and Heart Failure. Eur Thyroid J. 2017;6(3):130-7.

45. Morkin E. Regulation of myosin heavy chain genes in the heart. Circulation. 1993;87(5):1451-60.

46. Pascual A, Aranda A. Thyroid hormone receptors, cell growth and differentiation. Biochim Biophys Acta. 2013;1830(7):3908-16.

47. Wang K, Shen H, Gan P, Cavallero S, Kumar SR, Lien CL, et al. Differential roles of insulin like growth factor 1 receptor and insulin receptor during embryonic heart development. BMC Dev Biol. 2019;19(1):5.

48. Zielinsky P. Role of prenatal echocardiography in the study of hypertrophic cardiomyopathy in the fetus. Echocardiography. 1991;8(6):661-8.

49. Shields BM, Knight B, Hopper H, Hill A, Powell RJ, Hattersley AT, et al. Measurement of cord insulin and insulin-related peptides suggests that girls are more insulin resistant than boys at birth. Diabetes Care. 2007;30(10):2661-6.

50. Park JH, Bae JG, Kim S, Kim CS, Lee SL, Kim HS. Insulin and glucagon levels of umbilical cord blood in appropriate for gestational age - preterm infants with or without postnatal hypoglycemia. Ann Pediatr Endocrinol Metab. 
2016;21(2):86-91.

51. Zeleniuch-Jacquotte A, Chajes V, Van Kappel AL, Riboli E, Toniolo P. Reliability of fatty acid composition in human serum phospholipids. Eur J Clin Nutr. 2000;54(5):367-72.

52. Shao D, Tian R. Glucose Transporters in Cardiac Metabolism and Hypertrophy. Compr Physiol. 2015;6(1):331-51.

53. Grover-McKay M. Glucose transporter 3 (GLUT3) protein is present in human myocardium. Biochim Biophys Acta. 1999;1416:145-54.

54. Simsek DG, Ecevit A, Hatipoglu N, Coban A, Arisoy AE, Bas F, et al. Neonatal Hyperglycemia, which threshold value, diagnostic approach and treatment?: Turkish Neonatal and Pediatric Endocrinology and Diabetes Societies consensus report. Turk Pediatri Ars. 2018;53(Suppl 1):S234-S8.

55. Fisher DA, Klein AH. Thyroid development and disorders of thyroid function in the newborn. N Engl J Med. 1981;304(12):702-12.

56. Castello A, Rodriguez-Manzaneque JC, Camps M, Perez-Castillo A, Testar $\mathrm{X}$, Palacin $\mathrm{M}$, et al. Perinatal hypothyroidism impairs the normal transition of GLUT4 and GLUT1 glucose transporters from fetal to neonatal levels in heart and brown adipose tissue. Evidence for tissue-specific regulation of GLUT4 expression by thyroid hormone. J Biol Chem. 1994;269(8):5905-12.

57. Forhead AJ, Fowden AL. Thyroid hormones in fetal growth and prepartum maturation. J Endocrinol. 2014;221(3):R87-R103.

58. Bensley JG, Moore L, De Matteo R, Harding R, Black MJ. Impact of preterm birth on the developing myocardium of the neonate. Pediatr Res. 2018;83(4):8808.

59. Simental-Mendia L. Birth-weight, insulin levels, and HOMA-IR in newborns at term. BMC Pediatrics. 2012;12(94):5.

60. Lopaschuk GD, Jaswal JS. Energy metabolic phenotype of the cardiomyocyte during development, differentiation, and postnatal maturation. J Cardiovasc Pharmacol. 2010;56(2):130-40.

61. Lopaschuk GD, Spafford MA. Energy substrate utilization by isolated working hearts from newborn rabbits. Am J Physiol. 1990;258(5 Pt 2):H1274-80.

62. Lopaschuk GD, Collins-Nakai RL, Itoi T. Developmental changes in energy substrate use by the heart. Cardiovasc Res. 1992;26(12):1172-80.

63. Itoi T, Lopaschuk GD. The contribution of glycolysis, glucose oxidation, 
lactate oxidation, and fatty acid oxidation to ATP production in isolated biventricular working hearts from 2-week-old rabbits. Pediatr Res. 1993;34(6):735-41.

64. Buroker NE, Ning XH, Portman M. Cardiac PPARalpha Protein Expression is Constant as Alternate Nuclear Receptors and PGC-1 Coordinately Increase During the Postnatal Metabolic Transition. PPAR Res. 2008;2008:279531.

65. Devalla HD, Passier R. Cardiac differentiation of pluripotent stem cells and implications for modeling the heart in health and disease. Sci Transl Med. 2018;10(435).

66. Robertson C, Tran DD, George SC. Concise review: maturation phases of human pluripotent stem cell-derived cardiomyocytes. Stem Cells. 2013;31(5):82937.

67. Mummery CL, Zhang J, Ng ES, Elliott DA, Elefanty AG, Kamp TJ. Differentiation of human embryonic stem cells and induced pluripotent stem cells to cardiomyocytes: a methods overview. Circ Res. 2012;111(3):344-58.

68. Marroquin LD, Hynes J, Dykens JA, Jamieson JD, Will Y. Circumventing the Crabtree effect: replacing media glucose with galactose increases susceptibility of HepG2 cells to mitochondrial toxicants. Toxicol Sci. 2007;97(2):539-47.

69. Medina JM. The role of lactate as an energy substrate for the brain during the early neonatal period. Biol Neonate. 1985;48(4):237-44.

70. Ito M, Jaswal JS, Lam VH, Oka T, Zhang L, Beker DL, et al. High levels of fatty acids increase contractile function of neonatal rabbit hearts during reperfusion following ischemia. Am J Physiol Heart Circ Physiol. 2010;298(5):H1426-37.

71. van der Lee KA, Vork MM, De Vries JE, Willemsen PH, Glatz JF, Reneman $\mathrm{RS}$, et al. Long-chain fatty acid-induced changes in gene expression in neonatal cardiac myocytes. J Lipid Res. 2000;41(1):41-7.

72. Luiken JJ, van Nieuwenhoven FA, America G, van der Vusse GJ, Glatz JF. Uptake and metabolism of palmitate by isolated cardiac myocytes from adult rats: involvement of sarcolemmal proteins. J Lipid Res. 1997;38(4):745-58.

73. Taegtmeyer $\mathrm{H}$, Sen $\mathrm{S}$, Vela D. Return to the fetal gene program: a suggested metabolic link to gene expression in the heart. Ann N Y Acad Sci. 2010;1188:1918.

74. Tsang MY, Cowie SE, Rabkin SW. Palmitate increases nitric oxide synthase activity that is involved in palmitate-induced cell death in cardiomyocytes. Nitric Oxide. 2004;10(1):11-9. 
75. Gomez R, Caballero R, Barana A, Amoros I, Calvo E, Lopez JA, et al. Nitric oxide increases cardiac IK1 by nitrosylation of cysteine 76 of Kir2.1 channels. Circ Res. 2009;105(4):383-92.

76. Doss MX, Di Diego JM, Goodrow RJ, Wu Y, Cordeiro JM, Nesterenko VV, et al. Maximum diastolic potential of human induced pluripotent stem cell-derived cardiomyocytes depends critically on I(Kr). PLoS One. 2012;7(7):e40288.

77. Yang X, Rodriguez ML, Leonard A, Sun L, Fischer KA, Wang Y, et al. Fatty Acids Enhance the Maturation of Cardiomyocytes Derived from Human Pluripotent Stem Cells. Stem Cell Reports. 2019;13(4):657-68.

78. van der Vusse GJ, van Bilsen M, Glatz JF. Cardiac fatty acid uptake and transport in health and disease. Cardiovasc Res. 2000;45(2):279-93.

79. Dzeja PP, Chung S, Faustino RS, Behfar A, Terzic A. Developmental enhancement of adenylate kinase-AMPK metabolic signaling axis supports stem cell cardiac differentiation. PLoS One. 2011;6(4):e19300.

80. Rapedius M, Soom M, Shumilina E, Schulze D, Schonherr R, Kirsch C, et al. Long chain CoA esters as competitive antagonists of phosphatidylinositol 4,5-bisphosphate activation in Kir channels. J Biol Chem. 2005;280(35):30760-7.

81. Shumilina E, Klocker N, Korniychuk G, Rapedius M, Lang F, Baukrowitz T. Cytoplasmic accumulation of long-chain coenzyme A esters activates KATP and inhibits Kir2.1 channels. J Physiol. 2006;575(Pt 2):433-42.

82. Labarthe F, Gelinas R, Des Rosiers C. Medium-chain fatty acids as metabolic therapy in cardiac disease. Cardiovasc Drugs Ther. 2008;22(2):97-106.

83. Fuerstenau-Sharp M, Zimmermann ME, Stark K, Jentsch N, Klingenstein M, Drzymalski $M$, et al. Generation of highly purified human cardiomyocytes from peripheral blood mononuclear cell-derived induced pluripotent stem cells. PLoS One. 2015;10(5):e0126596.

84. Tohyama S, Hattori F, Sano M, Hishiki T, Nagahata Y, Matsuura T, et al. Distinct metabolic flow enables large-scale purification of mouse and human pluripotent stem cell-derived cardiomyocytes. Cell Stem Cell. 2013;12(1):127-37.

85. Fillmore N, Mori J, Lopaschuk GD. Mitochondrial fatty acid oxidation alterations in heart failure, ischaemic heart disease and diabetic cardiomyopathy. Br J Pharmacol. 2014;171(8):2080-90.

86. Correia C, Koshkin A, Duarte P, Hu D, Carido M, Sebastiao MJ, et al. 3D aggregate culture improves metabolic maturation of human pluripotent stem cell derived cardiomyocytes. Biotechnol Bioeng. 2018;115(3):630-44. 
87. Ulmer BM, Stoehr A, Schulze ML, Patel S, Gucek M, Mannhardt I, et al. Contractile Work Contributes to Maturation of Energy Metabolism in hiPSCDerived Cardiomyocytes. Stem Cell Reports. 2018;10(3):834-47.

88. Mills RJ, Titmarsh DM, Koenig X, Parker BL, Ryall JG, Quaife-Ryan GA, et al. Functional screening in human cardiac organoids reveals a metabolic mechanism for cardiomyocyte cell cycle arrest. Proc Natl Acad Sci U S A. 2017;114(40):E8372-E81.

89. Protze SI, Liu J, Nussinovitch U, Ohana L, Backx PH, Gepstein L, et al. Sinoatrial node cardiomyocytes derived from human pluripotent cells function as a biological pacemaker. Nat Biotechnol. 2017;35(1):56-68.

90. Iyer NV, Kotch LE, Agani F, Leung SW, Laughner E, Wenger RH, et al. Cellular and developmental control of $\mathrm{O} 2$ homeostasis by hypoxia-inducible factor 1 alpha. Genes Dev. 1998;12(2):149-62. 
Chapter 3:

\section{A cardiomyocyte show of force:
A fluorescent alpha-actinin reporter line sheds light on human cardiomyocyte contractility versus substrate stiffness}




\section{Chapter 3: A cardiomyocyte show of force: A fluorescent alpha-actinin reporter line sheds light on human cardiomyocyte contractility versus substrate stiffness}

Marcelo C. Ribeiro, PhD ${ }^{1 *}$, Rolf H. Slaats, $\mathrm{MSc}^{1 *}$, Verena Schwach ${ }^{1}, \mathrm{MSc}$, José M. Rivera-Arbelaez, $\mathrm{MSc}^{1}$, Leon G. J. Tertoolen, $\mathrm{PhD}^{2}$, Berend J. van Meer, $\mathrm{PhD}^{2}$, Robert Molenaar ${ }^{3}$, Christine L. Mummery, PhD ${ }^{1,2}$, Mireille M. A. E. Claessens, $\mathrm{PhD}^{3}$, Robert Passier, $\mathrm{PhD}^{1,2, \#}$

${ }^{*}$ Authors contributed equally to this work, ${ }^{1}$ Applied Stem Cell Technologies, TechMed Centre, University of Twente, Drienerlolaan 5, 7500AE, Enschede, The Netherlands, ${ }^{2}$ Department of Anatomy and Embryology, Leiden University Medical Centre, PO Box 9600, 2300 RC Leiden, The Netherlands, ${ }^{3}$ NanoBioPhysics Group, TechMed Centre, University of Twente, Drienerlolaan 5, 7500AE Enschede, The Netherlands, "Corresponding author: robert.passier@utwente.nl, Drienerlolaan 5, 7500AE, Enschede, The Netherlands. 


\begin{abstract}
:
Cardiovascular disease is often associated with cardiac remodeling, including cardiac fibrosis, which may lead to increased stiffness of the heart wall. This stiffness in turn may cause subsequent failure of cardiac myocytes, however the response of these cells to increased substrate stiffness is largely unknown. To investigate the contractile response of human pluripotent stem cell-derived cardiomyocytes (hPSC-CMs) to increased substrate stiffness, we generated a stable transgenic human pluripotent stem cell line expressing a fusion protein of $\alpha$-Actinin and fluorescent mRubyll in a previously characterized NKX2.5-GFP reporter line. Cardiomyocytes differentiated from this line were subjected to a substrate with stiffness ranging from $4 \mathrm{kPa}$ to $101 \mathrm{kPa}$, while contraction of sarcomeres and bead displacement in the substrate were measured for each single cardiomyocyte. We found that sarcomere dynamics in hPSC-CMs on polyacrylamide gels of increasing stiffness are not affected above physiological levels $(21 \mathrm{kPa})$, but that contractile force increases up to a stiffness of $90 \mathrm{kPa}$, at which cell shortening, deducted from bead displacement, is significantly reduced compared to physiological stiffness. We therefore hypothesize that this discrepancy may be the cause of intracellular stress that leads to hypertrophy and consequent heart failure in vivo.
\end{abstract}

Keywords: Transgenic model; alpha-actinin; contractility; substrate stiffness 


\section{Introduction}

Disease of the heart often leads to remodeling of the heart wall, which can eventually lead to heart failure.(1) Cardiac remodeling is an adaptive response to heart function impairment. It is influenced by a variety of factors, including genetic predisposition, loss of viable cardiac tissue, volume- and pressure overload and myocarditis, among others. The most common features of cardiac remodeling are increased cardiomyocyte size, fibroblast proliferation and increased deposition of extracellular matrix (ECM) proteins. Together, these changes lead to increased cardiac wall stiffness, which is associated with (diastolic) heart failure.(2-4) Regardless of the underlying cause, cardiomyocytes increase their contraction force in response to increased stiffness, which may ultimately lead to adverse cardiac hypertrophy and cell death. $(5,6)$ It is therefore important to determine how the cardiomyocyte adapts to an increase in stiffness and at which value the cell is not further able to contract, as this environment is a major stress trigger for adverse hypertrophy and cell death.

Sarcomeres are the smallest contractile units of cardiomyocytes. Sarcomeric organization, length and movement are key elements in the adaptability of cardiomyocyte contraction to increased stiffness. However, it is not clear how sarcomere length and movement are affected with increasing substrate stiffness in order to maintain cardiomyocyte contraction. Here, we generated a clonal transgenic $\alpha$-Actinin-mRubyll fusion reporter using CRISPR-Cas9-mediated genome editing in a previously described cardiomyocyte fluorescent (NKX2.5eGFP) human pluripotent stem cell (hPSC) reporter line.(7) The resulting Double Reporter of $m \underline{R} u b y I I-\underline{A} C T N 2$ and $\underline{G} F P-\underline{N} K X 2.5$ (DRRAGN) line allows real-time monitoring of z-disk distance and contractile movement in live cardiomyocytes as substrate stiffness increases. Using the DRRAGN reporter line we assessed the adaptive response of contraction force of single hPSC-derived cardiomyocytes (hPSC-CMs) to increased substrate stiffness and measured sarcomere length and movement within the same cells. We found that different aspects of sarcomere dynamics of hPSC-CMs are differentially affected by increased substrate stiffness.

\section{Methods}

Plasmid design and construction

The Cas9 plasmid (Addgene \#62988) carrying CAS9 and the gRNA sequences was generated as described by Ran et al.(8) Briefly, gRNA-coding Fwd DNA oligonucleotide 5'-CACCGTTCTCTTCCGCACTCTACG-3' and Rev DNA oligonucleotide 5'-AAACCGTAGAGTGCGGAAGAGAAC-3' were ordered as single strand complementary DNA oligonucleotides (Sigma-Aldrich) and subsequently phosphorylated and annealed using T4 PNK (ThermoFisher) in a thermocycler running the parameters set by the protocol from Ran et al, that creates sticky 
ends on the dsDNA fragment for seamless insertion into the plasmid. The annealed double stranded gRNA DNA oligo was then incorporated in the Cas9 plasmid by simultaneous cutting of the plasmid with restriction enzyme Bbsl (ThermoFisher) and T7 (ThermoFisher) ligation of the oligo at the cut site. The Cas9 gRNA plasmid was then transformed and expanded in DH5a (ThermoFisher) bacteria and subsequently isolated and sent for Sanger sequencing and stored for transfection.

The homology-directed repair template plasmid consisted of a pENTR1A backbone carrying the mRubyll sequence flanked by two homology arms of the target genomic locus of ACTN2, which would mediate homology-directed repairbased insertion of the mRubyll sequence into the host genome. The mRubyll sequence was amplified by hifi PCR (Phusion polymerase, ThermoFisher) using In-Fusion primers (mRubyll Fwd and Rev, see Suppl table 1) and plasmid mRubyll-N1 (Addgene \#54614) as template. Homology arm sequences were amplified by hifi PCR of isolated human genomic DNA of HUVECs using In-Fusion primers ( 5 ' flanking sequence Fwd and Rev for the upstream homology arm, and 3' flanking sequence Fed and Rev for the downstream flanking sequence, see Suppl table 1). Using primers designed for In-Fusion cloning created overlapping termini after hifi PCR between each DNA fragment and the plasmid backbone at the insertion site that is required for In-Fusion based assembly of the HDR plasmid, as described in the Takara Clontech In-Fusion cloning manual. Care was taken to mutate the PAM sequence in the plasmid to prevent Cas9 from cutting the template plasmid during transfection (see Fig 1C). To generate the targeting vector, amplified fragments were assembled by In-Fusion cloning (Takara CL 639648) according to the manufacturer's directions.

\begin{tabular}{|l|l|}
\hline Non-standard Abbreviations and Acronyms. \\
\hline ECM & extracellular matrix \\
\hline hPSC-CM & human pluripotent stem cell-derived cardiomyocyte \\
\hline PAA & polyacrylamide \\
\hline hESC & human embryonic stem cell \\
\hline bFGF & basic fibroblast growth factor \\
\hline MEF & mouse embryonic fibroblasts \\
\hline HDR & homology-directed repair \\
\hline PDMS & polydimethylsiloxane \\
\hline FACS & fluorescence-activated cell sorting \\
\hline hIPSC & human induced pluripotent stem cell \\
\hline CRISPR & Clustered Regularly Interspaced Short Palindromic Repeats \\
\hline
\end{tabular}

Stem cell maintenance

Human embryonic stem cells (hESCs, female) carrying a GFP reporter for NKX2.5(7) were maintained on irradiated mouse embryonic fibroblasts (MEF feeder cells) 
in hESC medium (DMEM/F12-based medium containing 20\% knockout serum replacement (ThermoFisher) and $10 \mathrm{ng} / \mathrm{ml}$ basic fibroblast growth factor (bFGF) (Miltenyi Biotech)). Passaging of hESCs on MEFs was done by dissociation using 1x TripLE Select (ThermoFisher), subsequent inactivation by dilution in hESC medium, collection of the cells by centrifugation at 240x $\mathrm{g}$ for three minutes, resuspension of the pellet in $1 \mathrm{~mL} h E S C$ medium, manual counting using Trypan blue (ThermoFisher) and finally seeding as single cells on freshly prepared plates with MEF cells on $0.1 \%$ gelatin.

\section{Transfection}

HPSCs were maintained in hESC medium (see above) and were seeded at a density of $50 \mathrm{~K}$ cells per $\mathrm{cm}^{2}$ on MEF cells one day before transfection. hPSCs were simultaneously transfected with $4 \mu \mathrm{g}$ Cas 9 plasmid and $2 \mu \mathrm{g}$ of HDR plasmid using Lipofectamine 2000 (ThermoFisher) according to manufacturer's instructions. Transfected cells were selected by puromycin exposure for 72 hours, followed by recovery culture on MEFs in hESC medium for seven days and passaged once to fresh feeder cells before single cell clonal expansion was initiated by flow cytometry-mediated single cell deposition onto MEF feeder cells in 96-well plates. Single cell colonies were manually identified and passaged to 48 well format on feeder cells. Insertion of the mRubyll sequence into one or both ACTN2 alleles was validated by hifi PCR and subsequent gel electrophoresis. Two passages after single cell sorting and clonal expansion, the cells were transferred to vitronectin-coated plates without feeder cells and grown in Essential 8 medium (ThermoFisher).

\section{Stem cell differentiation}

Differentiation to cardiomyocytes was done as described previously.(9) Briefly, hPSCs were seeded at a density of $25 \mathrm{~K}$ cells per $\mathrm{cm}^{2}$ on Matrigel-coated 6-well plates in Essential 8 medium (ThermoFisher) (described in (10)) on day -1. At day 0, mesodermal differentiation was initiated by addition of Wnt activator CHIR99021 (1.5 $\mathrm{mmol} / \mathrm{L}$, Axon Medchem 1386), Activin-A (20 ng/mL, Miltenyi 130-115-010) and BMP4 (20 ng/mL, R\&D systems 314-BP/CF) in BPEL medium. At day 3, Wnt was inactivated by adding XAV939 (5 $\mathrm{mol} / \mathrm{L}$, R\&D Systems 3748$)$ in BPEL. In addition, Matrigel (1:200) was added to promote adhesion of cells. Cell cultures were refreshed on Day 7 and 10 with BPEL after the start of differentiation until differentiation was completed (day 13).

\section{Cell line validation}

Proper insertion of the mRubyll sequence at the ACTN2 locus was validated by Sanger sequencing (Eurofins Genomics) of Phusion hifi PCR (Thermofisher) products covering the insert within the HDR template and at the site of insertion in the genome of the targeted cells. Primers used for sequencing can be found 
in supplementary table 2 . Human pluripotent stem cell identity was assessed by expression of TRA-1-60 (Miltenyi Biotech $\mathrm{GmbH}$ ) quantified by MACSQuant VYB flow cytometer (Miltenyi Biotech $\mathrm{GmbH}$ ). Potential off-target locations were identified using the Off-Spotter web tool of Jefferson.

\section{Acrylamide gel fabrication}

Coverslips of $15 \mathrm{~mm}$ diameter were micro-patterned with $1 \%$ gelatin lines (20 um width) using a PDMS stamp. Polyacrylamide (PAA) gels with varying degrees of stiffness were produced by mixing $40 \%$ acrylamide, HEPES ( $\mathrm{pH} 8.5$ ), ammonium persulphate $(10 \%)$ and $\mathrm{H}_{2} \mathrm{O}$ (volume depending on Bis solution volume). This mixture was vortexed and spun down to remove air. Subsequently, TEMED and a $2 \%$ Bis solution at incrementing dilutions were added: $0.02 \%, 0.08 \%, 0.15 \%$, $0.24 \%, 0.50 \%$ and $0.66 \%$, and completed with $1 \mu \mathrm{L}$ FluoSpheres, (Invitrogen, $\varnothing$ $0.2 \mu \mathrm{m}$ polystyrene beads loaded with dark red fluorophore $\mathrm{Ex} / \mathrm{Em}=660 / 680$ $\mathrm{nm})$. Precisely $9.2 \mu \mathrm{L}$ of the polyacrylamide mixture was added at the center of a silane coated coverslip of $25 \mathrm{~mm}$ diameter to control thickness, then topped with micro-patterned coverslip before the acrylamide polymerized. Patterning coverslips were removed after 18 minutes of polymerization. Coverslips with patterned gels were UV sterilized before use. To measure gel stiffness, 5 circles of $1.5 \mathrm{~mm}$ thick PAA gels per stiffness with a diameter of $25 \mathrm{~mm}$ were compressed linearly in a wet state by a rheometer (Anton-Paar Physica MCR 301), which measured gap distance (remaining thickness of the gel, in $\mathrm{mm}$ ) and the normal force $(\mathrm{N})$ required to compress the gel to this thickness. We then used these readouts to approximate the Young's modulus of the gel using the following formula:

Where $\mathrm{YM}=$ Young's Modulus, $\mathrm{dF}=$ the increase in normal force from baseline to current compression, $A=$ area of the plunger $(=25 \mathrm{~mm}), \mathrm{dL} / \mathrm{L}_{\mathrm{o}}=$ fraction of compression, with $\mathrm{dL}$ the gap distance at current compression compared to baseline $L_{0}$.

\section{Cell culture on gels}

HPSC-CMs were incubated in maturation medium(9) with a T3 hormone concentration of $5 \mu \mathrm{mol} / \mathrm{L}$ for three days starting at day 13 of the differentiation, followed by dissociation with $1 x$ TripLE (ThermoFisher) and replating on the patterned coverslips at a density of $60 \mathrm{~K}$ cells per $\mathrm{cm}^{2}$ on day 16 . Cells were then allowed to recover for 4 days in maturation medium until start of image acquisition at day 20.

Data collection and analysis

HPSC-CMs seeded on gelatin patterns were maintained at $37^{\circ} \mathrm{C}$ in $5 \% \mathrm{CO} 2$ during image analysis. Cardiomyocytes were paced at $1 \mathrm{~Hz}$. Image acquisition was done 
at 70 frames per second for both bead displacement recording and $\alpha$-Actinin tracking on a Nikon Eclipse TE2000-U fluorescence microscope fitted with a Nikon CFI Super Fluor 40x oil immersion objective (MRF01400) and a mercury light as excitation source. Alpha-Actinin-mRubyll was visualized at $60 x$ magnification (using a 1.5x enhancer on the microscope) with filters at excitation 542/20 nm and emission 560LP; the fluorescent beads at 40x magnification using filters at excitation 620/60 and emission 700/75 nm. Transmitted light was captured at 40x magnification. The GFP signal was used to confirm individual cell identity as cells of the working myocardium, excluding cells of the nodal lineage during analysis. All data was collected from hPSC-CMs derived from one heterozygous (3F4) and one homozygous (3A1) clone (4kPa: 58 and 44; $21 \mathrm{kPa}: 43$ and 44; 32 $\mathrm{kPa}: 33$ and 48; $59 \mathrm{kPa}: 49$ and 46; $90 \mathrm{kPa}: 43$ and 45; $101 \mathrm{kPa}: 27$ and 44 cells for the heterozygous and homozygous clone, respectively) of at least 3 independent differentiations ( $n=5$ for $4 \mathrm{kPa}$ group, $n=3$ for other stiffnesses). Data was pooled and averaged across all cells of the same experimental group.

Bead displacement in the PAA gel was quantified using the Mosaic Particle Tracker plugin on ImageJ. The travel distances of all beads were calculated using the raw $x$ and y coordinates of each particle in each frame. We exclusively analyzed moving beads that were located directly under the attached cardiomyocyte, using a tracing of the cell outline prepared manually for each cell on the transmitted light image. This outline was also used to determine cell area for normalization. Exerted stress (from here on referred to as force for ease of reading) of the cell onto the substrate was calculated using the known substrate stiffness and the sum of travel distances of the beads, using a previously described equation(11), and normalized to cell area using the cell outline trace for fair comparison:

In which $v=$ Poisson's ratio $(=0.457$ for PAA(12)), $b=$ bead diameter, $u$ is displacement and $E_{m}=$ Young's modulus, which is dependent on the stiffness of the gel. This equation assumes the beads are located at the surface of the gel for simplicity, which we took into account by focussing on the beads directly underneath the cell on the surface of the gel, using the $40 x$ objective. The unit of measure for contraction force in this paper is $\mu \mathrm{N} / \mathrm{mm}^{2}$, whereas stiffness of the substrate is defined in $\mathrm{kPa}$. These units of measure are interchangeable, but in order to facilitate comparison to literature we chose to report both forces in different units. For reference: $1 \mathrm{kPa}=1000 \mu \mathrm{N} / \mathrm{mm}^{2}$.

To assess cell contraction distance (shortening), bead movement on the short edges of the cell was quantified. We identified these beads from the total bead population under the cell by selecting the $5 \%$ of beads showing greatest movement in the collected data.

Sarcomere kinetics were analyzed by custom made LabView-based software 
quantifying z-line movement using the fluorescent $\alpha$-Actinin signal of the reporter cells (LabView, Vision and Motion, National Instruments Austin, Texas, USA). In short, eight individual Z-line profiles were recorded (for 8 to 10 contractionrelaxation cycles) per myofibril in the hPSC-CM (Suppl Fig 8A). The profiles were analyzed by fast Fourier transformation which gave a central peak which was fitted (Levenberg-Marquardt algorithm) with a gaussian profile. The peak of the

$$
Y M=\frac{d F / A}{d L / L_{0}}
$$

gaussian was taken for the computation of the amplitude at each point during the contraction relaxation amplitude (Suppl Fig 8B). Contraction relaxation profiles were then computed plotting the amplitude (calibrated for $\mathrm{mm} / \mathrm{pixel}$ ) with the known time interval during recording. Beginning and end of contraction and relaxation were determined using this plotted contraction-relaxation profile based on changes in slope, after which the software calculated time and distance parameters of contraction and relaxation.

\section{Statistics}

Results are displayed as mean \pm standard error of the mean (s.e.m.) unless stated otherwise. Statistical analyses were performed on IBM SPSS Statistics 25, comparing means of groups using one-way ANOVA and Bonferroni post-Hoc test.

\section{Results}

Characterization of the DRRAGN $\alpha$-Actinin/NKX2.5 double reporter line Incorporation of the DNA fragment (Suppl Fig 1) encoding mRubyll at the genomic locus of ACTN2 was facilitated by transfection of two vectors: A Cas9gRNA plasmid and HDR template plasmid (Supply Fig 2). The gRNA mediated DNA cleavage was directed 17 base pairs upstream of the stop codon at the end of the last exon of the ACTN2 gene where the mRubyll sequence was inserted in frame via homology-directed repair. Of 192 single cells deposited by FACS after transfection and antibiotic selection, 82 colonies could be identified (survival of $43 \%$ ), of which 22 clones were successfully targeted clones identified by PCR and subsequent gel electrophoresis. Fifteen of these were mono-allelic and 7 were bi-allelic (Fig 1B). Sanger sequencing of these clones validated the insertion of the mRubyll sequence according to the in silico design (Fig $1 \mathrm{~A}+\mathrm{C}$ ). Of the 22 clones, three clones demonstrated a genetic alteration, of which one was a frame-shift mutation knocking out mRubyll; the other two were silent mutations (see suppl. table 3 ). At this point, two sequence-validated mono-allelic (clone numbers $3 A 1$ and $3 A 6$ ) and two bi-allelic clones (numbers $4 D 2$ and $3 F 4$ ) were selected for 
further analysis. Off-target screening of these four clones revealed no mutations in the top 4 most likely targeted sites as predicted by the Off-Spotter web tool (Suppl Fig 3). Targeted clonal lines revealed a high percentage (>97\%) of stem cell marker TRA-1-60 as shown by flow cytometry (Suppl Fig 4).

Targeted hPSC cells differentiate efficiently to cardiomyocytes in vitro.

Upon differentiation, the DRRAGN hPSC line to cardiomyocytes showed a clear and organized striated pattern of fluorescent $\alpha$-Actinin along the long axis of

$$
F_{x}=\frac{2}{(1+v)(2-v)} E_{m} b u
$$

the cell upon differentiation to cardiomyocytes, of which the homozygous clone expressed a higher average mRubyll signal intensity than the heterozygous clone as detected by flow cytometry (Fig $2 \mathrm{C}$ ). Figure $2 \mathrm{~A}$ shows the fluorescent signal of the $\alpha$-Actinin under identical microscopic acquisition settings for both a mono-allelic (3A1) and a bi-allelic (3F4) clone, demonstrating that both genotypic variants were readily detectable. Compared to the parental cell line, all but mono-allelic clone $3 \mathrm{~A} 6$ of the double reporter cell line differentiated into comparable percentages of cardiomyocytes (parental line $65.3 \pm 3.2 \%$; mono-allelic clones $3 \mathrm{~A} 1$ : $59.5 \pm 4.0 \%$ \& $3 \mathrm{~A} 6$ : $36.6 \pm 4.5 \%$; bi-allelic clones $4 \mathrm{D} 2$ $63.5 \pm 3.1 \%$ \& $3 F 463.3 \pm 2.7 \%$ ), indicated by the NKX2.5-GFP+ populations (Suppl Fig 5+6). Interestingly, a subset of NKX2.5 $/$ ACTN2 $^{+}$(cardiomyocytes), NKX2.5 $/$ ACTN2, NKX2.5/ACTN2 ${ }^{+}$and NKX2.5\%/ACTN2 populations could be identified in differentiated DRRAGN cultures following analysis by flow cytometry, which suggested cell populations were heterogeneous (Fig 2B). Bi-allelic and monoallelic clones showed similar population distributions except for $3 A 6$, which had significantly $(p<0.001)$ fewer NKX2.5-GFP+/ACTN2-mRUBY+ cardiomyocytes, indicating less efficient cardiomyocyte differentiation.

Defined stiffness exposure of hPSC-CMs on gelatin patterned acrylamide gels.

Several studies have reported physiological human adult cardiac wall stiffness to range from $24 \mathrm{kPa}$ to $30 \mathrm{kPa}$, while patients suffering from congestive cardiomyopathy were reported to have cardiac wall stiffness over $100 \mathrm{kPa} .(13-15)$ To model for heart wall stiffening, we increased the stiffness of the cardiomyocyte substrate using polyacrylamide gels with a stiffness ranging from 4 to $101 \mathrm{kPa}$ (Fig 3) and measured sarcomere shortening and contraction force. In order to decrease the cell-to-cell variability we aligned hPCS-CMs on $20 \mu \mathrm{m}$ wide gelatin lines that were patterned on these acrylamide gels by microcontact printing (Fig 
3A). Adjustment of the PAA crosslinker concentration resulted in a near-linear increase of gel stiffness as measured by rheometry (Fig 3B). The presence of evenly aligned gelatin patterns was verified microscopically for gels with all stiffnesses (Fig 3C), on which hPSC-CMs were seeded. Single cardiomyocytes attached to the gelatin pattern were analyzed by real-time imaging of fluorescent beads in the acrylamide substrate and $\alpha$-Actinin-mRubyll in the cell (Fig 3D). We confirmed that the fusion of the mRubyll to the $\alpha$-Actinin did not alter the contraction force of these cells in comparison to the cardiomyocytes from the parental stem cell line, using the substrate stiffness previously published for these cardiomyocytes (5.8 kPa) (Suppl. Fig. 7).(9)

hPSC-CMs increase their applied contraction force in response to increased substrate stiffness.

HPSC-CMs displayed significantly increased contraction force as substrate stiffness increased up to $90 \mathrm{kPa}(p<0.01)$, above which the contraction force did not further increase (Fig. 4A). By tracking bead displacement on the contractile edges of the cardiomyocytes, we found that cell shortening was significantly higher at 4

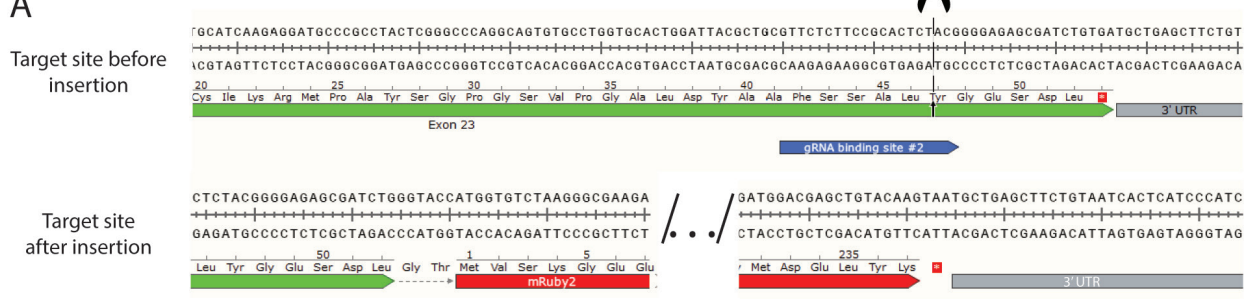

B

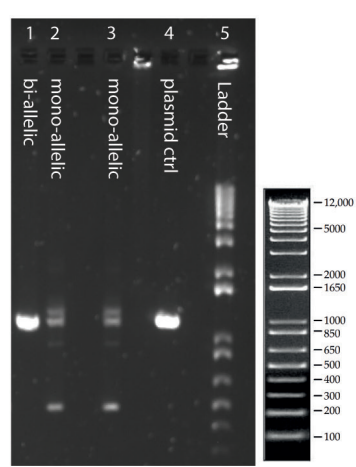

C

Predicted

GCGTTCTCTTCCGCACTCTACGgGGAGAGCGATCTG GGTACCATGGTGTCTAAGGGCGAG

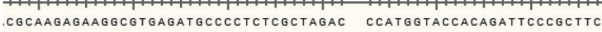
Ala Phe Ser Ser Ala Leu Tyr Gly Glu Ser Asp Leu
Exon 23 gRNA binding site 62

GCGTTCTCTTCCOCACTCTACGGGGAGAGCGATCTG TO-

Parent line

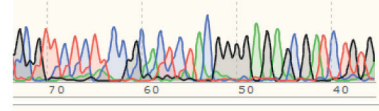

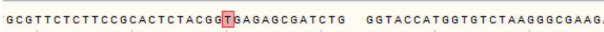

Targeted

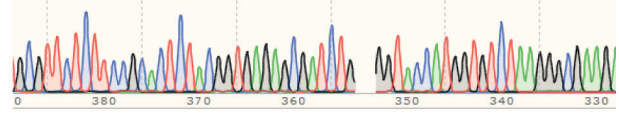

Figure 1: The designed and validated targeting of the $\alpha$-Actinin locus. A) The in-silico sequence of the $\alpha$-Actinin locus before and after targeting. B) Agarose gel demonstrating mono-allelic and biallelic targeted $\alpha$-Actinin loci. C) Sanger sequencing validation of the insert. Note the G->T mutation in the targeted genome that corresponds with the PAM sequence inactivation in the construct. 
$\mathrm{kPa}$ when compared to all the other stiffnesses $(p<0.001)$, indicating a significant change in cell response to its substrate between $4 \mathrm{kPa}$ and the physiological-like $21 \mathrm{kPa}$ stiffness. We observe a trend of decrease of cell shortening from $21 \mathrm{kPa}$ and $90 \mathrm{kPa}$, whereas cell shortening significantly decreased at $101 \mathrm{kPa}$ compared to the physiological-like $21 \mathrm{kPa}$ stiffness ( $<<0.05$, Fig. $4 \mathrm{~B}$ ), indicating that this is the level of stiffness at which cell shortening is significantly restrained by the substrate. Neither the time of contraction nor relaxation changed significantly between the different stiffnesses (Fig 4C), except the time of relaxation at $4 \mathrm{kPa}$, which was significantly lower than the time at $21 \mathrm{kPa}(424 \pm 19$ vs $520 \pm 29 \mathrm{~ms}$, $\mathrm{p}<0.05)$. However, the speed of contraction and relaxation decreased significantly from $4 \mathrm{kPa}$ to $-21 \mathrm{kPa}$ and to the higher stiffnesses. Both speed of contraction and relaxation gradually decreased from $21 \mathrm{kPa}$ and higher stiffnesses, with a significant change at $101 \mathrm{kPa}$ (Fig 4D).

Sarcomeric shortening does not change at supraphysiological substrate stiffnesses

Sarcomeric movement was measured on the same cardiomyocytes as in bead displacement measurement in figure 4 (Suppl video 1). Substrate stiffness A

Mono-allelic
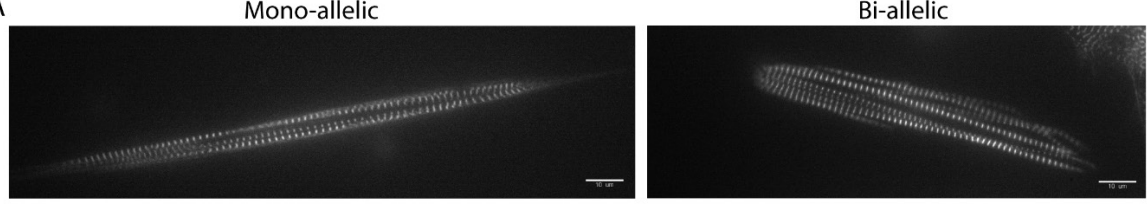

B

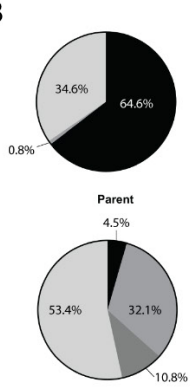

Clone 3 A 6 [mono-allelic]

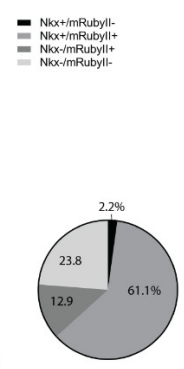

Clone $3 F 4$ [bi-allelic]
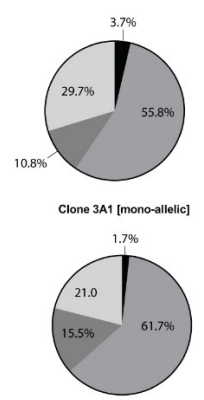

Clone $4 \mathrm{D} 2$ [bi-allelic]
C

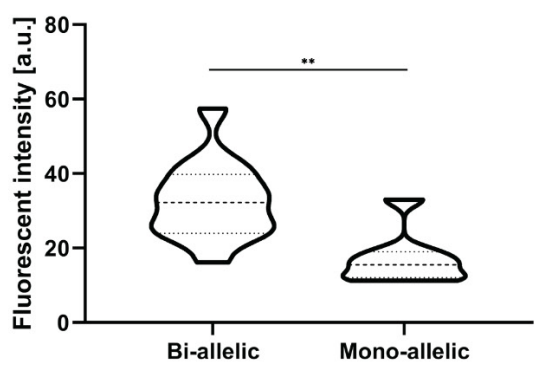

Figure 2: DRRAGN hESC differentiate to cardiac cells, and specifically to cardiomyocytes, in a similar fashion to the parent line. A) Photomicrograph of a single cardiomyocyte expressing mono-allelic or bi-allelic fluorescent $\alpha$-actinin after differentiation from the reporter cell line using identical acquisition settings. B) Populations of cells derived from monolayer differentiations $(n \geq 3)$ of parent line (dN3), mono-allelic reporters (3A1 and 3A6) and Bi-allelic reporters (3F4 and 4D2), with NKX2.5+/ACTN2+ population representing cardiomyocytes. C) Fluorescent signal intensity differs significantly $(p<0.001)$ between the homozygote clone 3F4 $(N=14)$ to heterozygote clone $3 A 1(N=8)$ as detected by flow cytometry. Significance: ${ }^{*}=p<0.05,{ }^{* *}=p<0.01, * * *=p<0.001, n s$ $=$ not significant. 

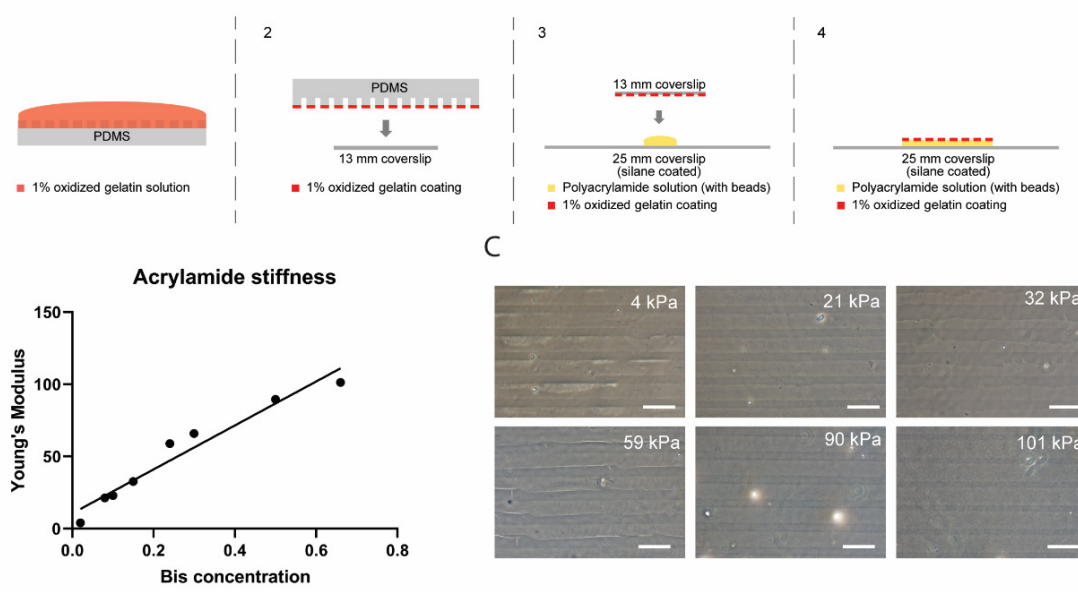

C
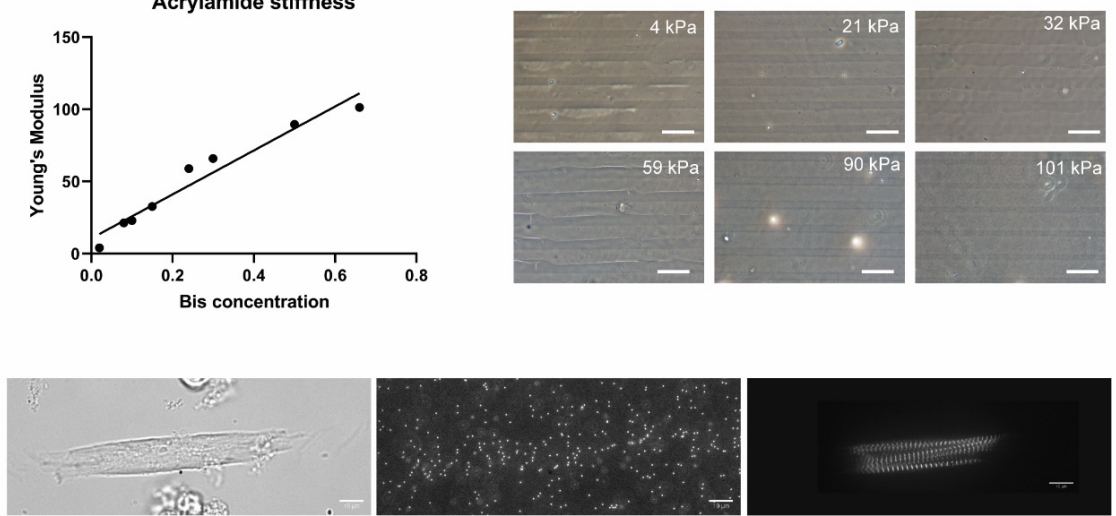

Figure 3: The manufacturing of substrates with defined stiffness and single cardiomyocyte attachment. A) Schematic representation of micro-contact printing gelatin line patterns on PAA gels. B) Increased crosslinker in the PAA mixture provides gels with increasing Young's Modulus (stiffness). C) Photomicrographic representations of gelatin lines on acrylamide gels ranging from 4 kPa to 101 kPa in Young's Modulus. Scale bars represent $20 \mu \mathrm{m}$. D) A single cardiomyocyte attached to a gelatin line, imaged in transmitted light microscopy (left), the underlying fluorescent beads in the PAA gel (middle), and the corresponding $\alpha$-Actinin signal of the cell (right). Scale bars represent $10 \mu \mathrm{m}$.

appeared not to affect sarcomeric organization of cardiomyocytes (Fig 5A), except for the lowest stiffness of $4 \mathrm{kPa}$, on which the cardiomyocytes retained a more elliptic morphology compared to other stiffnesses. The sarcomere length (spacing between two $\mathrm{z}$-disks) of $1.54 \pm 0.014 \mu \mathrm{m}$ at maximum contraction did not significantly change with the increase in substrate stiffness except between $4 \mathrm{kPa}$ and $32 \mathrm{kPa}(\mathrm{p}<0.05)$, and sarcomere length at full relaxation remained constant around $1.73 \pm 0.015 \mu \mathrm{m}$ (Fig $5 \mathrm{~B}$ ), except at $4 \mathrm{kPa}$, where sarcomere length was on average $1.85 \pm 0.02 \mu \mathrm{m}(\mathrm{p}<0.001)$. The shortening of the sarcomere (measured in z-disk displacement) significantly decreased from $0.34 \pm 0.014 \mu \mathrm{m}$ at $4 \mathrm{kPa}$ to $0.21 \pm 0.01 \mu \mathrm{m}$ at the physiological-like $21 \mathrm{kPa}(\mathrm{p}<0.001)$ and remained constant with further increase in substrate stiffness (Fig $5 \mathrm{C}$ ), indicating that the sarcomere shortening does not adapt to increase in substrate stiffness beyond physiologicallike stiffnesses. Even though the duration of both sarcomere contraction $(210 \pm 1.1$ $\mathrm{ms})$ and relaxation $(300 \pm 1.8 \mathrm{~ms})$ did not change with the increase in substrate stiffness (Fig. 5D), both sarcomere contraction and relaxation speed significantly decreased from $4 \mathrm{kPa}$ up to $32 \mathrm{kPa}(\mathrm{p}<0.001)$ and remained constant with the further increase in substrate stiffness (Fig $5 \mathrm{E}$ ), which reiterates the sarcomere 
A

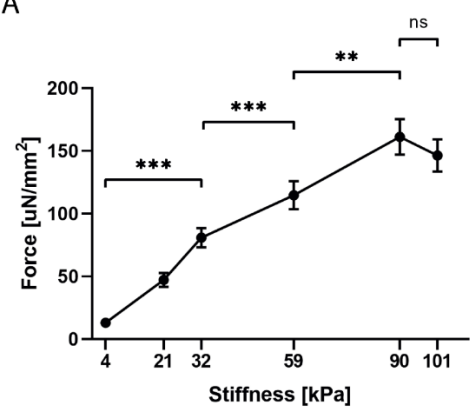

C

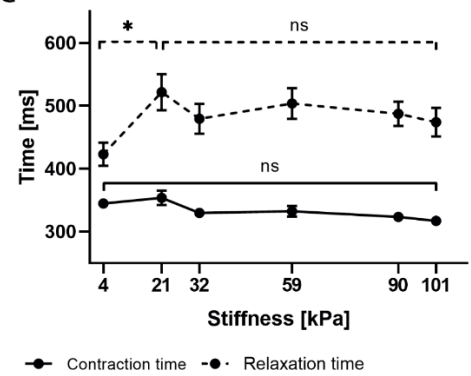

B

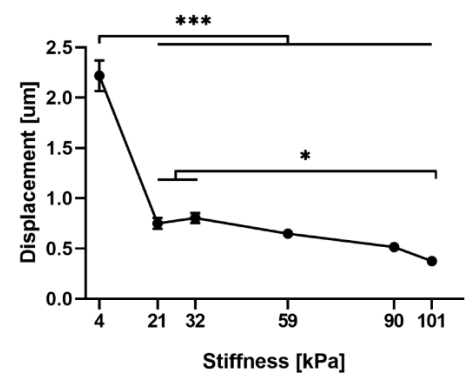

$\mathrm{D}$

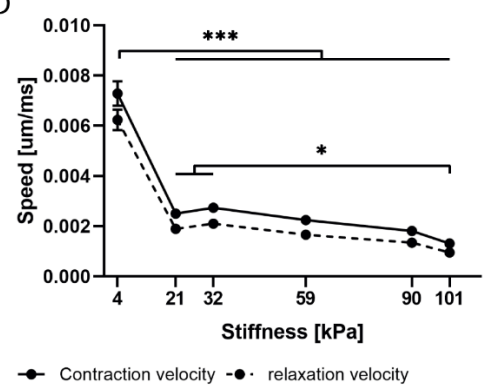

Figure 4: Quantification of the manipulation of the PAA substrate by the cardiomyocytes (pooled data from heterozygous and homozygous clone). A) Average applied force on the acrylamide gel by the cardiomyocyte per substrate stiffness, normalized to cell surface area B) Average length of bead travel trajectory in the PAA gel upon contraction of the cardiomyocyte. C) Average time of substrate shrinkage and elongation due to cardiomyocyte contraction and relaxation, respectively. D) The average speed of contraction and relaxation as a function of bead travel time and displacement. Data presented in mean \pm s.e.m. Significance: ${ }^{*}=p<0.05,{ }^{* *}=p<0.01, * * *=p<0.001, n s=n o t$ significant. ( $n=104,99,96,102,94$ and 98 cells for groups $4 \mathrm{kPa}, 21 \mathrm{kPa}, 32 \mathrm{kPa}, 59 \mathrm{kPa}, 90 \mathrm{kPa}$ and $101 \mathrm{kPa}$, respectively)

maximum adjustment up to a substrate stiffness between 21 and $32 \mathrm{kPa}$. No differences in sarcomeric dynamics were observed between the mono-allelic and bi-allelic clone (Suppl. Fig. 9).

Adaptation of sarcomere contraction diverges from cell contraction at higher substrate stiffnesses

We measured both contraction force and sarcomere shortening in the same cells in order to assess the correlation of these two parameters with the increase in substrate stiffness. Interestingly, both sarcomere shortening and bead displacement during contraction significantly decreased from a very soft substrate to a more physiological substrate. However, at higher stiffnesses the bead displacement significantly decreased while sarcomere shortening and elongation were maintained (Fig 6A, statistics in 4B \& 5C), implying a decoupling between 
A
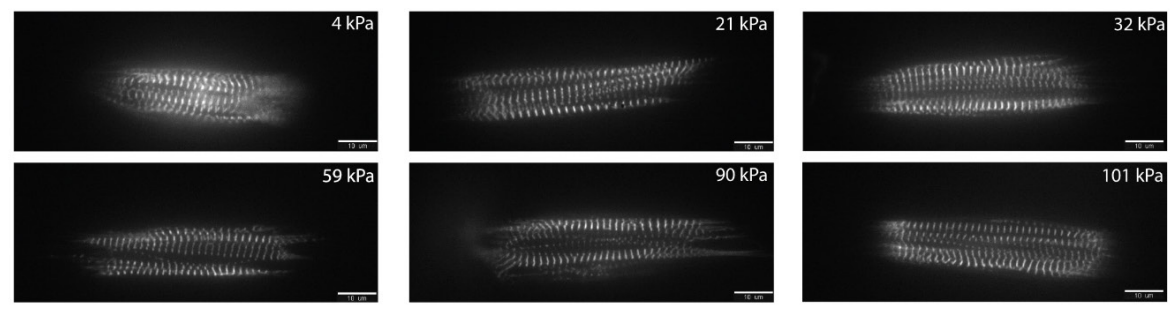

B

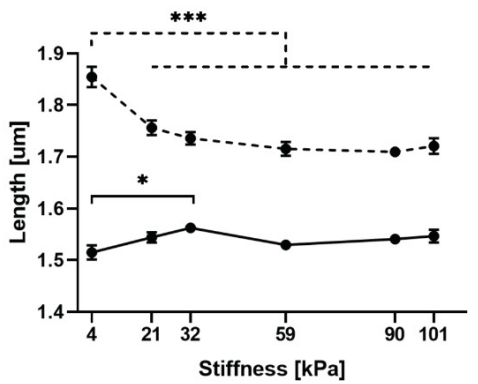

Sarcomere contraction

- Sarcomere relaxation

$D$

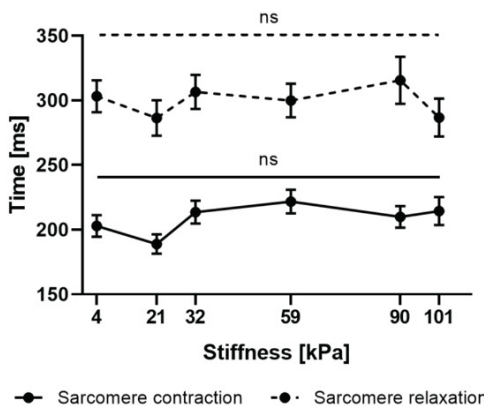

C

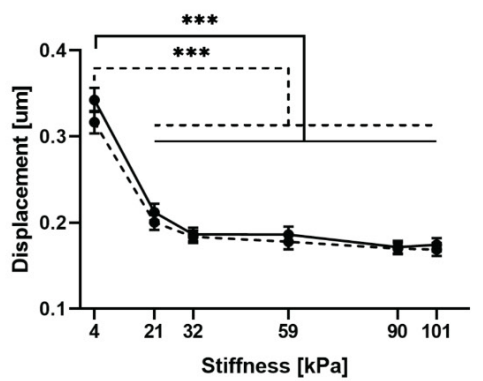

- Sarcomere relaxation

$E$

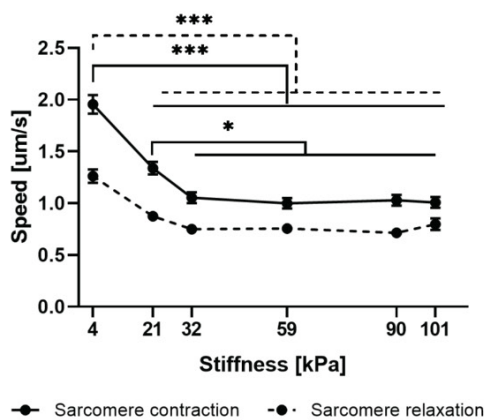

Sarcomere contraction

Figure 5: Sarcomeric dynamics in relation to substrate stiffness (pooled data from heterozygous and homozygous clone). A) Representative pictures of single cardiomyocytes attached to gelatin on all different PAA stiffness. B) The absolute maximum and minimum length of the space between two $z$-disks (a sarcomere) at full relaxation and full contraction, respectively. C) The absolute shortening and elongation of the space between two z-disks during contraction and relaxation, respectively. D) Travel time of the z-disk ( $\alpha$-actinin line) during contraction and relaxation of the sarcomere. E) The travel speed of the z-disk line during contraction and relaxation. Data presented in mean \pm s.e.m. Significance: ${ }^{*}=p<0.05, * *=p<0.01, * * *=p<0.001, n s=$ not significant. $(n=102,87,81,95,87$ and 71 cells for groups $4 \mathrm{kPa}, 21 \mathrm{kPa}, 32 \mathrm{kPa}, 59 \mathrm{kPa}, 90 \mathrm{kPa}$ and $101 \mathrm{kPa}$, respectively) 
the sarcomere shortening and actual cell shortening capacity. Furthermore, we observed that although sarcomere shortening was maintained through higher stiffnesses, the contraction force applied by the cell reached its limit around the $90 \mathrm{kPa}$ substrate stiffness (Fig 6B), indicating that the maximum force that the sarcomeres of these cells can generate is around $160 \pm 14 \mu \mathrm{N} / \mathrm{mm}^{2}$. This is corroborated by the fact that at a higher substrate stiffness $(101 \mathrm{kPa})$ both the bead displacement (cell shortening) is significantly smaller, and the contraction force reaches a plateau (Fig $6 \mathrm{C}$ ). Finally, we observed that time to contract and relax of hPSC-CMs based on bead displacement is more than 2-fold higher than the time required for combined sarcomeric contraction and relaxation. This observed difference was maintained with the increase in substrate stiffness (Fig $6 \mathrm{D})$. This discrepancy suggests that transfer of sarcomeric to cellular movement may be delayed by a stretch or relative movement of the adhesion complexes at the adhesion points of the cell to the gel.

\section{Discussion}

In this study we generated an $\alpha$-Actinin/NKX2.5 double reporter line (DRRAGN), which allowed live imaging of sarcomeric organization and dynamics specifically in cardiomyocytes of the working myocardium, differentiated from hPSCs, and enabled evaluation of both sarcomere shortening and contraction force in the same hPSC-CMs at increasing levels of substrate stiffness. We found that force generation increased up to $90 \mathrm{kPa}$ but cardiomyocyte shortening gradually decreased. Moreover, sarcomere shortening decreased up to physiological substrate stiffness $(21 \mathrm{kPa})$, but remained constant thereafter. By assessing both of these parameters in each cell we could show that sarcomere shortening did not correlate with cell shortening, and consequently with contraction force output, at stiffness higher than $90 \mathrm{kPa}$.

Increased myocardial wall stiffness through cardiac remodeling is a response to impaired heart function and may ultimately lead to end-stage heart failure. The use of a hPSC sarcomeric reporter line allows for the assessment of contraction force and sarcomere function within the same single hPSC-CM, in response to increased substrate stiffness. Stable endogenous expression of fluorescently tagged $\alpha$-Actinin has the advantage over previously reported lentiviral transduced constructs of uniform expression of $\alpha$-Actinin-mRubyll across all single cardiomyocytes in culture. $(16,17)$ Moreover, due to the double nature of our reporter for NKX2.5 and $\alpha$-Actinin, the DRRAGN line can also be used to study early stages of differentiation towards cardiac cells, as well as in the identification or separation of cardiac subpopulations. For example, sinoatrial pacemaker or nodal cells of the heart, which have been reported to lack expression of NKX2.5, leaving them single positive for $\alpha$-Actinin-mRubyll expression.(18) 


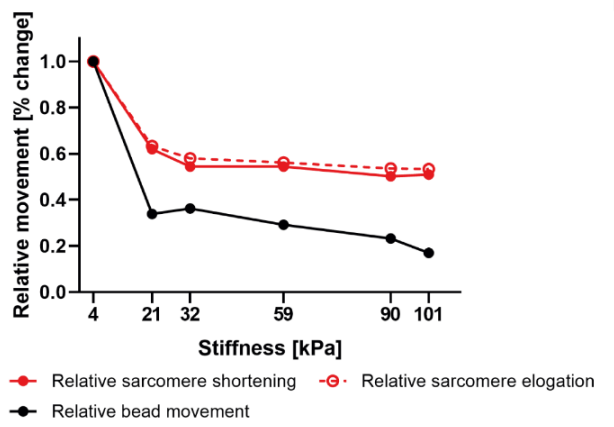

D

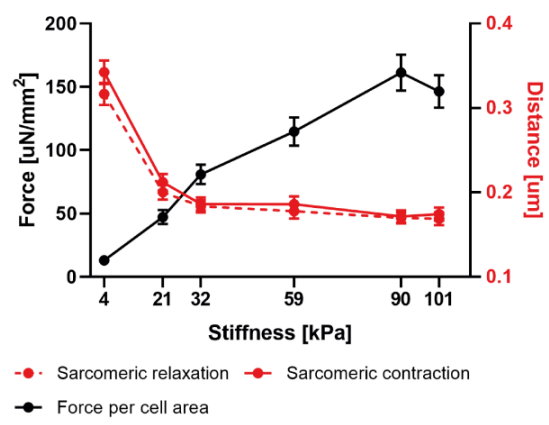

$\mathrm{D}$

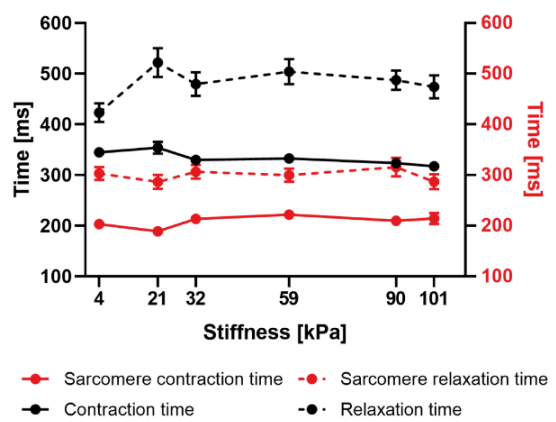

Figure 6: Correlations between sarcomere dynamics data and substrate displacement quantification. A) In contrast to sarcomere shortening (in red), bead displacement continues to drop with increasing stiffness. B) Increase of force generated by the cardiomyocytes at higher stiffness is not explained by changes in sarcomere shortening (in red). C) As maximum force of the cardiomyocyte is reached at $90 \mathrm{kPa}$, cell shortening is significantly reduced upon further increase in stiffness of substrate. D) Both sarcomere (in red) and bead contraction and relaxation time are unaffected by substrate stiffness. Note that cell contraction in general takes longer than sarcomere contraction. Data presented in mean \pm s.e.m.

Analysis of contraction force of single aligned cardiomyocytes cultured on a substrate with different stiffnesses showed their capacity to adapt to the increase in stiffness by increasing contractile force output up to $90 \mathrm{kPa}$, which is in agreement with previous descriptions using human induced pluripotent stem cell- (hiPSC-), hESC- and rat-derived cardiomyocytes by Hazeltine et al.(19) Interestingly, we showed for the first time that single hPSC-CMs are able to maximally generate a force of $160 \pm 14 \mu \mathrm{N} / \mathrm{mm}^{2}$, as this value was maintained on substrates from $90 \mathrm{kPa}$ to $101 \mathrm{kPa}$ stiffness. However, hPSC-CMs generate less force than their maximum capacity when maximum force is not required (lower substrate load reduced the required and thus generated force by the cardiomyocytes). This means that hPSC-CMs reach their maximum contraction force capacity at substrate stiffness of $90 \mathrm{kPa}$. These results are in accordance with diseases such as congestive cardiomyopathy where cardiac wall stiffness is 


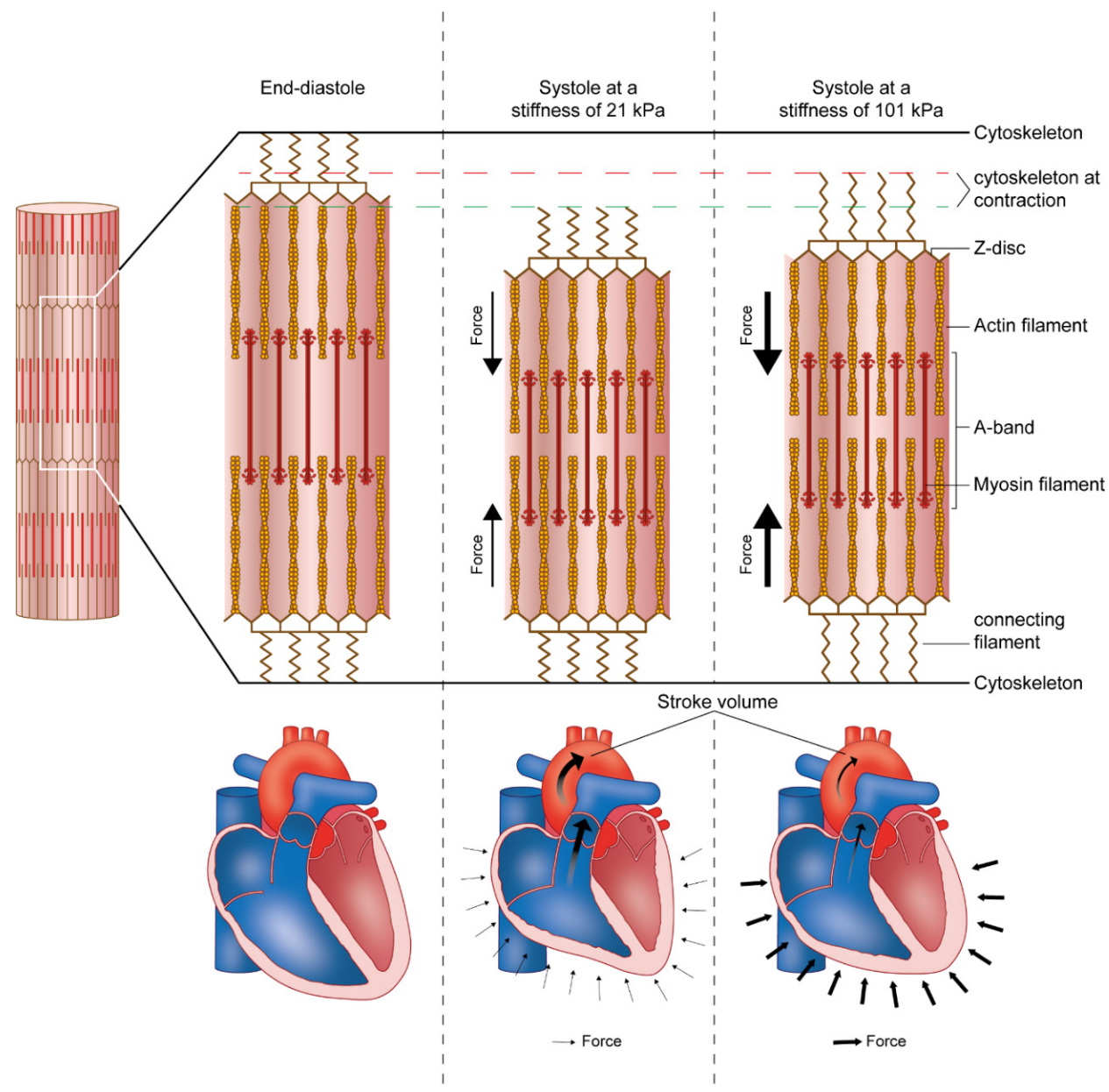

Figure 7: Schematic representation of a possible change in contractile behavior with increase in substrate stiffness. Left, the representation of a myofibril with sarcomeres connected in series. Center-top: When the cell contracts from end-diastole to end-systole the sarcomere length, shortens pulling the cytoskeleton and the adhesion proteins with it. At substrate stiffness of $21 \mathrm{kPa}$ the cytoskeleton and adhesion proteins are relatively free to move with the sarcomere shortening generated with a relatively low force, which in vivo can be translated into a large compression of the ventricle wall and consequent normal stroke volume (center-bottom). When the substrate stiffness increases to $101 \mathrm{kPa}$ or higher the cytoskeleton and adhesion proteins are restrained by the substrate from moving freely with the sarcomere shortening although the force generated has significantly increased. In the working myocardium in vivo cardiomyocytes have to generate an increasing amount of force, in order to increase intraventricular pressure and transition from isometric systole phase to ejection phase. At very high wall stiffnesses, this may translate to lower ventricle compression, despite the larger force applied by the cells, and consequently may lead to a reduction in stroke volume. 
well above $100 \mathrm{kPa}(2)$, leading to heart failure and ultimately cardiac death as the heart becomes unable to cope with the increasing load (contraction resistance) generated by the high stiffness of its walls.

The force applied on the $4 \mathrm{kPa}$ stiff gels was significantly lower than other substrate stiffnesses, while bead movement was significantly larger, meaning that the cell applies a relatively low force for maximal shortening. The most pronounced adaptation of hPSC-CMs occurred between $4 \mathrm{kPa}$ and physiologicallike $21-30 \mathrm{kPa}$, as both bead displacement (cell shortening) and sarcomere shortening, as well as corresponding speeds, significantly decreased over this range. This effect is a response to the increase in load applied by the substrate to the cell. As described by Engler et al. 2008, at lower stiffness the cardiomyocytes do not produce maximal force output due to the low opposing load of the substrate, while at physiological stiffness, the opposing load of the substrate is optimal for the cardiomyocyte to generate maximum contractile work.(20) Our results show that the increase in substrate stiffness from $4 \mathrm{kPa}$ to $21-32 \mathrm{kPa}$ induces a sarcomeric adjustment to both decreased contraction and elongation (increased sarcomere length at full contraction and decrease sarcomere length at full relaxation), which is translated to a decreased sarcomere shortening during contraction and consequently a decreased cell shortening distance. Interestingly, at higher stiffnesses this sarcomere length adjustment does not occur but the cell shortening distance continues to decrease, which suggests that at higher stiffnesses the cell is spending more energy to generate more force as the opposing load of the substrate restrains the cell from shortening maximally, in similarity to the increase in energetic cost of contraction in patients with hypertrophied hearts.(21) In vivo, this increase in stiffness beyond the healthy physiological range has the consequence of higher energy spending during isometric systole phase in order to increase intraventricular pressure and transition to the ejection phase, which at very high wall stiffnesses probably translates to lower ventricle compression capability and lower stroke volume (Fig 7). Such cardiac energy inefficiency has been described in patients with systolic dysfunction and associated with development and progression of diastolic heart failure. $(22,23)$

Furthermore, different studies have shown that cardiomyocytes are able to "sense" their surroundings and to respond to biomechanical cues. $(5,24)$ Our results show that at substrate stiffness higher than $90 \mathrm{kPa}$, cardiomyocytes shorten significantly less while sarcomere shortening is maintained. These observations suggest that the force generated by the sarcomere contraction is applied to, and partially absorbed by, stretching of internal cytoskeletal filaments that connect the sarcomeres to the focal adhesions and desmosomes (Fig 7). In vivo restraint of cardiomyocyte shortening by such increased wall stiffness has the 
effect of decreasing stroke volume, leading to a decreased cardiac output. One of the possible response of cardiomyocytes to counter this restrain is to build more contractile sarcomere myofilaments in order to overcome the opposing load imposed by the high wall stiffness, which by definition further increases the wall stiffness.(25) Such a self-propagating cycle has been shown to be the major biomechanical stress in the development and progression of cardiac diseases such as dilated and hypertrophic cardiomyopathies and heart failure. $(5,26,27)$ Our in vitro model for adaptation of sarcomere dynamics with variable substrate stiffness provides a first basis to model this aspect of heart failure. We establish a variable substrate stiffness with a clear readout on the sarcomere dynamics that can be further coupled with coculture of CMs with fibroblasts, sarcomere mutations and analysis on metabolic derangements and on calcium handling in order to investigate heart failure in a more comprehensive manner.

\section{Conclusion}

We generated a stable transgenic hPSC reporter line that expresses fluorescent $\alpha$-Actinin-mRubyll upon differentiation to cardiomyocytes, which enabled us to mimic and model "cardiac wall stiffening" in vitro. With this model we showed that increasing substrate stiffness affected cardiomyocyte contractile behavior of both sarcomere shortening and force generation. We conclude that the maximal sarcomere length adaptation to increased stiffness is reached in the physiological range of 21-32 $\mathrm{kPa}$, while the contraction force generated keeps rising until reaching its maximum at $90 \mathrm{kPa}$. Finally, the discrepancy between sarcomere shortening and the magnitude of cell shortening at stiffnesses higher than $90 \mathrm{kPa}$ suggests a "tipping" point at which stress-induced mechanisms are activated in cardiomyocytes. Here, we show an in vitro model which enables studying the underlying mechanisms of cardiac remodeling and heart failure at the cardiomyocyte level. 


\section{References}

1. Cohn JN, Ferrari R, Sharpe N. Cardiac remodeling-concepts and clinical implications: a consensus paper from an international forum on cardiac remodeling. Journal of the American College of Cardiology. 2000;35(3):569-82.

2. Chaturvedi RR, Herron T, Simmons R, Shore D, Kumar P, Sethia B, et al. Passive stiffness of myocardium from congenital heart disease and implications for diastole. Circulation. 2010;121(8):979-88.

3. Bortone AS, Hess OM, Chiddo A, Gaglione A, Locuratolo N, Caruso G, et al. Functional and structural abnormalities in patients with dilated cardiomyopathy. Journal of the American College of Cardiology. 1989;14(3):613-23.

4. Zile MR, Baicu CF, Ikonomidis JS, Stroud RE, Nietert PJ, Bradshaw AD, et al. Myocardial stiffness in patients with heart failure and a preserved ejection fraction: contributions of collagen and titin. Circulation. 2015;131(14):1247-59.

5. Pandey P, Hawkes W, Hu J, Megone WV, Gautrot J, Anilkumar N, et al. Cardiomyocytes Sense Matrix Rigidity through a Combination of Muscle and Non-muscle Myosin Contractions. Dev Cell. 2018;44(3):326-36 e3.

6. Piek A, de Boer RA, Sillje HH. The fibrosis-cell death axis in heart failure. Heart Fail Rev. 2016;21(2):199-211.

7. Elliott DA, Braam SR, Koutsis K, Ng ES, Jenny R, Lagerqvist EL, et al. NKX2$5(\mathrm{eGFP} / \mathrm{w}) \mathrm{hESCs}$ for isolation of human cardiac progenitors and cardiomyocytes. Nat Methods. 2011;8(12):1037-40.

8. Ran FA, Hsu PD, Wright J, Agarwala V, Scott DA, Zhang F. Genome engineering using the CRISPR-Cas9 system. Nat Protoc. 2013;8(11):2281-308.

9. Birket MJ, Ribeiro MC, Kosmidis G, Ward D, Leitoguinho AR, van de Pol V, et al. Contractile Defect Caused by Mutation in MYBPC3 Revealed under Conditions Optimized for Human PSC-Cardiomyocyte Function. Cell Rep. 2015;13(4):733-45.

10. Ng ES, Davis R, Stanley EG, Elefanty AG. A protocol describing the use of a recombinant protein-based, animal product-free medium (APEL) for human embryonic stem cell differentiation as spin embryoid bodies. Nat Protoc. 2008;3(5):768-76.

11. McCain ML, Yuan H, Pasqualini FS, Campbell PH, Parker KK. Matrix elasticity regulates the optimal cardiac myocyte shape for contractility. Am J Physiol Heart Circ Physiol. 2014;306(11):H1525-39. 
12. Takigawa T, Morino $\mathrm{Y}$, Urayama K, Masuda T. Poisson's ratio of polyacrylamide (PAAm) gels. Polymer Gels and Networks. 1996;4(1):1-5.

13. Mirsky I, Parmley WW. Assessment of passive elastic stiffness for isolated heart muscle and the intact heart. Circ Res. 1973;33(2):233-43.

14. Borbely A, van der Velden J, Papp Z, Bronzwaer JG, Edes I, Stienen GJ, et al. Cardiomyocyte stiffness in diastolic heart failure. Circulation. 2005;111(6):77481.

15. Kanai H. Propagation of spontaneously actuated pulsive vibration in human heart wall and in vivo viscoelasticity estimation. IEEE Trans Ultrason Ferroelectr Freq Control. 2005;52(11):1931-42.

16. Toepfer CN, Sharma A, Cicconet M, Garfinkel AC, Mucke M, Neyazi M, et al. SarcTrack. Circ Res. 2019;124(8):1172-83.

17. Mathur A, Loskill P, Shao K, Huebsch N, Hong S, Marcus SG, et al. Human iPSC-based cardiac microphysiological system for drug screening applications. Sci Rep. 2015;5:8883.

18. Sizarov A, Devalla HD, Anderson RH, Passier R, Christoffels VM, Moorman AF. Molecular analysis of patterning of conduction tissues in the developing human heart. Circ Arrhythm Electrophysiol. 2011;4(4):532-42.

19. Hazeltine LB, Simmons CS, Salick MR, Lian X, Badur MG, Han W, et al. Effects of substrate mechanics on contractility of cardiomyocytes generated from human pluripotent stem cells. Int J Cell Biol. 2012;2012:508294.

20. Engler AJ, Carag-Krieger C, Johnson CP, Raab M, Tang HY, Speicher DW, et al. Embryonic cardiomyocytes beat best on a matrix with heart-like elasticity: scar-like rigidity inhibits beating. J Cell Sci. 2008;121(Pt 22):3794-802.

21. Witjas-Paalberends ER, Guclu A, Germans T, Knaapen P, Harms HJ, Vermeer AM, et al. Gene-specific increase in the energetic cost of contraction in hypertrophic cardiomyopathy caused by thick filament mutations. Cardiovasc Res. 2014;103(2):248-57.

22. Hasegawa S, Yamamoto K, Sakata Y, Takeda Y, Kajimoto K, Kanai Y, et al. Effects of cardiac energy efficiency in diastolic heart failure: assessment with positron emission tomography with 11C-acetate. Hypertens Res. 2008;31(6):115762.

23. Bengel FM, Permanetter B, Ungerer M, Nekolla S, Schwaiger M. Noninvasive estimation of myocardial efficiency using positron emission tomography and carbon-11 acetate--comparison between the normal and failing human 
heart. Eur J Nucl Med. 2000;27(3):319-26.

24. Lyon RC, Zanella F, Omens JH, Sheikh F. Mechanotransduction in cardiac hypertrophy and failure. Circ Res. 2015;116(8):1462-76.

25. Grossman W, Paulus WJ. Myocardial stress and hypertrophy: a complex interface between biophysics and cardiac remodeling. J Clin Invest. 2013;123(9):3701-3.

26. Sheikh F, Raskin A, Chu PH, Lange S, Domenighetti AA, Zheng M, et al. An FHL1-containing complex within the cardiomyocyte sarcomere mediates hypertrophic biomechanical stress responses in mice. J Clin Invest. 2008;118(12):3870-80.

27. Oudit GY, Kassiri Z, Zhou J, Liu QC, Liu PP, Backx PH, et al. Loss of PTEN attenuates the development of pathological hypertrophy and heart failure in response to biomechanical stress. Cardiovasc Res. 2008;78(3):505-14. 
69 
Chapter 4:

\section{Generation of cardiac pacemakers using the DRRAGN cell line.}




\title{
Chapter 4: Generation of cardiac pacemakers using the DRRAGN cell line.
}

Rolf H. Slaats ${ }^{1}$, Verena Schwach ${ }^{1}$, Carla Cofiño Fabres ${ }^{1}$, Simone ten Den ${ }^{1}$, and Robert Passier ${ }^{1,2}$.

${ }^{1}$ Applied Stem Cell Technologies, TechMed Centre, University of Twente, Drienerlolaan 5, 7500

AE, Enschede, The Netherlands

${ }^{2}$ Department of Anatomy and Embryology, Leiden University Medical Center, PO Box 9600, 2300

RC Leiden, The Netherlands

\begin{abstract}
Pacemaker cells are a distinct subpopulation of cardiac cells that are responsible for generating a pace-setting action potential that controls cardiomyocyte contraction rate. Disturbances in action potential generation, shape or conduction may lead to life-threatening cardiac arrhythmias and death. Hence, understanding the underlying causes and pathophysiology of arrhythmias is of utmost importance. Existing models for arrhythmia depend heavily on animal models or in vitro models based on animal cells, which provide limited information on arrhythmias in humans and are not adequately predictive for disease modeling or safety screening. Human pluripotent stem cells (hPSCs) have the capacity to differentiate to specialized cardiac subtypes, which offers the opportunity to create human in vitro models of cardiac arrhythmia. In addition, hPSC-pacemaker cells may be used in the clinic for the treatment of pathologies of the sino-atrial node (SAN). Several protocols for the derivation of pacemaker cells have been reported in literature. Recently, we created an NKX2-5/ACTN2 double fluorescent reporter hPSC cell line (DRRAGN line), which may serve as a useful tool to identify and select pacemaker cells, since these cells are negative for the cardiomyocyte transcription factor NKX2-5, but positive for sarcomeric protein $\alpha$-Actinin. Current cardiomyocyte differentiation protocols yield only a small percentage $(<10 \%)$, of pacemaker cells as a side product, which indicates the need for establishing an efficient pacemaker differentiation protocol. Here, we applied three previously reported pacemaker differentiation protocols using the DRRAGN hPSC line in order to optimize the derivation of human pacemaker cells in vitro. Highest differentiation efficiency yielded 35,5\% pacemaker-like cells or possibly progenitor cells thereof. This indicates that further optimization and maturation towards pacemaker cells are required to obtain true SAN pacemakers.
\end{abstract}




\section{Introduction}

Pacemaker cells (PMs) of the heart determine the contraction frequency of atrial and ventricular myocardium by initiating rhythmic electrical impulses (action potentials) which are necessary for contraction of myocytes. The heart features two locations where pacemaker cells reside: the sino-atrial node (SAN) and the atrioventricular node (AVN), of which the SAN is pace-setting and upstream of the $A V N$ in the conduction system. During embryonic development, SAN pacemaker cells arise from a ISL1+ and TBX18+ subpopulation of the sinus horn, a part of the second heart field progenitor cells responsible for the development of the atria and the outflow tract of the heart, through the coordinated expression of SHOX2 and TBX3. $(1,2)$ They differ from pacemaker cells of the AVN in their origin and gene expression profile. AVN pacemaker cells develop from the AV ring, an embryonic heart feature that separates the early atria and ventricles and has low electrical conduction properties.(3) As progeny of the AV ring, composed of immature cardiomyocyte precursors, AVN pacemaker cells continue to express transcription marker NKX2-5, similar to fetal and adult cardiomyocytes (CMs), in contrast to SAN pacemaker cells, which lose NKX2-5 expression during development. Other distinguishing gene expression profiles include the expression of TBX2 and MSX2, which can be identified in the AVN, but not in the SAN.(3)

From the SAN, located at the top of the right atrium, the action potential (AP) travels across the atria, triggering the latter to contract synchronously, and ends in the AVN, located at the junction of the right atrium and ventricle. From there, the AP is transferred to the bundle of His and the Purkinje fibers, which subsequently conducts it to the apex of the heart, triggering a contraction of the ventricles from the bottom to the top to eject blood out of the ventricles into the pulmonary artery and the aorta. Any abnormalities in the initiation, characteristics and propagation of these electrical impulses may result in atrial or ventricular arrhythmia (such as ventricular fibrillation or atrial fibrillation), potentially causing life-threatening situations.(4)

Current treatment strategies, including anti-arrhythmic drugs, catheter ablation or the use of implantable cardioverter-defibrillators (ICD), are effective in controlling cardiac rhythm, but cannot exclude recurrence of cardiac arrhythmias and adverse effects of applied drugs and insufficiently take patient-to-patient variations into consideration. Due to the complex nature of the SAN and intercellular interactions of various cardiac cell subtype in health and disease, modelling of cardiac arrhythmia remains largely dependent on animal models. (5) Even though animal models have their specific usefulness in elucidating elements of arrhythmic disorders, successful translation to the clinic has been very limited, because of species differences in the anatomy and function of the heart and the difficulty to emulate patient-specific genetic and environmental 
factors. Therefore, there is an urgent need to develop predictable models for human pacemaker function.

Human pacemaker cells developed or cultured in vitro would provide a cell source that is relevant to human disease modelling and may be used to repair malfunctioning aspects of the human conduction system in the heart. Since adult human pacemaker cells from donors or patients are practically impossible to obtain in sufficient numbers, in vitro development of human pacemaker cells is sparked by the possibility to use human (patient-derived) pluripotent stem cells (hPSCs). Human PSCs (both embryonic and induced pluripotent stem cells; ESCS and iPSCs, respectively) have the capacity to differentiate to any cell-type, including specialized cardiac cells(6), while retaining the same genetic makeup as the patient they originate from. For disease modeling and clinical applications this is an important feature, since it enables research on hereditary conduction disorders specific to the situation of the patient, leading to personalized medicine.

As mentioned above, SAN pacemaker cells may be distinguished by their loss of NKX2-5 expression during development, in combination with the expression of pacemaker-specific genes TBX3, TBX18, ISL1 and SHOX2.(1, 2) Both cardiomyocytes from the myocardium as well as from the SAN express sarcomeric proteins (such as $\alpha$-Actinin) for contractile function, albeit that sarcomeres from myocardial cardiomyocytes are better organized, since they have to sustain a higher workload. Since we recently generated a double fluorescent reporter hPSC line for NKX2-5_GFP and $\alpha$-Actinin_mRubyll (DRRAGN hESC line, see chapter 3), we are able to distinguish myocardial cardiomyocytes (double positive cells) from SAN pacemaker cells (single positive for $\alpha$-Actinin-mRubyll) during and after differentiation by live cell imaging.(7)

We and others have previously shown that pacemaker-like cells can be derived during differentiation to the cardiac lineage $(7,8)$, however the typical yield of pacemaker cells in these differentiation protocols is very low. Therefore, we sought to develop a specific pacemaker protocol that could increase the efficiency of pacemaker cell differentiation from the DRRAGN hESC line and characterize these cells accordingly. Several groups have reported protocols that result in pacemaker-like contractile cells, yet their rationale differs substantially. $(1,8,9)$ Here we describe the systematic reproduction and variations of these protocols, in order to efficiently produce, purify and characterize pacemaker cells for subsequent use of modeling cardiac development and disease in vitro. 


\section{Results}

Cardiomyocyte differentiation of DRRAGN hESCs yields a small NKX2-5 negative subpopulation.

Efficient differentiation of the DRRAGN (Double Reporter mRubyll-Actinin/GFPNKX2-5) cell line to cardiomyocytes was demonstrated in chapter 3. DRRAGN hESCs feature a dual color reporter system for the expression of NKX2-5 in GFP, and $\alpha$-Actinin in mRubyll (Fig 1A). GFP replaced exon 1 of a single allele of the NKX2-5 gene and expression is thus regulated by the NKX2-5 promotor, so that GFP expression signals NKX2-5 transcription (Fig 1A). MRubyll was engineered into the ACTN2 gene at the last exon before the stop codon to create a fusion protein of $\alpha$-Actinin and mRubyll. Thus, mRubyll, but not GFP, can be used to study localization of the respective protein (see chapter 3 and Fig 1A). DRRAGN hESCs were differentiated to working cardiomyocytes according to the protocol described in chapter 3 (Protocol 1, see Fig 1B). Using this protocol, CMs could be generated at high efficiency of around 70 percent using the dN3 parental line (NKX2-5_GFP reporter only), and at $60 \%$ using the DRRAGN reporter line (Fig 1C$\mathrm{E})$. Since the parental line does not have a mRubyll reporter, no distinction can be made between NKX2-5 negative putative pacemaker myocytes (PPMs) and other non-CM cells, such as fibroblasts, smooth muscle cells and endothelial cells (Fig 1C). $\mathrm{CMs}$ are in this line represented by the GFP+ population in the top left panel of a flow cytometry (FC) dot plot (Fig 1C). However, with the DRRAGN-hESCs, the $\mathrm{CM}$ population is represented in the upper right panel for double positive cells, since CMs express both NKX2-5 and $\alpha$-Actinin. Moreover, in addition to differentiation to double positive (GFP+/mRuby+; $\mathrm{G}+/ \mathrm{R}+$ ) $\mathrm{CMs}$, we also observed a small fraction of $\alpha$-Actinin positive cells that were negative for NKX2.5 (R+/G-), which could represent PPMs based on a similar expression profile of pacemaker cells during cardiac development (indicated in the bottom right panel of the dot plot; Fig 1D). The protocol for robust CM differentiation does not result in a clear PPM population, indicated by the low yield of $R+/ G$ - cells $(<10 \%$, Fig $1 E)$.

Following fluorescence-assisted cell sorting (FACS) based on GFP and mRubyll expression, purified CMs or PPMs could be seeded into culture wells plates, whereafter the expression of $\alpha$-Actinin and NKX2-5 could be confirmed and evaluated in single cells by fluorescence microscopy (Fig 1F, upper panel). As expected, double positive CMs expressed GFP throughout the cytoplasm and demonstrated characteristic organized sarcomeric structures with $\alpha$-Actinin line patterns perpendicular to the cell's long axis. On the other hand, PPMs only display the $\alpha$-Actinin pattern, but no GFP signal can be observed in the cytoplasm (Fig 1F, lower panel). Both cell types are contractile, however confirming PM identity remains challenging given the low absolute cell number that is obtained 
Parental line

A

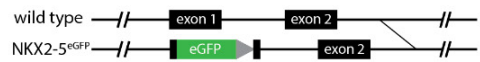

B

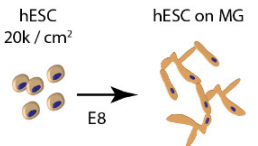

D-1

D

C

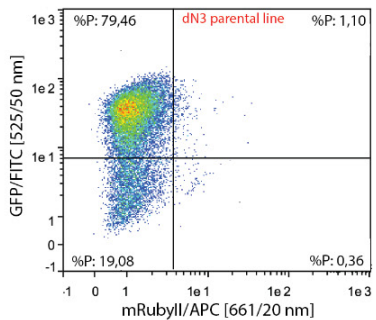

$\mathrm{F}$

Putative

pacemaker myocyte

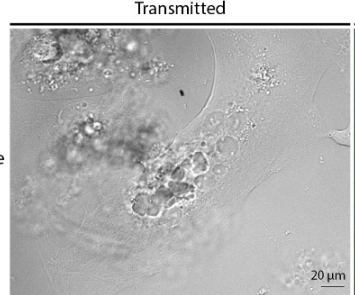

$20 \mu \mathrm{m}$

D

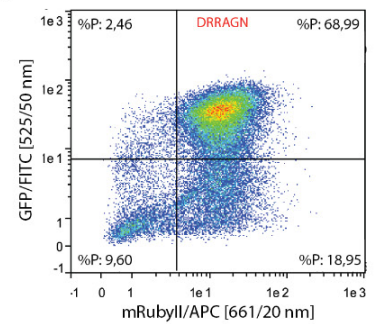

GFP (NKX2-5)

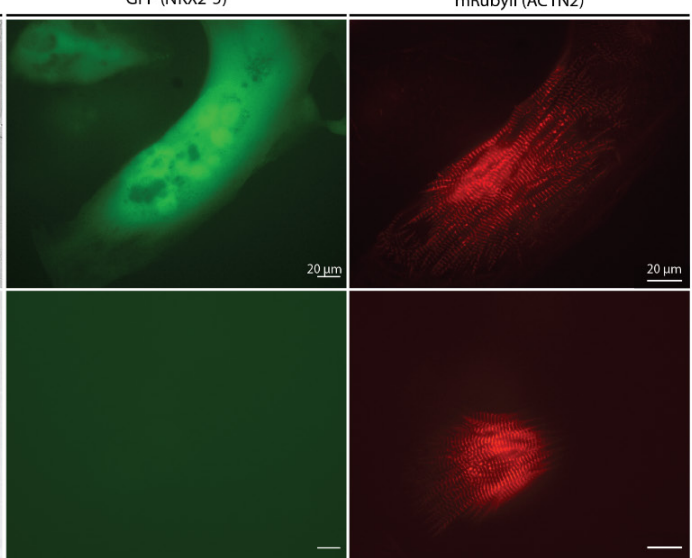

a-Actinin reporter

ACTN2 locus

cardiac progenitors

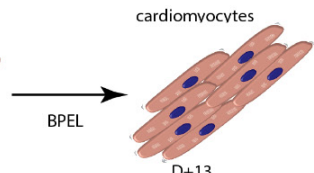

$\mathrm{D}+13$

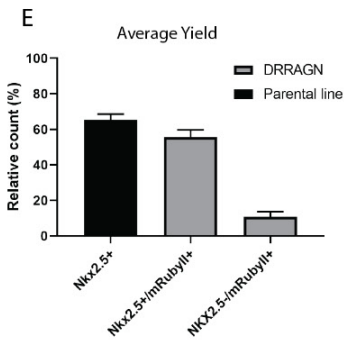

mRubyll (ACTN2)

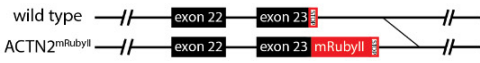

Figure 1: DRRAGN hESCS can be differentiated to CMs and contractile non-CMs that may be distinguished through NKX2-5 and $\alpha$-Actinin reporter signals. A) Genetic organization of the DRRAGN reporter line, showing the NKX2-5_GFP reporter construct and the $\alpha$-Actinin fusion protein construct. B) Schematic representation of the differentiation protocol of hESCs to CMs through monolayer induction of mesoderm and cardiac specification. $C+D$ ) Flow cytometry charts of the mixed population resulting from the CM differentiation protocol depicted in B; the parental NKX2-5 single reporter line (dN3) can distinguish only between NKX2-5 positive and negative cells, whereas the DRRAGN reporter line can identify sarcomere-positive cells in the absence of NKX2-5 expression (upper left corner). E) Quantification of double positive and single mRubyll positive cell populations (for the DRRAGN line only) resulting from a CM-directed differentiation of the NKX2-5 parental line and the DRRAGN reporter line. F) From left to right: Transmitted micrographs and corresponding GFP and mRubyll signals of a cardiomyocyte and putative pacemaker myocyte; both cell types express patterned fluorescent $\alpha$-Actinin (ACTN2), indicating the presence of organized sarcomeres. Only the cardiomyocyte co-expresses cytoplasmic GFP. Scale bars $=20$ um. Abbreviations: $A=a c t i v i n-a, B=$ BMP4, C= CHIR99021, MG= Matrigel 
from the standard CM differentiation protocol. Therefore, a more robust, PMdedicated differentiation protocol is required to adequately confirm the identity of these PPMs.

\section{Protocol optimization for effective pacemaker differentiation.}

In order to increase the yield of PPMs from hPSC differentiation, several previously reported protocols were reproduced or adjusted with minor modifications (Fig 2). Firstly, Ren et al emphasized the importance of reactivation of canonical Wnt signaling during differentiation to pacemakers.(9) Their differentiation protocol is very similar to a standard CM differentiation protocol, as depicted in Fig 1 (protocol 1, Fig 1B), with the addition of a Wnt activator CHIR on day 5 (Protocol $2 A$, Fig $2 A$ ). On $D+7$, medium was refreshed with $B P E L$, and cells were maintained in BPEL alone until FACS on day $D+17$. This differentiation yielded slightly more PPMs than the CM protocol (19,1\%, $n=1$ v. 10,8\%, n=8, respectively) (Fig 2E). The increase in GFP negative cells appeared to be at the cost of CM derivation, which was lower than typically found in a standard CM differentiation $(27,4 \%$ v. $55,8 \%$, respectively).

A second protocol for deriving nodal pacemaker cells is reported by Protze et al, and utilizes hypoxia signaling to drive pacemaker differentiation.(1) Comparable to that study, we generated embryoid bodies (EBs) in StemPro-based differentiation medium (containing various growth factors, see table 2 ) in $5 \% \mathrm{O}_{2}$ (Protocol 2B, Fig $2 \mathrm{~B}$ ). Since the basis of this medium (StemPro) differs from our standard medium (BPEL), we verified that StemPro medium supported cardiac differentiation of the hPSC lines used in this study (suppl Fig 1). At D+2, the developing EBs were dissociated into single cells and reaggregated into spheroids of $80 \mathrm{k}$ cells per well. From $D+5$ to the end of the differentiation $(D+17)$, the EBs were maintained in cardiomyocyte maintenance medium containing VEGF and were placed in atmospheric $\mathrm{O}_{2}$ pressure from $\mathrm{D}+11$ onwards. The incubation of differentiating cells in hypoxia did not result in an increase in the PPM population compared to the standard CM differentiation ( $4,8 \% \vee 10,8 \%$, Fig $2 \mathrm{E})$. In addition, we also tested the effect of hypoxia on our standard CM differentiation protocol to study the potential effect on differentiation to PM. Performing protocol 1 in $5 \%$ oxygen conditions resulted in $8,5 \%$ PPMs versus $3,1 \%$ PPMs in control conditions $(n=1)$. Hypoxia alone could therefore not induce the desired effect on pacemaker differentiation.

Finally, we used a modified protocol, described by Birket et al(8), that we previously used for derivation of pacemaker cells from expanding cardiac progenitor cells (CPC) in a MYC-inducible NKX2.5-GFP hPSC line.(8) To verify the efficacy of the protocol, we used a comparable MYC-inducible hPSC reporter line, which activates MYC in the presence of doxycycline and in which GFP was 


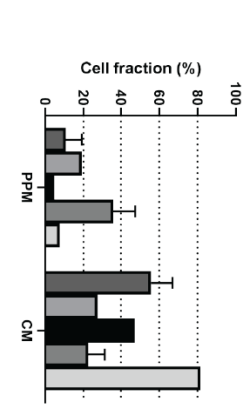

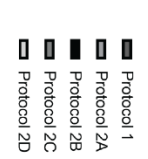

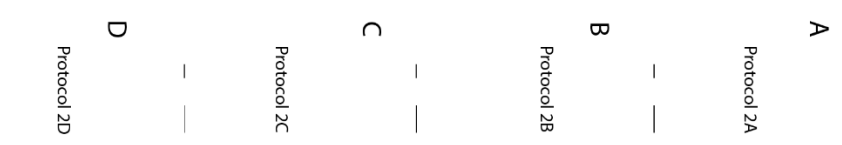

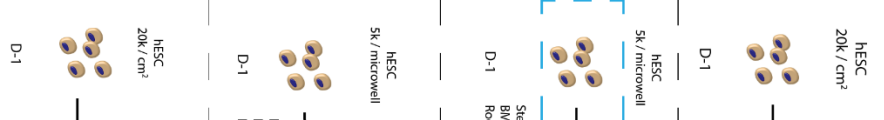

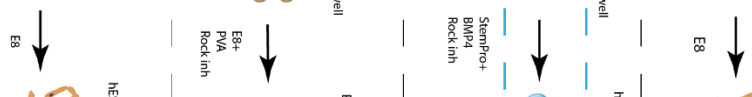

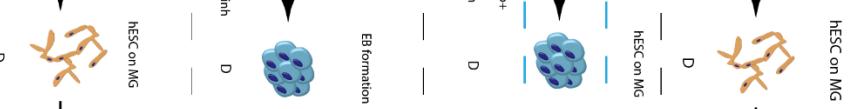

$\frac{1}{4}$

$\downarrow$

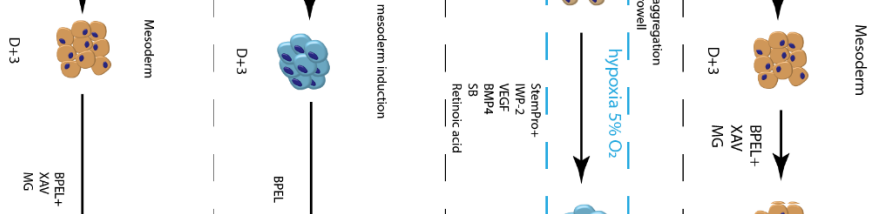

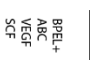

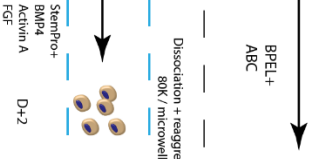

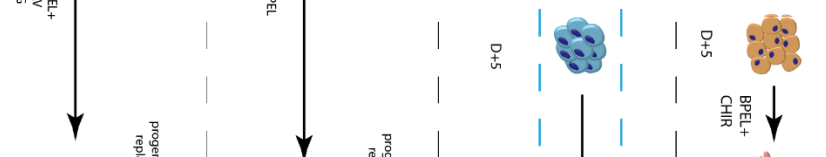

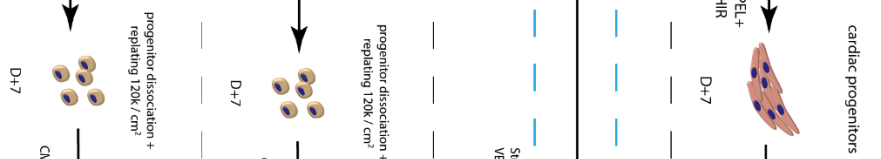

忿

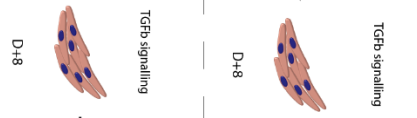

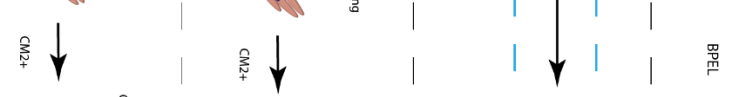

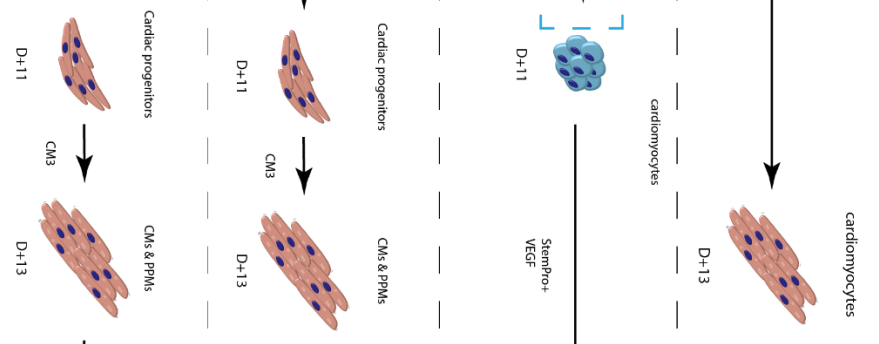

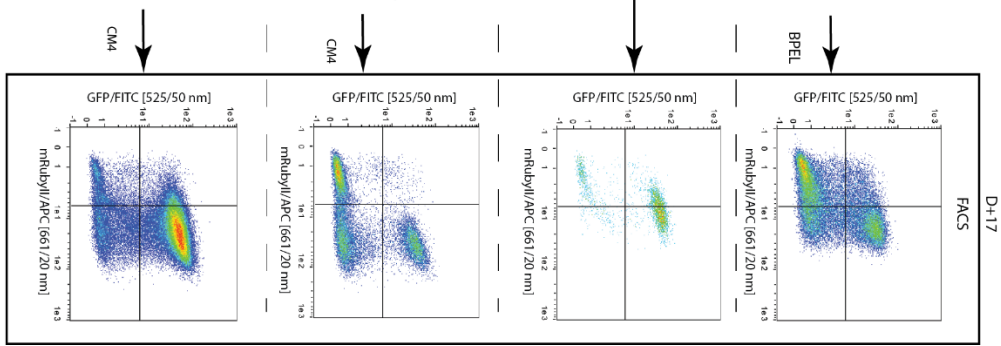


Figure 2 (previous page): Overview of pacemaker differentiation protocols from hPSCs adapted from literature. A) Monolayer-based differentiation towards mesoderm with an additional Wht induction step at D+5, adapted from Ren et al.(9) B) EB-based differentiation towards mesoderm, featuring hypoxic culture conditions for the initial 11 days of differentiation, and a dissociation and reaggregation step at $D+2$, protocol adapted from Protze et al.(1) $C+D$ ) Mesodermal differentiation in EB format (C) or monolayer (D), with dissociation of the EBs or monolayers at $D+7$ and subsequent reseeding as a monolayer. Protocol adapted from Birket et al.(8) E) Summary of the flow cytometry quantification of the PPM fraction in the resulting cardiac population following the above-described protocols.

incorporated in the NKX2.5 locus. In addition, mCherry was incorporated in the YAP1 (Yes-associated protein 1) genomic locus, for producing YAP1-mCherry fusion proteins, although this fluorophore was not used for analysis during PPM differentiation. This cell line was differentiated to PPMs according to the described protocol(8) and yielded a total of 70\% pacemaker-like cells according to flow cytometric analysis on the expression of cardiac Troponin -T.

In order to adjust this protocol in other cell lines than the MYC-inducible line, we used the DRRAGN reporter line and excluded the CPC expansion step present in the original protocol. For the derivation of PPMs from the DRRAGN line, mesodermal differentiation was initiated in an EB format, followed by dissociation of EBs at $\mathrm{D}+7$ at the CPC phase and replated as a monolayer on Matrigel-coated plates. Subsequently, cells were directed to a PM phenotype using specific culture media, as provided in table 2 . This method resulted in a profound increase in PPM population in the differentiated population, increasing to an average $35,5 \%$. Next, we adjusted this differentiation protocol in monolayer cultures, which would be beneficial with respect to the upscaling of cells and reduced labor intensity. However, the monolayer differentiations resulted in lower PPM differentiation efficiencies when compared to EB differentiations. Since the timing of dissociation in the original protocol described by Birket et al depends on the expansion of progenitor cells in EBs, which cannot be exactly estimated in monolayer differentiations, we varied the timing of dissociation. Monolayers were dissociated between D+4 to D+7 and replated according to the EB-based protocol, resulting in 11,8\% for D+4, 7,85\% for D+5, 12,34\% for D6 and $7,8 \%$ for D+7, versus 5,4\% PPMs in the control standard CM protocol. None of these monolayer differentiation protocols could recapitulate the yield of PPMs from the EB-protocol (Protocol 2C).

In conclusion, protocols $2 \mathrm{~A}$ and 2B failed to robustly increase the efficiency of pacemaker differentiation. Protocol $2 \mathrm{C}$ yielded the highest number of pacemakers and was selected to further characterize the $\mathrm{mRuby} \mathrm{Il}^{+} / \mathrm{GFP}^{-}$population in order to verify their pacemaker identity. 

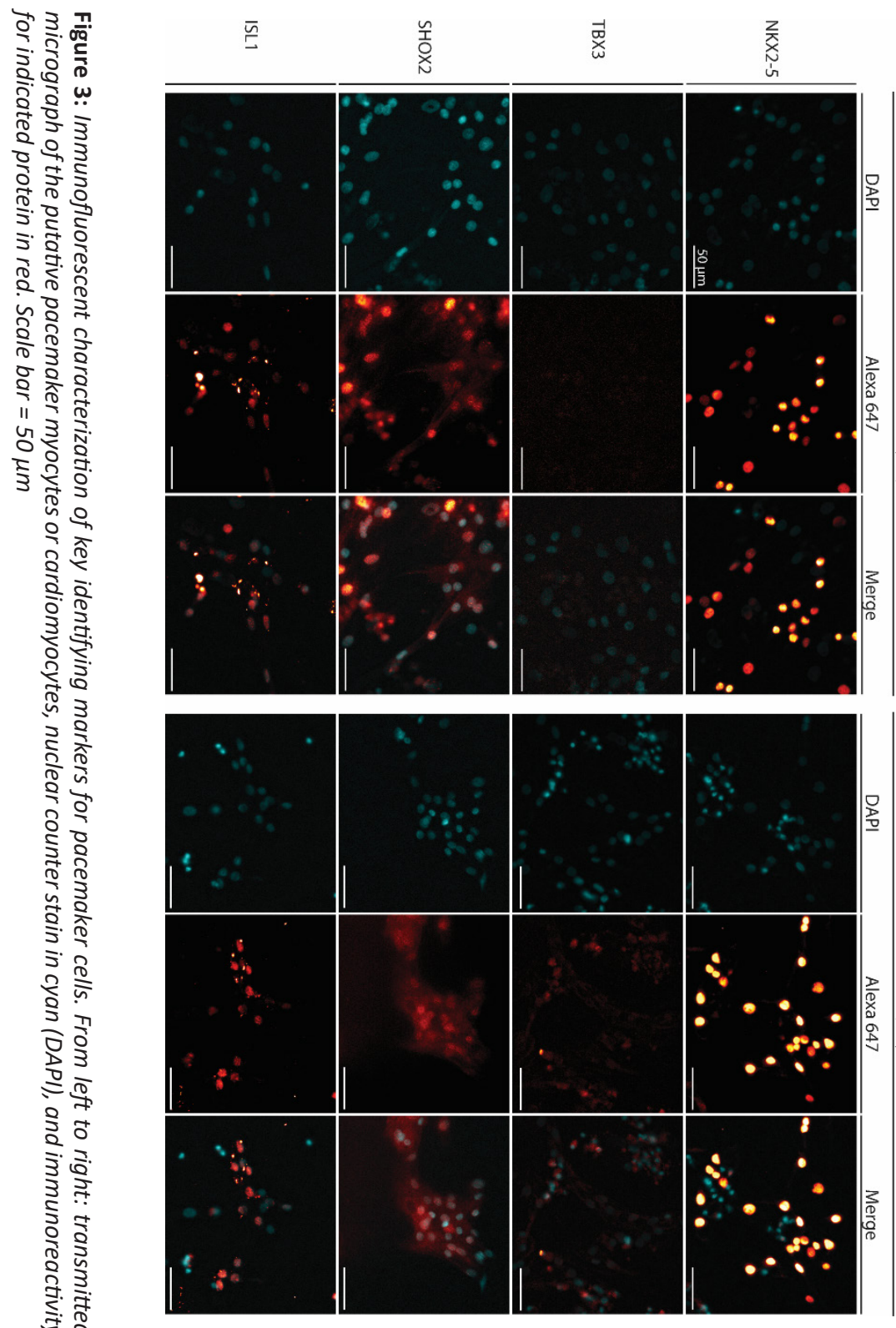


\section{Immunocytochemical characterization of putative pacemaker myocytes}

To verify the identity of the PPMs derived from protocol 2C as SAN pacemaker cells, we assessed the expression of pacemaker cell markers by immunocytochemistry. In SAN pacemaker cell development in vivo, the expression of NKX2-5 should diminish early in cardiogenesis, while expression of TBX3, ISL1 and SHOX2 have been described to mark the pacemaker population during embryonic development and adulthood. CMs and PPMs were isolated and purified based on their expression of GFP and mRubyll using flow cytometry as described before and plated in vitronectin-coated glass bottom microwell plates. Cells were allowed to recover for 10 days in CM-TDI (T3 hormone, Dexamethasone and hrIGF-1) medium (cardiomyocyte maturation medium, described in (10)) before fixation and subsequent immunostaining. Although the fluorescent intensity appeared lower in PPMs, surprisingly, both sorted PPMs and control CMs showed a positive immunoreactivity to NKX2-5 in the nucleus, while NKX2-5 expression in vivo is lost in PMs of the SAN. (see Fig 3). TBX3, which is enriched in pacemaker cells, was not detectable in PPMs but may show light immunoreactivity in CMs. SHOX2 expression was more pronounced in the PPM population compared to the CM control group, although not all cells of the PPM group expressed SHOX2. Finally, ISL1 was visible in both CM and PPM populations (Fig 3).

\section{Single cell RNAseq analysis of PPMs}

Further analysis of the transcriptome of the PPM and CM populations were done using single cell RNA sequencing (scRNAseq). GFP-/mRubyll+ and GFP+/ mRubyll+ populations were deposited as single cells in a 384 wells plate using FACS at D+14 of differentiation according to protocol 2C. The samples were then prepared using CEL-Seq2 protocol, reads were mapped against the human genome GRCh38 and a resulting cell-by-gene matrix was generated with the Kallisto | Bustools workflow (v0.24.4). First, each cell was clustered according to the GFP expression determined by the FACS sort, representing the PPM and $\mathrm{CM}$ populations as are obtained by FACS purification. Indeed, these populations form two distinct clusters of expression profiles as represented in the UMAP plot (Fig 4A). Then, both populations were subjected to automated Seurat clustering based on each cell's transcriptome signature, resulting in five separate clusters of cell types. Of these, Seurat clusters 1, 3 and 4 are corresponding to the GFPpopulation and clusters 0 and 2 correspond to the GFP+ population (Fig 4B). All clusters expressed genes related to the contractile phenotype of cardiac cells, namely GATA4, MYL7, RYR2 and ACTN2, however cluster 3 uniquely demonstrated a low expression of NKX2-5 combined with relatively high expressions of ISL1 and TBX18, making it the best candidate to represent the PPM population (Fig 4C). Even though cluster 1 demonstrated a higher level of ISL1 expression, with its 
relatively high count of NKX2-5 transcripts and relatively low TBX18 count, this cluster most likely represents a cardiac cell subtype other than PPMs. Cluster 0 , with high levels of NKX2-5 and IRX4, and low expression of ISL1 and TBX18 may represent the ventricular working cardiomyocyte population. Cluster 4 demonstrates high mRNA counts on MKI67, marking a proliferative population of cells, yet expressing cardiac genes related to contractility and development in combination with an elevated PDGFRA expression, and may thus represent a progenitor population. Cluster 2 expresses NKX2-5 and ISL1 at low levels, but no TBX18 nor MKI67 or IRX4. TBX3 expression was found low in all clusters and could therefore not be used to identify the PPM population, which is in agreement with the results of the immunostainings in figure 3.

\section{PPMs gain pacemaker marker expression upon long term culture}

Since our PPM population expressed TBX18 and ISL1 but not TBX3, the gene expression profile of the population does not completely match the expected

A

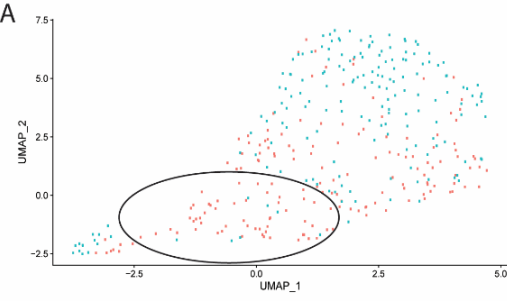

C

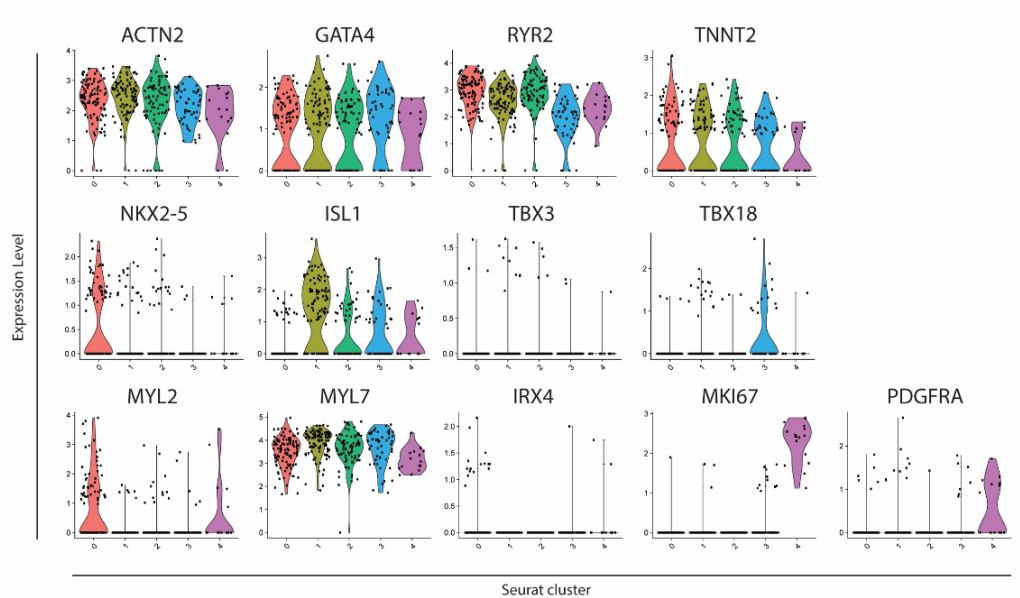

B

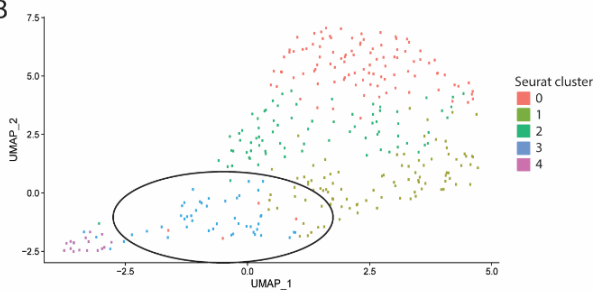

Figure 4: Single cell RNA sequencing analysis of the GFP- $/ m R u b y I^{+}$and $G F P^{+} / m R u b y / l^{+}$populations obtained from DRRAGN differentiation using protocol 2C. A) UMAP representation of relative similarity of transcriptome of GFP+ cells (in blue) and GFP-cells (in red) based on FACS-determined fluorophore thresholding. Circle represents the PPM Seurat cluster location B) UMAP representation from $A$, now clustered automatically in Seurat clusters based on correlation of gene expression profile. Circle represents PPM population C) Violin plots indicating the log counts of mRNA transcripts per target gene, categorized per Seurat cluster. 
pattern of mature SAN pacemaker cells. In order to evaluate whether this would improve upon maturation of the cells, we cultured the population of CMs and PPMs from a protocol $2 C$ differentiation until $D+28$ before fluorescent cell sorting of 384 random cells from all populations for scRNAseq analysis. UMAP representation demonstrates 5 populations of cells based on their fluorescent properties that correspond to 6 Seurat clusters of cells (Fig $5 A+B$ ). Of these, cluster 3 is predominantly composed of GFP negative cells (Fig $5 A+B$ ) and is characterized by the expression of cardiac transcription factor GATA4, contractilityrelated reges RYR2 and TNNT2, and transcription factors ISL1 and NR2F2, while being negative for NKX2-5. The expression of ISL1 and absence of NKX2-5 in this cluster is more pronounced in the $D+28$ sample group compared to the $D+14$ (Fig $4 C$ ), however the expression of TBX3 remains low (data not shown). Ventricular cardiomyocyte cluster 1 may be distinguished by the expression of NKX2-5 and IRX4 in addition to the cardiac markers GATA4, RYR2 and TNNT2, however it also expresses MYL7 instead of MYL2 indicating an immature phenotype. Cluster 5 represents a proliferative group of cells, co-expressing cardiac markers as well as ISL1, NKX2-5 and COI3A1 next to proliferation marker KI67.

\section{Selective gene expression analysis by qPCR}

We next validated the single cell RNAseq data using QPCR by quantifying the expression of genes that are characteristically found in pacemaker myocytes or cardiomyocytes. FACS-purified populations of GFP $/ \mathrm{mRubyll}^{+}$and $\mathrm{GFP}^{+} / \mathrm{mRubyll}^{+}$ were lysed for RNA isolation at D+17 of differentiation for qPCR analysis (Fig 6). As expected, the GFP- population (PPM) demonstrated a reduced expression of NKX2-5 compared to $\mathrm{GFP}^{+} \mathrm{CMs}$, which correlates with the reduced GFP signal of the NKX2-5_GFP reporter construct in PPMs. Expression levels of pacemakerrelated genes ISL1 and TBX18 were significantly increased in PPMs, whereas a trend towards elevated expression of CACNA1C and SHOX2 in PPMs was observed. However, expression levels of TBX3 and HCN4 were not different between PPM and $\mathrm{CM}$ populations.

A higher $C X 45 / C X 43$ expression ratio is characteristic for pacemaker cells in vivo. However, we did not observe any differences in expression of these gap junction proteins between the sorted PPMs and CMs. Both PPMs and CMs were found to express ACTN2, where CMs trended to a higher level of expression. Finally, we found a significantly higher expression of smooth muscle cell markers smooth muscle actin ( $\alpha-S M A)$ and a tendency to elevated expression of SM22, a smooth muscle transcription factor, and Myogenin-1, a skeletal muscle marker in the PPM group compared to CMs. Taken together, these gene expression data from PPMs show a transcription profile that differs from CMs and confirms the increased expression of several pacemaker identifying genes, including TBX18 and ISL1. Nevertheless, it is also clear the PPM gene expression profile does not 

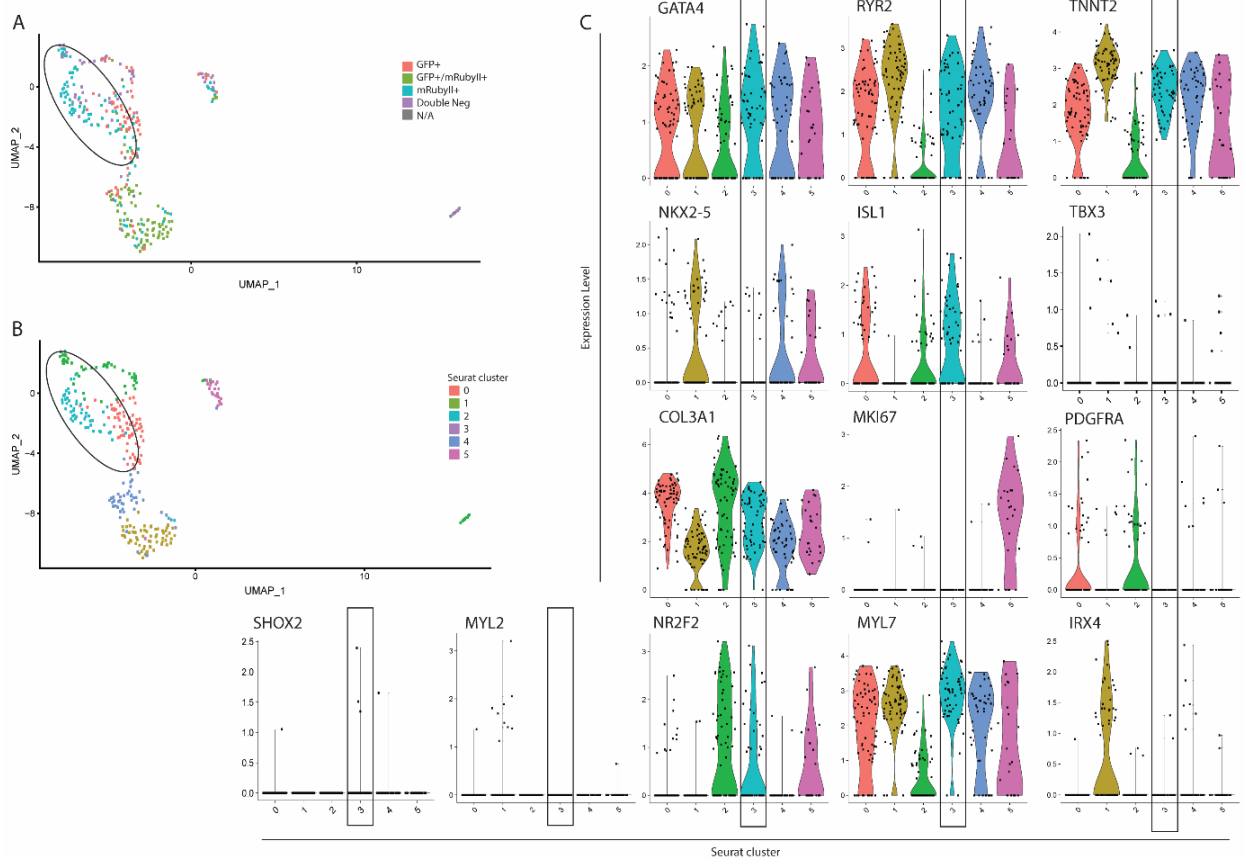

Figure 5: Single cell RNA sequencing result of the entire mixed population resulting from protocol C differentiation. A) UMAP representation of relative similarity of transcriptome of the cell population according to gene expression profile, marked with color based on fluorescent signal as determined by the cell sorter. The oval indicates the GFP-/mRubyll ${ }^{+} \mathrm{ppm}$ population. B) The same Seurat clustering, now identified with color on cells with similar gene expression profile. The oval again indicates the ppm population. The correlation of both the fluorescent identity as the gene expression profile indicates that the fluorescent marker can identify a specific subpopulation in the differentiation. C) Relative enrichment of mRNA within the clusters of cells indicated in B, identified by the color. Circled in black is the ppm population.

completely overlap with the adult SAN pacemaker gene expression profile.

\section{Discussion}

In this chapter, we performed various differentiation protocols for generating SAN pacemaker-like cells from hPSCs. We compared the efficiency of PM differentiation from previously reported studies and variations thereof and characterized cell-types using a specific double fluorescent hPSC DRRAGN reporter line. Since pacemaker cells of the SAN do not express NKX2-5, but are contractile and express $\alpha$-Actinin, the DRRAGN reporter enables quick screening for non-CM contractile pacemaker cells. Given the low efficiency of PM cell derivation from a standard CM differentiation protocol, a specific PM protocol with the possibility to purify these cells would be a great advancement for obtaining sufficient number of pacemaker cells without contamination of other cardiac subtypes for subsequent experimentation. 

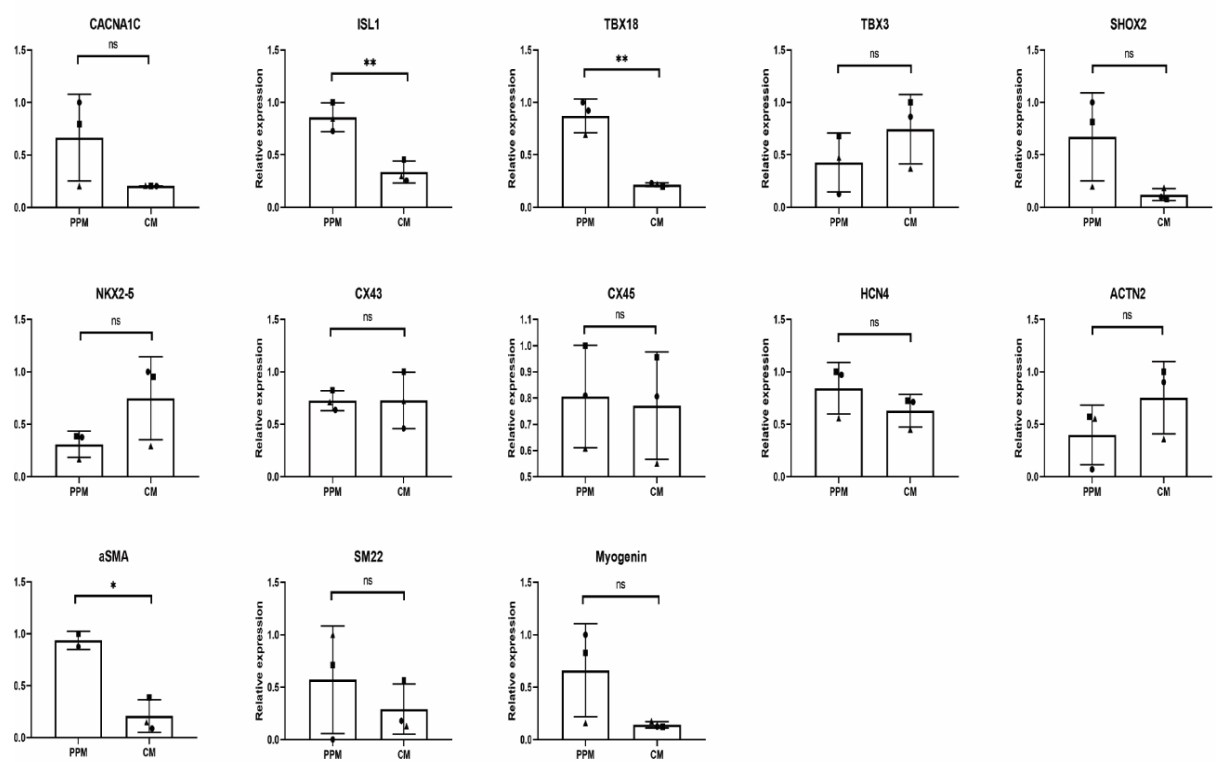

Figure 6: Gene expression analysis using qPCR for selected target genes that may identify the phenotype of the pacemaker cell. Symbol shape indicates replicate per target gene. Data plotted in mean $\pm S D$., $n=3$.

During embryonic development, the heart originates from mesodermal progenitor cells from the first and a second heart field (FHF and SHF). The FHF encompasses cells that will predominantly form the left ventricle of the heart, while the SHF mostly gives rise to the right ventricle, the atria and the outflow tract (arterial and venous connections). Cardiac pacemakers from the SAN arise as a subpopulation of $\mathrm{ISL1}^{+}$cardiac progenitor cells of the second heart field, influenced by activation of canonical Wnt signaling. Under the control of TBX18 and SHOX2, cells destined to become SAN pacemaker cells start to express TBX3 and lose their expression of NKX2-5.(2) For derivation of PM cells from hPSCs, mesoderm formation is required followed by a further specification towards to the SHF lineage, in order to emulate the molecular events during early cardiac development.

By following the stepwise approach from previous reported differentiations, not all protocols resulted in efficient and robust differentiation of PPM, based on FACS analysis using the DRRAGN reporter line and transcriptomic analysis. The protocols described by Protze et (protocol 2B) al and Ren et al (protocol 2A) showed no improvement $(4,8 \%$ v $10,8 \%$ for protocol $2 B)$, or a slight increase in PPM differentiation (19,1\% v 10,8\% for protocol $2 A)$ when compared to standard $\mathrm{CM}$ differentiation (protocol 1). Protocol $2 \mathrm{C}$ showed more promising results, with approximately a 3-fold increase in PPMs when compare to protocol 1 (35,5\% vs $10,8 \%$ ), based on flow cytometry analysis of $\mathrm{GFP}^{-} / \mathrm{mRubyll}^{+}$and $\mathrm{GFP}^{+} / \mathrm{mRubyll}^{+}$ 
cell populations.

It is not clear why the other protocols did not result in a strong PPM differentiation; however, several aspects need to be considered. While signaling pathways play an important role in cell fate determination, the protocols applied in this chapter differ considerably in modulating signaling pathways. Protocol 2A described by Ren et al.(9) "simply" activates, inactivates and reactivates canonical Wnt signaling on days 0,3 and 5, respectively, with a reported yield of $40-60 \%$ pacemaker-like cells, whereas protocols $2 \mathrm{~B}$ and $2 \mathrm{C}$, as described by Protze(1) and Birket(8), applied inhibitors and activators of various signaling pathways (e.g. Wnt, FGF, VEGF, RA, TGFb) that are considered to be important for early cardiac specification and differentiation towards the PM lineage, yielding a reported $55 \%$ and $>90 \%$ pacemaker cells, respectively. Depending on the hPSC line, basic culture conditions, microenvironment, and subtle differences in timing and activity of exogenous and endogenous factors that interfere with signaling pathways, great differences in cell fate determinations may be apparent.

Differentiation efficiency to pacemaker cells is quantified in all three publications by FC, where Protze and Birket both used the NKX2-5_eGFP reporter cell line (of which the DRRAGN line is derived, described in chapter 3 ) in combination with antibodies specific for SIRPA (Protze) or posterior heart field marker PDPN (Birket) to distinguish between pacemaker and cardiomyocyte populations. $(1,8)$ Ren et al quantified cardiomyocytes by FC by cardiac troponin-2 expression and determined the fraction of pacemakers in this population by quantifying NKX2-5 expression by immunohistochemistry.(9)

The FGF and Wnt signaling pathways crosstalk and have a reciprocal regulation during cell specification.(11) It is therefore difficult to determine their exact role in pacemaker differentiation, although it seems perceivable that Wnt signaling may play an important role in all three reported protocols. It has been previously shown that dissociation of cells, which is also part of Protze's and Birket's differentiation protocol at the CPC stage (protocol 2B and C, respectively), may activate $W n t$ signaling through the release of $\beta$-catenin from cadherin adhesion complexes.(11) In addition, Wnt activation (or inhibition of Wnt inhibitor DKK1) at specific stages has been previously described to facilitate PM differentiation and inhibit the CM phenotype.(12) Interestingly, Wnt reactivation is also most effective around day 4 - day 8 of differentiation, corresponding to the dissociation steps of protocols $2 B$ and C.(12) Reactivation of $W n t$ in protocol $2 A$ on $D+5$ (similar to Ren et al) led to a slight increase in the pacemaker population, but the increase was not significant. Interestingly, Wnt reactivation did not interfere with $\mathrm{CM}$ development when compared to the standard $\mathrm{CM}$ differentiation protocol (Protocol 1 ), suggesting that canonical Wnt activation at $D+5$, or at later stages, is not inhibitory to $\mathrm{CM}$ development, but may be permissive for PM differentiation. 
Since Protocol $2 \mathrm{C}$ yielded the highest percentage of mRubylI ${ }^{+} / \mathrm{GFP}^{-}$cells following differentiation, we continued to characterize the phenotype of these cells. Although several SAN-specific markers were increased, the putative pacemaker population did not reveal a mature pacemaker phenotype. The reduced expression of NKX2-5 was confirmed with both ICC, qPCR and scRNAseq, and is in agreement with strongly reduced GFP intensity using the DRRAGN reporter. The apparent enriched expression of SHOX2 in PPMs compared to CMs, as identified by ICC and qPCR, also points to a pacemaker-like phenotype, however SHOX2 could not be detected by scRNAseq. In addition, the GFP- population was enriched for ILS1 and TBX18 (both expressed in SAN in vivo(2)), according to scRNAseq analysis, which was confirmed by qPCR. However, another SAN marker, TBX3, was not differentially expressed between the two populations according to ICC, sCRNAseq and $q P C R$.

The SAN comprises a heterogeneous cell population, including pacemaker myocytes, fibroblasts, atrial-like cardiomyocytes, immune cells and endothelial cells, among others.(2) In particular, the transitional cardiomyocytes in the pacemakernode are of a blended phenotype, sharing functional and morphological features with both atrial cardiomyocytes and SAN pacemaker cells. However, the exact molecular fingerprint of these transitional cells remains unknown.(2) Since the sorted PPMs in our study share characteristics of both PM and (atrial) CMs it is feasible that these PPMs are more comparable to transitional cells. Indeed, at $\mathrm{D}+28$ of differentiation, the PPM Seurat cluster 3 presents an expression of both PM-related genes $\left(I S 1^{+}, T B X 18^{+}, N K X 2-5^{-}\right)$and atrial marker COUPTFII $\left(N R 22^{+}\right)$, which highlights their relation to the atrial population of cardiac cells.

Alternatively, PPMs are immature and therefore more comparable to progenitor cells of PMs. During development, activation of transcription factors changes over time as the heart develops to maturity.(2) For example, TBX3 expression is downstream regulated by TBX18 and ISL1, thus a lack of TBX3 expression in our cells may suggest a differentiation stage prior to activation of TBX3 activation. On the other hand, TBX18 expression is gradually lost during fetal development, until it is undetectable in neonates. In addition, the comparable expression levels of $\mathrm{HCN}_{4}$ between the GFP- and GFP ${ }^{+}$populations may be explained by the immature state of the hPSC-CMs, which are known to express HCN4 in vitro.(13) Transient expression patterns during differentiation and specification both in vitro as well as in vivo, may explain why certain markers are expressed, whereas others are not (yet) expressed. Enhancing the maturity of PPMs may therefore be a valid strategy to improve the phenotype of PPMs to adult SAN pacemaker cells. Several strategies to mature hPSC-derived cardiac cells have been followed, including co-culture with relevant cell types in a 3D configuration to mimic native cardiac tissue, mechanical load, electrical pacing or supplementing media with 
maturation-inducing factors (e.g., thyroid hormone, fatty acids, etc.). A similar approach can be envisioned for maturation of PPMs by defined 3D organization of PPMs, combined with other cell types such as fibroblasts, atrial cardiomyocytes or macrophages. $(10,14)$ In our study, we cultured our PPM population for an additional two weeks after differentiation, which resulted in a more pronounced ISL1 expression and loss of NKX2-5, suggesting that time-dependent maturation may already drive the PPM population to a more distinctive PM expression profile. Nevertheless, additional approaches to mature cells are required to establish a SAN PM phenotype.

To characterize pacemaker cells more extensively, it is important to analyze their functional aspects. Pacemaker cells are typically identified by their alternate electrophysiological profile and response to blockers of ion channels specific to pacemakers (e.g., funny current inhibitor ivabradine), which provide, together with the gene expression profile, a more definitive conclusion on the identity of the PPMs. $(1,8,9)$ Future studies will determine whether differentiation and maturation strategies will lead to genetic and functional profiles that are more closely resembling SAN in vivo.

\section{Conclusion}

Here, we describe the differentiation of an NKX2-5/ $\alpha$-Actinin double reporter cell line (DRRAGN) towards pacemaker-like cardiac cells. DRRAGN cells could indeed be used to differentiate between $\mathrm{NKX2}-5^{+}$working myocardial cells and a pacemaker-like, NKX2-5 contractile cardiac subtype. A protocol for the derivation of the NKX2-5 cells could be optimized in order to generate an adequate cell number for future experiments. Although further characterization of these potential pacemaker cells (PPMs) did not completely match with a SAN phenotype, our findings suggest that PPMs may represent transitional or SAN progenitor cells. In order to further drive the differentiation of the PPMs to a mature pacemaker phenotype, the addition of supporting cell types and/ or maturation strategies such as maturation medium or electro/mechanical stimulation will be applied in future studies.

\section{Materials and methods}

\section{Cell culture}

Double Reporter mRubyll Actinin GFP NKX2-5 (DRRAGN) hESCs were maintained on vitronectin and cultured in Essential 8 medium (ThermoFisher). Cells were passaged twice a week to maintain the line as follows. Dissociation to single cell suspension was done with 0,5 mM EDTA (ThermoFisher) for 3 minutes, after which EDTA was aspirated, and cells were resuspended in $1 \mathrm{~mL}$ E8 medium. After counting using Trypan blue (ThermoFisher), cells were seeded at $\sim 18 \mathrm{~K}$ cells $/ \mathrm{cm}^{2}$ on Mondays, or $\sim 10 \mathrm{k}$ cells per $\mathrm{cm}^{2}$ on Thursdays. 


\section{PPM differentiation protocols}

\section{Protocol 1}

Human ESCs were differentiated to CMs in monolayer as described in chapter 3(9). Briefly, hPSCs were seeded at a density of $25 \mathrm{~K}$ cells per $\mathrm{cm}^{2}$ on Matrigelcoated 6-well plates in Essential 8 medium (ThermoFisher) (described in(10)) one day before the start of the differentiation (D-1). The next day (D0), mesodermal differentiation was initiated by addition of Wnt activator CHIR99021 $(1.5 \mu \mathrm{mol} / \mathrm{L}$, Axon Medchem 1386), Activin-A (20 ng/mL, Miltenyi 130-115-010) and BMP4 ( $20 \mathrm{ng} / \mathrm{mL}$, R\&D systems 314-BP/CF) in BPEL medium (see(15)). At D+3, Wnt was inactivated by adding XAV939 (5 $\mathrm{mmol} / \mathrm{L}$, R\&D Systems 3748 ) in BPEL. In addition, Matrigel (1:200) was added to promote adhesion of cells. Cell cultures were refreshed on $D+7, D+10$ and $D+13$ with $B P E L$ after the start of differentiation until differentiation was completed ( $D+17)$.

\section{Protocol $2 A$}

Differentiation was initiated according to protocol 1 (see above). On D+5, CHIR was added at a final concentration of $1.5 \mu \mathrm{M}$ to the BPEL medium. Control wells were equally refreshed with BPEL on $D+5$, without the addition of CHIR. Remainder of the differentiation was equal to protocol 1.

\begin{tabular}{|c|c|c|c|}
\hline Study & qPCR & imaging & (electro-)physiology \\
\hline $\begin{array}{l}\text { Birket et al(8) } \\
\text { (protocol 2C) }\end{array}$ & $\begin{array}{l}\text { 个 TBX18, TBX3, SHOX2, HCN4 } \\
\downarrow \text { MYL2, SCN5A, NKX2-5 } \\
=\text { TNNT2, MYL7, TBX5, MEF2C, } \\
\text { GATA4, SMARCD3, HAND1, } \\
\text { HAND2, MYOCD, NPPA, CX40, } \\
\text { CX43 }\end{array}$ & $\downarrow N K X 2-5$, MYL2 & $\begin{array}{l}\uparrow \mathrm{DDR}_{100} \\
\downarrow \mathrm{MDP}, \mathrm{dV} / \mathrm{dt}_{\max }, \mathrm{APA}, \mathrm{APD}_{20^{\prime}} \\
\mathrm{APD}_{50^{\prime}} \quad \mathrm{APD}_{90^{\prime}} \text { cycle length, } \\
\text { contraction stress } \\
=\text { cell area }\end{array}$ \\
\hline $\begin{array}{l}\text { Protze et al(1) } \\
\text { (protocol 2B) }\end{array}$ & $\begin{array}{l}\text { 个 NR2F2, TBX18, SHOX2, TBX3, } \\
\text { ISL1, KCNJ3 } \\
\downarrow \text { SCN5A } \\
=\text { NPPA, TBX2, MSX2, HCN1, } \\
\text { HCN4 }\end{array}$ & $\begin{array}{l}\text { 个 SHOX2 } \\
\downarrow \text { MLC2V, NKX2-5 } \\
=\text { cTnT }\end{array}$ & $\begin{array}{l}\downarrow \mathrm{dV} / \mathrm{dt}_{\text {max }}, \\
\uparrow \mathrm{I}_{\mathrm{t},} \mathrm{I}_{\mathrm{Na}^{\prime}}, \mathrm{CCH} / \text { ATR response } \\
=\mathrm{ISO} / \mathrm{PRP} \text { response }\end{array}$ \\
\hline $\begin{array}{l}\text { Ren et al(9) } \\
\text { (Protocol 2A) }\end{array}$ & $\begin{array}{l}\text { 个 TBX18, BMP4, SHOX2, HCN4, } \\
\text { ISL1, TBX3 } \\
\downarrow N K X 2-5 \\
=\text { WT1, TCF21 }\end{array}$ & $\begin{array}{l}\uparrow \mathrm{SHOX} 2 \\
\downarrow \text { NKX2-5 } \\
=\text { TNNT2 }\end{array}$ & $\uparrow$ beat rate \\
\hline
\end{tabular}

Table 1: Pacemaker identity confirmation of each reported protocol, by type of analysis. $\uparrow$ indicated increase of value compared to CM population within the differentiation, $\downarrow$ indicates lower value compared to $C M$, and = indicates no difference between $P M$ and $C M$. 


\section{Protocol 2B}

Stem cells were seeded at $5 \mathrm{k}$ cells per well of a 96 -well V-bottom microplate, in StemPro-based D-1 medium (see table 2) and plate was placed in $5 \% \mathrm{O}_{2}$. A control plate was kept at atmospheric $\mathrm{O} 2$ pressure, and a control plate submitted to Protocol 1 was placed in $\mathrm{O}_{2}$ in order to evaluate the effect of low oxygen tension on pacemaker differentiations. On D0, medium was refreshed with SANLPC DO medium (see table 2) that was allowed to equilibrate to $5 \% \mathrm{O}_{2}$ for two hours before use. On D+2, cell aggregates were dissociated in 1x TripLE Select (ThermoFisher) for 5 minutes at $37^{\circ} \mathrm{C}$. TripLE was subsequently inactivated by dilution in StemPro basal medium, and the cell suspension was spun down at 240x $\mathrm{g}$ for 3 minutes. Next, the pellet was resuspended in SANLPC D2 medium (table 2) and single cells were reseeded at $80 \mathrm{k}$ cells per microwell in a 96 -well V-bottom microplate and allowed to reaggregate. From $\mathrm{D}+5$ onwards, cell aggregates were maintained in cardiac maintenance medium (table 2 ) and refreshed every third day. On D+11, plates were placed in atmospheric $\mathrm{O}_{2}$ pressure until FC quantification, while refreshed with cardiac maintenance medium every two days.

\section{Protocol 2C}

For EB differentiation, $5 \mathrm{~K}$ cells were seeded in 96-well V-bottom plate (GreinerBioOne) in E8 + 1:1000 Rock inhibitor + 0,025\% PVA on D-1. On D0, mesodermal differentiation was induced by replacing the culture medium with BPEL + BMP4 (20 ng/mL) + ACTA (20 ng/mL) + CHIR (1,5 $\mu \mathrm{M})+$ SCF $(40 \mathrm{ng} / \mu \mathrm{L})+$ VEGF (30 ng/ $\mu \mathrm{L}), 3 \mathrm{~mL}$ per 6 -well. Medium was refreshed on $\mathrm{D}+3$ with BPEL. On $\mathrm{D}+7, \mathrm{EBs}$ were dissociated to single cells in 1x TripLE Select (ThermoFlsher) for 10' at RT, which was inactivated by dilution in DMEM/F12 Glutamax (ThermoFisher), followed by a spin down at 240 rcf for $3^{\prime}$ and subsequent resuspension in CM2 medium (see table 2). Cells were counted with Trypan blue and seeded in matrigelcoated $\left(8,3 \mathrm{ng} / \mathrm{cm}^{2}\right) 6$-wells at a density of $125 \mathrm{~K}$ cells $/ \mathrm{cm}^{2}$. On D+8, medium was refreshed with $\mathrm{CM} 2+$ medium (see table 2), followed by refreshments on $\mathrm{D}+10$ with $\mathrm{CM} 3$, and $\mathrm{D}+12$ and $\mathrm{D}+14$ with $\mathrm{CM} 4$. On D+17, cells were dissociated for FACS purification (see below).

\section{FACS}

Cells on D+17 of differentiation were dissociated to single cells with 10x TripLE (ThermoFisher) for $10^{\prime}$ at RT. TripLE was deactivated through dilution with $3 \mathrm{~mL}$ DMEM per $\mathrm{mL}$ TripLE, then spun down for 3' at 240 rcf. The pellet was resuspended in PEB buffer $(0,25 \%$ BSA +2 mM EDTA in DPBS), filtered through a cell strainer into a $5 \mathrm{~mL}$ FACS tube. FACS was performed on fluorescent reporter signals GFP for NKX2-5 (525/50), and mRubyll for ACTN2 (661/20). The pacemaker population was identified as single positive for $\mathrm{mRubyll}\left(\mathrm{GPF} / \mathrm{mRuby} \mathrm{I}^{+}\right.$), whereas cardiomyocytes were identified by their double positive fluorescent signal (GFP+ 


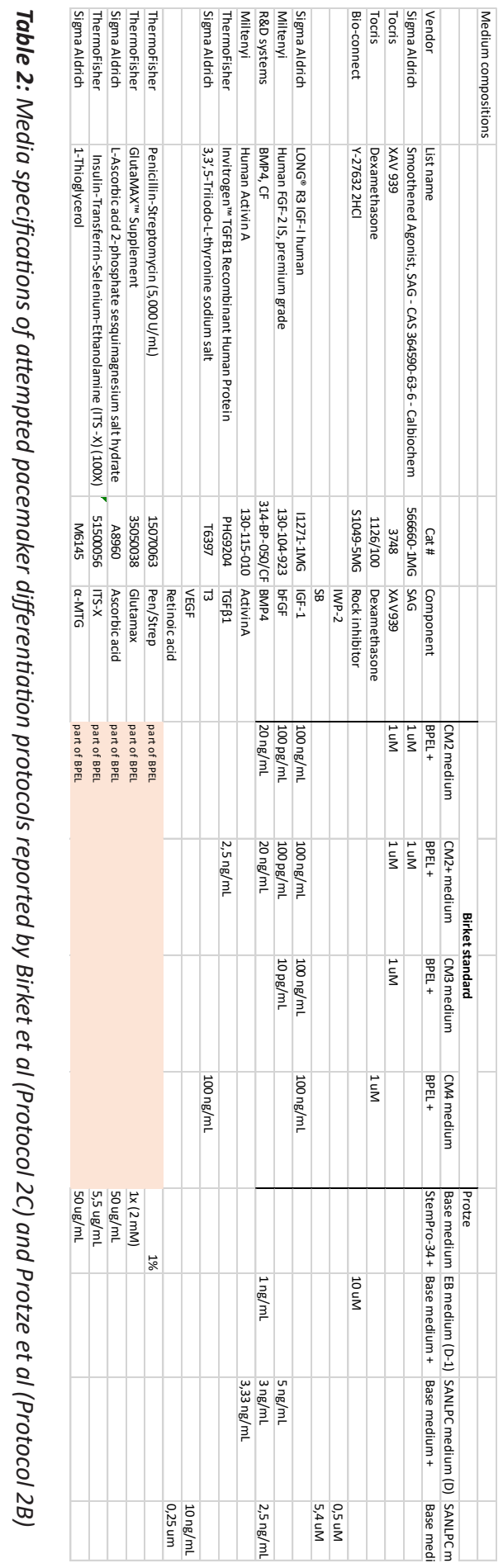

92 
mRubyll + ). Quantification of PMs in YAP control line was done by staining with $\alpha$-TNNT2-VioBlue antibody (Miltenyi) for 30 minutes at $4^{\circ} \mathrm{C}$ in PEB buffer. Cells were sorted into CM-TDI medium (see appendix 2), then spun down at $240 \mathrm{rcf}$ for 3 ', after which the pellet was resuspended in CM-TDI medium for cell seeding in imaging plates, or RLT buffer (Qiagen) for RNA isolation. Cells seeded for imaging were seeded at a density of $125 \mathrm{k}$ cells $/ \mathrm{cm}^{2}$ in a 96 well glass bottom plate (PerkinElmer) on vitronectin.

ICC

Cells in 96 well glass bottom plate were cultured for 10 days in CM-TDI medium before fixation with 4\% FA (Sigma-Aldrich) for 10' at RT. No wash was performed before fixation. Wells were washed 3 times in DPBS after fixation finished, after which the wells were incubated with 0,1\% Triton-X100 (Sigma-Aldrich) in PBS for 8 minutes. After washing, the wells were blocked with $2 \%$ BSA and $10 \%$ normal goat serum (Sigma-Aldrich) for $>1$ hour at RT. Primary antibody was added after removal of the blocking buffer without intermediate washing and incubated for 1.5 hours at RT or $\mathrm{O} / \mathrm{N}$ at $4^{\circ} \mathrm{C}$. Antibody buffer was $2 \% \mathrm{BSA}$ in PBS, antibody concentrations can be found in table 3 . After incubation, wells were washed with PBS $3 \times 5$ ' before adding the secondary antibody. Secondary antibody buffer was added in 2\% BSA in PBS (table 2) and incubated for 1 hour at RT. Wells were washed $3 \times 5^{\prime}$ in PBS, then mounted in ProLong Gold antifade reagent with DAPI (ThermoFisher) to stabilize the fluorophores for long term storage.

RNA isolation, cDNA synthesis and qPCR

RNA was isolated from FACS sorted PPM or CM populations using the RNeasy mini kit (Qiagen), according to manufacturer's protocol. Briefly, after FACS purification of the respective cell populations, the cells suspension was spun down at $240 \mathrm{rcf}$ for 3', supernatant was aspirated, and RLT lysis buffer was added to the cell pellet. Cells were lysed by careful resuspension with a pipet, after which the RLT mixture was stored at $-80^{\circ} \mathrm{C}$ until RNA isolation. CDNA synthesis was performed using the

\begin{tabular}{|l|l|l|l|}
\hline Antibody name & vendor & cat \# & dilution \\
\hline NKX2-5 & Cell Signaling Technology & 87925 & $1: 200$ \\
\hline SHOX2 & Abcam & AB55740 & $1: 400$ \\
\hline ISL1 & DSHB & $40.2 D 6$ & $1: 400$ \\
\hline TBX3 & Sigma Aldrich & SAB1409728 & $1: 400$ \\
\hline Alexafluor 647 Donkey-a-Mouse & Thermofisher & A31571 & $1: 400$ \\
\hline AlexaFluor 647 Goat-a-Rabbit & ThermoFisher & A21244 & $1: 400$ \\
\hline
\end{tabular}

Tabel 3: Antibody origins and concentrations 
iScript cDNA synthesis kit (Bio-Rad) according to manufacturer's protocol. QPCR was performed using $6 \mathrm{ng}$ of cDNA per reaction well in a 384 wells plate (Bio-Rad) in the CFX384 Touch real-time PCR detection system (Bio-Rad), using primers as indicated in table 4.

\section{Single cell RNA seq}

DRRAGN hESCs were differentiated using protocol $C$ and dissociated on $D+17$ for FACS sorting. GFP/mRubyll ${ }^{+}$and $\mathrm{GFP}^{+} / \mathrm{mRubyll}^{+}$populations were gated and cells from both populations were deposited as a single cell in lysis buffer directly inside a 384 wells plate. The plate was then frozen at $-80^{\circ} \mathrm{C}$ until analysis (see below).

\begin{tabular}{|c|c|c|c|}
\hline Target & Primer name & sequence $5^{\prime}$-> $3^{\prime}$ & $\mathrm{Tm}$ \\
\hline \multirow{2}{*}{ RPLPO } & hARP fwd569 & CACCATTGAAATCCTGAGTGATGT & 59,3 \\
\hline & hARP rev684 & TGACCAGCCCAAAGGAGAAG & 59,6 \\
\hline \multirow{2}{*}{ АСТВ } & ACTB Fwd & AGAGCTACGAGCTGCCTGAC & 61,7 \\
\hline & ACTB Rev & AGCACTGTGTTGGCGTACAG & 60,9 \\
\hline \multirow{2}{*}{ ACTN2 } & ACTN2 Fwd & CTGCTGCTTTGGTGTCAGAG & 59,1 \\
\hline & ACTN2 Rev & TTCCTATGGGGTCATCCTTG & 56,3 \\
\hline \multirow{2}{*}{ ACTA2 } & aSMA Fwd & CCAACTGGGACGACATGGAAA & 60,5 \\
\hline & aSMA Rev & GCGTCCAGAGGCATAGAGAGACA & 63,7 \\
\hline \multirow{2}{*}{ CACNA1C } & CACNA1C Fw & CAATCTCCGAAGAGGGGTTT & 54,5 \\
\hline & CACNA1C Rv & TCGCTTCAGACATTCCAGGT & 56,2 \\
\hline \multirow{2}{*}{ CX43 } & CX43 Fwd & GCGCACATGAGAGATTGGGA & 60,5 \\
\hline & Cx43 Rev & GGTGACTGGAGCGCCTTAG & 60,2 \\
\hline \multirow{2}{*}{ CX45 } & CX45 Fwd & GAGCTTCCTGACTCGCCTGCT & 64,5 \\
\hline & CX45 Rev & CCCGGCTGTTCTGTGTTGCAC & 64,6 \\
\hline \multirow{2}{*}{ HCN4 } & HCN4 Fw & CAATGAGGTGCTGGAGGAGT & 59,4 \\
\hline & HCN4 Rv & GGTCGTGCTGGACTTTGTG & 59,1 \\
\hline \multicolumn{4}{|l|}{ ISL1 } \\
\hline \multirow{2}{*}{ MYOG } & Myogenin Fwd & GCTCAGCTCCCTCAACCA & 58,9 \\
\hline & Myogenin Rev & GCTGTGAGAGCTGCATTCG & 59,3 \\
\hline \multirow{2}{*}{ NKX2-5 } & NKX2.5 Fwd & AGCTCTTTCTTTTTCGGCTCTAGG & 60,4 \\
\hline & NKX2.5 Rev & CCCGCCTTCTATCCACGTG & 60,2 \\
\hline \multirow{2}{*}{ SHOX2 } & hSOX2 Fwd & GCCGAGTGGAAACTTTTGTCG & 60,3 \\
\hline & hSOX2 Rev & GCAGCGTGTACTTATCCTTCTT & 58,5 \\
\hline \multirow{2}{*}{ TBX18 } & TBX18 Fwd & TTAACCTTGTCCGTCTGCCTGAGT & 63,8 \\
\hline & TBX18 Rev & GTAATGGGCTTTGGCCTTTGCACT & 64,4 \\
\hline \multirow{2}{*}{ TBX3 } & TBX3 Fwd & CGAAATGCCAAAGAGGATGT & 56,4 \\
\hline & TBX3 Rev & GAATTCAGTTTCGGGGAACA & 56,0 \\
\hline \multirow{2}{*}{ SM22 } & SM22 Fwd & CGCGAAGTGCAGTCCAAAATCG & 63,1 \\
\hline & SM22 Rev & GGGCTGGTTCTTCTTCAATGGGC & 64,1 \\
\hline
\end{tabular}

Table 4: Primer list of oligos used for qPCR gene expression analysis 
Single-cell RNA sequencing library construction and sequencing

The sorted 384-well plates were processed using the CEL-Seq2 protocol(16). In short, ERCC spike-in $(1: 50,000)$ were dispensed using a Nanodrop II (BioNex Solutions Inc.) in each well. After a 5 min. incubation step at $65^{\circ} \mathrm{C}, 150 \mathrm{~nL}$ of the Reverse Transcription (RT) mix was dispensed into each well and the first strand synthesis was performed with the following thermal cycles: $4^{\circ} \mathrm{C}$ for $5 \mathrm{~min}, 25^{\circ} \mathrm{C}$ for $10 \mathrm{~min}, 42^{\circ} \mathrm{C}$ for $1 \mathrm{hr}, 70^{\circ} \mathrm{C}$ for $10 \mathrm{~min}$. Within an incubation of $2 \mathrm{hrs}$ at $16^{\circ} \mathrm{C}$ the second strand synthesis was performed in the plate. After each of the dispensing steps, the plates were spun down at $1000 \mathrm{rcf}$ for $1 \mathrm{~min}$ at $4^{\circ} \mathrm{C}$. Subsequently, the well of a plate were pooled and purified using AmpureXP (New England BioLabs). Overnight in vitro transcription (Ambion MEGAScript; $14 \mathrm{hrs}$ at $37^{\circ} \mathrm{C}$ ) was followed by a $20 \mathrm{~min}$ at $37^{\circ} \mathrm{C}$ exonuclease step and chemical fragmentation of the amplified RNA. The sample was purified using the magnetic beads, after which a library RT and amplification PCR (with 9 cycles) was performed to introduce unique sample indices to the plate libraries and prepare the samples for Illumina sequencing (NextSeq 500), at a depth of 20 million reads per plate.

Read mapping, dataset processing and downstream analysis

Reads were mapped against the human genome GRCh38 and a resulting cellby-gene matrix was generated with the Kallisto | Bustools workflow (v0.24.4) (17). The R package Scater $(\mathrm{v} 1.10 .1,(18))$ was used for sample filtering and quality check of the cells. Only the genes with $>1 \mathrm{UMI}$ counts in at least 2 cells were kept in the analysis, and cells were filtered on the basis of the total amount of UMI counts $(>1000)$, the total amount of genes $(>1000)$, mitochondrial percentage $(<$ $40 \%$ of total reads) and percentage of reads mapped to ERCC spike ins $(<20 \%)$. Further downstream analysis on the filtered dataset was performed in Seurat V3.(19) 


\section{References}

1. Protze SI, Liu J, Nussinovitch U, Ohana L, Backx PH, Gepstein L, et al. Sinoatrial node cardiomyocytes derived from human pluripotent cells function as a biological pacemaker. Nat Biotechnol. 2017;35(1):56-68.

2. Liang X, Evans SM, Sun Y. Development of the cardiac pacemaker. Cell Mol Life Sci. 2017;74(7):1247-59.

3. Bakker ML, Moorman AF, Christoffels VM. The atrioventricular node: origin, development, and genetic program. Trends Cardiovasc Med. 2010;20(5):164-71.

4. John RM, Kumar S. Sinus Node and Atrial Arrhythmias. Circulation. 2016;133(19):1892-900.

5. Clauss S, Bleyer C, Schuttler D, Tomsits P, Renner S, Klymiuk N, et al. Animal models of arrhythmia: classic electrophysiology to genetically modified large animals. Nat Rev Cardiol. 2019;16(8):457-75.

6. Passier R, Orlova V, Mummery C. Complex Tissue and Disease Modeling using hiPSCs. Cell Stem Cell. 2016;18(3):309-21.

7. Ribeiro MC, Slaats RH, Schwach V, Rivera-Arbelaez JM, Tertoolen LGJ, van Meer BJ, et al. A cardiomyocyte show of force: A fluorescent alpha-actinin reporter line sheds light on human cardiomyocyte contractility versus substrate stiffness. J Mol Cell Cardiol. 2020;141:54-64.

8. Birket MJ, Ribeiro MC, Verkerk AO, Ward D, Leitoguinho AR, den Hartogh SC, et al. Expansion and patterning of cardiovascular progenitors derived from human pluripotent stem cells. Nat Biotechnol. 2015;33(9):970-9.

9. Ren J, Han P, Ma X, Farah EN, Bloomekatz J, Zeng XI, et al. Canonical Wnt5b Signaling Directs Outlying Nkx2.5+ Mesoderm into Pacemaker Cardiomyocytes. Dev Cell. 2019;50(6):729-43 e5.

10. Birket MJ, Ribeiro MC, Kosmidis G, Ward D, Leitoguinho AR, van de Pol V, et al. Contractile Defect Caused by Mutation in MYBPC3 Revealed under Conditions Optimized for Human PSC-Cardiomyocyte Function. Cell Rep. 2015;13(4):733-45.

11. Gibbs HC, Chang-Gonzalez A, Hwang W, Yeh AT, Lekven AC. MidbrainHindbrain Boundary Morphogenesis: At the Intersection of Wnt and Fgf Signaling. Front Neuroanat. 2017;11:64.

12. Liang W, Han P, Kim EH, Mak J, Zhang R, Torrente AG, et al. Canonical Wnt signaling promotes pacemaker cell specification of cardiac mesodermal cells 
derived from mouse and human embryonic stem cells. Stem Cells. 2020;38(3):35268.

13. Schulze ML, Lemoine MD, Fischer AW, Scherschel K, David R, Riecken $\mathrm{K}$, et al. Dissecting hiPSC-CM pacemaker function in a cardiac organoid model. Biomaterials. 2019;206:133-45.

14. Hulsmans $M$, Clauss $S$, Xiao L, Aguirre $A D$, King $K R$, Hanley $A$, et al. Macrophages Facilitate Electrical Conduction in the Heart. Cell. 2017;169(3):51022.e20.

15. Elliott DA, Braam SR, Koutsis $\mathrm{K}, \mathrm{Ng}$ ES, Jenny R, Lagerqvist EL, et al. NKX2$5($ eGFP/w) hESCs for isolation of human cardiac progenitors and cardiomyocytes. Nat Methods. 2011;8(12):1037-40.

16. Hashimshony T, Senderovich N, Avital G, Klochendler A, de Leeuw Y, Anavy L, et al. CEL-Seq2: sensitive highly-multiplexed single-cell RNA-Seq. Genome Biol. 2016;17:77.

17. Melsted P, Booeshaghi AS, Liu L, Gao F, Lu L, Min KHJ, et al. Modular, efficient and constant-memory single-cell RNA-seq preprocessing. Nat Biotechnol. 2021.

18. McCarthy DJ, Campbell KR, Lun AT, Wills QF. Scater: pre-processing, quality control, normalization and visualization of single-cell RNA-seq data in R. Bioinformatics. 2017;33(8):1179-86.

19. Stuart T, Butler A, Hoffman P, Hafemeister C, Papalexi E, Mauck WM, 3rd, et al. Comprehensive Integration of Single-Cell Data. Cell. 2019;177(7):1888-902 e21. 


\section{Supplementary Figures}
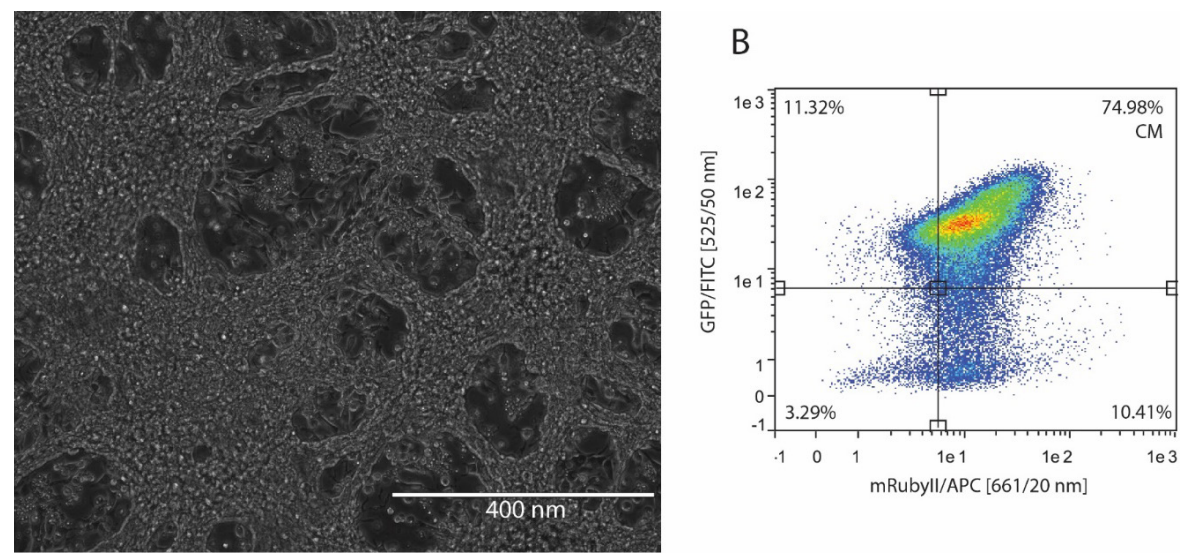

Supplementary Figure 1: DRRAGN hESC differentiation to CMs in StemPro medium. A) CM culture at $D+14$ of the differentiation. B) Flow cytometry plot presenting the relative CM yield of this differentiation, indicating that an efficiency of $74.98 \%$ can be achieved using StemPro medium as the basis instead of BPEL.
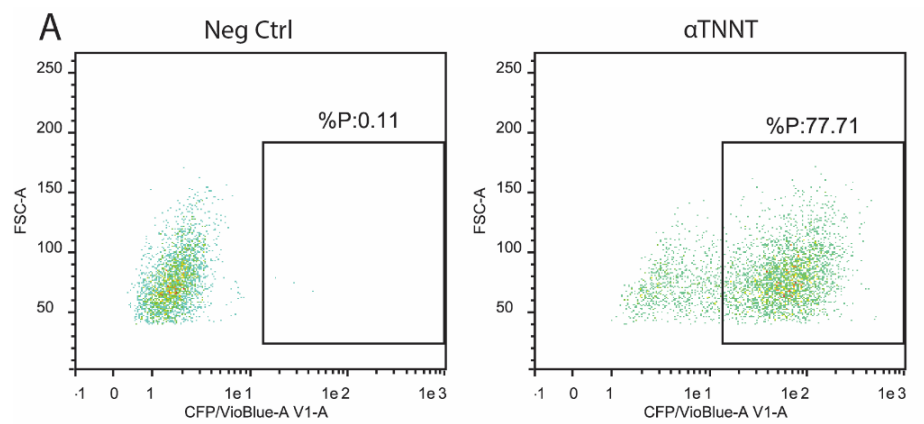

B

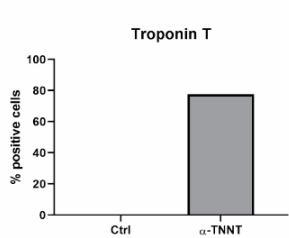

Supplementary Figure 2: Quantification of PM differentiation from the YAP inducible c-MYC line using protocol $2 C$, including the expansion of the progenitor population at $D+7$, as described in (8). A) Flow cytometry dotplot showing the unstained control (left) and population stained with antiTNNT-VioBlue antibody. B) quantification of posititve population for TNNT of all differentiations $(n=2)$. 
99 
Chapter 5:

\section{Human pluripotent stem cell-derived cardiomyocytes for assessment of anticancer drug-induced cardiotoxicity.}


102 


\title{
Chapter 5: Human pluripotent stem cell-derived cardiomyocytes for assessment of anticancer drug- induced cardiotoxicity.
}

\author{
Verena Schwach ${ }^{1}$, Rolf Slaats ${ }^{1}$ \& Robert Passier ${ }^{1,2}$
}

${ }^{1}$ Applied Stem Cell Technologies, TechMed Centre, University of Twente, Drienerlolaan 5, 7500 AE, Enschede, The Netherlands, ${ }^{2}$ Department of Anatomy and Embryology, Leiden University Medical Centre, PO Box 9600, 2300 RC Leiden, The Netherlands

\begin{abstract}
Cardiotoxicity is a major cause of high attrition rates among newly developed drugs. Moreover, anti-cancer treatment-induced cardiotoxicity is one of the leading reasons of mortality in cancer survivors. Cardiotoxicity screening in vitro may improve predictivity of cardiotoxicity by novel drugs, using human pluripotent stem cell (hPSC)-derived-cardiomyocytes. Anthracyclines, including Doxorubicin, are widely used and highly effective chemotherapeutic agents for the treatment of different forms of malignancies. Unfortunately, anthracyclines cause many cardiac complications early or late after therapy. Anthracyclines exhibit their potent anti-cancer effect primarily via induction of DNA damage during the DNA replication phase in proliferative cells. In contrast, studies in animals and hPSC-cardiomyocytes have revealed that cardiotoxic effects particularly arise from 1) the generation of oxidative stress inducing mitochondrial dysfunction, 2) disruption of calcium homeostasis, and 3) changes in transcriptome and proteome, triggering apoptotic cell death. To increase the therapeutic index of chemotherapeutic Doxorubicin therapy several protective strategies have been developed or are under development, such as 1) reducing toxicity through modification of Doxorubicin (analogs), 2) targeted delivery of anthracyclines specifically to the tumor tissue or 3) cardioprotective agents that can be used in combination with Doxorubicin. Despite continuous progress in the field of cardiooncology, cardiotoxicity is still one of the major complications of anti-cancer therapy. In this review, we focus on current hPSC-cardiomyocyte models for assessing anthracycline-induced cardiotoxicity and strategies for cardioprotection. In addition, we discuss latest developments towards personalized advanced preclinical models that are more closely recapitulating the human heart, which are necessary to support in vitro screening platforms with higher predictivity. These advanced models have the potential to reduce the time from bench-to-bedside of novel antineoplastic drugs with reduced cardiotoxicity.
\end{abstract}




\section{Introduction}

Cardiovascular diseases and cancer are the two leading causes of death in industrialized countries. Although in recent years new anti-cancer therapies improved long-term survival rates, this is unfortunately also accompanied by an increased risk of cardiovascular complications because of adverse side effects of these anti-cancer drugs. Anthracyclines are a group of widely used anti-cancer drugs that are known to cause cardiac complications, either early or late after start of treatment.(1-7) The history of anthracyclines originates in the 1950s when Daunorubicin was isolated from the bacteria Streptomyces peucetius. Ten years later Doxorubicin, a more effective derivative of Daunorubicin, was identified.(8) However, Doxorubicin received the ominous nickname "Red Devil" because of the detrimental side effects in combination with its red color. In approximately $11 \%$ of patients, Doxorubicin-induced cardiotoxicity leads to an acute response within 2-3 days of administration (early onset of cardiotoxicity), manifested by chest pain resulting from different forms of arrhythmia.(3) Chronic Doxorubicin-induced cardiomyopathy has a lower incidence (ranging from 4-36 $\%$ dependent on the dose) and can occur as late as 10 years after the last dose (late onset of chronic cardiotoxicity), with only a $50 \% 1$ year survival prognosis when cardiomyopathy further develops into congestive heart failure. $(3,7)$ Importantly, anthracycline-induced cardiotoxicity endangers cancer patients since the early $70 \mathrm{~s} .(9,10)$ At present, almost half a century later, success in preventing or counteracting anthracycline-induced cardiotoxicity has been very limited. Moreover, although novel anti-cancer therapeutic compounds to specific target molecules, such as tyrosine kinase inhibitors, have been developed, druginduced cardiotoxicity remains a persistent problem. One major reason for this is that current in vitro and animal models fail to show sufficient predictive power and limit extrapolation to patients, which consequently leads to high attrition rates during the process of drug development.

Development of preclinical human cell-based models for drug discovery that mimic human physiology and pathophysiology, has the potential to improve the predictability of adverse drug events.(11) In particular, human pluripotent stem cells (hPSCs) are excellent candidates for developing these models since they replicate indefinitely and have the capacity to differentiate to any cell type of the human body, including functional cardiomyocytes. This is especially embraced in the cardiac field, since isolated primary human cardiomyocytes are extremely difficult to obtain and maintain in culture. Advances in differentiation and purification of hPSC-derived cardiomyocytes (hPSC-Cardiomyocytes) and their unlimited availability has promoted strategies to use these cells for cardiotoxicity assessment of new drugs.(12) Previously, the Food and Drug Administration 
(FDA), the supreme body worldwide that checks the quality and safety of medical products, initiated the so-called "Comprehensive In vitro Proarrhythmia Assay (CIPA)", which represents a paradigm shift and encompass evaluation of lifethreatening proarrhythmic risk for all new compounds in a preclinical assay using hPSC-Cardiomyocytes.(13) This CIPA initiative signifies the enormous potential of hPSCs-derived cardiomyocytes for preclinical drug screening. Here, we describe underlying mechanisms of anthracycline-induced cardiotoxicity, as well as therapeutic approaches for cardioprotection. Furthermore, we will discuss the potential to use hPSC-derived cardiac models for improved safety assessment of anti-cancer drugs and strategies to overcome current limitations for developing in vitro drug testing platforms with a higher predictivity.

\section{Mechanism of anthracycline-induced cardiotoxicity in hPSC- cardiomyocytes}

The potent therapeutic anti-cancer effect of Doxorubicin is mediated primarily via inhibition of topoisomerase lla, an enzyme responsible for unwinding DNA before replication or transcription. This inhibition leads to DNA damage and consequently death of highly proliferating cancer cells, but also affects healthy proliferating cells, such as hematopoietic precursors, epithelial lining of the intestine and hair follicle cells. Fully mature cardiomyocytes are typically quiescent and do not express topoisomerase Il $\alpha$, however studies performed in hPSC-cardiomyocytes demonstrated that Doxorubicin may bind to the enriched topoisomerase $\| \beta$ in cardiomyocytes, and knock-out of this isotype improved cell viability significantly when exposed to Doxorubicin. $(14,15)$ A comprehensive review on damage mechanisms of anthracycline-induced cardiotoxicity has been published elsewhere.(16) The underlying mechanisms of Doxorubicin-induced cardiotoxicity is not yet completely understood. However, several studies in hPSC-cardiomyocytes have shown that mitochondrial dysfunction, disruption of calcium homeostasis, as well as altered gene and protein expression levels triggering apoptotic cell death, play important roles in anthracycline-induced cardiotoxicity (Figure 1). Increased oxidative stress by elevated production of reactive oxygen (ROS) and nitrogen species (NOS) in the mitochondria of cardiomyocytes are major factors of Doxorubicin-induced cardiotoxicity, since cardiomyocytes are more sensitive to these molecules because they possess lower levels of antioxidant enzymes than other cell types.(1, 3, 4, 17-20) As a consequence, higher stress levels in cardiomyocytes under oxidative stress circumstances can lead to cardiotoxicity.(20) An increase in intracellular levels of ROS and NOS cause mitochondrial dysregulation, lipid peroxidation, DNA damage and protein carbonylation. Cardiac mitochondria are the major site of Doxorubicin-induced ROS/NOS levels due to the localization of the major redox 
cycling enzymes such as $\mathrm{NAD}(\mathrm{P}) \mathrm{H}$. Additionally, Doxorubicin becomes nearly irreversibly bound to cardiolipin. Cardiolipin is an essential phospholipid, almost exclusively expressed on the inner mitochondrial membrane. It has been shown that pathological changes in cardiolipin trigger ROS production and impair mitochondrial function.(21) In addition, Doxorubicin also increases mitochondrial iron accumulation which further increases ROS production in the mitochondria. Indeed, cellular and mitochondrial (as measured by cellular $\mathrm{H}_{2} \mathrm{O}_{2}$ production and intra-mitochondrial $\mathrm{O}^{2-}$ levels) ROS production in hPSC-cardiomyocytes increases already 24 hours after exposure to Doxorubicin at concentrations as low as 0.01 $\mu \mathrm{M}$ (patient serum levels of Doxorubicin vary in the range of $5-10 \mu \mathrm{M}$ after single injection). Moreover, short term exposure to $5 \mu \mathrm{M}$ Doxorubicin induces dramatic reduction of the mitochondrial transmembrane potential indicating mitochondrial dysfunction. $(14,22)$ To meet the high energy demand required to sustain contractile function, cardiomyocytes rely on efficient mitochondrial oxidative metabolism for energy production instead of anaerobic glycolysis. Thus, a disturbed energy metabolism is a high risk for cardiomyocyte survival. Repeated Doxorubicin exposure reduces ATP levels which cannot be restored after Doxorubicin removal suggesting a prolonged effect of Doxorubicin on energy generation in hPSC-cardiomyocytes. Together these effects pinpoint to the fact that Doxorubicin induces mitochondrial dysfunction in hPSC-cardiomyocytes.(22, 23) Importantly, structural and functional disturbances are more pronounced

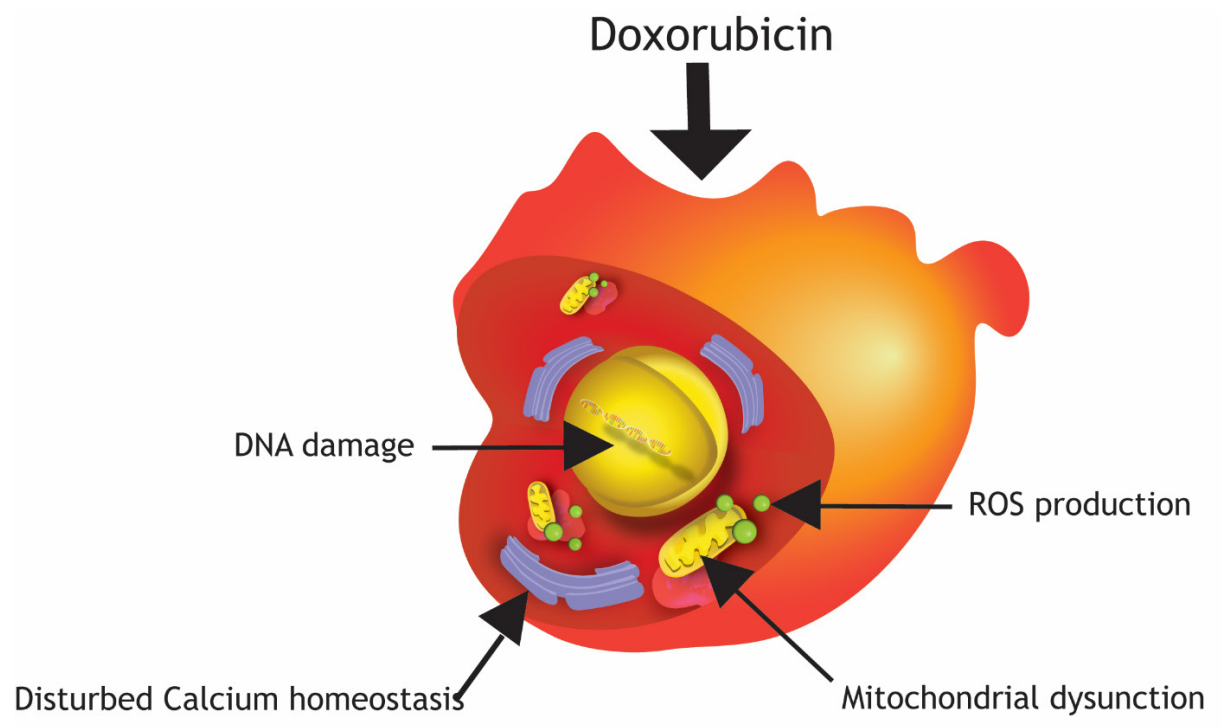

Figure 1: Damage mechanisms of Doxorubicin in hPSC-cardiomyocytes. Major mechanisms of anthracycline-induced cardiotoxicity in hPSC-cardiomyocytes are DNA damage, production of reactive oxygen species (ROS), mitochondrial dysfunction and disturbed calcium homeostasis. 
after repeated dosing of Doxorubicin (mimicking chronic exposure).(23-25)

Another mechanism by which anthracyclines fight cancer is the induction of apoptosis. Doxorubicin effectively induces apoptotic cell death via activation of so-called death receptors (DRs), such as TNF receptor 1 (TNFR1), Fas receptor, DR4 and DR5, in many cancer types. Activation of these DRs induces the assembly of death inducing signaling complex (DISC), which starts the caspase cascade to mediate cleavage of cellular proteins and ultimately apoptosis of the cell. This DR-mediated apoptosis machinery has been shown to be conserved in human cardiomyocytes. Indeed, a Doxorubicin concentration-dependent increase of caspase 3 and 7 and Annexin V, a marker of early apoptosis, and 7-aminoactinomycin $D(7-A A D)$ or propidium iodide as markers of late apoptosis or necrosis, suggest a strong contribution of programmed cell death to reduced cell survival after exposure to Doxorubicin. Interestingly, in hPSC-cardiomyocytes Doxorubicin induces the expression of all four DRs in a dose-dependent fashion with p53 being the key upstream activator. This suggests a p53-regulated DRmediated apoptotic pathway as key mechanisms involved in early Doxorubicininduced cardiotoxicity. In accordance with these findings, Doxorubicin-induced apoptosis was effectively blocked by pretreating hPSC-cardiomyocytes with a DR5 neutralizing antibody. This cardiotoxic effect was reversible since expression of DR4 and 5 proteins decreased after recovery for 7 days after washout of Doxorubicin.(14, 15, 22, 26, 27) In contrast to these studies with acute exposure to Doxorubicin, Li et al. showed that p53 can protect against chronic Doxorubicin exposure by counteracting mitochondrial DNA depletion after chronic exposure of hPSC-cardiomyocytes (and mice) to low doses of Doxorubicin.(28) Disturbed calcium homeostasis in cardiomyocytes hampers proper cardiac contraction. Doxorubicin has been shown to induce accumulation of intracellular calcium release from the sarcoplasmic reticulum (SR) causing calcium overload with sarcomeric disarray and myofibril deterioration in hPSC-cardiomyocytes. Moreover, Doxorubicin exposure led to downregulation of several ion channel genes, including genes that encode for calcium channels CACNs.(14, 22, 26)

In summary this data shows that mitochondrial dysfunction, apoptosis, as well as disturbed calcium homeostasis are the main mechanisms of anthracyclineinduced cardiotoxicity. However, in 2018, a new mechanism of Doxorubicininduced cardiotoxicity via downregulation of the RNA-binding-protein Quaking has been identified.(29) Downregulation of Quaking regulates a set of circular RNAs involved in Doxorubicin-induced apoptosis suggesting that other mechanisms cannot be excluded. 


\section{Protective mechanisms to prevent or reduce anthracycline-induced cardiotoxicity}

To increase the dose window of effective treatment without severe adverse side effects (therapeutic index) of conventional Doxorubicin therapy, several protective mechanisms have been developed, including modifications/analogues of Doxorubicin, targeted delivery or protective agents (Figure 2).

\section{Analogues of Doxorubicin}

The cardiotoxic nature of Doxorubicin pushed the development of Doxorubicin analogues into overdrive in the 1970s and 1980s, with over a 1000 analogues manufactured or discovered since.(30) However, most of them failed to reach anti-tumor efficacy comparable to Doxorubicin and others were considered too toxic based on trials in rodents.(30) Only a handful of analogues reached clinical trial phase, such as epirubicin, pirarubicin (also known as THP), idarubicin, mitoxanthrone, and others.(31-42) The success of these analogues varies per clinical setting and malignancy, and a reduction in cardiotoxicity was not always achieved. In patients, cardiotoxic events are classically detected through loss of the left ventricular ejection fraction (LVEF), irregularities in ECG readings (in particular ST-T changes), changes in systolic time intervals (STI, indicating heart muscle failure) and in more recent work, the release of biomarkers in blood, such as cardiac Troponin-T and brain natriuretic peptide (BNP).(31, 33, 35-38, 41-45) Due to the year of discovery, early Doxorubicin analogues have not been tested in vitro using hPSC-cardiomyocytes to evaluate their cardiotoxicity, since these models were not available at the time. Whereas biomarker release can also be assessed in vitro using hPSC-Cardiomyocytes, other clinical read-outs are more difficult to evaluate in vitro. Nevertheless, measurement of changes in action potential, contractility and cell survival in vitro may be associated with ECG/STI changes and impaired LVEF and therefore it will be of interest to test Doxorubicin analogues in hPSC-Cardiomyocytes for cardiac safety.

\section{Targeted delivery strategies}

An alternative to reducing cardiotoxic properties of anthracyclines is specifically delivering anthracyclines at the location where cancer cells reside. This can be achieved by carriers that encapsulate the compound and release it at the desired location. For example, liposomal encapsulation of anthracycline inhibits transfer from the circulation to tissues with a tight endothelial barrier (e.g. the heart), but allow transfer to tissues with leaky or fenestrated vasculature, such as in tumors, but also in organs such as lung, bone marrow, lymph nodes and liver. $(39,46$, 47) In the last two decades, numerous trials have been conducted to assess the safety and benefit of liposome-encapsulated Doxorubicin. Success of liposomal 
encapsulated anthracyclines is inconsistent. Liposomal encapsulation could abolish cardiotoxicity in some clinical trials, allowing a higher cumulative dose for treatment.(39, 48-50) However, in some clinical settings, liposomal Doxorubicin did not reduce cardiotoxicity compared to free anthracyclines(51), suggesting that liposomal encapsulation only has limited benefit. Unmasked liposomes such as described thus far are relatively quickly cleared from the circulation by the reticulo-endothelial system (RES), which limits the therapeutic index of NPLDoxorubicin.(39)

PEGylated liposomal Doxorubicin (PLD) features an anchored polyethylene glycol (PEG) group on the exterior lipid surface that masks them from the RES, thus reducing uptake from the circulation.(52) Caelyx (Doxil), a commercialized PLD, showed significant reduction in cardiotoxicity compared to free Doxorubicin in several studies, even when used for patients who have increased risk of cardiac complications.(53-55) Unfortunately, PLDs are limited in their use because of increased incidence and severity of non-cardiac side effects such as palmar-plantar erythrodysesthesia (PPE), mucositis and haematogenic disorders. $(54,56)$ Liposomes (PEGylated or not) cannot prevent severe adverse effects of Doxorubicin entering off-target tissues. The mechanism of specific delivery of classical liposomes depends greatly on the difference in endothelial barrier permeability, which is equally high in tumors and several healthy tissues alike, and not all malignancies cohere to the "tumor with a leaky vasculature" phenotype. In an attempt to increase specific targeting of cancer cells, liposomes were conjugated with antibodies that are directed against the human epidermal growth factor receptor 2 (HER2), which is highly expressed in breast cancer cells. In vitro, these liposomes were effective in killing HER2-positive cancer cells, but did not affect hPSC-cardiomyocytes, highlighting their specificity.(47) The HERMIONE phase II trial is now being conducted to test the safety and efficacy in patients.(57) Another recent development is the encapsulation of anthracyclines in nanocages, constructed of organic (virus-like particles (VLPs), protein, DNA or carbon-based particles) or inorganic particles (supramolecular nanosystems, hybrid metal-organic, gold, or silica-based systems). Advantages of this encapsulation method are: 1) a large carrier storage capacity, 2) a targeted release of the drug at the site of interest, 3) combined with a porous structure and 4) a low immunogenic surface.(58) Nanocages have not been tested in clinical trials yet, however in vitro data suggests improved drug targeting of cancer cells and killing efficacy, and a lower cardiotoxicity, when administered in rodents. (59-63) Unfortunately, nanocages have not been specifically tested in vitro on hPSC-cardiomyocytes to test their cardiotoxicity.

In addition to Doxorubicin encapsulation, latest modifications to Doxorubicin 
are being tested on cell cultures prior to animal testing to assess their safety for the heart, using currently available hPSC-cardiomyocyte in vitro models. These modifications of Doxorubicin are aimed at preventing the anthracycline from exerting its toxicity on cardiomyocytes by making the drug delivery more specific. For example, DTS-201, a Doxorubicin prodrug that is injected in a stable, cell-impermeable state, is cleaved by endopeptidases that are released by tumors, enabling entry into nearby cells and specific anti-tumor activity. In a phase I trial, DTS-201 could be administered at a cumulative dose equivalent to three times the recommended dose of free Doxorubicin, without triggering a significant drop in LVEF.(64) Another promising technique is the development of Doxorubicin-dendrimer conjugates with acetylgalactosamine attached to the dendrimer surface. These conjugates are specifically taken up by hepatic cancer cells, increasing therapeutic index and reducing cardiac exposure and thus toxicity in mice. In addition, in vitro, these conjugates did not affect hPSC-cardiomyocytes viability and electrophysiology, or induce apoptosis, demonstrating the specificity for drug uptake by the target cell type.(65)

\section{Protective agents to alleviate cardiotoxicity}

Cardioprotection during anthracycline-based therapies can also be offered by combining the anthracycline with a protective compound. As the cardiotoxic mechanism of anthracyclines involves inducing oxidative stress and mitochondrial dysfunction, protective agents that are able to lower the production of ROS or lower the workload of the heart during anthracycline treatment may be beneficial to reduce anthracycline-induced cardiotoxicity. Factors that may reduce oxidative stress in the heart, such as statins and natural antioxidants, and compounds that reduce the workload of the heart, such as angiotensinconverting-enzyme (ACE) inhibitors and beta-blockers, have been combined with anthracyclines in clinical trials, with mixed success.(66-77) As far as known, these compounds have never been tested in hPSC-Cardiomyocytes for assessment of their direct cardioprotective potential, even though reducing oxidative stress in particular can be readily modelled in vitro. Since both ischemic heart disease and anthracycline-mediated cardiotoxicity share common pathological pathways, therapies for one disease could also be beneficial for the other. Trials with more original approaches, such as remote ischemic conditioning or physical exercise and caloric restriction, strategies that were beneficial in the setting of ischemic heart disease, have been started with the purpose to reduce cardiotoxicity caused by chemotherapy. $(78,79)$ Results of these trials are not yet available.

In hPSC-cardiomyocytes it has been shown that Doxorubicin causes arrhythmic contractions by inducing the accumulation of calcium in the cell and thereby disturbing calcium homeostasis. $(14,22)$ This would suggest that calcium antagonists can help to reduce Doxorubicin-induced cardiotoxicity. Interestingly, 
a calcium antagonistic compound called prenylamine, was able to reduce cardiotoxic effects when co-administered with Doxorubicin, before it was withdrawn from the market one year later.(80) Reason for withdrawal was the pro-arrhythmic properties of prenylamine, inducing long QT syndrome.(81) Other calcium agonists are currently primarily used at lower doses to reduce Doxorubicin resistance of cancer cells, by inhibiting their capacity to pump out drugs via the P-glycoprotein ATP-dependent efflux pumps.(82) Low doses of these calcium antagonists could be repurposed to reduce Doxorubicin-induced cardiotoxicity.

Neuregulin-1 $\beta$, an ErbB receptor (HER2) family ligand, has been proven effective against Doxorubicin-induced cardiotoxicity, but is also pro-neoplastic in many cancers via formation of ErbB2/3 interactions.(83-86) Even if neuregulin, as key mediator of endothelial-cardiomyocyte crosstalk, is able to protect ventricular

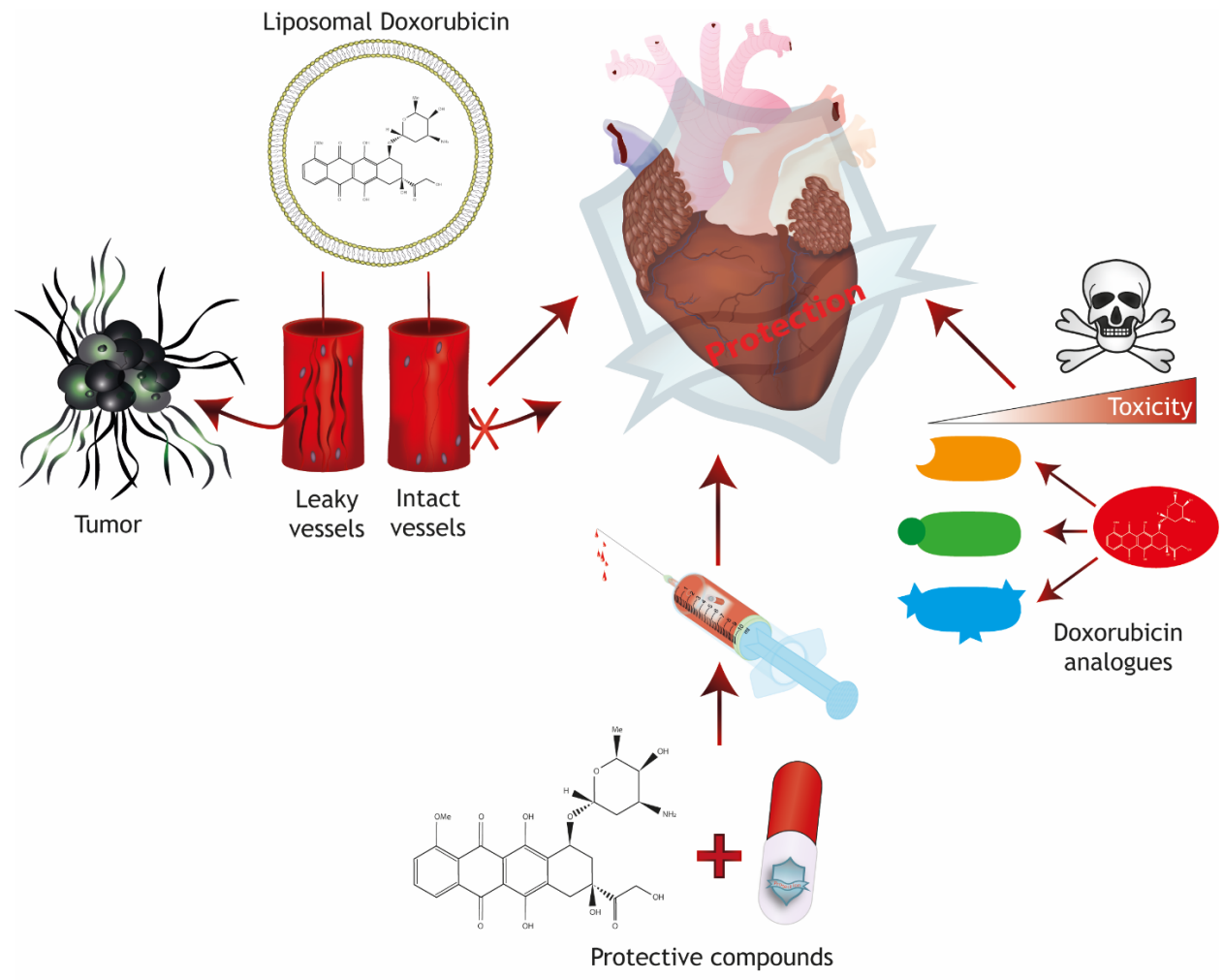

Figure 2: Strategies for cardioprotection. Protective mechanisms for anthracycline-induced cardiotoxicity include the generation of Doxorubicin analogues with reduced toxicity, the combined treatment with protective compounds and targeted therapy approaches including liposomal packaging of Doxorubicin. Liposomal packaging prevents Doxorubicin from exiting the vasculature in tissues with tight endothelial barriers such as the heart but allows targeting of a tumor with leaky capillaries. 
cardiomyocytes from anthracycline-induced apoptosis, its use might thus be controversial in the clinic. Nevertheless, phase I, II and III clinical trials have been completed or are ongoing (NCT01251406, NCT1214096, and NCT01541202).(8486) Patients with symptomatic heart failure (HF) and left ventricular dysfunction showed improved cardiac function with increased LVEF after treatment with recombinant human neuregulin 1 . In contrast to native neuregulin-1 $\beta$, engineered bivalent neuregulin- $1 \beta$ has reduced pro-neoplastic potential because of a shift towards ErbB3 homotypic interactions. Bivalent neuregulin-1 $\beta$ is anti-neoplastic or cytostatic in cancer cells. Importantly, bivalent neuregulin- $1 \beta$ showed similar cardioprotective properties as neuregulin in hPSC-cardiomyocytes and in mice with chronic cardiomyopathy.(87) Especially the reduced pro-neoplastic potential of bivalent neuregulin- $1 \beta$ offers translational potential for cardioprotection after anthracycline therapy, however to date, no bivalent neuregulin- $1 \beta$ has not been taken into clinical trial.

Dexrazoxane, a catalytic topoisomerase inhibitor and iron chelator, is the only marketed cardioprotective agent that is used specifically to counteract the adverse effects of anthracyclines.(88) In children with acute lymphoblastic leukemia, leukemia or lymphoma, the combined treatment with Doxorubicin and Dexrazoxane significantly reduces release of troponin (as biomarker of cardiotoxicity) and Doxorubicin-induced cardiac remodeling. Importantly, the combination with Dexrazoxane improves left ventricular function compared to Doxorubicin alone. $(89,90)$ Dexrazoxane is also effective in relapsed patients with leukemia when administered prior or after a high cumulative dose.(91) In breast cancer patients with increased risk of cardiotoxicity because of an enhanced cumulative dose of anthracycline, Dexrazoxane also robustly reduced the incidence of cardiac events, such as decreased ejection fraction, and incidence and severity of CHF. $(92,93)$ Even in a retrospective 2-20 year follow-up, Dexrazoxane demonstrated late-clinical and subclinical cardioprotective effect.(94) Treatment of cardiomyocytes with Dexrazoxane is therefore expected to prevent cardiotoxicity. However, pre- and co-treatment of hPSC-cardiomyocytes with Dexrazoxane could not alleviate Doxorubicin-induced cardiotoxicity and increased cardiotoxicity at concentrations as low as $0.1 \mu \mathrm{M} .(22,95)$ This discrepancy between in vivo and in vitro may be related to the relative immature character of hPSC-Cardiomyocytes. Early stage hPSC-Cardiomyocytes may be more sensitive to Doxorubicin because of higher expression levels topoisomerase Il $\alpha$ and are thus more prone to severe DNA damage (as mentioned earlier: Doxorubicin primarily affects topoisomerase $\| \alpha$ ), whereas in mature cardiomyocytes topoisomerase Il $\alpha$ switches to the $\| \beta$ isoform. Importantly, Dexrazoxane might exert its protective effects via depletion of topoisomerase $\| \beta$, the major topoisomerase isoform in more mature cardiomyocytes. $(95,96)$ This suggests that more advanced models are needed to assess cardiotoxicity in vitro. 


\section{HPSC-cardiomyocyte models in drug screening of tyrosine kinase inhibitors (TKis)}

Not only anthracyclines, but also safety assessment of other classes of anti-cancer drugs may benefit from hPSC-based in vitro models. For example, malignancies caused by hyperactive receptor tyrosine kinases (RTKs), which drive proliferation and survival, are treated with FDA-approved tyrosine-kinase inhibitors (TKis). However, a number of TKis have been associated with adverse cardiac side effects following treatment of cancer patients, such as reduced LVEF, myocardial infarction, arrhythmias and heart failure.(97) While animal models have often failed to predict cardiotoxic effects during safety assessment(98), TKis have shown to inhibit viability, contractility, electrophysiology, calcium handling and cardiac oxidative phosphorylation of hPSC-cardiomyocytes.(99-101) Different TKis show cell type specific cytotoxicity, either in hPSC-derived cardiomyocytes, endothelial cells and fibroblasts or hPSCs, suggesting that TKis differently affect cardiovascular and non-cardiovascular cell types.(99)

TKis can be subdivided into small molecules, including crizotinib, sunitinib or sorafenib, and monoclonal antibodies. Importantly, different TKis have distinct toxicity profiles and not all TKIs induce cardiotoxicity.(97) The broad-range TKi sunitinib, for example, decreased hPSC-cardiomyocyte viability, as well as AMPactivated protein kinase (AMPK), increased lipid accumulation and induced arrhythmic events in sunitinib-treated hPSC-cardiomyocytes. Crizotinib, an ALK/MET inhibitor, increased ROS production and caspase activation, induced cholesterol accumulation and an irregular beat pattern. Similarly, Nilotinib, a second generation Bcr-Abl inhibitor, increased ROS generation and caspase activation and induced arrhythmic beating. Interestingly, compared to the TKis sunitinib, crizotinib and nilotinib, the relatively cardiac-safe TKi erlotinib only displayed minor effects on hPSC-cardiomyocyte health in the same study(98) which suggests that hPSC-cardiomyocytes may represent a reliable in vitro model for predicting cardiotoxic side effects.

RTK activity may also be reduced by blocking the human epidermal growth factor receptor 2 (HER2), which activation is a common feature of a subset of malignant diseases, particularly breast cancer.(102) While trastuzumab (TZM), a TKi monoclonal antibody blocking HER2, greatly improves treatment against HER2 positive malignancies, inhibition of HER2 signaling was found to be detrimental for cardiac function.(102-104) In a subset of breast cancer patients, treatment with TZM led to mild to severe decrease in LVEF without apparent myocardial tissue damage or cell loss. Using patient-derived hPSC-cardiomyocyte 2D monolayer cultures it was shown that TZM affected metabolic and mitochondrial processes, of which the severity depended on genetic variation. Moreover, this disease phenotype could be rescued using metabolism-stimulating agents, such 
as AMPK.(102) Additionally, HER2 activation triggered by exogenous neuregulin-1 could reduce hPSC-CM damage and cell loss during Doxorubicin exposure, an effect that was lost upon inhibition of the HER2 receptor by TZM. $(103,104)$ These findings indicate that hPSC-cardiomyocyte $2 \mathrm{D}$ models may serve as a valuable tool to identify cardioprotective compounds in a high throughput system, which can be further validated in more advanced human-based 3D cardiac models.

\section{Generation of advanced hPSC-derived in vitro models for accurate assessment of cardiac safety.}

Although cardiotoxic effects could be observed in hPSC-cardiomyocyte based models, not all aspects of in vivo cardiotoxicity are recapitulated in current human in vitro models. One of the important shortcomings of hPSC-cardiomyocyte models is their relative immature phenotype. Reviews on the topic of the immaturity of hPSC-cardiomyocytes, including strategies to increase the level of maturity have already been described elsewhere.(105-107) Figure 3 shows a description of current in vitro models utilizing hPSC-cardiomyocytes, including their advantages and limitations. It is therefore crucial to develop innovative advanced human models that approximate the adult human heart. In order to achieve this, defined multicellular models, consisting of the main cell-types of the heart, such as atrial or ventricular cardiomyocytes, endothelial cells, smooth muscle cells and fibroblasts, need to be constructed.

Cardiac tissue formation in 3D tissues, such as cardiac microtissues, more closely mimics native heart tissue which might allow studying more physiologically relevant dosing profiles and deciphering acute versus chronic cardiotoxicity. (25) For generating other 3D advanced cardiac models, so-called engineered heart tissues (EHTs), hPSC-cardiomyocytes are mixed with fibroblasts (or other cardiac cells) in a hydrogel and poured into a casting mold around silicon posts, leading to beating structures within the first week under continuous mechanical strain. Previously, it has been shown that 3D EHTs display a higher degree of maturation based on sarcomeric organization, formation of T-tubules and functional characterization (e.g. contraction force, electrophysiology).(108-110) Cardiotoxicity of anti-cancer agents, other than anthracyclines, such as the TKi sunitinib, has already been assessed in EHTs, which resulted in triggered activation of apoptosis and loss of contractile force, spontaneous beating and mitochondrial membrane potential.(111)

Until now studies did not consider subtype-specific cardiomyocytes for cardiotoxicity testing. This would be of high importance, as different cardiac subtypes may exhibit different susceptibility to Doxorubicin. Especially, because of the well-established arrhythmogenic potential of Doxorubicin $(31,112,113)$, it is highly relevant to assess arrhythmogenic effects of Doxorubicin on hPSC-derived 
atrial and ventricular cardiomyocytes. Moreover, in a trial comparing Doxorubicin to Epirubicin in treatment of breast cancer, a quarter of all cardiac side effects of Doxorubicin was identified as sinus tachycardia, for Epirubicin this was half of the cardiotoxic responses in the trial population.(31) In addition, a recent study showed that genetic loci are associated with both increased sensitivity to Doxorubicin-induced hPSC-pacemaker cell death and a higher risk of arrhythmia in patients(114), which justifies to perform cardiotoxicity testing on pacemaker cells. Previously, we and others have shown efficient production of atrial, ventricular and pacemaker Cardiomyocytes from hPSCs.(115-118)

In the cardiac microenvironment in vivo, each cardiomyocyte is surrounded by 3-4 capillaries with a distance between each cardiomyocyte and an endothelial cell of about $1 \mu \mathrm{m}$.(119) This delicate build-up allows for defined cardiomyocyteendothelium crosstalk via paracrine signaling and cell-cell contact.(119-122) This data suggests that the crosstalk of human cardiomyocytes with highly metabolic active cardiac endothelial cells is very important. Recent advances in microengineering and stem cell technologies enabled development of microfluidic devices in which living cells (mostly several cell-types) are cultured in channels or small compartments and perfused in a controlled manner, mimicking the microenvironment and responses of tissues or organs.(123-125) These so-called organ-on-chips can be combined with integrated sensors (for example for biochemical and electrical readouts) and are compatible with live imaging (for example using stem cell-based fluorescent reporter lines)(126) and human cell and tissue sampling. Very recently, Weng and colleagues(127) generated a multiple chambered tissue chip, a so-called organ-on-a-chip, which allowed simultaneous culturing of tumor tissue and hPSC-cardiomyocytes while being connected via a microfluidic channel, lined with endothelial cells. This design enables simultaneous testing of potential anti-tumor effects and cardiotoxicity of drugs administered via the endothelial layer. Another important aspect of drug efficacy and safety assessment is to predict pharmacokinetic parameters, determined by absorption, distribution, metabolism and excretion (ADME) of drugs, which are difficult to measure or model in vitro. As mentioned before, organ-on-chips mimic organlike function and responses in perfusable mircophysiological systems and may offer an opportunity to overcome current limitations related to pharmacokinetic modelling. Multiple organ-on-chip devices with organ-level functionality could be connected to each other with vascularized, endothelium-lined channels mimicking blood circulation and recapitulating tissue-tissue interfaces, thus modelling organ crosstalk and metabolism of compounds in a single system.(128, 129) For predictive physiologically based pharmacokinetic (PBPK) modelling, it is of paramount importance to combine defined hPSC culture methods and 3D tissue engineering or organoid formation with technical advances in the field of organ-on-chip technology, ultimately leading to interconnected multiple human 
organ-on-chip platforms (for example, combining heart-, liver- and gut-on-chip models).

\section{Future outlook:}

Because of the previously mentioned shortcomings, a full recapitulation of clinical cardiotoxic manifestations is beyond the capacity of current in vitro models. Interestingly, recent developments have shown that it is feasible to build human in vitro models that are more closely resembling functional human hearts for assessment of clinically relevant parameters, which may greatly enhance the predictivity of these in vitro models for safety pharmacology and disease phenotypes. Recently, $\mathrm{Li}$ et al. created for the first time a human ventricularlike cardiac organoid chamber (hvCOC) with hPSC-cardiomyocytes and dermal fibroblasts.(130) Similarly, Macqueen and colleagues generated a one cell layer thick ventricular-like tube from hPSC-cardiomyocytes.(131) Both HvCOCs and ventricular tubes were able to pump fluid, which allowed measuring ejection fraction and pressure-volume loops as readouts for cardiac function. Although these developments are promising, combination with other cardiac cells, such as endothelial and smooth muscle cells and fibroblasts, may lead to further maturation and improvement of function. Future studies will be required in order to evaluate the predictive values of these human advanced 3D cardiac models in preclinical drug testing and their potential to reduce time for bringing new drugs from bench-to-bedside and repurposing of drugs.

Moreover, state-of-the-art multiple organ-on-chip platforms will also advance predictivity of efficacy and toxicity of combinatorial drug (cardioprotective) treatment and specific target delivery.

It is evident that interpatient variability further complicates development of predictive in vitro models for drug screening. This is also true for anthracyclineinduced cardiotoxicity, which varies tremendously from patient to patient. These variations may be caused due to environmental factors, lifestyle or genetic variance. Patient-derived (or genetically modified) hPSCs provide the possibility to include disease-associated genetic risk factors in these in vitro models, which can be directly compared to isogenic control hPSC lines. Interestingly, studies with hPSC-cardiomyocytes have shown that cardiotoxic effects of Doxorubicin were dependent on the genetic background of patient-derived hPSC-cardiomyocytes. (22) Similarly, characterization of hPSC-cardiomyocytes from 45 individuals showed inter-individual variation in transcriptional response after 24 hour exposure to different concentrations of Doxorubicin, which were predictive of in vitro cell damage as measured by cardiac troponin release of cardiomyocytes. (132) These findings highlight the importance of personalized medicine and risk stratification, which will allow us to predict for which patients new therapies will 


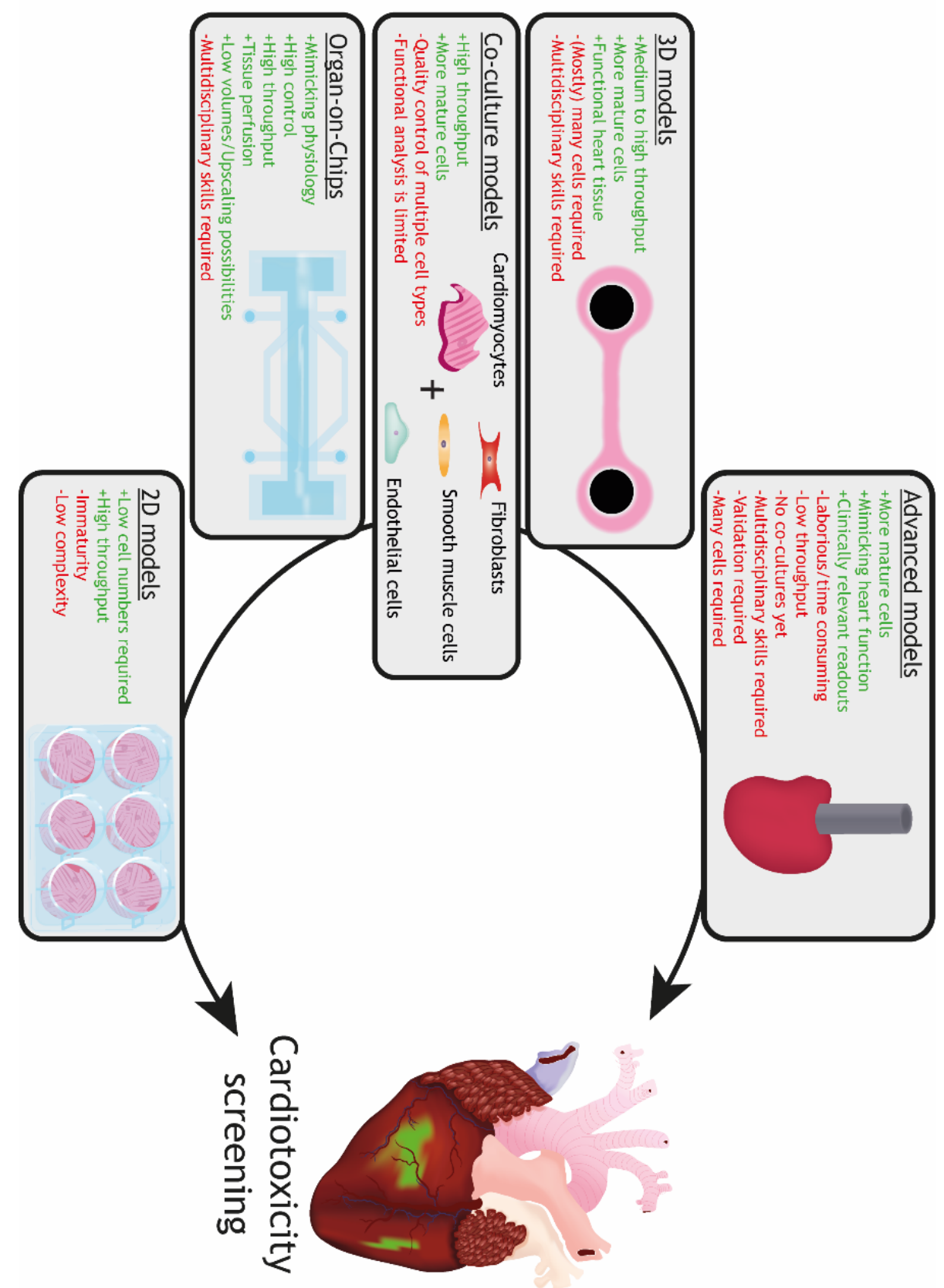


Figure 3 (previous page): Current in vitro models with hPSC-cardiomyocytes and their advantages (+ green) and limitations (- red). Models with increasing complexity (from 2D monolayers to $3 D$ advanced models) are available for assessment of drug-induced cardiotoxicity utilizing hPSCcardiomyocytes. Whereas 2D monolayer cardiomyocyte cultures can be used for high troughputscreening for specific cellular responses, they lack the physiology, multicellular interactions and tissue organization, which can be provided by organ-on-chip, co-culture or 3D tissue models (for instance engineered heart tissues). Advanced cardiac models, such as an engineered mini heart tube with the capacity to pump fluid, mimic clinically relevant function(s) of the heart.

be effective and safe and for which not. This will reduce the attrition rate, costs and time of drug development and facilitate repurposing of drugs that have shown a lack of efficacy or risk of toxicity. Consequently, successful implementation of these advanced human stem cell-based models will lead to better and safer drugs. 


\section{References}

1. Simunek T, Sterba M, Popelova O, Adamcova M, Hrdina R, Gersl V. Anthracycline-induced cardiotoxicity: overview of studies examining the roles of oxidative stress and free cellular iron. Pharmacol Rep. 2009;61(1):154-71.

2. Albini A, Pennesi G, Donatelli F, Cammarota R, De Flora S, Noonan DM. Cardiotoxicity of anticancer drugs: the need for cardio-oncology and cardiooncological prevention. J Natl Cancer Inst. 2010;102(1):14-25.

3. Chatterjee K, Zhang J, Honbo N, Karliner JS. Doxorubicin cardiomyopathy. Cardiology. 2010;115(2):155-62.

4. Sterba M, Popelova O, Vavrova A, Jirkovsky E, Kovarikova P, Gersl V, et al. Oxidative stress, redox signaling, and metal chelation in anthracycline cardiotoxicity and pharmacological cardioprotection. Antioxid Redox Signal. 2013;18(8):899-929.

5. Franco $\mathrm{VI}$, Lipshultz SE. Cardiac complications in childhood cancer survivors treated with anthracyclines. Cardiol Young. 2015;25 Suppl 2:107-16.

6. Kankeu C, Clarke K, Passante E, Huber HJ. Doxorubicin-induced chronic dilated cardiomyopathy-the apoptosis hypothesis revisited. J Mol Med (Berl). 2017;95(3):239-48.

7. Dong J, Chen H. Cardiotoxicity of Anticancer Therapeutics. Front Cardiovasc Med. 2018;5:9.

8. Volkova $M$, Russell $R$, 3rd. Anthracycline cardiotoxicity: prevalence, pathogenesis and treatment. Curr Cardiol Rev. 2011;7(4):214-20.

9. Lefrak EA, Pitha J, Rosenheim S, Gottlieb JA. A clinicopathologic analysis of adriamycin cardiotoxicity. Cancer. 1973;32(2):302-14.

10. Rinehart JJ, Lewis RP, Balcerzak SP. Adriamycin cardiotoxicity in man. Ann Intern Med. 1974;81(4):475-8.

11. Moreno L, Pearson AD. How can attrition rates be reduced in cancer drug discovery? Expert Opin Drug Discov. 2013;8(4):363-8.

12. Devalla HD, Passier R. Cardiac differentiation of pluripotent stem cells and implications for modeling the heart in health and disease. Sci Transl Med. 2018;10(435).

13. Colatsky T, Fermini B, Gintant G, Pierson JB, Sager P, Sekino $Y$, et al. 
The Comprehensive in Vitro Proarrhythmia Assay (CiPA) initiative - Update on progress. J Pharmacol Toxicol Methods. 2016;81:15-20.

14. Maillet A, Tan K, Chai X, Sadananda SN, Mehta A, Ooi J, et al. Modeling Doxorubicin-Induced Cardiotoxicity in Human Pluripotent Stem Cell DerivedCardiomyocytes. Sci Rep. 2016;6:25333.

15. Zhao L, Zhang B. Doxorubicin induces cardiotoxicity through upregulation of death receptors mediated apoptosis in cardiomyocytes. Sci Rep. 2017;7:44735.

16. Nebigil CG, Desaubry L. Updates in Anthracycline-Mediated Cardiotoxicity. Front Pharmacol. 2018;9:1262.

17. Arena E, D'Alessandro N, Dusonchet L, Geraci M, Rausa L, Sanguedolce R. Repair kinetics of DNA, RNA and proteins in the tissues of mice treated with doxorubicin. Arzneimittelforschung. 1979;29(6):901-2.

18. Abou El Hassan MA, Verheul HM, Jorna AS, Schalkwijk C, van Bezu J, van der Vijgh WJ, et al. The new cardioprotector Monohydroxyethylrutoside protects against doxorubicin-induced inflammatory effects in vitro. $\mathrm{Br} \mathrm{J}$ Cancer. 2003;89(2):357-62.

19. Zhang S, Liu X, Bawa-Khalfe T, Lu LS, Lyu YL, Liu LF, et al. Identification of the molecular basis of doxorubicin-induced cardiotoxicity. Nat Med. 2012;18(11):1639-42.

20. Cappetta D, De Angelis A, Sapio L, Prezioso L, Illiano M, Quaini F, et al. Oxidative Stress and Cellular Response to Doxorubicin: A Common Factor in the Complex Milieu of Anthracycline Cardiotoxicity. Oxid Med Cell Longev. 2017;2017:1521020.

21. Dudek J. Role of Cardiolipin in Mitochondrial Signaling Pathways. Front Cell Dev Biol. 2017;5:90.

22. Burridge PW, Li YF, Matsa E, Wu H, Ong SG, Sharma A, et al. Human induced pluripotent stem cell-derived cardiomyocytes recapitulate the predilection of breast cancer patients to doxorubicin-induced cardiotoxicity. Nat Med. 2016;22(5):547-56.

23. Chaudhari U, Ellis JK, Wagh V, Nemade H, Hescheler J, Keun HC, et al. Metabolite signatures of doxorubicin induced toxicity in human induced pluripotent stem cell-derived cardiomyocytes. Amino Acids. 2017;49(12):195563.

24. Louisse J, Wust RCl, Pistollato F, Palosaari T, Barilari M, Macko P, et al. Assessment of acute and chronic toxicity of doxorubicin in human induced 
pluripotent stem cell-derived cardiomyocytes. Toxicol In Vitro. 2017;42:182-90.

25. Verheijen M, Schrooders Y, Gmuender H, Nudischer R, Clayton O, Hynes $\mathrm{J}$, et al. Bringing in vitro analysis closer to in vivo: Studying doxorubicin toxicity and associated mechanisms in 3D human microtissues with PBPK-based dose modelling. Toxicol Lett. 2018;294:184-92.

26. Holmgren G, Sartipy P, Andersson CX, Lindahl A, Synnergren J. Expression Profiling of Human Pluripotent Stem Cell-Derived Cardiomyocytes Exposed to Doxorubicin-Integration and Visualization of Multi-Omics Data. Toxicol Sci. 2018;163(1):182-95.

27. McSweeney KM, Bozza WP, Alterovitz WL, Zhang B. Transcriptomic profiling reveals $\mathrm{p} 53$ as a key regulator of doxorubicin-induced cardiotoxicity. Cell Death Discov. 2019;5:102.

28. Li J, Wang PY, Long NA, Zhuang J, Springer DA, Zou J, et al. p53 prevents doxorubicin cardiotoxicity independently of its prototypical tumor suppressor activities. Proc Natl Acad Sci U S A. 2019;116(39):19626-34.

29. Gupta SK, Garg A, Bar C, Chatterjee S, Foinquinos A, Milting H, et al. Quaking Inhibits Doxorubicin-Mediated Cardiotoxicity Through Regulation of Cardiac Circular RNA Expression. Circ Res. 2018;122(2):246-54.

30. Weiss RB, Sarosy G, Clagett-Carr K, Russo M, Leyland-Jones B. Anthracycline analogs: the past, present, and future. Cancer Chemother Pharmacol. 1986;18(3):185-97.

31. Ambrosini G, Balli M, Garusi G, Demicheli R, Jirillo A, Bonciarelli G, et al. Phase III randomized study of fluorouracil, epirubicin, and cyclophosphamide $v$ fluorouracil, doxorubicin, and cyclophosphamide in advanced breast cancer: an Italian multicentre trial. J Clin Oncol. 1988;6(6):976-82.

32. Dittrich C, Baur M, Mader R, Schlappack O, Dudczak R, Leitha T, et al. Phase I-II study on weekly administration of pirarubicin in patients with metastatic breast cancer. Am J Clin Oncol. 1990;13 Suppl 1:S29-39.

33. Drings P, Gunther IU, Gatzemeier U, Berdel W, Stahl M, Salewski E, et al. Pirarubicin in advanced non-small cell lung cancer. A trial of the Phase I/II Study Group of the Association for Medical Oncology of the German Cancer Society. Onkologie. 1990;13(3):180-4.

34. Dhingra K, Frye D, Newman RA, Walters R, Theriault R, Fraschini G, et al. Phase II clinical and pharmacological study of pirarubicin in combination with 5-fluorouracil and cyclophosphamide in metastatic breast cancer. Clin Cancer 
Res. 1995;1(7):691-7.

35. Zinzani PL, Martelli M, Storti S, Musso M, Cantonetti M, Leone G, et al. Phase III comparative trial using CHOP vs CIOP in the treatment of advanced intermediate-grade non-Hodgkin's lymphoma. Leuk Lymphoma. 1995;19(34):329-35.

36. Llombart-Cussac A, Pivot X, Rhor-Alvarado A, Le Cesne A, Le Chevalier $\mathrm{T}$, Tursz $\mathrm{T}$, et al. First-line vinorelbine-mitoxantrone combination in metastatic breast cancer patients relapsing after an adjuvant anthracycline regimen: results of a phase II study. Oncology. 1998;55(5):384-90.

37. Nielsen OS, Dombernowsky P, Mouridsen H, Crowther D, Verweij J, Buesa $\mathrm{J}$, et al. High-dose epirubicin is not an alternative to standard-dose doxorubicin in the treatment of advanced soft tissue sarcomas. A study of the EORTC soft tissue and bone sarcoma group. Br J Cancer. 1998;78(12):1634-9.

38. Srokowski TP, Liebmann JE, Modiano MR, Cohen GI, Pro B, Romaguera JE, et al. Pixantrone dimaleate in combination with fludarabine, dexamethasone, and rituximab in patients with relapsed or refractory indolent non-Hodgkin lymphoma: phase 1 study with a dose-expansion cohort. Cancer. 2011;117(22):5067-73.

39. Rivankar S. An overview of doxorubicin formulations in cancer therapy. J Cancer Res Ther. 2014;10(4):853-8.

40. Xue K, Gu JJ, Zhang Q, Liu X, Wang J, Li XQ, et al. Cardiotoxicity as indicated by LVEF and troponin T sensitivity following two anthracycline-based regimens in lymphoma: Results from a randomized prospective clinical trial. Oncotarget. 2016;7(22):32519-31.

41. Hara T, Yoshikawa T, Goto H, Sawada M, Yamada T, Fukuno K, et al. R-THPCOP versus R-CHOP in patients younger than 70 years with untreated diffuse large B cell lymphoma: A randomized, open-label, noninferiority phase 3 trial. Hematol Oncol. 2018;36(4):638-44.

42. Xu PP, Fu D, Li JY, Hu JD, Wang X, Zhou JF, et al. Anthracycline dose optimisation in patients with diffuse large B-cell lymphoma: a multicentre, phase 3, randomised, controlled trial. Lancet Haematol. 2019;6(6):e328-e37.

43. Kang YK, Ryoo BY, Kim TY, Im YH, Kim BS, Park YH, et al. A phase II trial of DA-125, a novel anthracycline, in advanced non-small-cell lung cancer. Cancer Chemother Pharmacol. 1999;44(6):518-21.

44. Obasaju C, Manola J, Hudes GR, Khandekar JD, Citrin DL, Carbone P, et al. Phase II evaluation of menogaril in advanced prostate cancer: Eastern 
Cooperative Oncology Group EST P-A885. Am J Clin Oncol. 2001;24(2):150-4.

45. Hofheinz RD, Porta C, Hartung G, Santoro A, Hanauske AR, Kutz K, et al. BBR 3438, a novel 9-aza-anthrapyrazole, in patients with advanced gastric cancer: a phase II study group trial of the Central European Society of Anticancer-Drug Research (CESAR). Invest New Drugs. 2005;23(4):363-8.

46. Tardi PG, Boman NL, Cullis PR. Liposomal doxorubicin. J Drug Target. 1996;4(3):129-40.

47. Reynolds JG, Geretti E, Hendriks BS, Lee H, Leonard SC, Klinz SG, et al. HER2-targeted liposomal doxorubicin displays enhanced anti-tumorigenic effects without associated cardiotoxicity. Toxicol Appl Pharmacol. 2012;262(1):1-10.

48. Giotta F, Lorusso V, Maiello E, Filippelli G, Valerio MR, Caruso M, et al. Liposomal-encapsulated doxorubicin plus cyclophosphamide as first-line therapy in metastatic breast cancer: a phase II multicentric study. Ann Oncol. 2007;18 Suppl 6:vi66-9.

49. Xing M, Yan F, Yu S, Shen P. Efficacy and Cardiotoxicity of Liposomal Doxorubicin-Based Chemotherapy in Advanced Breast Cancer: A Meta-Analysis of Ten Randomized Controlled Trials. PLoS One. 2015;10(7):e0133569.

50. Fridrik MA, Jaeger U, Petzer A, Willenbacher W, Keil F, Lang A, et al. Cardiotoxicity with rituximab, cyclophosphamide, non-pegylated liposomal doxorubicin, vincristine and prednisolone compared to rituximab, cyclophosphamide, doxorubicin, vincristine, and prednisolone in frontline treatment of patients with diffuse large B-cell lymphoma: A randomised phase-III study from the Austrian Cancer Drug Therapy Working Group [Arbeitsgemeinschaft Medikamentose Tumortherapie AGMT](NHL-14). Eur J Cancer. 2016;58:112-21.

51. Chan S, Davidson N, Juozaityte E, Erdkamp F, Pluzanska A, Azarnia N, et al. Phase III trial of liposomal doxorubicin and cyclophosphamide compared with epirubicin and cyclophosphamide as first-line therapy for metastatic breast cancer. Ann Oncol. 2004;15(10):1527-34.

52. Gabizon A, Shmeeda H, Barenholz Y. Pharmacokinetics of pegylated liposomal Doxorubicin: review of animal and human studies. Clin Pharmacokinet. 2003;42(5):419-36.

53. Lyass $\mathrm{O}$, Uziely B, Ben-Yosef R, Tzemach D, Heshing NI, Lotem M, et al. Correlation of toxicity with pharmacokinetics of pegylated liposomal doxorubicin (Doxil) in metastatic breast carcinoma. Cancer. 2000;89(5):1037-47.

54. O'Brien ME, Wigler N, Inbar M, Rosso R, Grischke E, Santoro A, et al. 
Reduced cardiotoxicity and comparable efficacy in a phase III trial of pegylated liposomal doxorubicin $\mathrm{HCl}$ (CAELYX/Doxil) versus conventional doxorubicin for first-line treatment of metastatic breast cancer. Ann Oncol. 2004;15(3):440-9.

55. Gil-Gil MJ, Bellet M, Morales S, Ojeda B, Manso L, Mesia C, et al. Pegylated liposomal doxorubicin plus cyclophosphamide followed by paclitaxel as primary chemotherapy in elderly or cardiotoxicity-prone patients with highrisk breast cancer: results of the phase II CAPRICE study. Breast Cancer Res Treat. 2015;151(3):597-606.

56. Ansari L, Shiehzadeh F, Taherzadeh Z, Nikoofal-Sahlabadi S, MomtaziBorojeni AA, Sahebkar A, et al. The most prevalent side effects of pegylated liposomal doxorubicin monotherapy in women with metastatic breast cancer: a systematic review of clinical trials. Cancer Gene Ther. 2017;24(5):189-93.

57. Miller K, Cortes J, Hurvitz SA, Krop IE, Tripathy D, Verma S, et al. HERMIONE: a randomized Phase 2 trial of MM-302 plus trastuzumab versus chemotherapy of physician's choice plus trastuzumab in patients with previously treated, anthracycline-naive, HER2-positive, locally advanced/metastatic breast cancer. BMC Cancer. 2016;16:352.

58. Karimi M, Zangabad PS, Mehdizadeh F, Malekzad H, Ghasemi A, Bahrami $S$, et al. Nanocaged platforms: modification, drug delivery and nanotoxicity. Opening synthetic cages to release the tiger. Nanoscale. 2017;9(4):1356-92.

59. Zhen Z, Tang W, Chen H, Lin X, Todd T, Wang G, et al. RGD-modified apoferritin nanoparticles for efficient drug delivery to tumors. ACS Nano. 2013;7(6):4830-7.

60. Du B, Jia S, Wang Q, Ding X, Liu Y, Yao H, et al. A Self-Targeting, Dual ROS/pH-Responsive Apoferritin Nanocage for Spatiotemporally Controlled Drug Delivery to Breast Cancer. Biomacromolecules. 2018;19(3):1026-36.

61. Han X, Jiang Y, Li S, Zhang Y, Ma X, Wu Z, et al. Multivalent aptamermodified tetrahedral DNA nanocage demonstrates high selectivity and safety for anti-tumor therapy. Nanoscale. 2018;11(1):339-47.

62. Ji M, Qiu X, Hou L, Huang S, Li Y, Liu Y, et al. Construction and application of a liver cancer-targeting drug delivery system based on core-shell gold nanocages. Int J Nanomedicine. 2018;13:1773-89.

63. Xu Q, Wan J, Bie N, Song X, Yang X, Yong T, et al. A Biomimetic Gold Nanocages-Based Nanoplatform for Efficient Tumor Ablation and Reduced Inflammation. Theranostics. 2018;8(19):5362-78. 
64. Schoffski P, Delord JP, Brain E, Robert J, Dumez H, Gasmi J, et al. Firstin-man phase I study assessing the safety and pharmacokinetics of a 1-hour intravenous infusion of the doxorubicin prodrug DTS-201 every 3 weeks in patients with advanced or metastatic solid tumours. Eur J Cancer. 2017;86:240-7.

65. Kuruvilla SP, Tiruchinapally G, Crouch AC, ElSayed MEH, Greve JM. Dendrimer-doxorubicin conjugates exhibit improved anticancer activity and reduce doxorubicin-induced cardiotoxicity in a murine hepatocellular carcinoma model. PLoS One. 2017;12(8):e0181944.

66. Georgakopoulos P, Roussou P, Matsakas E, Karavidas A, Anagnostopoulos $\mathrm{N}$, Marinakis T, et al. Cardioprotective effect of metoprolol and enalapril in doxorubicin-treated lymphoma patients: a prospective, parallel-group, randomized, controlled study with 36-month follow-up. Am J Hematol. 2010;85(11):894-6.

67. Zhang H, Shen WS, Gao CH, Deng LC, Shen D. Protective effects of salidroside on epirubicin-induced early left ventricular regional systolic dysfunction in patients with breast cancer. Drugs R D. 2012;12(2):101-6.

68. Seicean S, Seicean A, Plana JC, Budd GT, Marwick TH. Effect of statin therapy on the risk for incident heart failure in patients with breast cancer receiving anthracycline chemotherapy: an observational clinical cohort study. J Am Coll Cardiol. 2012;60(23):2384-90.

69. Chotenimitkhun R, D’Agostino R, Jr., Lawrence JA, Hamilton CA, Jordan $\mathrm{JH}$, Vasu $\mathrm{S}$, et al. Chronic statin administration may attenuate early anthracyclineassociated declines in left ventricular ejection function. Can J Cardiol. 2015;31(3):302-7.

70. Tashakori Beheshti A, Mostafavi Toroghi H, Hosseini G, Zarifian A, Homaei Shandiz F, Fazlinezhad A. Carvedilol Administration Can Prevent DoxorubicinInduced Cardiotoxicity: A Double-Blind Randomized Trial. Cardiology. 2016;134(1):47-53.

71. Hao W, Liu S, Qin Y, Sun C, Chen L, Wu C, et al. Cardioprotective effect of Platycodon grandiflorum in patients with early breast cancer receiving anthracycline-based chemotherapy: study protocol for a randomized controlled trial. Trials. 2017;18(1):386.

72. Janbabai G, Nabati M, Faghihinia M, Azizi S, Borhani S, Yazdani J. Effect of Enalapril on Preventing Anthracycline-Induced Cardiomyopathy. Cardiovasc Toxicol. 2017;17(2):130-9.

73. Nabati M, Janbabai G, Baghyari S, Esmaili K, Yazdani J. Cardioprotective 
Effects of Carvedilol in Inhibiting Doxorubicin-induced Cardiotoxicity. J Cardiovasc Pharmacol. 2017;69(5):279-85.

74. Skrypnyk I, Maslova G, Lymanets T, Gusachenko I. L-arginine is an effective medication for prevention of endothelial dysfunction, a predictor of anthracycline cardiotoxicity in patients with acute leukemia. Exp Oncol. 2017;39(4):308-11.

75. Abuosa AM, Elshiekh AH, Qureshi K, Abrar MB, Kholeif MA, Kinsara AJ, et al. Prophylactic use of carvedilol to prevent ventricular dysfunction in patients with cancer treated with doxorubicin. Indian Heart J. 2018;70 Suppl 3:S96-S100.

76. Cardinale D, Ciceri F, Latini R, Franzosi MG, Sandri MT, Civelli M, et al. Anthracycline-induced cardiotoxicity: A multicenter randomised trial comparing two strategies for guiding prevention with enalapril: The International CardioOncology Society-one trial. Eur J Cancer. 2018;94:126-37.

77. Gupta V, Kumar Singh S, Agrawal V, Bali Singh T. Role of ACE inhibitors in anthracycline-induced cardiotoxicity: A randomized, double-blind, placebocontrolled trial. Pediatr Blood Cancer. 2018;65(11):e27308.

78. Chung R, Maulik A, Hamarneh A, Hochhauser D, Hausenloy DJ, Walker JM, et al. Effect of Remote Ischaemic Conditioning in Oncology Patients Undergoing Chemotherapy: Rationale and Design of the ERIC-ONC Study--A Single-Center, Blinded, Randomized Controlled Trial. Clin Cardiol. 2016;39(2):72-82.

79. Kirkham AA, Paterson DI, Prado CM, Mackey JR, Courneya KS, Pituskin $\mathrm{E}$, et al. Rationale and design of the Caloric Restriction and Exercise protection from Anthracycline Toxic Effects (CREATE) study: a 3-arm parallel group phase II randomized controlled trial in early breast cancer. BMC Cancer. 2018;18(1):864.

80. Milei J, Marantz A, Ale J, Vazquez A, Buceta JE. Prevention of adriamycininduced cardiotoxicity by prenylamine: a pilot double blind study. Cancer Drug Deliv. 1987;4(2):129-36.

81. Shah RR, Stonier PD. Withdrawal of prenylamine: perspectives on pharmacological, clinical and regulatory outcomes following the first QT-related casualty. Ther Adv Drug Saf. 2018;9(8):475-93.

82. Nobili S, Landini I, Giglioni B, Mini E. Pharmacological strategies for overcoming multidrug resistance. Curr Drug Targets. 2006;7(7):861-79.

83. Stove C, Bracke M. Roles for neuregulins in human cancer. Clin Exp Metastasis. 2004;21(8):665-84.

84. Gao R, Zhang J, Cheng L, WuX, Dong W, Yang X, et al. A Phase II, randomized, double-blind, multicenter, based on standard therapy, placebo-controlled study 
of the efficacy and safety of recombinant human neuregulin-1 in patients with chronic heart failure. J Am Coll Cardiol. 2010;55(18):1907-14.

85. Galindo CL, Ryzhov S, Sawyer DB. Neuregulin as a heart failure therapy and mediator of reverse remodeling. Curr Heart Fail Rep. 2014;11(1):40-9.

86. Lenihan DJ, Koren M, Eisen A, Caggiano A. SUSTAINED IMPROVEMENT OF LEFT VENTRICULAR EJECTION FRACTION WITH INTRAVENOUS CIMAGLERMIN IN PATIENTS WITH SYMPTOMATIC SYSTOLIC DYSFUNCTION. Journal of the American College of Cardiology. 2018;71(11 Supplement):A667.

87. Jay SM, Murthy AC, Hawkins JF, Wortzel JR, Steinhauser ML, Alvarez LM, et al. An engineered bivalent neuregulin protects against doxorubicin-induced cardiotoxicity with reduced proneoplastic potential. Circulation. 2013;128(2):15261.

88. Zhang J, Cui X, Yan Y, Li M, Yang Y, Wang J, et al. Research progress of cardioprotective agents for prevention of anthracycline cardiotoxicity. Am J TransI Res. 2016;8(7):2862-75.

89. Lipshultz SE, Rifai N, Dalton VM, Levy DE, Silverman LB, Lipsitz SR, et al. The effect of dexrazoxane on myocardial injury in doxorubicin-treated children with acute lymphoblastic leukemia. N Engl J Med. 2004;351(2):145-53.

90. Asselin BL, Devidas M, Chen L, Franco VI, Pullen J, Borowitz MJ, et al. Cardioprotection and Safety of Dexrazoxane in Patients Treated for Newly Diagnosed T-Cell Acute Lymphoblastic Leukemia or Advanced-Stage Lymphoblastic Non-Hodgkin Lymphoma: A Report of the Children's Oncology Group Randomized Trial Pediatric Oncology Group 9404. J Clin Oncol. 2016;34(8):854-62.

91. Lemez P, Maresova J. Efficacy of dexrazoxane as a cardioprotective agent in patients receiving mitoxantrone- and daunorubicin-based chemotherapy. Semin Oncol. 1998;25(4 Suppl 10):61-5.

92. Swain SM, Whaley FS, Gerber MC, Weisberg S, York M, Spicer D, et al. Cardioprotection with dexrazoxane for doxorubicin-containing therapy in advanced breast cancer. J Clin Oncol. 1997;15(4):1318-32.

93. Marty M, Espie M, Llombart A, Monnier A, Rapoport BL, Stahalova V, et al. Multicenter randomized phase III study of the cardioprotective effect of dexrazoxane (Cardioxane) in advanced/metastatic breast cancer patients treated with anthracycline-based chemotherapy. Ann Oncol. 2006;17(4):614-22.

94. Elbl L, Hrstkova H, Tomaskova I, Michalek J. Late anthracycline cardiotoxicity protection by dexrazoxane (ICRF-187) in pediatric patients: 
echocardiographic follow-up. Support Care Cancer. 2006;14(2):128-36.

95. Cui N, Wu F, Lu WJ, Bai R, Ke B, Liu T, et al. Doxorubicin-induced cardiotoxicity is maturation dependent due to the shift from topoisomerase Ilalpha to Ilbeta in human stem cell derived cardiomyocytes. J Cell Mol Med. 2019;23(7):4627-39.

96. Deng S, Yan T, Jendrny C, Nemecek A, Vincetic M, Godtel-Armbrust U, et al. Dexrazoxane may prevent doxorubicin-induced DNA damage via depleting both topoisomerase II isoforms. BMC Cancer. 2014;14:842.

97. Force T, Krause DS, Van Etten RA. Molecular mechanisms of cardiotoxicity of tyrosine kinase inhibition. Nat Rev Cancer. 2007;7(5):332-44.

98. Doherty KR, Wappel RL, Talbert DR, Trusk PB, Moran DM, Kramer JW, et al. Multi-parameter in vitro toxicity testing of crizotinib, sunitinib, erlotinib, and nilotinib in human cardiomyocytes. Toxicol Appl Pharmacol. 2013;272(1):245-55.

99. Sharma A, Burridge PW, McKeithan WL, Serrano R, Shukla P, Sayed N, et al. High-throughput screening of tyrosine kinase inhibitor cardiotoxicity with human induced pluripotent stem cells. Sci Transl Med. 2017;9(377).

100. Li C, Zou R, Zhang H, Wang Y, Qiu B, Qiu S, et al. Upregulation of phosphoinositide 3-kinase prevents sunitinib-induced cardiotoxicity in vitro and in vivo. Arch Toxicol. 2019;93(6):1697-712.

101. Wang H, Sheehan RP, Palmer AC, Everley RA, Boswell SA, Ron-Harel N, et al. Adaptation of Human iPSC-Derived Cardiomyocytes to Tyrosine Kinase Inhibitors Reduces Acute Cardiotoxicity via Metabolic Reprogramming. Cell Syst. 2019;8(5):412-26 e7.

102. Kitani T, Ong SG, Lam CK, Rhee JW, Zhang JZ, Oikonomopoulos A, et al. Human-Induced Pluripotent Stem Cell Model of Trastuzumab-Induced Cardiac Dysfunction in Patients With Breast Cancer. Circulation. 2019;139(21):2451-65.

103. Eldridge S, Guo L, Mussio J, Furniss M, Hamre J, 3rd, Davis M. Examining the protective role of ErbB2 modulation in human-induced pluripotent stem cellderived cardiomyocytes. Toxicol Sci. 2014;141(2):547-59.

104. Kurokawa YK, Shang MR, Yin RT, George SC. Modeling trastuzumabrelated cardiotoxicity in vitro using human stem cell-derived cardiomyocytes. Toxicol Lett. 2018;285:74-80.

105. Veerman CC, Kosmidis G, Mummery CL, Casini S, Verkerk AO, Bellin M. Immaturity of human stem-cell-derived cardiomyocytes in culture: fatal flaw or soluble problem? Stem Cells Dev. 2015;24(9):1035-52. 
106. Denning C, Borgdorff V, Crutchley J, Firth KS, George V, Kalra S, et al. Cardiomyocytes from human pluripotent stem cells: From laboratory curiosity to industrial biomedical platform. Biochim Biophys Acta. 2016;1863(7 Pt B):172848.

107. Schwach V, Passier R. Native cardiac environment and its impact on engineering cardiac tissue. Biomater Sci. 2019;7(9):3566-80.

108. Hansen A, Eder A, Bonstrup M, Flato M, Mewe M, Schaaf $S$, et al. Development of a drug screening platform based on engineered heart tissue. Circ Res. 2010;107(1):35-44.

109. Hirt MN, Boeddinghaus J, Mitchell A, Schaaf S, Bornchen C, Muller C, et al. Functional improvement and maturation of rat and human engineered heart tissue by chronic electrical stimulation. J Mol Cell Cardiol. 2014;74:151-61.

110. Wijnker PJ, Friedrich FW, Dutsch A, Reischmann S, Eder A, Mannhardt I, et al. Comparison of the effects of a truncating and a missense MYBPC3 mutation on contractile parameters of engineered heart tissue. J Mol Cell Cardiol. 2016;97:8292.

111. Truitt R, Mu A, Corbin EA, Vite A, Brandimarto J, Ky B, et al. Increased Afterload Augments Sunitinib-Induced Cardiotoxicity in an Engineered Cardiac Microtissue Model. JACC Basic Transl Sci. 2018;3(2):265-76.

112. Kilickap S, Barista I, Akgul E, Aytemir K, Aksoy S, Tekuzman G. Early and late arrhythmogenic effects of doxorubicin. South Med J. 2007;100(3):262-5.

113. Buza V, Rajagopalan B, Curtis AB. Cancer Treatment-Induced Arrhythmias: Focus on Chemotherapy and Targeted Therapies. Circ Arrhythm Electrophysiol. 2017;10(8).

114. Chen S. Abstract 476: Pharmacogenetics and Drug Discovery for Anthracycline-Induced Cardiotoxicity Enabled by Sinoatrial Node-like Cells Derived From Human Pluripotent Stem Cells. Circulation Research. 2019;125(Suppl_1).

115. Birket MJ, Ribeiro MC, Verkerk AO, Ward D, Leitoguinho AR, den Hartogh SC, et al. Expansion and patterning of cardiovascular progenitors derived from human pluripotent stem cells. Nat Biotechnol. 2015;33(9):970-9.

116. Devalla HD, Schwach V, Ford JW, Milnes JT, El-Haou S, Jackson C, et al. Atrial-like cardiomyocytes from human pluripotent stem cells are a robust preclinical model for assessing atrial-selective pharmacology. EMBO Mol Med. 2015;7(4):394-410.

117. Protze SI, Liu J, Nussinovitch U, Ohana L, Backx PH, Gepstein L, et al. 
Sinoatrial node cardiomyocytes derived from human pluripotent cells function as a biological pacemaker. Nat Biotechnol. 2017;35(1):56-68.

118. Schwach V, Passier R. Generation and purification of human stem cellderived cardiomyocytes. Differentiation. 2016;91(4-5):126-38.

119. Strijdom H, De Boever P, Walzl G, Essop MF, Nawrot TS, Webster I, et al. Cardiovascular risk and endothelial function in people living with HIV/AIDS: design of the multi-site, longitudinal EndoAfrica study in the Western Cape Province of South Africa. BMC Infect Dis. 2017;17(1):41.

120. Leucker TM, Bienengraeber M, Muravyeva M, Baotic I, Weihrauch $D$, Brzezinska $A K$, et al. Endothelial-cardiomyocyte crosstalk enhances pharmacological cardioprotection. J Mol Cell Cardiol. 2011;51(5):803-11.

121. Talman V, Kivela R. Cardiomyocyte-Endothelial Cell Interactions in Cardiac Remodeling and Regeneration. Front Cardiovasc Med. 2018;5:101.

122. Colliva A, Braga L, Giacca M, Zacchigna S. Endothelial cell-cardiomyocyte crosstalk in heart development and disease. J Physiol. 2019.

123. Huh D, Matthews BD, Mammoto A, Montoya-Zavala M, Hsin HY, Ingber DE. Reconstituting organ-level lung functions on a chip. Science. 2010;328(5986):1662-8.

124. Passier R, Orlova V, Mummery C. Complex Tissue and Disease Modeling using hiPSCs. Cell Stem Cell. 2016;18(3):309-21.

125. van den Berg A, Mummery CL, Passier R, van der Meer AD. Personalised organs-on-chips: functional testing for precision medicine. Lab Chip. 2019;19(2):198-205.

126. Den Hartogh SC, Passier R. Concise Review: Fluorescent Reporters in Human Pluripotent Stem Cells: Contributions to Cardiac Differentiation and Their Applications in Cardiac Disease and Toxicity. Stem Cells. 2016;34(1):13-26.

127. Weng KC, Kurokawa YK, Hajek BS, Paladin JA, Shirure VS, George SC. Human Induced Pluripotent Stem-Cardiac-Endothelial-Tumor-on-a-Chip to Assess Anticancer Efficacy and Cardiotoxicity. Tissue Eng Part C Methods. 2020;26(1):4455 .

128. Skardal A, Shupe T, Atala A. Organoid-on-a-chip and body-on-achip systems for drug screening and disease modeling. Drug Discov Today. 2016;21(9):1399-411.

129. Prantil-Baun R, Novak R, Das D, Somayaji MR, Przekwas A, Ingber DE. 
Physiologically Based Pharmacokinetic and Pharmacodynamic Analysis Enabled by Microfluidically Linked Organs-on-Chips. Annu Rev Pharmacol Toxicol. 2018;58:37-64.

130. Li RA, Keung W, Cashman TJ, Backeris PC, Johnson BV, Bardot ES, et al. Bioengineering an electro-mechanically functional miniature ventricular heart chamber from human pluripotent stem cells. Biomaterials. 2018;163:116-27.

131. MacQueen LA, Sheehy SP, Chantre CO, Zimmerman JF, Pasqualini FS, Liu $\mathrm{X}$, et al. A tissue-engineered scale model of the heart ventricle. Nat Biomed Eng. 2018;2(12):930-41.

132. Knowles DA, Burrows CK, Blischak JD, Patterson KM, Serie DJ, Norton N, et al. Determining the genetic basis of anthracycline-cardiotoxicity by molecular response QTL mapping in induced cardiomyocytes. Elife. 2018;7:1-25. 
Chapter 6:

\section{A hPSC-CM-based safety screening platform reveals reduced cardiotoxic effect of doxorubicin analogue.}




\section{Chapter 6: A hPSC-CM-based safety screening platform reveals reduced cardiotoxic effect of doxorubicin analogue.}

Rolf H. Slaats ${ }^{1}$, Verena Schwach ${ }^{1}$, Carla Cofiño Fabres ${ }^{1}$, Simone ten Den ${ }^{1}$, José M. Rivera Arbelaez ${ }^{1}$, Chiara van Boheemen ${ }^{1}$, Marcelo C. Ribeiro ${ }^{1}$, Lu Ciao ${ }^{2}$, Sabina van der Zanden ${ }^{3}$, Jacques Neefjes ${ }^{3}$, and Robert Passier ${ }^{1,4}$.

${ }^{1}$ Applied Stem Cell Technologies, TechMed Centre, University of Twente, Drienerlolaan 5, 7500

AE, Enschede, The Netherlands

${ }^{2}$ Leiden Institute of Advanced Computer Science (LIACS), Universiteit Leiden, Niels Bohrweg 1, 2333 CA, Leiden, The Netherlands

${ }^{3}$ ONCODE Institute, Leiden University Medical Center, Einthovenweg 20, 2333 ZC Leiden, The Netherlands.

${ }^{4}$ Department of Anatomy and Embryology, Leiden University Medical Center, PO Box 9600, 2300 RC Leiden, The Netherlands

\section{Abstract}

Doxorubicin (DOXO) and its chemical analogues are widely used for the treatment of malignancies due to their effectiveness against cancer cells but are hampered by severe cardiotoxic side effects. Recent studies have described DOXO analogues with reduced toxicity found in animal models, however their effect on human heart tissue remains unknown. We sought to develop a drug screening platform based on human pluripotent stem cell-derived cardiomyocytes (hPSC-CMs) that could accurately predict the toxic parameters caused by DOXO as described previously, in order to screen DOXO analogues for their improved cardiac safety. To this end we combined 2D assays and 3D engineered heart tissue (EHT) models to capture DOXO damage mechanisms and tested these models by exposure of the hPSC-CMs to DOXO and its analogues Amrubicin (AMR) and Aclarubicin (ACLA). We found that our platform could faithfully capture the dose-dependent cardiotoxic effects of DOXO and were able to identify the less toxic analogue $\mathrm{AMR}$ as a potential candidate for further (pre-)clinical testing for the treatment of malignancies without severe cardiac side effects.

\section{Introduction}

Since its discovery decades ago, the anthracycline Doxorubicin (DOXO) has played an important role in treatment of various malignancies, however not without a cost. Nicknamed "the Red Devil", DOXO treatment has been associated with a number of toxic side effects, among which DOXO-induced cardiotoxicity is a prevalent and life-threatening complication.(1) Despite the development of several approaches to reduce DOXO-induced (cardio-)toxicity, through development of analogues(2), DOXO-encapsulation(3) or co-treatment with 
protective compounds(4), DOXO-induced cardiotoxicity remains a substantial limitation of its use in the fight against cancer. Because of its success in combating neoplasms, DOXO is still widely used for treatment, despite the drawback. Finding a solution for the DOXO-induced toxicity may therefore be very valuable to oncology, however to date, that solution has not been found. This may be due to the lack of an appropriate model to investigate the mechanisms of DOXO toxicity, which rely mostly on animal models, and only recently involved the use of human pluripotent stem cells (hPSCs).(4)

The exact mechanism of DOXO-toxicity to human cardiomyocytes (CMs) remains unclear, however several suggested mechanisms have been published based on hPSC-CM models. DOXO toxicity in proliferating cells is mostly mediated through interaction with Topoisomerase Il $\alpha$, where it induces DNA damage.(5) As discussed in the previous chapter, in adult $\mathrm{CMs}$, which do not proliferate, toxicity is thought to be induced via a combination of DOX-mediated disturbances. It was recently suggested that cardiotoxicity is mediated through both the poisoning of topoisomerase II $\beta$ in CMs, leading to double strand breaks (DSBs) in the DNA and through the eviction of histones, causing chromatin damage.(6) Moreover, DOXO is found to cause mitochondrial dysfunction, triggering elevated release of reactive oxygen species (ROS) and nitrous oxide (NOS), calcium ion (Ca2+) handling errors leading to $\mathrm{Ca} 2+$ overload, and the direct induction of apoptosis.(4) All these effects may affect the contractile function of the $\mathrm{CM}$, and as such, DOXO-induced cardiotoxicity is mostly diagnosed by reductions in left ventricular ejection fraction

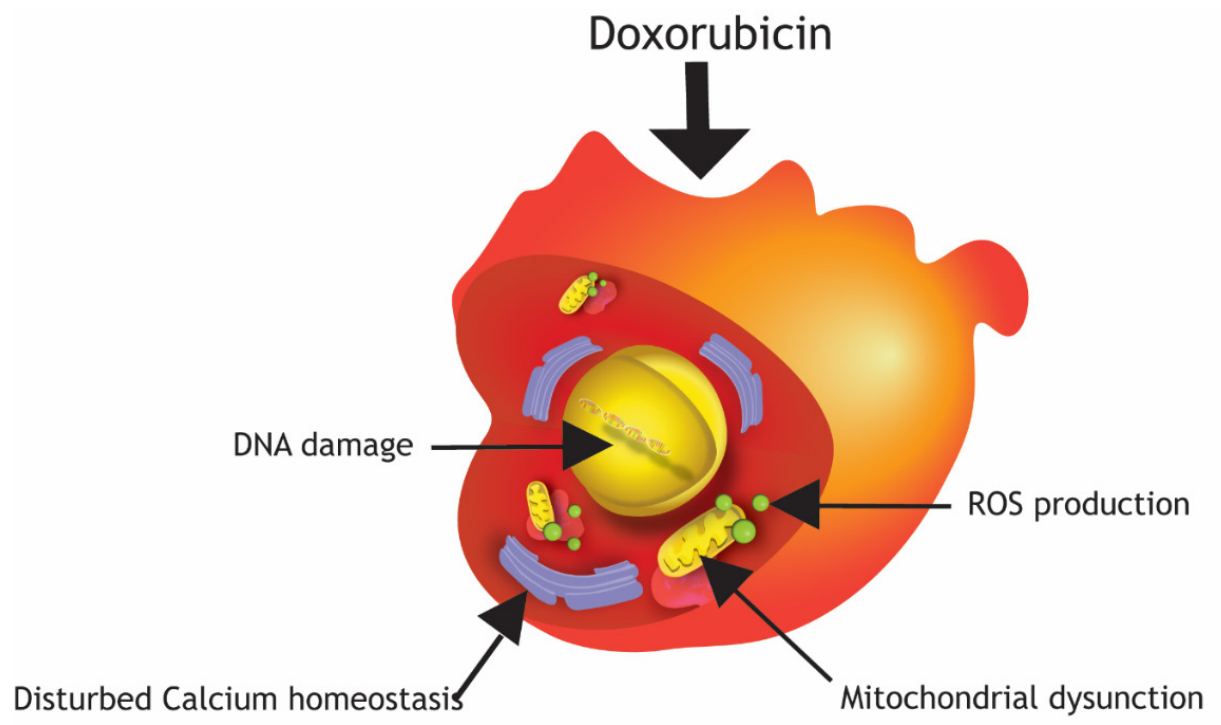

Figure 1: Mechanisms of DOXO-induced cell damage to cardiomyocytes described by literature. Adapted from chapter 5 
(LVEF) in patients, indicating a loss-of-function of heart contractility. Over the years, many chemical analogues of Doxorubicin have been developed in an attempt to find a molecular cousin to doxorubicin that is equally potent in combating malignancies, but less toxic to other organs, such as the heart. However, the less cardiotoxic nature of these compounds remains to be evaluated before entering clinical testing.

Here, we describe the development of a toxicity screening platform, delivering read-outs on several of the proposed toxicity mechanisms described above (Fig. 1). DOXO exposure on hPSC-CMs was found to substantially affect cell viability and function, in confirmation of earlier clinical reports on DOXO toxicity. The loss of LVEF was recapitulated by culturing hPSC-CMs in a 3D EHT platform, capable of generating functional data on contractility of the cardiac tissue, as has been demonstrated previously.(7) Additionally, we tested the toxicity of two analogues, Amrubicin (AMR) and Aclarubicin (ACLA), demonstrating that AMR, but not ACLA, could be administered to hPSC-CMs at clinically relevant doses without affecting cardiomyocyte viability or contractile function. Thus, we show that our combination of assays provides a platform for thorough toxicity screening of Anthracyclines that is capable of distinguishing less harmful analogues of DOXO for further use in (pre-)clinical development.

\section{Results}

Doxorubicin is internalized by CMs in our hPSC-CM based platform.

For the cardiotoxicity platform we generated CMs from hPSCs in vitro, both from hESCs and hiPSCs (Fig 2A). Upon differentiation, hPSC-CMs were further lactatepurified, resulting in a cell population comprised of $\sim 90 \%$ cardiac Troponin $\mathrm{T}+$ cells quantified by flow cytometry analysis (Fig 2B). These CMs were then used for EHT formation or 2D monolayer assays (Fig 2A). In order to confirm that DOXO is taken up by hPSC-CMs, we performed a time lapse of DOXO uptake at a concentration of $1 \mu \mathrm{M}$ over the course of 24 hours, quantifying the intrinsic fluorescent property of DOXO in the cell by fluorescent microscopy (Fig 2C) and flow cytometry (Fig 2D). We observed that in the first three hours, DOXO is taken up by an increasing number of cells, until it reaches a plateau phase where no additional cells take up the agent (Fig $2 \mathrm{D}+\mathrm{E})$. During this time however, the amount of DOXO that accumulates inside the cells is still increasing up to 5 hours after the start of exposure (Fig 2F).

Doxorubicin induces an acute cardiotoxic response in 2D hPSC-CMs

We next assessed the toxicity of DOXO on hPSC-CMs in a monolayer configuration to validate that the suggested toxicity mechanisms of literature could indeed be observed in our model. For this, we cultured hPSC-CMs at full confluency in cell culture dishes, exposed them to DOXO or DMSO as control at different 
concentrations for 24 hours, and assessed toxicity by quantification of viability and $\mathrm{Ca} 2+$ handling. Monolayers of hPSC-CMs were stained with Calcein live cell dye to assess the surface area covered by cells as a measure of survival (Fig 3A). Loss of cells was observed in a dose-dependent manner, where a significant reduction in covered area was demonstrated at a DOXO concentration of $1 \mu \mathrm{M}$ and above, compared to DMSO control and 0,1 $\mu \mathrm{M}$ DOXO (Fig 3B). The area covered by cells did not change between DMSO control and 0,1 $\mu \mathrm{M}$ DOXO, indicating that $0,1 \mu \mathrm{M}$ DOXO is not lethal to hPSC-CMs within the timeframe of 24 hours. We continued to determine the kinetics of $\mathrm{Ca} 2+$ ions in the hPSC-CMs, since $\mathrm{Ca}^{2+}$ overload and arrhythmic behavior in CMs is found in vivo after DOXO exposure. To this end, we again cultured hPSC-CMs in a monolayer fashion, exposed them to the DOXO concentration range or DMSO as control, for 24 hours, and added Fluo-4 $\mathrm{Ca}^{2+}$ dye subsequently, which allows for real-time quantification of $\mathrm{Ca}^{2+}$ using fluorescent microscopy. As seen in figure 3C, a dose-dependent increase in fluorescent signal indicated an increase of $\mathrm{Ca}^{2+}$ within the cell, regardless of contraction cycle fluctuations, pointing to a DOXO-dependent $\mathrm{Ca}^{2+}$ overload in our hPSC-CMs. An exposure to $5 \mu \mathrm{M}$ or $10 \mu \mathrm{M}$ DOXO for 24 hours resulted in a significantly higher amount of $\mathrm{Ca}^{2+}$ inside the CMs (Fig 3C, D). The live imaging of $\mathrm{Ca}^{2+}$ in hPSC-CM culture also provided information on the $\mathrm{Ca}^{2+}$ handling by the CMs in the presence of DOXO, as well as the frequency of $\mathrm{Ca}^{2+}$ influx that serves as an approximate of contraction frequency. DOXO concentrations above $1 \mu \mathrm{M}$ substantially affected normal $\mathrm{Ca}^{2+}$ handling, as indicated by the significant increase in beating frequency, as well as the reduction of the time-to-peak and time-to-decay of $\mathrm{Ca}^{2+}$ signal (Fig 3E-G). In summary, DOXO thus induced dosedependent cardiomyocyte toxicity within 24 hours of administration, which can be visualized and quantified in our 2D hPSC-CM model.

\section{Prolonged DOXO exposure leads to functional defects in hPSC-CMs}

In vivo, acute extensive cell loss due to DOXO exposure is not apparent, and thus does not represent the pathophysiology of DOXO toxicity to the heart. At the lowest DOXO dose at which cardiotoxic effects could be readily observed in the monolayer assays, we continued to evaluate multiple day exposure to $1 \mu \mathrm{M}$ DOXO over time using various subtle CM damage assays. The DRRAGN reporter line is very suitable to study the effect of DOXO on sarcomeric function and integrity, due to its fusion protein of $\alpha$-Actinin and mRubyll which makes sarcomeres visible in live fluorescent microscopy (see Chapter 3 ). We therefore used CMs differentiated from DRRAGN hESCs (DRRAGN-CMs) to assess the organization of sarcomeres following exposure to $1 \mu \mathrm{M}$ DOXO for 5 days (Fig $4 \mathrm{~A})$. Through custom software, we determined that the sarcomeric organization was significantly affected upon exposure to DOXO over the time course of 5 days, compared to the control (DMSO treated) group (Fig 4B). Whereas the control group only showed minimal changes in sarcomeric organization, the 
DOXO-treated group demonstrated excessive loss of sarcomeric organization, which is also apparent in the fluorescent images (Fig 4A). Since DRRAGN-CMs also express GFP in the cytosol, their survival could be quantified by measuring total area covered by GFP signal, similar to the Calcein quantification described in figure 3 (Fig 4C). While DMSO-only treated CM monolayers remain constant in the area covered by cells, the DOXO group shows a gradual decrease in covered area over time, losing up to $75 \%$ of area coverage after 5 days of exposure to 1

A

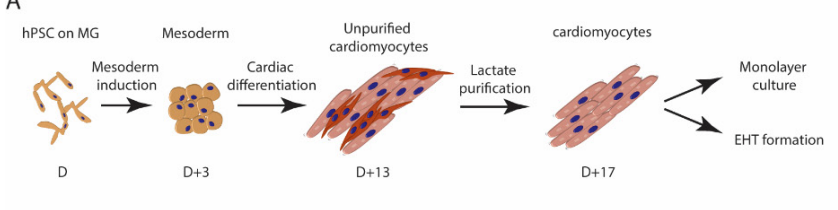

B

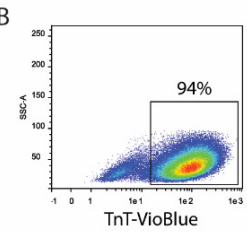

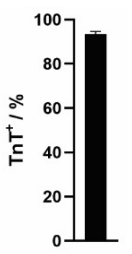

C

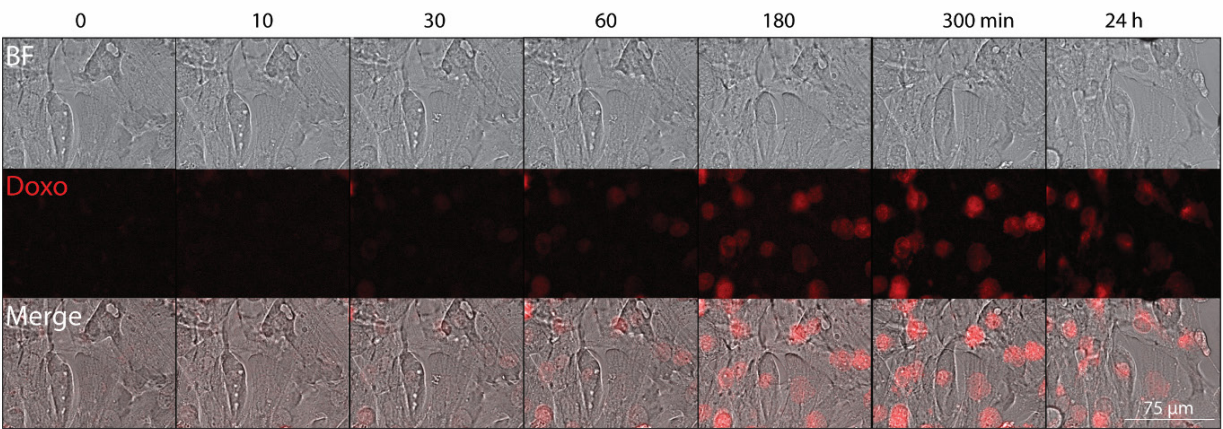

D

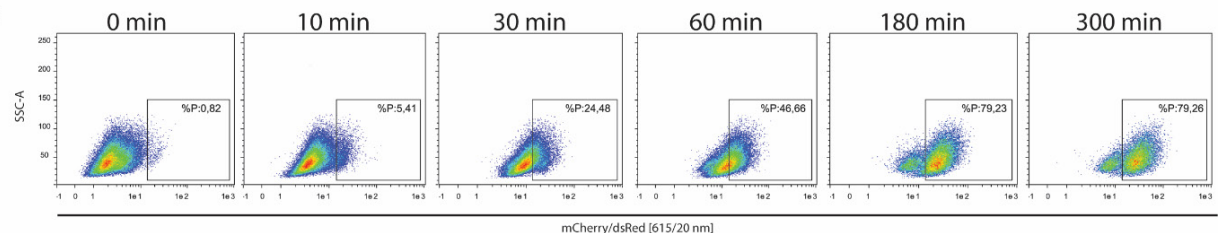

$\mathrm{E}$
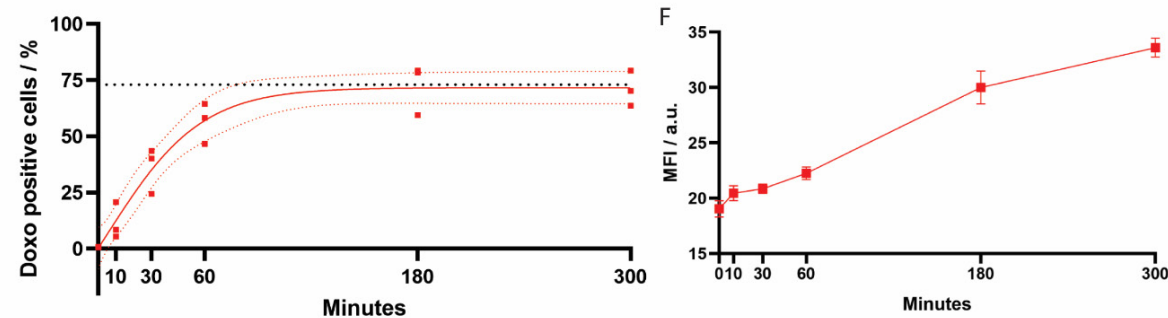

Figure 2: Experimental setup and DOXO uptake validation. A) schematic representation of the experimental workflow. B) Quantification of hPSC-CM purity after differentiation and subsequent purification using lactate-enrichment. C) Micrograph series of the DOXO uptake in hPSC-CMs over the course of 24 hours. Scale bar represents $75 \mu \mathrm{m}$. D) flow cytometric quantification of DOXO within the CMs over time. E) Quantification of the percentage of cells positive for DOXO signal as determined by FC, over time. F) Mean fluorescent intensity of the cell population positive for DOXO, over time. 
$\mu \mathrm{M}$ DOXO (Fig 4D). Cardiomyocyte damage and loss was further quantified by the release of troponin I (Tnl), a biomarker commonly used in the clinic. Hitherto, we exposed hPSC-CM monolayers to DOXO concentrations ranging from 0 to 10 $\mu \mathrm{M}$ and quantified the amount of released $\mathrm{Tnl}$ in the culture media after 4 days using ELISA (Fig 4E). Release of Tnl indicates damage or death of cardiomyocytes since $\mathrm{Tnl}$ is not released outside of the cell under normal circumstances. In our monolayers, we observed a $\mathrm{Tnl}$ release correlating to the increase of DOXO

A
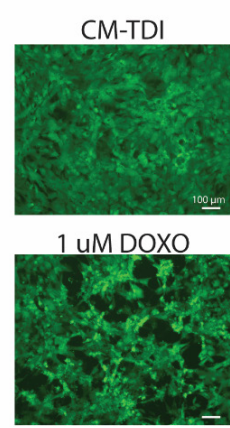

C

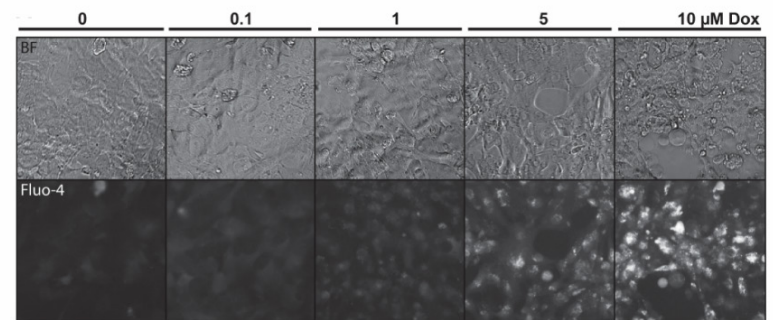

E

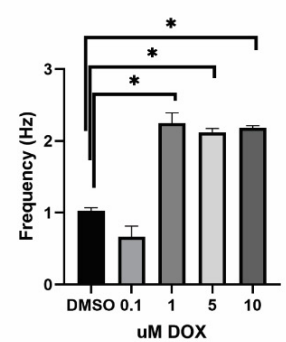

DMSO

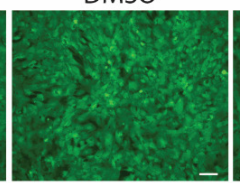

5 UM DOXO

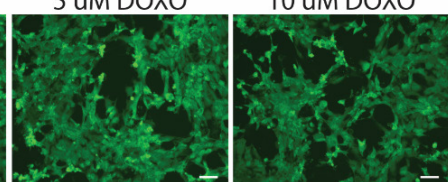

$10 \mu \mathrm{M} \mathrm{Dox}$

F

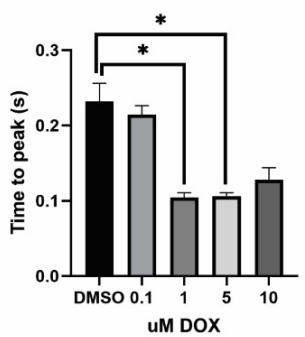

B
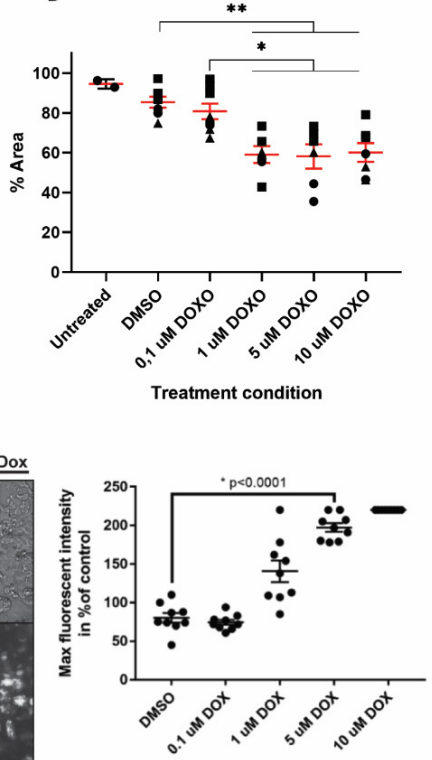

G

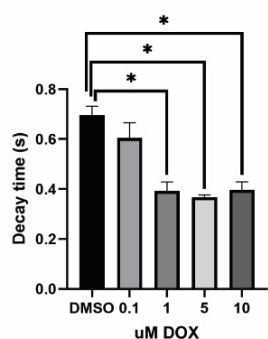

Figure 3: Short-term read-outs for DOXO-induced cytotoxicity following 24-hour exposure in hPSC-CMs. A) Loss of hPSC-CMs in a monolayer as a result of DOXO exposure quantified by area covered by Calcein live cell dye. B) Quantification of cell loss depicted in A. C) Micrograph images demonstrating the accumulation of $\mathrm{Ca}^{2+}$ inside hPSC-CMs in a monolayer after 24 hours of exposure to DOXO using Fluo-4 calcium dye in live hPSC-CMs. D) Quantification of calcium accumulated in the hPSC-CMs visualized by fluorescent microscopy. E-G) Quantification of $\mathrm{Ca}^{2+}$ kinetics using Fluo-4 dye, showing the effect of DOXO exposure on beating frequency $(E)$, time-to-peak $(F)$, and time-to$\operatorname{decay}(G) . p<0,05=*, p<0,01=* *, P<0,001=* * *, n s=$ not significant. Significance tested by one-way-ANOVA. 
concentration, further confirming that DOXO actively damages hPSC-CMs in a monolayer culture. We then proceeded to assess the toxicity of DOXO in a 3D format using the EHT platform, previously established by our group. The extend of disruption of CM function caused by DOXO exposure led to severe reductions in contractile force measured in EHTs formed with hPSC-CMs and exposed to DOXO ranging from $0 \mu \mathrm{M}$ to $10 \mu \mathrm{M}$ over a time course of 3 days. Whereas on a macroscopic level the EHTs remained intact throughout the experiment (Fig $4 \mathrm{~F}$ ), contractility of the tissues was affected substantially. Force of contraction remained constant over three days of culture for the DMSO treated control group and the $0.1 \mu \mathrm{M}$ DOXO-treated tissues, while $1 \mu \mathrm{M}$ DOXO exposure triggered an intermediate decrease of force over time, and $5 \mu \mathrm{M}$ and $10 \mu \mathrm{M}$ DOXO resulted in a complete loss of measurable force of contraction within the three-day period (Fig 4G). A similar trend can be observed for contraction and relaxation speed of the tissues, suggesting that Doxorubicin affects the contractile capability of hPSC-CMs in a dose-dependent manner.

DOXO analogue AMR, but not ACLA, demonstrates reduced cardiomyocyte toxicity.

The data so far has demonstrated that the platform of 2D CM monolayer and 3D EHT constructs could faithfully reproduce the damage to CMs that is also observed in vivo. We therefore applied the platform to test whether doxorubicin analogues, designed to have a similar anti-neoplastic effect without the adverse cardiac sideeffect, could be screened for their cardiotoxic properties in our platform. We thus applied the same readouts as described above for DOXO, to assess cardiotoxicity of compounds AMR and ACLA. To validate the anti-neoplastic activity of the anthracyclines, we treated hPSCs and tumor cells with DOXO, AMR and ACLA at 510 and $20 \mu \mathrm{M}$ and confirmed that the agents were cytotoxic to proliferative cells (Suppl Fig 1). Next, hPSC-CM viability after 24 hours of exposure to AMR and ACLA was determined by Calcein live stain imaging and subsequent analysis (Fig 5A). In comparison to DMSO control and corresponding DOXO concentrations, ACLA appeared to cause a similar loss of covered area by viable cells to the DOXO counterpart at $5 \mu \mathrm{M}, 10 \mu \mathrm{M}$ and $20 \mu \mathrm{M}$ (Fig 6B). In contrast, AMR performed markedly better with a surface area covered similarly to DMSO after 24 hours of exposure at 5, 10 and $20 \mu \mathrm{M}$. Analogue toxicity was further assessed by long-term exposure of the compounds on monolayer hPSC-CM cultures, and TnI release was again measured at 4 days post-exposure (Fig 5C). AMR at $5 \mu \mathrm{M}$ and $10 \mu \mathrm{M}$ again displayed a very low impact on CM damage and survival, indicated by the low level of $\mathrm{Tnl}$ released in the culture medium, comparable to DMSO control. ACLA, on the other hand, clearly demonstrated an increased release of $\mathrm{Tnl}$ at a concentration of 5 and $10 \mu \mathrm{M}$, which was comparable to the $5 \mu \mathrm{M}$ DOXOtreated condition. This further supports the results found in the viability assay in Figure 5A. Lastly, we assessed the impact of the analogues on contractility of 
EHTs made from hPSC-CMs, in comparison to DOXO. While ACLA affected force of contraction (Fig 5D) and contraction and relaxation velocities (Figs $5 \mathrm{E}+\mathrm{F}$ ) at all tested concentrations to a similar degree as DOXO at $5 \mu \mathrm{M}, \mathrm{AMR}$ at $5 \mu \mathrm{M}$ did not affect force of contraction and only slightly affected contraction and relaxation velocities of the EHTs. All together, these findings provide evidence of reduced
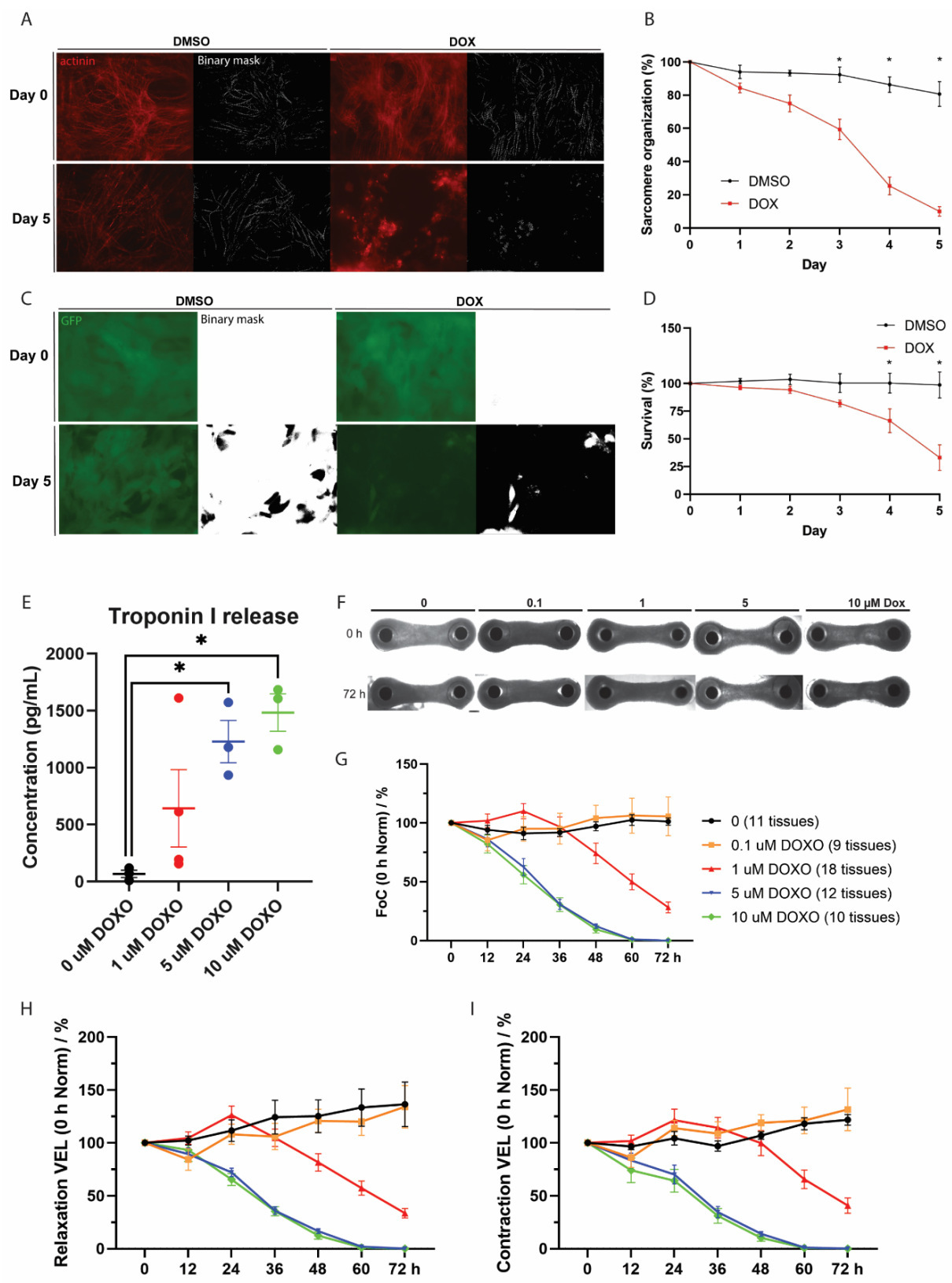
Figure 4 (previous page): Long term exposure of DOXO to hPSC-CMs. A) Fluorescent images of the a-Actinin_mRubyll signal of DRRAGN CMs before and after 5 days of exposure to DMSO or 1 $\mu M D O X O$, and the corresponding binary mask of the signal. B) Quantification of the sarcomeric organization based on the binary masks, determined by custom software. C) The cytosolic GFP signal expressed by DRRAGN-CMs in monolayer as a proxy for cell area coverage, after 5 days of exposure to DMSO or $1 \mu \mathrm{M} D O X O$, and the corresponding binary mask used for image analysis. D) Quantification of surface area covered by GFP signal as determined by the binary mask analysis. E) Quantification of Troponin I release by hPSC-CMs in monolayer after 4 days of exposure to DOXO at a range of concentrations, measured by ELISA. F) Brightfield images of EHTs at baseline and after 3 days of exposure to the range of DOXO concentrations. G) The contractile force of the EHTs during exposure to DOXO over the time course of 3 days. $\mathrm{H}+\mathrm{l}$ ) The speed of contraction and relaxation of the EHTs during exposure to DOXO over the time course of 3 days. $p<0,05=*, p<0,01=* *, P<$ $0,001=* * *, n s=$ not significant. Significance tested by one-way-ANOVA.

cardiotoxic properties of anti-neoplastic agent AMR, whereas ACLA displayed cardiotoxic effects, which was comparable to DOXO.

DNA damage response measurement reveals transcription factor eviction from nucleus.

One other aspect of DOXO induced cell damage is the development of DNA damage in the cell (Fig 1). We assessed the induction of DNA double strand breaks (DSBs) in our platform by quantifying the number of cells expressing phosphorylated histone $\mathrm{H} 2 \mathrm{AX}(\mathrm{yH} 2 \mathrm{AX})$, which is known to be triggered upon DNA double strand break repair.(6) To this end, we treated monolayers of hPSC-CMs with our DOXO range or analogues for 24 hours, and then fixed the cells for immunocytochemical analysis of $\mathrm{yH} 2 \mathrm{AX}$ (Fig 6). We found that, compared to DMSO-treated control cells, substantially more CMs exposed to $0,1 \mu \mathrm{M}$ or $1 \mu \mathrm{M}$ DOXO were positive for $\mathrm{yH} 2 \mathrm{AX}$ in the nucleus (Fig 6A). However, at higher concentrations of DOXO, the fluorescent signal of $\mathrm{yH} 2 \mathrm{AX}$ as well as the DAPI counterstain appeared to fade. This effect may be due to histone eviction, which has been described before. (6) Interestingly, AMR-treated cells displayed yH2AX signal at all concentrations, whereas ACLA did not show this DNA damage response (Fig $6 B+C$ ). Instead, $A C L A$, but not AMR, caused a loss of histone H2AX, comparable to DOXO treatment. Thus, DOXO induces DSBs at concentrations as low as $0,1 \mu \mathrm{M}$, a level that appeared non-toxic in the viability assay of Figure $3 \mathrm{~A}$ and in the EHT data of figure 4G-I. Similarly, AMR induced substantial phosphorylation of H2AX, while expressing a low toxicity level in previous assays, suggesting that DSBs may occur as an effect of anthracycline exposure, but it has little apparent effect on CM function or viability within the timeframe of our assays, and may therefore not be a dominant contributor to clinical cardiotoxicity.

\section{Anthracycline treatment causes NKX2-5 depletion in hPSC-CMs}

While counterstaining $\mathrm{CM}$ monolayers in the $\mathrm{yH} 2 \mathrm{AX}$ assay for transcription factor NKX2-5 to validate their cardiac phenotype, we observed that the NKX2-5 signal of the immunofluorescent tag diminished with an increasing concentration of 
A

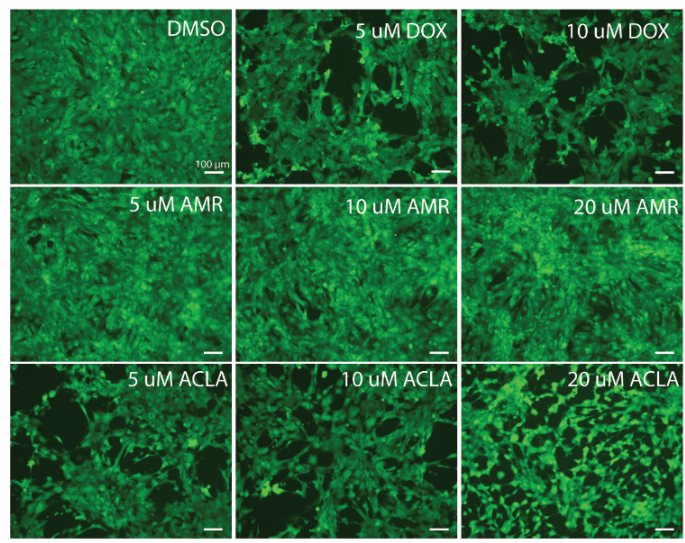

B

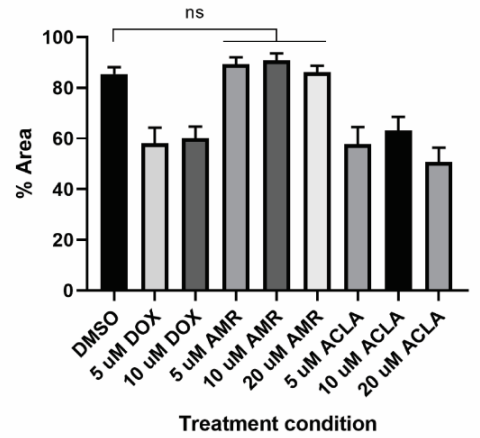

C

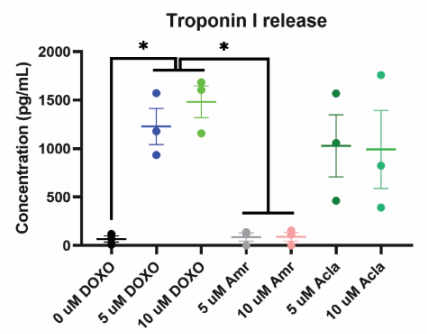

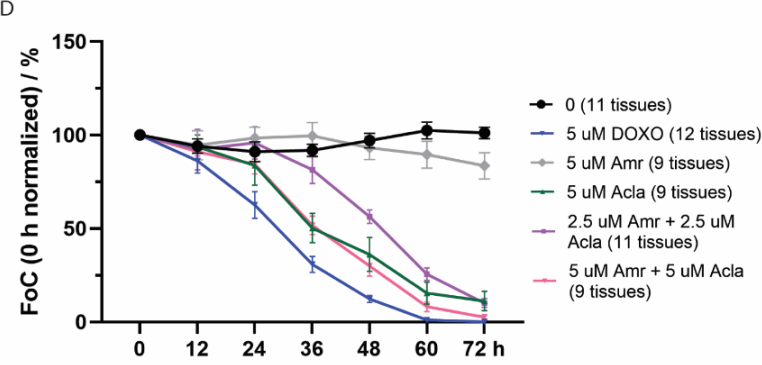

E
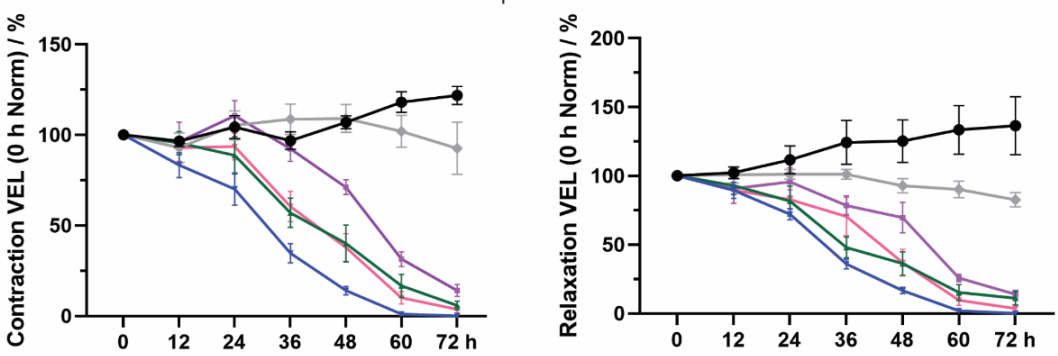

Figure 5: Evaluation of the cardiotoxic effect of DOXO analogues Amrubicin and Aclarubicin on hPSC-CMs. A) Calcein live staining of hPSC-CMs after 24 hours of exposure to DOXO or the analogue at indicated concentration. B) Quantification of total area covered by hPSC-CMs after 24 hours of exposure to the anthracycline. $N=3$. C) Quantification of Troponin-I release following 4 days of exposure to DOXO or analogues at specified concentration, as determined by ELISA. D) Normalized force of contraction of EHTS made of hPSC-CMs during exposure to DOXO or analogue at indicated concentration over the course of 3 days. E+F) The speed of contraction and relaxation of the EHTs during exposure to DOXO or analogue over the time course of 3 days. $p<0,05=*$, ns = not significant. Significance tested by one-way-ANOVA. 
DOXO (Fig 7A). We therefore also assessed NKX2-5 expression after 24 hours of exposure to $A M R$ and $A C L A$ at various concentrations (Fig $7 B+C$ ). Interestingly, the sensitivity to loss of NKX2-5 caused by DOXO, AMR and ACLA appears to vary between the agents: DOXO induced NKX2-5 loss at a concentration of $1 \mu \mathrm{M}$ and above, ACLA at $5 \mu \mathrm{M}$ still showed a low signal of fluorescence, although NKX2-5 immunoreactivity was lost at higher concentrations, whereas for AMR, NKX2-5 was retained at $5 \mu \mathrm{M}$, and only displayed reduced immunoreactivity at the highest concentration $(20 \mu \mathrm{M})$. This indicates a distinct difference in working mechanism of both analogues and DOXO and may provide an explanation of the difference in toxicity to hPSC-CMs. Since $y H 2 A X$ signal does not correlate with NKX2-5 loss, NKX2-5 loss cannot be attributed to DNA damage caused by the anthracyclines. To determine whether the observed loss of NKX2-5 fluorescent signal is a technical artifact of the immunostaining, we tracked the disappearance of NKX2-5 in a time-lapse, to determine the dynamics of NKX2-5 loss (Fig 7D). We found that the NKX2-5 signal disappears between 4 and 6 hours after adding $1 \mu \mathrm{M}$ DOXO to the culture medium, suggesting that the loss of fluorescent signal is not caused by a technical error. Indeed, earlier studies suggest that DOXO enhances the activity of a specific proteasome that accelerates co-factor P300 breakdown and consequently diminishes NKX2-5 gene expression.(8) This mechanism would match the time-course of 4-6 hours in which NKX2-5 is gradually lost. A loss of NKX2-5 expression in CMs may have profound consequences to function(9), and may therefore be of great interest in the screen for less cardiotoxic anthracycline analogues.

DOXO induces transcriptional changes related to P300 and NKX2-5 depletion.

Next, we explored whether anthracyclines affected expression levels of other cardiomyocyte-related genes. We therefore performed a qPCR analysis on isolated total RNA from EHTs exposed to DOXO or analogues (Fig 8). First, we confirmed the loss of NKX2-5 due to DOXO or ACLA-mediated suppression of transcription, while AMR at $5 \mu \mathrm{M}$ failed to down-regulate NKX2-5. This corresponds well with the initial observation done by immunohistochemistry in Figure 7A-C. A similar effect could be observed for the transcriptional level of MEF2C and HAND2, which both have been reported in literature to be vulnerable to DOXO-mediated downregulation. Importantly, we found that NKX2-5 downstream targets ACTN2, SERCA and CAGNA1 are downregulated in $5 \mu \mathrm{M}$ DOXO and ACLA, but not in AMR or DMSO control, suggesting a loss of a positive regulatory effect of NKX25. Interestingly, not all cardiac-specific genes were similarly affected; proton channel HCN4 was only downregulated after treatment with $5 \mu \mathrm{M}$ DOXO and ACLA when compared to $5 \mu \mathrm{M}$ AMR-treated samples; GJA1, encoding for gap junction channel protein connexin-43, was only significantly downregulated at $1 \mu \mathrm{M}$ DOXO; and transcription factor IRX4 and calcium channel CAV1.3 were 
not significantly affected by anthracycline exposure. Surprisingly, HAND1, a transcription factor involved in early cardiac development and expressed in the first heart field, was upregulated at $1 \mu \mathrm{M}$ DOXO. Overall, our qPCR analysis of the transcriptome of EHTs exposed to DOXO, ACLA or AMR indicates a specific effect of the compounds on cardiac genes related to the NKX2-5 or P300 regulatory pathway, which suggests that the downregulation of NKX2-5 is not caused by a cell-wide reduction in transcription.

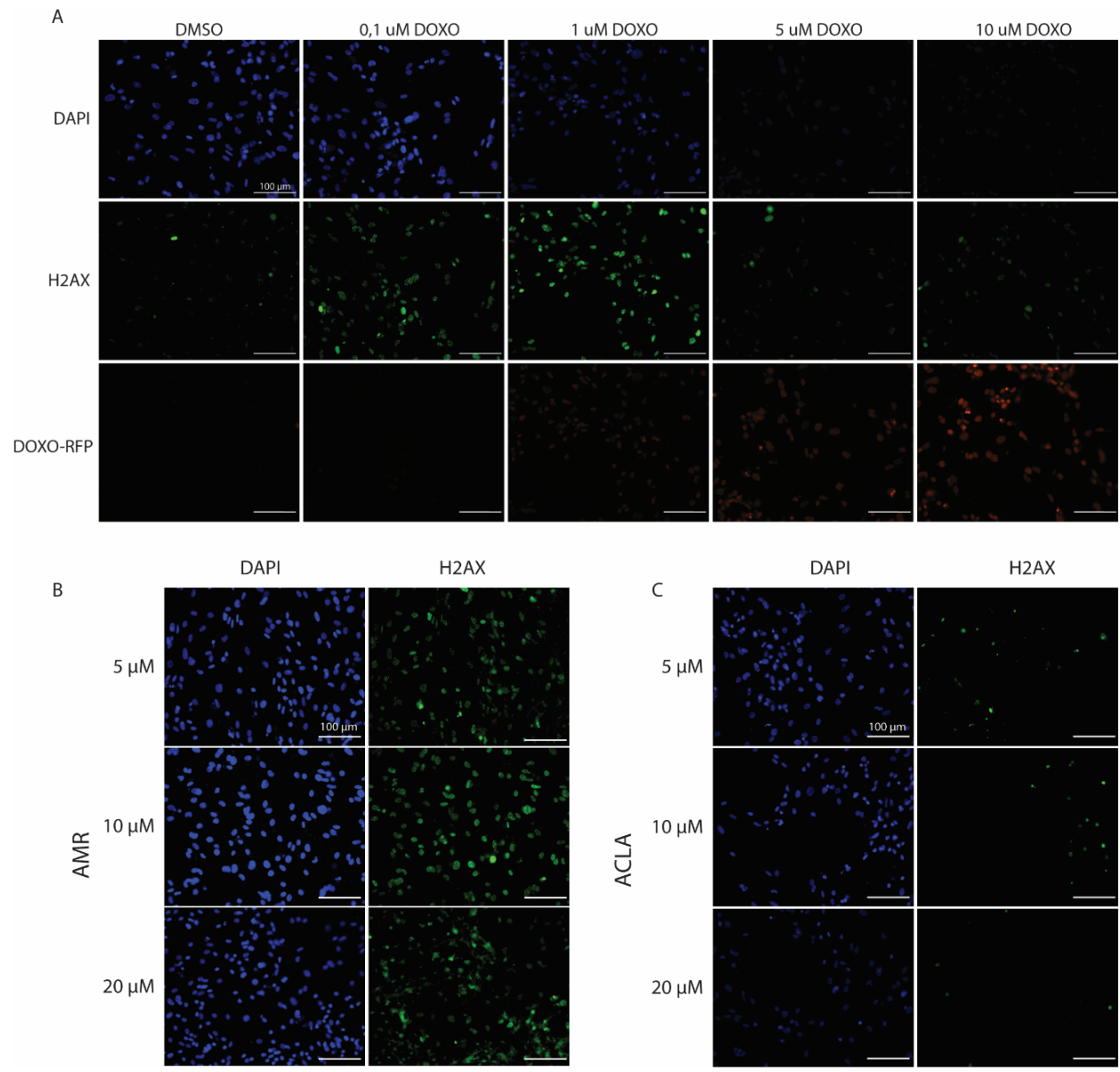

Figure 6: DNA damage in hPSC-CMs in a monolayer culture following DOXO or analogue treatment $(A M R$ and $A C L A)$, assessed by yH2AX immunofluorescent imaging. A) panel of immunostaining for $y$ H2AX after 24 hours of incubation with DOXO at indicated concentration. DOXO-RFP channel represents the fluorescent signal of DOXO, used for identification of the nuclei at higher DOXO concentrations. $B+C)$ Fluorescent micrographs showing the presence of phosphorylated $H 2 A X$ after $24 \mathrm{~h}$ of analogue incubation at indicated concentration. Note the loss of DAPI signal due to DNA binding competition between DOXO/ACLA and DAPI. Scale bar $=100 \mu \mathrm{m}$ 
A

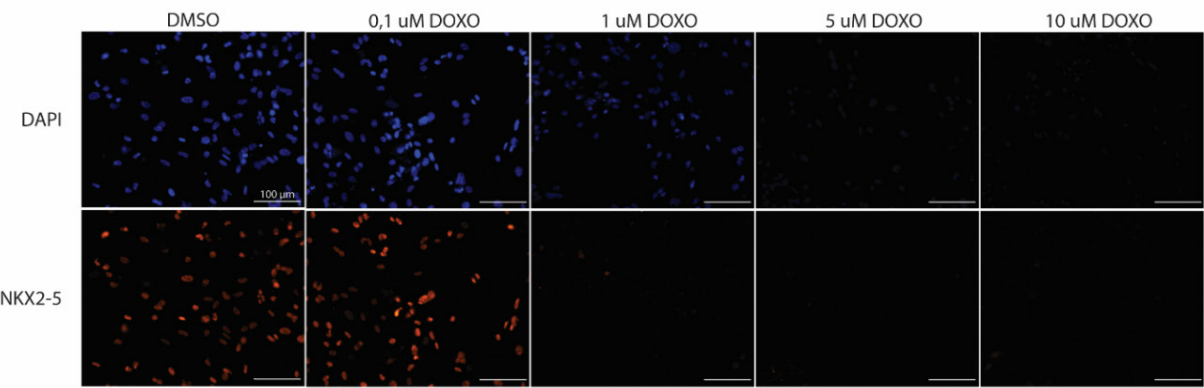

B

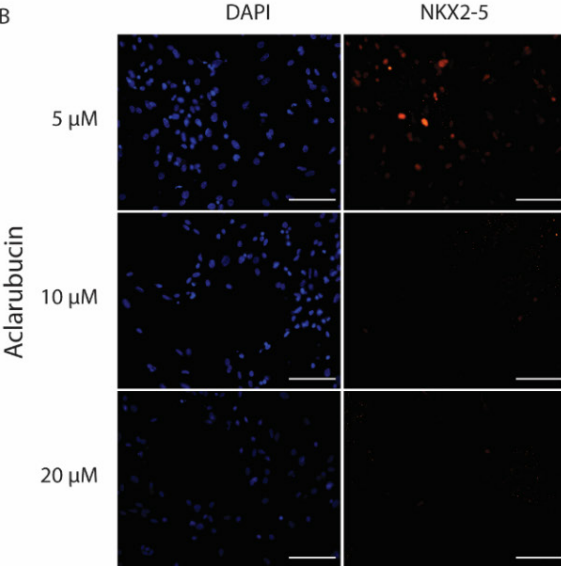

D
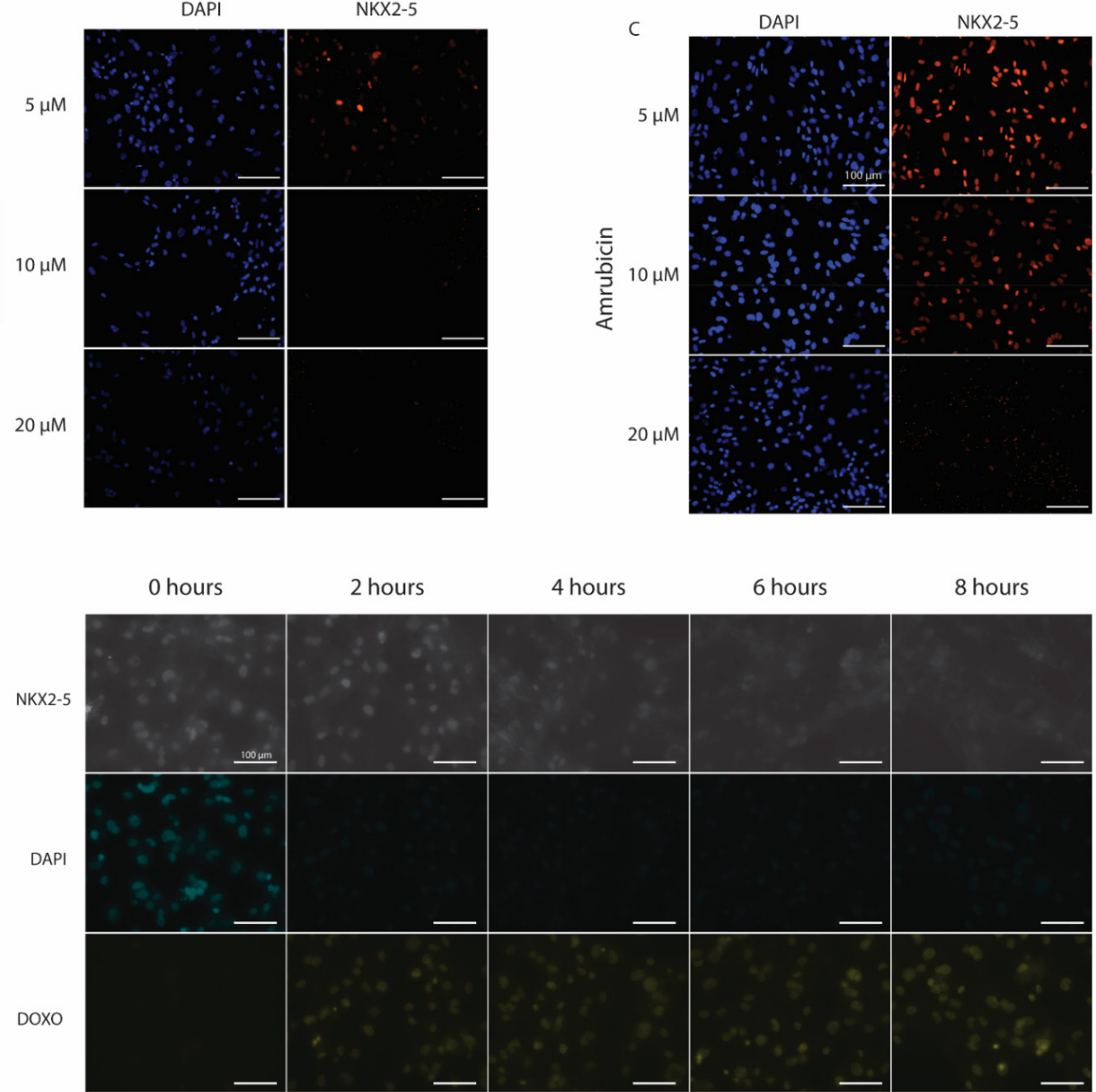

6 hours

8 hours

Figure 7: Quantification of transcription factor NKX2-5 in the nucleus of hPSC-CMs using immunofluorescent tagging. A) NKX2-5 protein localization after $24 \mathrm{~h}$ of DOXO exposure to hPSC$C M s$ at the indicated concentration. $B+C)$ NKX2-5 protein localization after ACLA and AMR exposure for $24 \mathrm{~h}$ at indicated concentration. D) Time course of NKX2-5 loss upon exposure to DOXO. E) Time course of NKX2-5 recovery after $24 \mathrm{~h}$ DOXO incubation followed by washout at the $24 \mathrm{~h}$ timepoint. 


\section{Discussion}

This chapter is dedicated to the application of hPSC-CMs in safety pharmacology in a $2 \mathrm{D}$ and $3 \mathrm{D}$ organization. We created a platform of assays capable of predicting cardiac toxicity caused by doxorubicin exposure, with readouts that match observations in vivo. We demonstrated that DOXO at physiologically relevant concentrations can 1) cause direct cell damage and loss, 2) trigger calcium accumulation and alter ion balance, 3) induces double strand DNA breaks in CMs (at low concentrations), 4) affect functional performance of 3D EHTs with respect to contractile force and contraction kinetics, and 5) affects the CM transcriptome partially through downregulation of NKX2-5 and subsequent down-stream targets of the transcription factor. Moreover, we demonstrated that toxicities of analogues AMR and ACLA could be distinguished from DOXO due to the combination of assays within the platform, exposing differential working mechanisms of toxicity between the three compounds. Our findings indicated that AMR treatment is more favorable than DOXO in terms of cell viability and functional EHT performance. In accordance with previously reported in vivo studies, AMR only induced DSBs, but did not evict histones from the nucleus. Its action on cardiomyocyte viability and performance is therefore more benign than ACLA.(6) ACLA on the other hand showed a very similar pattern of damage induction compared to DOXO: EHT performance is affected in a dose-dependent manner and it lowered cell viability to a level equal to DOXO. DNA damage is difficult to assess, since ACLA may invoke the same histone eviction response as DOXO, hampering H2AX quantification. The significance of DNA damage in CMs to the total cardiotoxic event is unclear. In our data, we observed DNA damage at 0,1 $\mu \mathrm{M}$ DOXO, a concentration that does not seem to affect viability of the monolayers, contractility of the EHTs, or transcription of NKX2-5 and other genes. Therefore, the onset of DNA damage as a marker for cardiotoxicity is perhaps more sensitive than other assays performed in this platform but may also be less predictive of $\mathrm{CM}$ malfunction and thus toxicity itself.

The significance of NKX2-5 loss requires additional evaluation, but first evidence seems to point to an important role. NKX2-5 as a transcription factor is involved in the expression of key cardiac genes in cardiomyocytes, including calciumhandling proteins RYR2 and SERCA2.(9) The speed at which the function of these proteins would be disturbed upon loss of the transcription of their respective genes is unknown, however it is striking to observe both a mishandling of calcium in DOXO treated cardiomyocytes in our platform, and the loss of NKX2-5 as a regulator for the proteins responsible for the calcium handling. Indeed, RYR2 and SERCA2 transcription is negatively affected by a loss of NKX2-5 (NKX2-5 facilitates the transcription of these genes), and a loss of function of either, or both, would result in an accumulation of calcium ions in the cytoplasm, which corresponds well with the calcium overload that is observed in treated CMs. Our data shows 

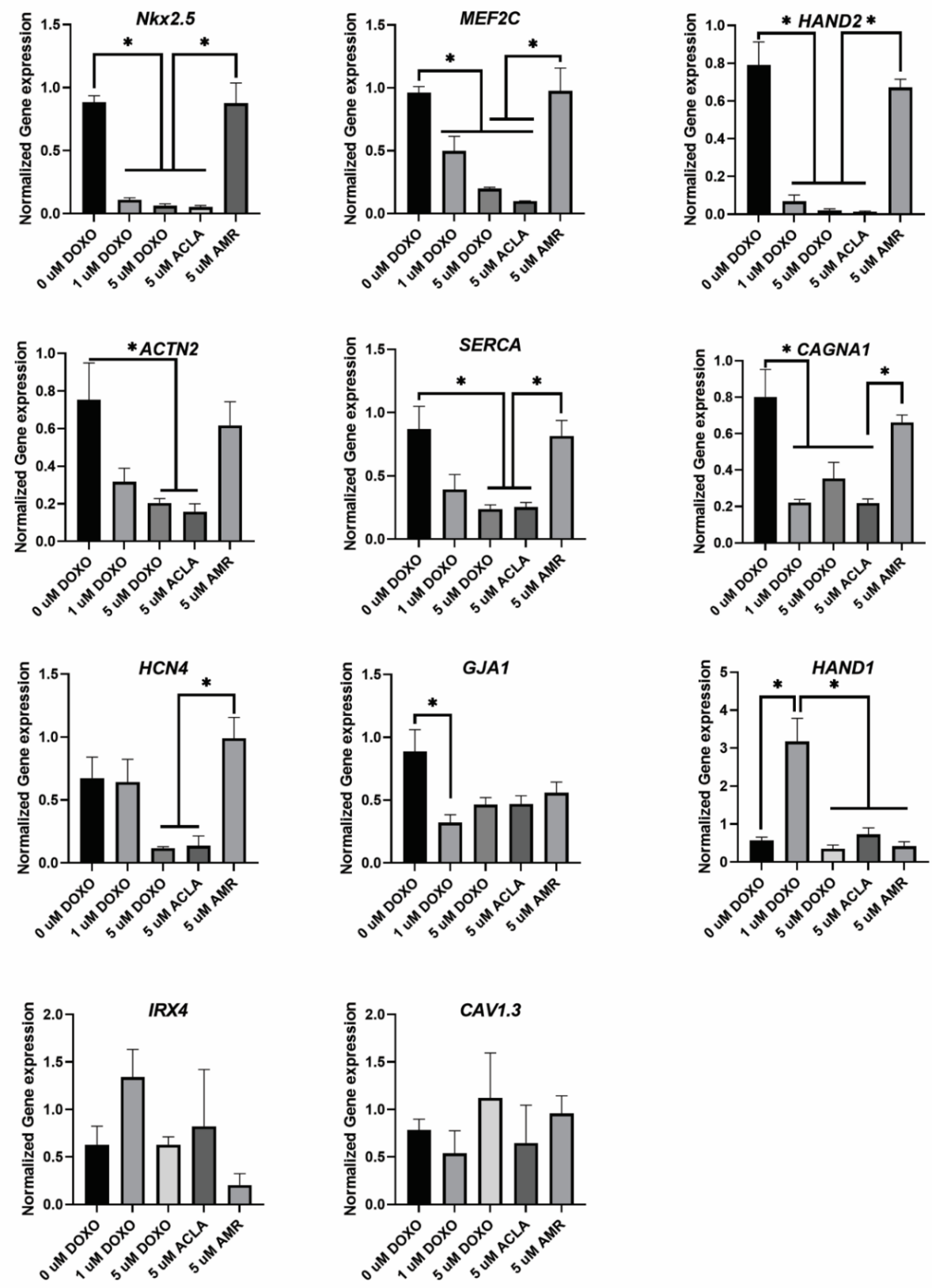

Figure 8: Gene expression analysis by qPCR of transcriptome isolation from EHTs after $72 \mathrm{~h}$ exposure to DOXO. 
that NKX2-5 protein disappears from the nucleus within 6 hours after DOXO exposure, a timing that holds clinical relevance, since patients are treated with a single high dose bolus infusion per treatment. Recovery time of NKX2-5 in the nucleus may be crucial to the extent of disruption the loss of the transcription factor will cause. If this period of NKX2-5 protein loss is long enough to affect protein function of the downstream targets of NKX2-5, it may explain some of the cardiotoxic mechanisms observed in CMs. The loss of NKX2-5 signal in ACLA treated cells is correlated to the loss of $\mathrm{H} 2 \mathrm{AX}$ and is more severe than in cells treated with AMR. If the loss of NKX2-5 proves to be another contributor to CM damage, this may point to a more toxic nature of ACLA compared to AMR, making $A M R$ the preferable analogue to use in terms of cardiotoxicity.

Some limitations to this study may be mentioned. Firstly, Calcein live staining is used to quantify the integrity of hPSC-CM monolayers as a measure of cell viability.

\begin{tabular}{|l|l|l|}
\hline Antibody target & dilution & Supplier \\
\hline Mouse- $\alpha$-yH2AX & $1: 200$ & Merck (05-636) \\
\hline Rabbit- $\alpha$-NKX2-5 & $1: 400$ & Cell signalling technology (\#8792) \\
\hline Goat- $\alpha$-Rabbit AlexaFluor 647 & $1: 400$ & ThermoFisher (A21244) \\
\hline Goat- $\alpha$-Mouse AlexaFluor 488 & $1: 400$ & ThermoFisher (R37120) \\
\hline
\end{tabular}

Table 1: List of antibodies with dilution factor and supplier.

While it is expected that subsequent loss of monolayer integrity is due to cell death, it cannot be excluded that some loss may also be caused by detachment of the hPSC-CM before the cell is dead. Therefore, loss of monolayer integrity may represent both cell death and cell detachment, although cell detachment in case of CMs may also be considered a substantial toxic effect. Secondly, the exposure to DOXO or analogues in this work is strictly speaking not like clinical exposure, since patients in the clinic are infused with one bolus per treatment, resulting in a fast peak and decline of DOXO in the serum. Our study exposes the hPSC-CMs at least for 24 hours, depending on the stability of DOXO in the culture medium, and up to 5 days with continuous refreshment of DOXO in the EHT platform. Whether this exposure regime mimics the in vivo setting properly is up for debate, however in our platform this handling resulted in expected toxicity outcome and proved able to determine the difference in toxicity between DOXO and analogues. Thus, even though the exposure regime does not completely align with the clinical situation, it proves adequate in our platform. Thirdly, the 2D and 3D models described here are a simplistic representation of the in vivo heart, and other factors may play a role in cardiotoxicity in the patient. It is expected that endothelial cells in the heart may have a great effect on actual cardiomyocyte exposure to the anthracycline, since they effectively shield the CMs from the circulation. At what rate the endothelial cells allow DOXO to pass on to the CMs 
is unclear, however the endothelial layer of the heart is rather permeable and may thus not pose a major barrier for anthracyclines to pass.

This, however, does not diminish the contribution of other cell types in the heart to the complete cardiotoxic effect of DOXO. It has been reported that endothelial dysfunction as a result of DOXO may directly be responsible for the acute cardiotoxic response of the organ, demonstrating the importance of including other cell types to the platform. DOXO-induced toxicity may also involve the development of cardiac arrhythmias, especially in the atria(10), which may suggest that DOXO toxicity may vary between cardiomyocyte subtypes. Moreover, resident macrophages have recently been implied as important supportive cells in the heart, specifically the atrio-ventricular node, that may directly influence the gene expression profile of the surrounding tissue, thus affecting contractility and action potential signal conduction. If DOXO also affects the function of these residential macrophages, it is not unthinkable that their altered / loss of function may induce impaired contractility of the heart. LVEF reductions observed in patients may be caused by a reduced contractile capacity of cardiomyocytes on the level of sarcomeres but may also be caused by an impaired signal transduction and thus cardiomyocyte activation. It has been previously suggested that DOXO may not only directly induce cardiotoxicity in cardiomyocytes themselves, but may also exert an effect on contractility via affecting cardiac subtypes such as nodal pacemaker cells(11), and proliferative cell types of the heart, such as endothelial cells, fibroblasts, smooth muscle cells and others. Therefore, it is of great interest to assess the effect of DOXO exposure on cardiac subtypes when screening for toxicity in vitro, since ventricular cardiomyocytes alone might not provide a complete picture of the toxicity.

\section{Conclusion}

In this chapter, we describe the development of a screening platform capable of predicting cardiotoxic effects of anti-cancer drug Doxorubicin and its analogues. We show that the toxic mechanisms of DOXO described in literature could be faithfully recapitulated in a dose-dependent manner and could be successfully applied to determine the toxicity of the analogues AMR and ACLA in relation to DOXO. Our platform indicates that AMR is less toxic to hPSC-CMs with respect to cell viability and contractility than DOXO or ACLA and proposes it as a preferred anti-neoplastic agent to be evaluated for further use in the clinic.

\section{Materials and Methods}

Cell maintenance

Two previously characterized stem cell lines were used in this study, one iPSC line designated FLB (LUMC0020iCTRL-06) and the DRRAGN (ACTN2 ${ }^{\text {mRubyll }}$ / NKX2-5 ${ }^{\text {GFP }}$ double reporter) hESC line reported in Chapter 3 of this thesis, only 
used for the sarcomere organization assay. Both cell lines were maintained as described previously. Briefly, the cells were maintained in Essential 8 medium (ThermoFisher) on vitronectin-coated CellStar cell culture plates. Passaging was done twice per week, by dissociation using 0,5 mM EDTA in PBS, resuspension in E8 medium, counting using Trypan blue and reseeding at a density of $17 \mathrm{~K}$ cells / $\mathrm{cm}^{2}$ on Mondays and $10 \mathrm{~K}$ cells $/ \mathrm{cm}^{2}$ on Thursdays for the DRRAGN line, and 50K cells on Monday and 30K cells on Thursday for the FLB line.

\section{Cardiac differentiation}

Differentiation to ventricular cardiomyocytes was done as described previously. (12) Briefly, hPSCs were seeded at a density of $25 \mathrm{~K}$ cells per $\mathrm{cm}^{2}$ for the DRRAGN line and $15 \mathrm{~K}$ cells per $\mathrm{cm}^{2}$ for the FLB line, on Matrigel (Corning)-coated 6-well plates in Essential 8 medium (ThermoFisher) on day -1. At day 0, mesodermal differentiation was initiated by addition of Wnt activator CHIR99021 $(1.5 \mu \mathrm{mol} / \mathrm{L}$, Axon Medchem 1386), Activin-A (20 ng/mL, Miltenyi 130-115-010) and BMP4 (20 $\mathrm{ng} / \mathrm{mL}$, R\&D systems 314-BP/CF) in BPEL medium (described in (13)). At day 3 , Wnt was inactivated by adding XAV939 ( 5 umol/L, R\&D Systems 3748$)$ in BPEL. In addition, Matrigel (1:200) was added to promote adhesion of cells. Cell cultures were refreshed on Day 7 and 10 with BPEL after the start of differentiation until differentiation was completed (day 13). At day 13 of differentiation, CMs were purified in glucose-free-lactate-containing medium for 3 days. After purification, CMs were cultured in CM-TDI medium.(14) For all assays in 2D, CMs were seeded as monolayers into CellCarrier-96 well special optics plates (PerkinElmer). HPSC$\mathrm{CMs}$ were maintained in a humidified incubator at $37 \circ \mathrm{C}$ and $5 \% \mathrm{CO}_{2}$ and were refreshed with CM-TDI medium twice a week.

\section{Anthracycline exposure}

HPSC-CMs were maintained for 10 days after seeding in the test plate or after formation of the EHT to allow full recovery after dissociation. Then, CM-TDI medium containing $10 \mu \mathrm{M}$ dimethylsulfoxide (DMSO) or compound at respective concentration was added to the cells, starting the exposure to the compound. Depending on the experiment, the cells were incubated with the medium and compound for 24 hours or 5 days. EHTs required refreshment of the medium every day and were refreshed with CM-TDI with the compound, however monolayers exposed to compounds for multiple days were not refreshed in between.

\section{Flow Cytometry}

CMs were stained with Cardiac Troponin TAntibody-VioBlue and were immediately quantified with a MACSQuant VYB flow cytometer (Miltenyi Biotech). Plots were analyzed with FlowLogic software. 


\section{hPSC-CM viability assay}

Cardiomyocytes cultured in monolayer in 96 well culture plates for imaging (CellCarrier-96, PerkinElmer) at a density of 30k cells per well were exposed to 24 hours of anthracycline in a concentration range. Calcein AM (ThermoFisher) live cell dye in PBS at $4 \mu \mathrm{M}$ was added to the cells in the well after washing the well $1 \mathrm{x}$ with DPBS. The dye was incubated with the cells for 30 minutes at $37^{\circ} \mathrm{C}$ inside a $\mathrm{CO}_{2}$ incubator, followed by microscopic analysis using the EVOS auto II (ThermoFisher) imaging system. Keeping the acquisition settings constant, the Calcein AM fluorescent signal was captured using the GFP filter cube at 482/25 $\mathrm{nm}$ excitation; 524/24 nm emission, making 12 images per culture well. Calcein signal as a fraction of total surface area was then assessed by a custom ImageJ macro, selecting the Calcein signal using a hard (manual) threshold set constant per replicate batch, of which the area was divided over the total area of the image. This fraction represented the area covered by live cells, thus viability of the hPSC-CMs.

\section{Immunocytochemistry}

Monolayer hPSC-CMs were exposed to anthracyclines equal to the Calcein live cell quantification but were fixed in the culture plate with $4 \%$ formaldehyde for 15 minutes after the anthracycline exposure was completed. After fixation, plates were stored at $4^{\circ} \mathrm{C}$ until immunostaining was performed. For this, cells were permeabilized with $0,1 \%$ Triton-x100 for 8 minutes at RT, followed by blocking with $10 \%$ normal goat serum $+2 \%$ BSA in PBS for 1 hour at RT. Next, primary antibodies were added in 2\% BSA in PBS buffer, and incubated for 1,5 hours at $\mathrm{RT}$, or overnight at $4^{\circ} \mathrm{C}$. Secondary antibody was added after $3 x$ washing with PBS in a $2 \%$ BSA in PBS buffer, and incubated for 1 hour at RT. Finally, the secondary antibody solution was washed off by $3 x$ rinse in PBS of 5 minutes each, followed by a DAPI counterstain for 5 minutes at RT. Plates we kept at $4^{\circ} \mathrm{C}$ in PBS for microscopic analysis and further storage. A list of antibodies with their respective dilutions is provided in table 1.

\section{$\mathrm{Ca}^{2+}$ kinetics measurements}

Calcium kinetics were analyzed by fluorescent microscopy using the Fluo-4-AM (ThermoFisher) $\mathrm{Ca}^{2+}$ imaging dye. For this, cells were cultured in 96 well monolayer format, incubated for 24 hours with anthracyclines or DMSO as described above and stained with Fluo-4 solution at $1 \mu \mathrm{M}$ with Pluronic-127 at 1:20 for 30 minutes at $37^{\circ} \mathrm{C}$. After incubation, cells were washed and put back in CM-TDI medium for subsequent analysis by microscope. Calcium imaging was performed on a Nikon Eclipse TE2000-U fluorescent microscope equipped with a mercury light source at $37^{\circ} \mathrm{C}$ and $5 \% \mathrm{CO}_{2}$. Fluo-4 signal was captured in a video of tiff-stacks at $70 \mathrm{fps}$ with constant acquisition settings between samples, using a FITC cube at $465-495 \mathrm{~nm}$ excitation; $515-555 \mathrm{~nm}$ emission at $20 x$ magnification. Images 
were thereafter analysed with custom software assessing fluorescent intensity per tiff frame, plotting intensity versus time and calculating the beat frequency, time-to-peak and time-to-decay from these plots. The minima of the fluorescent intensity provided the data for calcium accumulation within the cells.

Engineered heart tissue fabrication and contractility measurement.

Engineered heart tissues were generated as described previously. Force of contraction and contraction kinetics were recorded 10-12 days after tissue formation. During measurement, tissues were paced at $2 \mathrm{~Hz}$. The next day, a second force measurement was performed, and treatment was started. Fresh DOXO medium was prepared for each daily treatment. To study a cumulative dose of DOXO tissues were refreshed daily. Force of contraction and contraction kinetics were measured every 12 hours for 72 hours.

qPCR

RNA was isolated from EHTs 72 hours after treatment using the Nucleospin mini kit (Macherey-nagel, 740955.250). CDNA was synthesized using the iScript CDNA synthesis kit (Bio-Rad, 1708891) and QPCR was carried out using SensiMix SYBRGreen (Meridian Bioscience, QT615-05) on the CFX384 real-time PCR detection system (Bio-Rad).

Statistical analysis

Statistical analysis was performed using GraphPad Prism 8. Groups were compared using One-way ANOVA, unless stated otherwise. Data is represented in mean \pm s.e.m. unless stated otherwise. 


\section{References}

1. Chatterjee K, Zhang J, Honbo N, Karliner JS. Doxorubicin cardiomyopathy. Cardiology. 2010;115(2):155-62.

2. Weiss RB, Sarosy G, Clagett-Carr K, Russo M, Leyland-Jones B. Anthracycline analogs: the past, present, and future. Cancer Chemother Pharmacol. 1986;18(3):185-97.

3. Rivankar S. An overview of doxorubicin formulations in cancer therapy. J Cancer Res Ther. 2014;10(4):853-8.

4. Schwach V, Slaats RH, Passier R. Human Pluripotent Stem Cell-Derived Cardiomyocytes for Assessment of Anticancer Drug-Induced Cardiotoxicity. Front Cardiovasc Med. 2020;7:50.

5. Nebigil CG, Desaubry L. Updates in Anthracycline-Mediated Cardiotoxicity. Front Pharmacol. 2018;9:1262.

6. Qiao X, van der Zanden SY, Wander DPA, Borras DM, Song JY, Li X, et al. Uncoupling DNA damage from chromatin damage to detoxify doxorubicin. Proc Natl Acad Sci U S A. 2020;117(26):15182-92.

7. Truitt R, Mu A, Corbin EA, Vite A, Brandimarto J, Ky B, et al. Increased Afterload Augments Sunitinib-Induced Cardiotoxicity in an Engineered Cardiac Microtissue Model. JACC Basic Transl Sci. 2018;3(2):265-76.

8. Poizat C, Sartorelli V, Chung G, Kloner RA, Kedes L. Proteasome-mediated degradation of the coactivator p300 impairs cardiac transcription. Mol Cell Biol. 2000;20(23):8643-54.

9. Toko H, Zhu W, Takimoto E, Shiojima I, Hiroi Y, Zou Y, et al. Csx/Nkx2-5 is required for homeostasis and survival of cardiac myocytes in the adult heart. J Biol Chem. 2002;277(27):24735-43.

10. Ambrosini G, Balli M, Garusi G, Demicheli R, Jirillo A, Bonciarelli G, et al. Phase III randomized study of fluorouracil, epirubicin, and cyclophosphamide $v$ fluorouracil, doxorubicin, and cyclophosphamide in advanced breast cancer: an Italian multicentre trial. J Clin Oncol. 1988;6(6):976-82.

11. Chen S. Abstract 476: Pharmacogenetics and Drug Discovery for Anthracycline-Induced Cardiotoxicity Enabled by Sinoatrial Node-like Cells Derived From Human Pluripotent Stem Cells. Circulation Research. 2019;125(Suppl_1).

12. Ribeiro MC, Slaats RH, Schwach V, Rivera-Arbelaez JM, Tertoolen LGJ, van Meer BJ, et al. A cardiomyocyte show of force: A fluorescent alpha-actinin 
reporter line sheds light on human cardiomyocyte contractility versus substrate stiffness. J Mol Cell Cardiol. 2020;141:54-64.

13. Birket MJ, Ribeiro MC, Verkerk AO, Ward D, Leitoguinho AR, den Hartogh SC, et al. Expansion and patterning of cardiovascular progenitors derived from human pluripotent stem cells. Nat Biotechnol. 2015;33(9):970-9.

14. Birket MJ, Ribeiro MC, Kosmidis G, Ward D, Leitoguinho AR, van de Pol V, et al. Contractile Defect Caused by Mutation in MYBPC3 Revealed under Conditions Optimized for Human PSC-Cardiomyocyte Function. Cell Rep. 2015;13(4):733-45.

Supplementary figures

Supplementary Figure 1 (next page): DOXO, ACLA and AMR toxicity on hESCs. Stem cells were treated with 1 uM of either compound and monitored over the course of 24 hours. Disruption of the stem cell colony can be seen in the transmitted channel images, while the RFP fluorescent filter was used to visualize uptake of the anthracycline. Scale bar $=50 \mu \mathrm{m}$. 


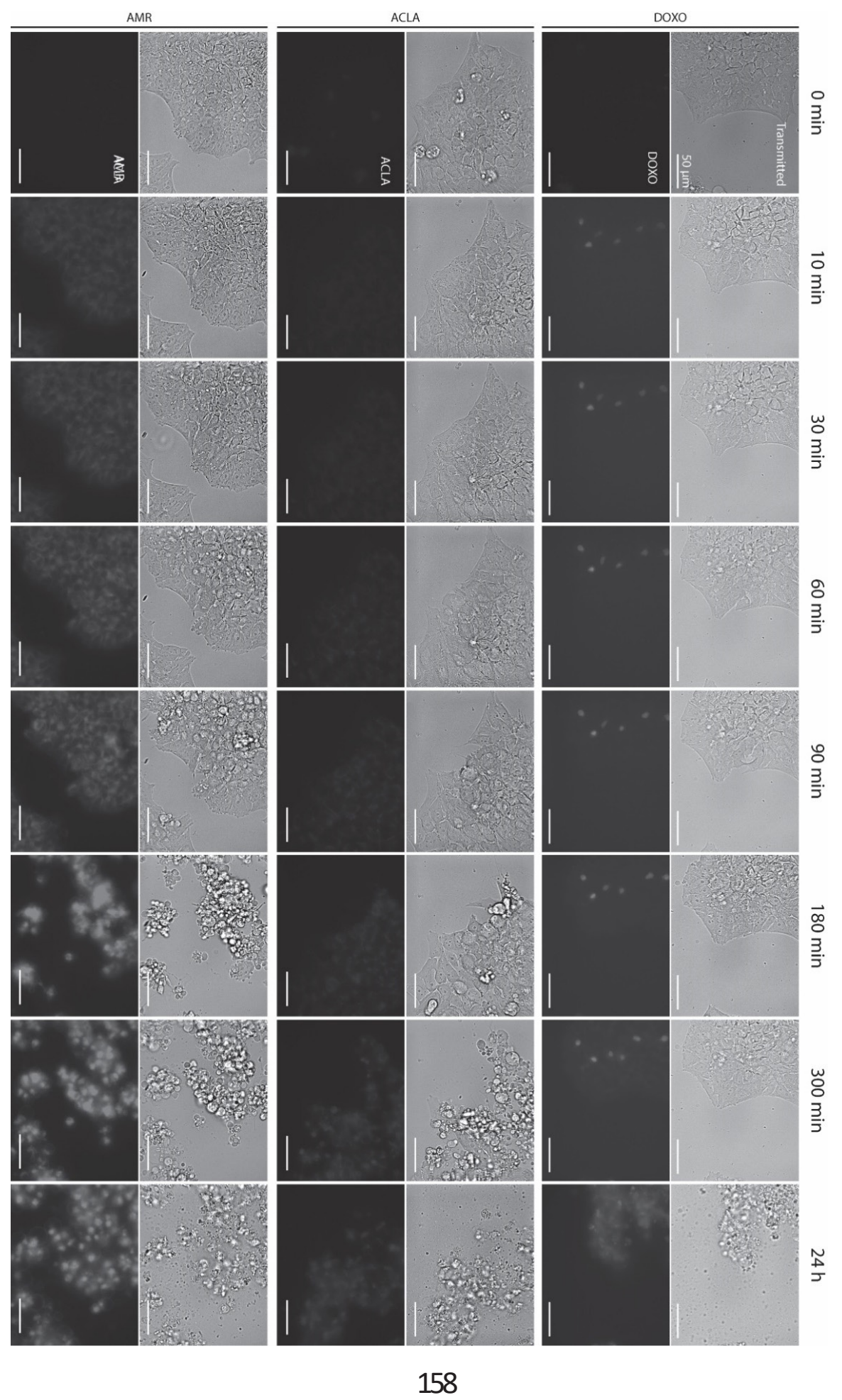




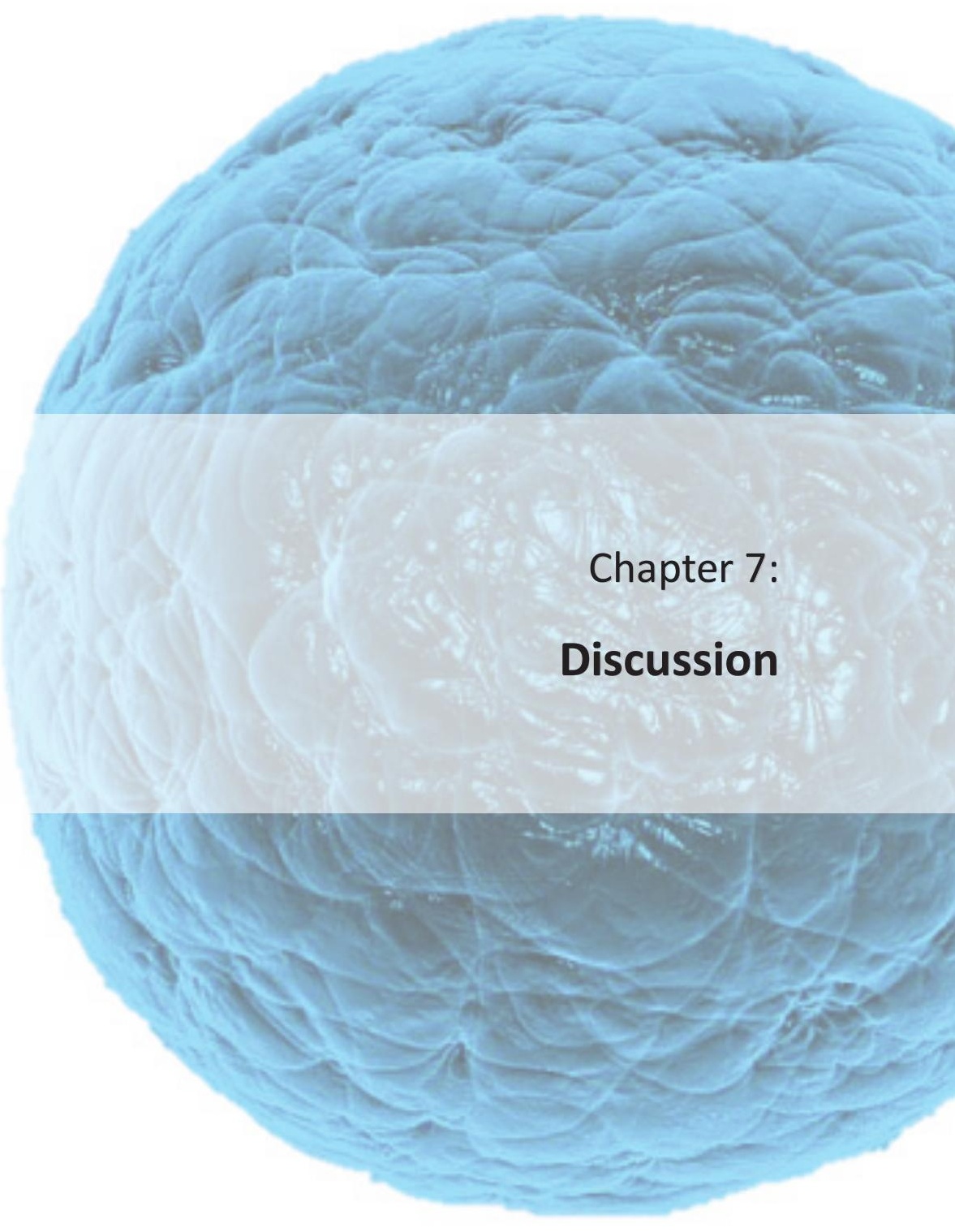

161 


\section{Chapter 7: Discussion}

This work encompasses experimental and theoretical data on the use of human pluripotent stem cells (hPSCs) in modeling health and disease of the heart. In Chapter 2, we postulate that adverse exposure to metabolites may, as seen in vivo, lead to a type of "fetal programming" of the hPSC-derived cardiomyocyte (hPSC-CM), limiting their maturation and affecting their function.(1) We designed an optimal culture medium for hPSC-CMs based on metabolite values found in the serum during embryonic, fetal and adult stages of life, containing lactate and fatty acids in a metabolically relevant quantity. This alternative culture medium may partially alleviate the shortcomings in (metabolic) maturity of the hPSC-CMs in in vitro heart modelling. In Chapter 3, we apply CRISPR gene editing technology to generate the Double Reporter of mRubyll_ACTN2 and GFP_NKX2-5 (DRRAGN reporter) cell line that allowed us to visualize striated sarcomeres for live cell imaging and evaluate the contractile properties of hPSC-CMs on substrates with increasing stiffness.(2) We found that hPSC-CMs are able to adjust their contractile power output in response to increased substrate resistance, up to a maximum of $90 \mathrm{kPa}$ of stiffness. A higher stiffness could not induce more force output of the CMs but demonstrated a potential tipping point where sarcomeres continued to shorten but the cytoskeleton could not follow, which may be a trigger for CM hypertrophy in the setting of cardiac remodeling after insult. In Chapter 4, we describe the use of these DRRAGN cells to derive and characterize a cell population closely related to the sino-atrial node (SAN) pacemaker cells found in the adult human heart. Because of the absence of NKX2-5 expression in SAN pacemaker cells, the DRRAGN reporter proved useful in the distinction between cardiomyocytes (CMs) and putative pacemaker myocytes (PPMs) and could be differentiated into cells that may be precursors of the nodal pacemaker cell, presenting a substantial overlap of expressed PM marker genes. In Chapters 5 and 6, we discuss and apply the use of hESC-CMs, including the DRRAGN line, in cardiotoxicity screening of anti-neoplastic drugs, in particular Doxorubicin (DOXO) and its analogues. We discuss the current role of hPSC-CM models in cardiotoxicity screening, revealing a shortcoming of these models that limit their usefulness to screening, and highlight that latest 3D models and microfluidic models are promising new tools to screen for toxicity with hPSC-CMs as the cell source.(3) We then apply our own hPSC-CMs on a model for DOXO-induced cardiotoxicity and show in 2D and 3D formats that the mechanisms of DOXOinduced cardiac damage may be recapitulated in vitro using these cells, and that differences in toxicity between DOXO and analogues could be quantified. Overall, pluripotent stem cell-derived cardiomyocytes have a central role in the chapters of this thesis and, despite their limitations, demonstrate a clear usefulness in modeling cardiac physiology and disease. 
Cardiomyocyte differentiation from hPSCs has been widely established, and can be achieved with high efficiency and productivity.(4) Cardiac subtypes can be derived and isolated on demand, in order to combine cell types in a controlled ratio, thus enabling highly controlled cardiac cultures or tissues. The main advantage of this cell source is the human origin of the $\mathrm{CMs}$, which make the CMs a more relevant cell type than $\mathrm{CMs}$ originating from animal sources because of, amongst others, the fundamental difference in (electro)physiology between CMs of different species. Also, the use of human stem cells enables the generation of various cell types of the heart in theoretically unlimited numbers, in contrast to using adult cells derived from patient biopsies, which come in extremely limited availability. However, differentiating CMs and other cell types from hPSCs has its drawbacks, including uncertainty of derived cell phenotype and general immature state of the differentiated cell. These drawbacks are partially linked, as immature cells may not reflect the adult counterparts found in the human body and as such may be classified as "precursor" or "progenitor" cells that, as a consequence, express a different phenotype than the intended cell type of the adult stage. Proper characterization of the derived cell type is therefore important, and conclusions based on these cells should be carefully considered. For example, in Chapter 4 we describe the derivation of PPMs which have substantial overlap in phenotypic traits with the SAN pacemaker cell found in the adult heart, however since the overlap is not complete, we could not state that these cells are indeed SAN PMs and are thus of a different phenotype. This may be caused due to incomplete differentiation, or immaturity, but could also be caused by a differentiation protocol that simply steers the stem cells to a different cell type. Either way, in vitro derived cardiac cells reflect the human adult counterpart to more or lesser extent, which can affect their usefulness in organ and disease modelling. Indeed, work in this thesis shows signs of deficient maturity of CMs used in various experiments. In Chapter 3 , immaturity of the CMs can be directly observed in the lower absolute contractile force of the cells compared to adult human CMs $\left(160 \mu \mathrm{N} / \mathrm{mm}^{2}\right.$ in the hESC-CMs versus $51.000 \mathrm{uN} / \mathrm{mm}^{2}$ in adult human $\mathrm{CMs}(5)$ ), and the irregular contraction of the sarcomeres within one myofibril. Nevertheless, immaturity does not make the hPSC-CM useless in obtaining valuable information on human heart physiology. In Chapter 6 , toxicity of Doxorubicin and analogues is quantified in CMs that lack the mature state of the adult heart CMs, however the cells do recapitulate cardiac toxicity that has been described in other studies and in the clinic. $(3,6)$, Moreover, immature CMs do demonstrate a contractile response to increased substrate stiffness that recapitulates the hypertrophic response of adult $\mathrm{CMs}$ in cardiomyopathic circumstances in Chapter 3.(7) Due to the short culture time on these substrates (4 days), this effect must be attributed to a short term response of the CMs to the stiffness of the substrate, however mechanical loading is also known to enhance maturation of hPSC-CMs.(8) It may therefore be worth investigating whether the 
CM response is purely hypertrophic or whether these cells show initial signs of enhanced maturity. The maturity of hPSC-CMs across the scientific field is typically regarded as fetal, and thus may not recapitulate all functional and pathological responses of a mature cardiomyocyte. As mentioned above, one may speculate that the relative immaturity of hPSC-CMs is effectively caused by an incomplete differentiation or development of the cell towards adult CMs. This incomplete differentiation must be due to the absence of a trigger found in vivo, that is not recapitulated in vitro. Multiple studies describe or speculate on the value of an added trigger for improved maturation of the cardiomyocyte, including mechanical or electrical stimulation, co-culture with other cardiac cell types, 3D culture, and maturation factors added to the culture medium.(8) All of these maturation triggers are designed to recapitulate an exposure presumably found during in vivo development and aim to enhance CM maturation through improved biomimicry. However, none of these stimuli truly imitate the in vivo situation for the in vitro differentiated $\mathrm{CMs}$, and consequently fail to mature the $\mathrm{CM}$ to the level of an adult cardiomyocyte. It would thus seem that, in order to achieve full maturation, all but a complete human heart needs to be developed in vitro, a task that is as daunting as it is unrealistic at this point. The choice of using hPSC-CMs for heart model development, although more relevant due to the use of human cells, thus suffers from reduced predictability through cellular immaturity. Nevertheless, step-by-step, the culture conditions for hPSCs are moving in that direction. One major factor in cell environment that has been largely ignored, is the artificial exposure of cells to their metabolites in conventional in vitro systems. In static culture systems, cell culture medium is refreshed in regular intervals to provide cells with nutrients and remove waste products, however this practice leads to fluctuations of metabolite concentrations that rapidly change upon medium refreshment. Cells in static cultures are for example exposed to diabetically high initial glucose levels that decline to subphysiological levels over time because of cellular consumption, only to be refreshed back to overdose in an instant. This fluctuation of metabolites cannot be found in vivo. Although metabolite levels may fluctuate according to fasting state, an equilibrium is rapidly restored so that serum concentrations remain constant over time. Since it has been shown that cells respond to surrounding metabolite concentrations(9-11), in vitro fluctuations during culture may affect their behavior and, although sufficient to keep the cells alive, may affect their state of maturity and function. The conclusions made in Chapter 2 concerning the physiological nutrient levels in culture medium therefore need to be adjusted to the notion that this optimal culture medium should be supplied to the cells in a steady flow or refreshment. In the field of Organ-on-chips (OOCs), this continuous refreshment is achieved by culturing cardiac cells in fluidic channels that may be connected to fluid pumps, allowing precise control over culture medium, or even whole blood, flow speed and pattern. Although OOC systems 
thus recapitulate this continuous refreshment, mimicking blood circulation, the effect of continuous refreshment versus static culture on CM maturation or metabolism has not been extensively explored. Continuous flow in OOCs is required for cell survival since the culture volume is extremely low and the medium would otherwise be depleted of nutrients rapidly without refreshment. This necessity and the ability to administer factors to cells with a temporal resolution makes OOCs an interesting model for exposure studies such as cardiotoxicity studies. Complex OOCs with coculture of endothelial cells lining the perfused microchannel may, for example, better mimic the delivery of Doxorubicin to the CMs, as DOXO may be administered with more controlled pharmacokinetics and has to cross the endothelial barrier of the "blood vessel" which is more in line with the in vivo situation. Purely for maintaining CM cultures in vitro though, OOCs have too little a capacity to be efficient in deriving adequate numbers of $\mathrm{CMs}$ or other cell types and would only be used for experimental purposes. This argues for a larger culture system that can house CMs in the order or millions and be perfused steadily with a physiologically appropriate culture medium. Devices such as bioreactors may be appropriate for this purpose, alternatively larger scale millifluidic devices may be constructed to enable vast numbers of cells to be cultured under flow conditions. Be that as it may, mimicking the exact cardiac micro-environment is incredibly hard, since there are no means to exactly quantify the content of the extracellular space directly surrounding the developing CM in vivo. The optimized culture media proposed in Chapter 2 are based on measurements of metabolites in fetal and adult serum, and since CMs in vivo are not directly exposed to serum because of the endothelial layer of the blood vessels, they do not exactly reflect the cardiac micro-environment. In addition, factors released by surrounding cells are not taken into account but may play an important role in cardiomyocyte development and behavior. Therefore, even under flow conditions, it will be challenging to completely recapitulate the exposure of hPSC-CMs to metabolites and other factors in a manner that reflects the in vivo situation. Still, a considerable advancement on cell maturation and function may be gained by improving cell culture techniques in this direction, especially when combined with complex multicellular 3D formats such as engineered heart tissues (EHTs), organoids or mini-heart tissues.

Chapter 6 of this thesis contains data generated by 3D culture of CMs and related cardiac cell types in the form of EHTs. The primary readout of these EHTs is contractility, specifically contractile force, which is approximated using the optical determination of support pole deflection by tissue contraction and the material stiffness value of the pillar.(12) EHTs and other 3D cardiac constructs provide information on cardiomyocyte function and generate data that are more closely related to heart function in vivo. Even though these EHTs or equivalent constructs have been reported in literature extensively as an invaluable model 
of cardiac functionality in for example toxicology research, they are susceptible to misinterpretation of the individual contractile force of cardiomyocytes within the tissue and can only provide information on the performance of the tissue as a whole. This is due to two major issues with pillar deflection as a readout: 1) contracting cells that do not produce enough power to deflect the pillars are registered as "non-contractile" or no force generated, which may not be true for individual cells in the tissue. The EHT thus suffers from a lower limit of detection. This limitation was also encountered in chapter 3 , where individual $\mathrm{CMs}$ on substrates with a high stiffness were measured as 0 force generated, but indeed showed sarcomeric shortening and contraction. Thus, cell shortening, and indeed tissue shortening, are not the same as generated force by the sarcomere. 2) As in the adult heart, where timing of contraction is crucial for effective contraction of the ventricle, coordinated CM contraction in the EHT is crucial for generated force. If CMs in the ventricle or the EHT do not contract simultaneously, the serial contraction of the individual cells may not be able to build up pressure in the ventricle or deflect the pillars of an EHT. Serial contraction of the cardiomyocytes leads to focal shortening in subparts of the EHT tissue and subsequent "sliding" of the tissue along the pillars instead of deflecting them, resulting in a false contraction force measurement. Well-timed contractions of all cells in the tissue may be considered a hallmark of maturation, and thus EHT contraction force may represent maturation of the tissue, however contractile force or state of maturity of the CMs in an EHT may be underestimated if other factors affect proper EHT tissue formation. Interestingly, this effect of ill-timed contractions affecting force measurements may also be found on a sarcomeric level. Measurements in Chapter 3 provided information on CMs in which the sarcomeres within a myofibril did not contract simultaneously, resulting in reduced to no cell shortening but a high sarcomeric shortening measurement. This effect may be one of the underlying causes of sarcomere and cellular mismatch in shortening due to inadequate maturity of the CMs. Field pacing of cardiac tissues may alleviate non-synchronous contractions between cells in the same tissue, however field pacing cannot always be applied, for instance when monitoring action potential propagation in modeling arrhythmia. In addition, field pacing was applied in Chapter 3 when assessing sarcomeric dynamics and cellular contraction on several substrate stiffnesses, but this could not prevent cases of non-synchronous sarcomeric contractions.

Despite their above-described weakness, EHTs remain very effective in modeling heart tissue function, directly due to the contraction measurements that can be performed with these constructs, but perhaps also because of their 3D tissue architecture and continuously present mechanical stretch on the tissue. These features can add to CM maturity and may make the EHT model more predictable in certain heart tissue models.(8) Improvements may be made by increasing the 
complexity and organization of the EHTs though, as they are generally formed in fibrin gels with random cell distributions. Organized tissues with endothelial cells lining the cardiomyocytes on a more physiologically relevant ECM protein such as collagen I may result in better metabolic biomimicry, especially when combined with continuous perfusion, a combination that still requires testing in the lab. For instance, by applying a layer-by-layer approach for formation of the EHT, it may be possible to add a perfusable network of endothelial cells to the tissue. This would greatly enhance the relevance of the model when performing toxicity screens, drug tests or metabolic experiments, since a more in vivo like endothelial barrier separates the CMs from the compound of interest. The addition of other supportive cell types such as smooth muscle cells and fibroblasts may be necessary to facilitate a stable capillary bed, as well as to support the CMs in the tissue.

Clinically relevant read-outs can currently be obtained from recently developed 3D models, featuring a hollow structure of cardiac cells that can contract and pump fluid upon contraction of the cardiomyocytes within.(13) Such "minihearts" have the potential to provide clinical read-outs such as ejection fraction, cardiac output and stroke volume, read-outs that were previously impossible to emulate using 2D models or indeed 3D organoids and EHTs. They represent the most complex in vitro hPSC-based cardiac models and could be extremely interesting in the fields of cardiac toxicity and disease and may promote new ways to improve $\mathrm{CM}$ maturation through biomimicry. A proper combination of cardiac cell types with structured organization, relevant ECM and continuous perfusion (which is mediated by the tissue itself) would be required to reach this advanced model, which is starting to resemble the deemed impossible in vitro derived whole human heart.

\section{Outlook to the future}

The introduction of this thesis mentioned that, despite the long history of cardiac research, some of the greatest challenges have not yet been resolved. Challenges such as the use of animal models in prediction of drug efficacy or compound safety, in elucidating a mechanism of disease, or even in exploring fundamental heart physiology. To date, no combination of in vitro models can completely replace animal models in medical science. From a moral point of view, this is especially wry since mounting evidence supports the notion that the predictability of animal models is subpar, yet we do not have a better alternative. The main advantage of an animal model is the superior complexity of the model compared to anything developed in vitro. This includes not only physiological organ architecture, containing the appropriate populations of cell types, ECM material and exposure to nutrients, oxygen, and other soluble factors, but also the interaction with the immune system and the communication between organs 
and the rest of the body of the animal. Even if a mini heart could be developed in vitro containing all relevant cell types, incorporating it in a complex multiple organ system found in vivo is beyond the engineering capability of the current state of the art. Moreover, complex models suffer from complicated production processes and an enormous demand for cells, which make them rather low throughput. High complexity may not always be necessary for every study. It is thus worthwhile to evaluate whether more simple methods could provide the required answers. For example, in chapter 6 we show that a combination of assays of a relatively simple design could already predict differences in toxicity between Anthracycline analogues.

Still, considering the drawbacks of animal models, it is of great interest, for us and the animals, to develop in vitro models of equal or better predictive value than what animals can provide. Technologies such as organ-on-chips, perhaps more so than complex 3D tissue engineering, may provide a solution to this challenge. The development of multiple organs-on-chips, linked in series to allow for organ crosstalk, has already be reported in literature.(14) This represents a proof-of-concept system that may illustrate how an entire human-on-chip could replace animals in research if the system can be made complex enough to mimic all processes of the human body relevant to the research question. Since it is not always clear which systems are relevant, preferably the human-on-chip contains all systems. It goes without saying that this is a very ambitious technological goal, however research is moving into that direction already. Some concerns are the maturity status of the cells used in the organs-on-chips. Additionally, some drugs or toxins may have chronic or long-term effects, rather than acute, which needs to be accounted for when designing a human-on-chip model.(14) The advantage of human-on-chip technology is that it requires relatively low amounts of cells compared to for instance mini-heart models, and it is particularly compatible with a personalized medicine approach, since the organs of the human-on-chip could be produced using iPSCs that originate from the patient in question.

Personalized medicine encompasses the development of disease models or drug efficacy and safety screening models that contain cells, or the (epi-)genetic background, of a specific patient. This is valuable to another major challenge in (cardiac) research: Since drug response and level of toxicity varies from person to person, depending on genetic background and personal factors such as age or behavior, it is all but impossible to develop a single model (one-size-fits-all) that can accurately predict the outcome of every patient. The difference in response to drugs may lead to situations where an approved drug with successful history does not work well in a particular patient, or that the drug elicits a negative side effect not seen in other patients. Personalized drug discovery models may provide information on the robustness of the drug on the development side (i.e., will it 
work for everyone?) by including models derived from a variety of people, as well as provide information on which drug would elicit the best response in a specific patient (i.e., will it work for me?). Using a personalized medicine approach, a drug or therapy may be tailored to a specific patient so that the drug that provides the best outcome with the least side effects could be administered.(15) This makes therapies more successful and less costly.(15) Personalized medicine is not only applicable in organ-on-chip devices but can be applied on simple assays like the ones described in this thesis. For example, differences in contractility of cardiomyocytes derived from iPSCs from a patient with hereditary heart failure, such as a MYBPC3 mutation (encoding for myosin binding protein C, important for sarcomere function), compared to a healthy control may be apparent in our single cell analysis of contraction on different substrate stiffnesses described in Chapter 3. Similarly, iPSCs could be developed from patients that experienced heavy or light DOXO cardiotoxicity and could then be compared in parallel in the assays of Chapter 6 . subsequently, iPSC-CMs from a patient about to be treated with anthracyclines could be used to screen whether the cardiomyocytes will be resistant or vulnerable to DOXO exposure. From a drug development point of view, this approach would require a stem cell bank with iPSC-lines from people with a variety of backgrounds that could be used for efficacy and safety screening. From the patient's point of view, not every situation may be suitable for iPSC-based safety or efficacy screening, as it takes weeks to months to develop a patientspecific cell line and run all the required assays on them. Holding off treatment until the results of these assays are available may thus be more damaging than applying a suboptimal drug. Nevertheless, personalized medicine may greatly contribute to making medical treatment safer, cheaper, and more effective.

A final challenge for cardiac research can be found in the field of regenerative medicine. Whereas the challenges above mainly cover prevention of cardiac disease or managing it, regenerative medicine aims to repair the damage and restore the heart to a healthy condition. Since the conception of the idea, heart regeneration has not been successful, however considering the burden of CVD on quality of life and the economy, repairing a broken heart is of great interest. The field advances slowly towards functional replacement of loss cardiac tissue but is hindered by poor engraftment and coupling of a tissue engineered graft into the host tissue, often leading to arrhythmias and low retention rates of the implanted tissue. $(16,17)$ Advances in techniques to enhance complexity and maturation of in vitro developed 3D tissues could also be of interest for the field of regenerative medicine. Improving the graft architecture and maturation, in vitro or in situ, may alleviate some of these complications and enable advanced tissue engineering applications in the clinic.(17) In this sense, depending on the tissue engineering approach, improving hPSC-CM maturation as described in Chapter 2 could enhance the success rate of engraftment. Another aspect of regenerative 
medicine may be the repair of damaged parts of the cardiac conduction system. Hereditary or acquired loss of pacemaker function in the SAN is currently treated with the implantation of an electrical pacemaker device, one that cannot respond to cues of the body. A more elegant solution would be to regenerate the SAN tissue by implantation of healthy, patient-specific (personalized medicine) nodal pacemaker cells. This has the clear advantage of being independent of a battery and to be less invasive, and, more importantly, it has the capacity to respond to hormonal or neural regulation by the body.(18) A tissue engineering approach for SAN malfunction might not even be as challenging as a repair to the myocardium but relies heavily on the quality of the pacemaker cells that can be developed for implantation. Obviously, when it comes to repairing the SAN node, it is of vital importance that the engineered tissue performs flawlessly, for any irregularity may cause life-threatening arrhythmias. As seen in Chapter 4 of this book, the process of differentiating nodal pacemaker cells is not clearly defined yet, but considerable progress has been made here and by others.(1921) A combination of such a differentiation protocol with additional maturation steps may enable production of clinically applicable pacemaker cells. Heart repair by tissue engineering appears to be within reach but requires final refinements before use in the clinic.

\section{Conclusion}

This thesis contains the evidence to support the use of hPSC-CMs in modeling heart physiology and disease. We demonstrate the successful application of these CMs and related hPSC-derived cardiac cells in models related to cardiomyopathy, arrhythmia, and cardiotoxicity, which provided relevant new insights that may contribute to advancement in cardiac organ and disease modeling. Having said that, it is important to remain critical when evaluating the value of hPSC-based models and the data that they may generate. Room for improvement may be found mainly in cell maturation and model complexity, on which continuous improvements can be found in literature. Follow-up steps may include the inclusion of patient-specific iPSC-CMs to develop a more personalized platform for drug screening, toxicity evaluation, or disease elucidation. An advanced in vitro-derived human whole heart model is on the horizon and may not be as unrealistic as previously thought. 


\section{References}

1. Slaats RH, Schwach V, Passier R. Metabolic environment in vivo as a blueprint for differentiation and maturation of human stem cell-derived cardiomyocytes. Biochim Biophys Acta Mol Basis Dis. 2020;1866(10):165881.

2. Ribeiro MC, Slaats RH, Schwach V, Rivera-Arbelaez JM, Tertoolen LGJ, van Meer BJ, et al. A cardiomyocyte show of force: A fluorescent alpha-actinin reporter line sheds light on human cardiomyocyte contractility versus substrate stiffness. J Mol Cell Cardiol. 2020;141:54-64.

3. Schwach V, Slaats RH, Passier R. Human Pluripotent Stem Cell-Derived Cardiomyocytes for Assessment of Anticancer Drug-Induced Cardiotoxicity. Front Cardiovasc Med. 2020;7:50.

4. Devalla HD, Passier R. Cardiac differentiation of pluripotent stem cells and implications for modeling the heart in health and disease. Sci Transl Med. 2018;10(435).

5. van der Velden J, Klein LJ, van der Bijl M, Huybregts MA, Stooker W, Witkop J, et al. Force production in mechanically isolated cardiac myocytes from human ventricular muscle tissue. Cardiovasc Res. 1998;38(2):414-23.

6. Nebigil CG, Desaubry L. Updates in Anthracycline-Mediated Cardiotoxicity. Front Pharmacol. 2018;9:1262.

7. Oudit GY, Kassiri Z, Zhou J, Liu QC, Liu PP, Backx PH, et al. Loss of PTEN attenuates the development of pathological hypertrophy and heart failure in response to biomechanical stress. Cardiovasc Res. 2008;78(3):505-14.

8. Tu C, Chao BS, Wu JC. Strategies for Improving the Maturity of Human Induced PluripotentStem Cell-Derived Cardiomyocytes. Circ Res. 2018;123(5):5124.

9. Birket MJ, Ribeiro MC, Kosmidis G, Ward D, Leitoguinho AR, van de Pol V, et al. Contractile Defect Caused by Mutation in MYBPC3 Revealed under Conditions Optimized for Human PSC-Cardiomyocyte Function. Cell Rep. 2015;13(4):733-45.

10. Rana P, Anson B, Engle S, Will Y. Characterization of human-induced pluripotent stem cell-derived cardiomyocytes: bioenergetics and utilization in safety screening. Toxicol Sci. 2012;130(1):117-31.

11. Govindsamy A, Naidoo S, Cerf ME. Cardiac Development and Transcription Factors: Insulin Signalling, Insulin Resistance, and Intrauterine Nutritional Programming of Cardiovascular Disease. J Nutr Metab. 2018;2018:8547976. 
12. Mannhardt I, Breckwoldt K, Letuffe-Breniere D, Schaaf S, Schulz H, Neuber $C$, et al. Human Engineered Heart Tissue: Analysis of Contractile Force. Stem Cell Reports. 2016;7(1):29-42.

13. Kupfer ME, Lin WH, Ravikumar V, Qiu K, Wang L, Gao L, et al. In Situ Expansion, Differentiation and Electromechanical Coupling of Human Cardiac Muscle in a 3D Bioprinted, Chambered Organoid. Circ Res. 2020.

14. Zhao Y, Kankala RK, Wang SB, Chen AZ. Multi-Organs-on-Chips: Towards Long-Term Biomedical Investigations. Molecules. 2019;24(4).

15. Vogenberg FR, Isaacson Barash C, Pursel M. Personalized medicine: part 1: evolution and development into theranostics. P T. 2010;35(10):560-76.

16. Agarwal T, Fortunato GM, Hann SY, Ayan B, Vajanthri KY, Presutti D, et al. Recent advances in bioprinting technologies for engineering cardiac tissue. Mater Sci Eng C Mater Biol Appl. 2021;124:112057.

17. Liew LC, Ho BX, Soh BS. Mending a broken heart: current strategies and limitations of cell-based therapy. Stem Cell Res Ther. 2020;11(1):138.

18. Ravindran D, Kok C, Farraha M, Selvakumar D, Clayton ZE, Kumar S, et al. Gene and Cell Therapy for Cardiac Arrhythmias. Clin Ther. 2020;42(10):1911-22.

19. Protze SI, Liu J, Nussinovitch U, Ohana L, Backx PH, Gepstein L, et al. Sinoatrial node cardiomyocytes derived from human pluripotent cells function as a biological pacemaker. Nat Biotechnol. 2017;35(1):56-68.

20. Birket MJ, Ribeiro MC, Verkerk AO, Ward D, Leitoguinho AR, den Hartogh $\mathrm{SC}$, et al. Expansion and patterning of cardiovascular progenitors derived from human pluripotent stem cells. Nat Biotechnol. 2015;33(9):970-9.

21. Ren J, Han P, Ma X, Farah EN, Bloomekatz J, Zeng XI, et al. Canonical Wnt5b Signaling Directs Outlying Nkx2.5+ Mesoderm into Pacemaker Cardiomyocytes. Dev Cell. 2019;50(6):729-43 e5. 


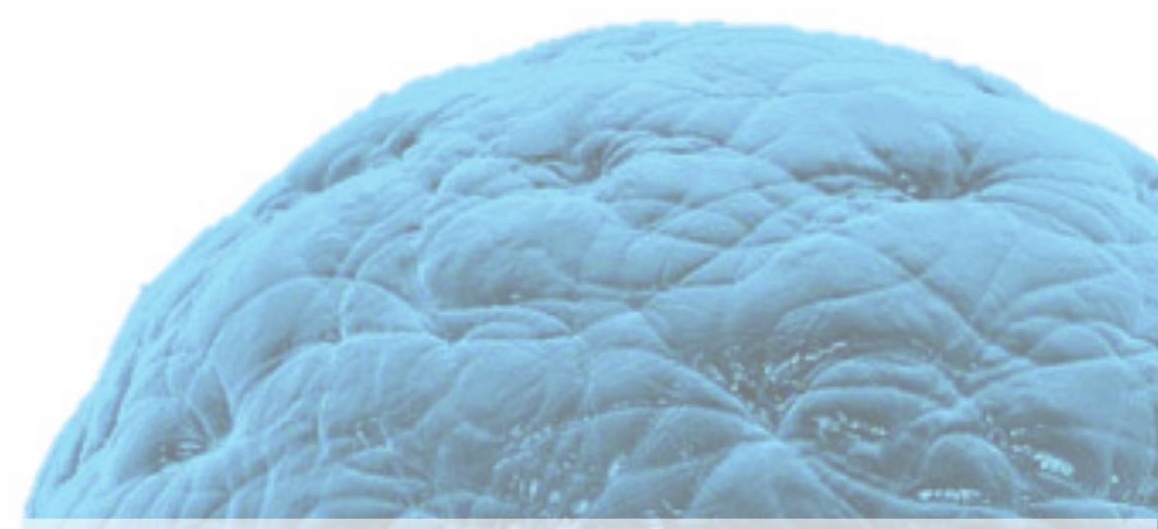

Appendix:

Scientific output

\section{Words of gratitude}




\section{Scientific output}

\section{Peer-reviewed journal articles:}

Tanumihardja E, de Bruijn DS, Slaats RH, Olthuis W, van den Berg A.

Monitoring Contractile Cardiomyocytes via Impedance Using Multipurpose Thin Film Ruthenium Oxide Electrodes - Sensors (Basel) 2021 Feb 18;21(4):1433. doi: $10.3390 / \mathrm{s} 21041433$.

Tanumihardja E, Slaats RH, van der Meer AD, Passier R, Olthuis W, van den Berg A.

Measuring Both $\mathrm{pH}$ and $\mathrm{O} 2$ with a Single On-Chip Sensor in Cultures of Human Pluripotent Stem Cell-Derived Cardiomyocytes to Track Induced Changes in Cellular Metabolism - ACS Sens. 2021 Jan 22;6(1):267-274. doi: 10.1021/ acssensors.0c02282. Epub 2020 Dec 29.

Slaats RH, Schwach V, Passier R.

Metabolic environment in vivo as a blueprint for differentiation and maturation of human stem cell-derived cardiomyocytes - Biochim Biophys Acta Mol Basis Dis. 2020 Oct 1;1866(10):165881.

Schwach V, Slaats RH, Passier R.

Human Pluripotent Stem Cell-Derived Cardiomyocytes for Assessment of Anticancer Drug-Induced Cardiotoxicity - Front Cardiovasc Med. $2020 \mathrm{Apr}$ 8;7:50. doi: 10.3389/fcvm.2020.00050. eCollection 2020.

Slaats RH, Ribeiro MC, Schwach V, Rivera-Arbelaez JM, Tertoolen LGJ, van Meer $\mathrm{BJ}$, Molenaar R, Mummery CL, Claessens MMAE, Passier R.

A cardiomyocyte show of force: A fluorescent alpha-actinin reporter line sheds light on human cardiomyocyte contractility versus substrate stiffness - J Mol Cell Cardiol. 2020 Apr;141:54-64. doi: 10.1016/j.yjmcc.2020.03.008. Epub 2020 Mar 20. 


\section{Conference contributions (presenter):}

Rolf H. Slaats, Marcelo C. Ribeiro, Verena Schwach, José Rivera Arbelaez, Leon G. J. Tertoolen, Berend J. van Meer, Robert Molenaar, Christine L. Mummery, Mireille M. A. E. Claessens, Robert Passier

An alpha-actinin reporter cell line to model sarcomeric dynamics in human hESC-derived cardiomyocytes relative to substrate stiffness - ISSCR 2019 Amsterdam, NL

Rolf H. Slaats, Marcelo C. Ribeiro, Kim Vermeul, Roman Mikulich, Dinis Faustino, Andries D. van der Meer and Robert Passier.

Optimizing human pluripotent stem cell-derived cardiomyocytes for application in a human myocardial ischemia-reperfusion on a chip model - EUROoC 2018, Stuttgard, DE

Rolf H. Slaats, Marcelo C. Ribeiro, Yawar Abbas, Kim Vermeul, Séverine Le Gac, Andries D. van der Meer and Robert Passier.

Myocardial Ischemia and Reperfusion on a chip using human pluripotent stem cell-derived cardiomyocytes - IOOCS 2017, Lausanne, CH 


\section{Words of gratitude}

My memories on the PhD period start in 2015, when I applied for a PhD position in Leiden with Christine Mummery. At the time, she could not offer me a position, but gave me the advise to talk to Robert instead. So my first encounter with Robert was an unplanned and spontaneous one, yet felt very positive and comfortable. It took another (planned) meeting to accept me as a PhD candidate, if I were willing to start in Enschede instead of Leiden. Robert was starting a new group at the University of Twente, planned to take two Post-Docs there, but managed to convert one budget to a PhD position for me. On my first day I arrived late and was lost inside the Zuihorst, but found myself receiving a very hospitable welcome by the fresh new team. We started small with the "inner circle" of the AST group (quite literal on the ASTable) Robert, Andries, Kim, Heleen and Ingrid, to whom I owe my gratitude for the happy memories and the friendly work environment. Throughout the years, I have seen AST grow and develop. attracting more PhD candidates, students and staff. Very important is that Robert prioritised team spirit when hiring new members, which greatly contributed to the overall experience of my time at AST. We still are, after 5 years of growth and change, a great team with lots of happiness, one that I think colleages of other groups at the University of Twente are jealous of.

Robert can be formidable when fighting for something he wants, and competitive when challenged for a competition of any kind. I know him as a gentle ruler of the group, knowing when to be tough and when to let go. As a boss, he greatly values team spirit and positive working environment, becoming evident when he urged us, the team, to have more social activities, organize more drinks, have more fun. He also joined himself whenever possible. On the other side he has been a great mentor, scientifically and personally, always trying to get the best possible outcome for me and everyone else involved. He likes to talk (a lot) but is also a good listener, and his door is always open for anyone who needs him. In short, Robert has shown himself as the best boss I could ask for. Of course I am grateful for him giving me the job in the first place, but even more so, for being patient with me and supportive to me at times when the project (or when I) was struggling. I am grateful for the great work environment he provided and the trust he showed when offering me a position at AST after the PhD track. Robert, I cannot thank you enough for all the support and guidance. This PhD has been quite an adventure, and you are definitely a major factor in its success and of the happy memories that dominate it.

My PhD project was not progressing well at the start. It took me quite some time to find my way in organizing my own tasks and in pushing the project forward. When Marcelo joined our group, this changed. He became my daily supervisor 
and started me off on the DRRAGN cell ine project. His guidance in running this project gave me the necessary push to see the project through and to work in a more efficient way. In that sense, he is part of the success of this thesis, and I find it great to have him as my co-promotor at the defense. Many thanks for the great collaboration and all that you've done Marcelo! I wish you, your family and River Biomedics all the best.

My first work together with Verena was in Leiden, where we performed the targeting of the dN3 stem cells to make the DRRAGN cell line. That first impression was of a hard-working, enthousiastic and expert professional that made the whole thing look incredibly simple. Frankly, that first impression still applies to Verena, except now I know her also as a great colleague and friend who is always willing to help and always willing to listen. Verena, we worked together quite a lot in the last phase of my PhD, made a couple of (almost) papers together and will continue to work together in my new project, and I am looking forward to it! Thanks a bunch for the happy times in the lab and of course for being my co-promotor :)

To my paranymphs Heleen and Yusuf, I am most grateful for all the years we spent together in the trenches. We were there at the very start of AST, making traditions and laying the basis for a happy team at work. Heleen left AST after a year or so, but truthfully, was never really gone, and could start her PhD just around the corner soon enough. The drinks at Starbucks never stopped at least, and neither did the Roomies dinners. We shared a lot of laughs together, and also some tears, but in the end we pulled through and here we are. Great that you could be my paranymph, it is only fitting. Bilgehan (aka billy, aka will, aka william, or Yusuf) started only a few months after me, and joined us in the room as the forth officer. Soon the quotes of Ace Ventura started flying around the office (not only because of you). Those were fun times. As the first two PhD students of AST we went through a lot, finding our way in the labs and going on trips and activities. You've been a constant factor throughout the whole ordeal and a constant friend to rely on. I am very happy to hear that finally you've been granted a permanent residency in the Netherlands, something you've been talking about for years. I hope we can stay in touch even after we both finish at AST. For now, I am just very grateful that you asked me to be your paranymph for your defense, and that you accepted to be mine. Thank you both for all the years of great friendship, it definitely made my PhD life much easier to bear.

Almost six years ago, I made a promise to my brand new colleague Kim, to formally acknowledge her live-saving generosity that provided free coffee to Heleen and me. So here it is Kim: Thank you for single-handedly rescuing the first two weeks of my PhD life by sharing your coffee card with us. But I am even more gratetful that that little gesture led to what I now would like to call a solid friendship. As one 
of the Founding Six, you've been at my side from the very beginning, helping me, teaching me, and sharing drinks, movies and dinners. In all, I have been lucky to have you in the group and as a friend and I hope we can continue this friendship for years to come. With Kim comes Andries, I learned on my first day at AST. Although not directly involved in my supervision, Andries somehow always has some great advice when you ask for it. He might come in for small talk, but when he leaves you feel like you see the whole project clearly again. Something that is retained on my memory is his "back-of-the-envelope" calculation that he likes to do during presentations. Anything can be calculated (at least by him), which often was not that simple for me. Andries adds a lot of cheerfulness to the group, with his lively discussions, sometimes about random stuff, but also with great laughs and optimism. It has been great having you around Andries!

Ingrid, the last of the Founding Six, but definitely not the least. You've been most helpful in all my years at AST. Always going out of your way to lend a hand, from the moment you guided me through the maze that is Carré five years ago. I hope you can continue for a while, because we can't go without you! Thank you for all the support, and all the good stories and laughs we have had over coffee. You've been great!

Passaging stem cells is not fun without Marco Borsato, right Simone? Everybody in the ML1 must have hated us singing along with Marco while doing our cell work. But we had the best time that you can have with cell work. You've been a good friend and lab buddy for me, not only in support of all the practical stuff, but also for the coffees, the beachvolleyball, the climbing, the water fights, and of course all the complaining we needed to do while working. Thank you for the good times, I would have struggled without you!

My gratitute also goes out to all the PhD students that have been with us at AST. Together, we make a great team for science, but maybe more so for fun. Anyone of you has aded to the great atmosphere in the group, and your contribution to that happiness is greatly appreciated. Aisen, always very calm and casual. Almost walked into the water at sailing weekend :) You first joined as a student of AST (the first?), and later returned for a PhD, brave choice. We've had some good trips and fun together. Thanks for being a good friend and a fun guy to be around. Wesley I remember you telling me that at the first time we met, you were seriously wondering why everybody was not hating me. I hope you found a good answer to that question. It is truly sad for AST that we parted ways, and even though I understand your decision, AST is not the same without you. You've been great fun at the group and a good friend outside work. Perhaps a bit too good at bouldering though ;) Hope to stay in touch and share some more good times and drinks José, the party maker. Always trying to buy Tequilla or some other cocktail in secret, so that you're surpised by a shot. Un poco loco, but in a good way. Mi 
casa es su casa. Mariel started not so long ago in the middle of the pandemic and thought AST was a boring group... Thankfully we found some opportunities to change that opinion. You bring a lot of optimism, cheerfullness and laughter to the group. It was fun having you around in the last part of my PhD, and it will be fun in the next couple of years I'm sure. Tarek, you are solely responsible for most of the heart attacks in the last year or so, with those super fast games of Ristretto and the one with the mouse (I don't even remember the name), but I always had a lot of fun in those evenings. Thanks for all the good times and if you ever want to trade some vegetable plants, I'll be happy to accomodate ;). Laura The AST bake-off award goes to Lena, who always manages to bake the most delicious pies and cookies. Next to a great baker, you're also an extremely nice and helpful colleague. Even though you joined us mid-project, I am still happy to have a couple of years of Lena in the group. Thank you for the happy moments at AST. Maybe out of pity I have to add Iom and Jim to the list of "PhD people", since there is no other place to go for them... But all jokes aside, these two, together with José, maybe responsible for my future wealth, in case you read this some years from now. Thanks for all the financial advise (not allowed to call it that), but also for the lively discussions during coffee or lunch. It has been great to have you around.

She only worked in Enschede for a small period of time, but our collaboration endures to this day. Lu has always been a friendly face and a willing help for all the questions and challenges we faced in our projects at AST. Thanks you for all the time you spent overcoming the hurdles that we threw at you, but more importantly for your kindness.

All other members of AST I will have to thank in bulk, otherwise I will be saying the same sentence ten times over. That doesn't make it less true or well earned. I've enjoyed working at AST mainly because of the great colleagues that work there, and you are directly responsible for that. So I would like to thank you all for your kindness, joy and support, it really is a big morale booster if your teammates are helping you out and lifting the spirits. Many thanks to Carla Annink, Kerensa, Danique, Anne, Federica, Anke, Ellen, Huub and all the students that were buzzing around during the last five years.

I would also like to mention the great neighbors that we have in the Zuidhorst. A special thanks to Robert Molenaar for every time I came over with a microscopy problem, and you helping out even if you do not have to. You've done me (and us) a great favor.

A special gratitude to the technicians of the Zuidhorst, Jacqueline, Irene, Kirsten, Yvonne and Wilma, who, regardless of group affiliation, were always happy to assist with all troubles and challenges that I've faced, as well as to the staff of the 
BioNanoLab, Ine and Henk, for all their unconditional support.

Thanks to the fantastic DBE, NBP, and BME groups for making the Zuidhorst the best building of the UT. The joint borrels with the other groups in the building created an ambiance of collaboration and supportiveness. Jan in particular deserves some credit for organizing joint AST-DBE drinks on the Thursday of Friday evenings, something I think we should pick up btw. Lord knows we pulled off some great Borrels together, and they were much appreciated by the groups. Thanks also to Michelle and Lisanne for their friendship, fun, and for introducing me to bouldering!

Finally, I would like to close with a special thank you to the family and friends, who provided a stable and happy home front during the PhD period. Your continued trust and love, even when there was little time to meet eachother, means a lot. It helped me through the rough patches of the PhD and made it a success. Carla, I will try to keep it professional, but it goes without saying that you've changed my life since you arrived at AST. I am happy to say that you motivated me to work harder and helped abundantly in planning and performing my work. We even made some futuristic (but feasible) project plans together that will change AST forever ;) But next to that, you took care of me at home, which means the world to me. I am lucky to have had you by my side the past couple of years, and I hope I can be there for you like you have been there for me. Team Slafiño for the win! 